EVANDRO JOSÉ DA SILVA

\title{
UM MODELO COMPUTACIONAL PARA ANÁLISE DE CONFORMIDADE DE ÁREAS E SUPERFÍCIES DE PROTEÇÃO DE AERÓDROMOS AOS CRITÉRIOS DA ICAO
}

\begin{abstract}
Tese apresentada à Escola Politécnica da Universidade de São Paulo para a obtenção do título de Doutor em Ciências.
\end{abstract}

São Paulo, 
EVANDRO JOSÉ DA SILVA

\section{UM MODELO COMPUTACIONAL PARA ANÁLISE DE CONFORMIDADE DE ÁREAS E SUPERFÍCIES DE PROTEÇÃO DE AERÓDROMOS AOS CRITÉRIOS DA ICAO}

Tese apresentada à Escola Politécnica da Universidade de São Paulo para a obtenção do título de Doutor em Ciências.

Área de Concentração:

Engenharia de Transportes

Orientador:

Prof. Dr. Nicolau Dionísio Fares Gualda

São Paulo, 
Este exemplar foi revisado e corrigido em relação à versão original, sob responsabilidade única do autor e com a anuência de seu orientador.

São Paulo de de

Assinatura do autor:

Assinatura do orientador:

Catalogação-na-publicação

Silva, Evandro José da

Um modelo computacional para análise de conformidade de áreas e superfícies de proteção de aeródromos aos critérios da ICAO / E. J. Silva versão corr.-- São Paulo, 2017.

$150 \mathrm{p}$.

Tese (Doutorado) - Escola Politécnica da Universidade de São Paulo. Departamento de Engenharia de Transportes.

1.Aeroportos 2.Terminais de Transportes 3.Anexo 14 da ICAO 4.CAD 5.Python I.Universidade de São Paulo. Escola Politécnica. Departamento de Engenharia de Transportes II.t. 


\section{AGRADECIMENTOS}

Em primeiro lugar agradeço à minha família, fonte de inspiração, estímulo e incondicional apoio. É impossível não citar meus pais, Cláudio e Marlise e a minha irmã Deise, que além de tudo, foram muito compreensivos com as renúncias que uma tese implica. Estendo também estes agradecimentos à minha família como um todo, que constituiu a base necessária para a busca desse objetivo. Antes do esforço que empreendi, tive a sorte de nascer com uma base material e afetiva que podem ser consideradas enormes privilégios diante da dura realidade brasileira.

Agradeço também ao meu orientador, Prof. Dr. Nicolau D. F. Gualda, pelos ensinamentos, discussões e pelo apoio desde que cheguei em São Paulo para fazer a pós-graduação. Aprendi muito com o senhor, e me senti seguro para trilhar os caminhos da dissertação, e agora da tese.

Também agradeço aos professores da banca examinadora, pelo interesse em avaliar e contribuir para este trabalho, em especial ao prof. Dr. Jorge Pimentel Cintra, pelas contribuições em relação ao problema das projeções locais.

Agradeço à Capes, pela bolsa de estudos concedida na pesquisa de doutorado.

O meu obrigado também se direciona aos professores do Departamento de Engenharia de Transportes da EPUSP, pela confiança depositada e pelos ensinamentos durante o mestrado e o doutorado.

Às pessoas queridas que encontrei em São Paulo, pelas horas descontraídas, pelas boas conversas, pelos momentos ricos. Obrigado, Beto, Círia, Eliana, Henrique, Hermínio, Inaê, Nestor, Paulo e Renan.

O meu obrigado vai também aos colegas e amigos do LPT/EPUSP e do programa de Engenharia de Transportes, especialmente ao Auro, Daniel, Felipe, Medau, Jorge, Patrícia Lavieri, Patrícia Santana, Renato e Wagner.

E ainda, aos que eu tenha, por pura desatenção, esquecido de mencionar. 


\section{RESUMO}

Esta tese propõe um modelo computacional para análise de conformidade de áreas e superfícies de proteção de aeródromos aos critérios de projeto geométrico previstos no Anexo 14 da ICAO (International Civil Aviation Organization). Não foram encontrados na literatura softwares open source com esta finalidade. Os critérios da ICAO impõem áreas e superfícies imaginárias de proteção que se originam na vizinhança de cada uma das pistas de pouso e/ou de decolagem. Dessas exigências normativas decorre um complexo conjunto de áreas em solo e superfícies no espaço aéreo, as quais ordenam a presença de objetos fixos e móveis dentro e fora dos limites do sítio aeroportuário. Os dados de entrada do modelo proposto compreendem: informações sobre a topografia e sobre os limites internos e externos do sítio; a posição de objetos fixos e móveis; a categoria da aeronave; o procedimento de aproximação empregado; e informações sobre a configuração do sistema de pistas. O modelo computacional proposto integra conceitos de CAD (Computer Aided Design) e de GIS (Geographic Information System) para a geração automática de geometrias georreferenciadas, de acordo com um MDE (Modelo Digital de Elevação), internamente representado por uma malha TIN (Triangulated Irregular Network). Além da geração virtual das geometrias, o modelo permite a detecção automática de eventuais interferências nas áreas e superfícies de proteção pelos objetos fixos e móveis. O modelo apresenta os resultados das análises por meio de janelas gráficas e permite a exportação dos arquivos KML para um globo virtual, como o Google Earth. Os arquivos KML representam as áreas e superfícies de proteção e os objetos fixos e móveis, destacando os obstáculos detectados. A modelagem proposta foi implementada em linguagem Python, testada e validada para instâncias fictícias e para um caso real, relacionado ao Aeroporto de Viracopos em Campinas, no Brasil (SBKP). Buscas sistemáticas na literatura científica nacional e internacional indicam que a modelagem aqui proposta é inédita, contribuindo para preencher a lacuna identificada na revisão bibliográfica realizada.

Palavras-Chave: Aeródromos. Anexo 14 da ICAO. Linguagem Python. CAD. GIS 


\begin{abstract}
This thesis proposes a computational model for analysis of conformity of aerodrome protection areas and surfaces according to ICAO (International Civil Aviation Organization) Annex 14 geometric design criteria. No open source software with this purpose could be found in the literature. ICAO criteria impose imaginary protection areas and surfaces that start at the vicinity of each runway, leading to a complex set of geometries on the ground and in the airspace. Fixed and movable objects, both inside and outside the aerodrome property limits, are controlled by means of this set of imaginary surfaces. Input data for the herein proposed model comprises: aerodrome site topography and internal and external boundaries; fixed and movable objects position; aircraft category; approach procedures; and runway system configuration data. The model integrates CAD (Computer Aided Design) and GIS (Geographic Information System) technologies in order to automatically generate georeferenced geometries, that take into account a DEM (Digital Elevation Model), internally represented by a TIN (Triangulated Irregular Network) approach. In addition to geometry generation, the proposed model also performs obstacle assessment regarding the suppositional geometric interferences between protection areas and surfaces and the fixed and movable objects. The model results are outputted by means of screen plots, execution console (detected geometric interferences) and $\mathrm{KML}$ (Keyhole Markup Language) files, to be exported to virtual globes, like Google Earth. The KML files represent the geometries of protection areas and surfaces as well as fixed and movable objects, highlighting detected obstacles. The model was implemented in Python language and tested for validation, employing both fictitious and a real instance, related to the Viracopos International Airport (SBKP), in Campinas, Brazil. The undergone bibliographic search, considering national and international literature, indicates that this research introduces an unprecedented model, filling in a gap in the literature.
\end{abstract}

Keywords: Aerodromes. ICAO Annex 14. Python Language. CAD. GIS 


\section{LISTA DE ILUSTRAÇÕES}

Figura 1-1 Vista das sup. de proteção no Aeroporto de Guraulhos (SBGR) ..................18

Figura 1-2 Vista de satélite do Aeroporto de Chicago, IL, EUA (ICAO KORD)..............19

Figura 1-3 Superfícies previstas no Anexo 14 da ICAO ..............................................25

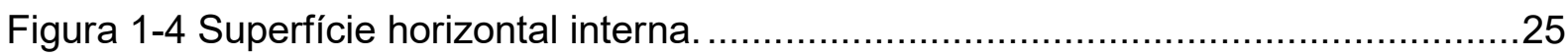

Figura 1-5 Sup. de aproximação interna, transição interna e pouso interrompido. .........26

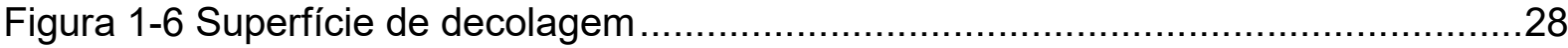

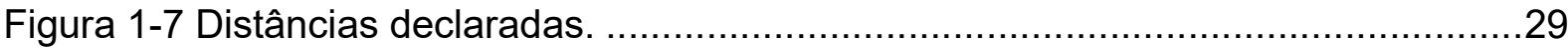

Figura 3-1 Diferentes representações de objetos geométricos em um sistema CAD. ...44

Figura 3-2 Aproximação de curvas e de superfícies ................................................45

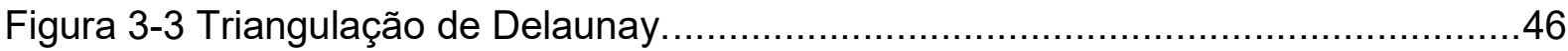

Figura 3-4 Alteração geométrica e topológica em um modelo. ...................................46

Figura 3-5 Polígonos e convexidade. ...............................................................49

Figura 3-6 Operações não comutativas. ..............................................................

Figura 3-7 Rotação de geometrias e sua posição em relação à origem. ......................51

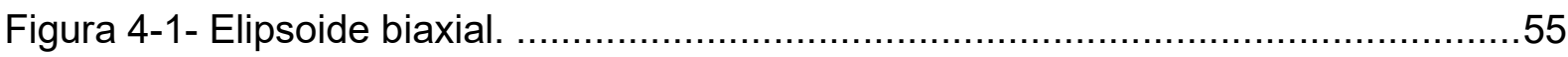

Figura 4-2- Coordenadas cartesianas e geodésicas.................................................56

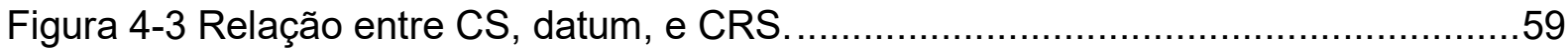

Figura 4-4 Superfícies do elipsoide e do geoide......................................................61

Figura 4-5 Convergência meridiana, grid e graticule. .............................................63

Figura 4-6 Medição de distâncias horizontais.......................................................65

Figura 4-7 Ilustração da esfera de adaptação de Gauss. .........................................66

Figura 4-8 Modelagem do fator de ajuste da altura em uma projeção.........................67

Figura 4-9 Análise das combinações críticas entre latitude e excentricidade .................68

Figura 4-10 Relação entre h e (c-1) para latitude=0. Ver Equação 4-14 ......................69

Figura 4-11 Ilustração da projeção UTM.................................................................71

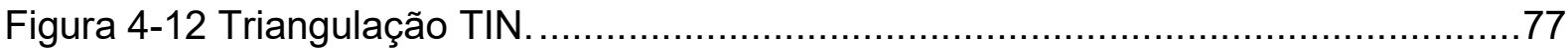

Figura 4-13 Exemplos de erros em triangulações............................................... 77

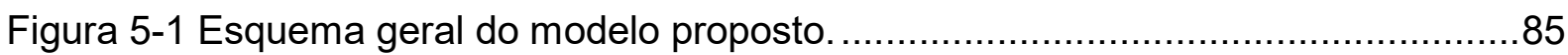

Figura 5-2 Formatos de entrada de dados em formato geodésico. ............................87

Figura 5-3 Formatos de entrada sob algum sistema de projeção. ..............................88

Figura 5-4 Limites externos do sítio.....................................................................92

Figura 5-5 Dados de entrada para o sítio e para o projeto. ........................................94

Figura 5-6 Dados de entrada para o sistema de pistas de pouso e decolagem.............97

Figura 5-7 Representação da geometria da RWY. ...............................................98 
Figura 5-8 Divisão da faixa de pista de pouso e decolagem em duas áreas. ................99

Figura 5-9 Distâncias declaradas e a faixa de pista (letras 3 e 4 do ARC) ...................100

Figura 5-10 Etapas para a geração da faixa de pista de pouso e decolagem. ............101

Figura 5-11 Geração da superfície de transição interna.........................................104

Figura 5-12 Geração da superfície de horizontal interna. ........................................105

Figura 5-13 Geração da superfície cônica............................................................. 106

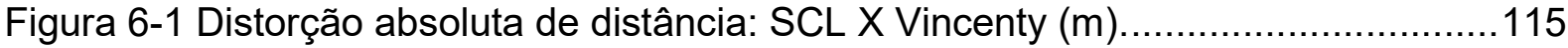

Figura 6-2 Distorção absoluta: Projeção estabelecida pela NBR 14.166 X Vincenty...116

Figura 6-3 Distância entre pontos periféricos: SCL X PTL....................................117

Figura 6-4 Diferença absoluta SCL, PTL e Vincenty. Ponto central $5^{\circ} \mathrm{N} 10^{\circ} \mathrm{W} . \ldots \ldots \ldots \ldots 117$

Figura 6-5 Diferença absoluta SCL, PTL e Vincenty. Ponto central $70^{\circ} \mathrm{N} 10^{\circ} \mathrm{W} \ldots \ldots \ldots . . .117$

Figura 6-6 Projeção UTM zona 32N X Vincenty. Pontos centrais coincidentes. ...........118

Figura 6-7 Projeção UTM zona 32N X Vincenty. Pontos centrais não coincidentes. ....118

Figura 6-8 Sítio para a instância fictícia 1 -InstFICT1 ...........................................119

Figura 6-9 Construção da pista para diferentes disponibilidades do sítio. ...................120

Figura 6-10 Faixa de pista de pouso e decolagem e área interna da faixa da RWY....121

Figura 6-11 Distâncias declaradas na geração da faixa de pista................................121

Figura 6-12 Sup. de pouso interrompido e de aproximação interna para InstFICT2 ....122

Figura 6-13 Conjunto de superfícies para InstFICT3 ….......................................123

Figura 6-14 Distâncias declaradas para o Aeroporto de Campinas (SBKP) .................124

Figura 6-15 Recorte arbitrário para o sítio do Aeroporto de Campinas (SBKP) ............125

Figura 6-16 Tratamento dos dados raster do sítio do Aeroporto de Campinas (SBKP) 126

Figura 6-17 Dados do sítio (SBKP) carregados no modelo ...................................126

Figura 6-18 Geometrias internas para a instância INST_SBKP via Google Earth .......127

Figura 6-19 Geometrias internas para a instância INST_SBKP ...............................128

Figura 6-20 Geometrias externas para a instância INST_SBKP via Google Earth .......129

Figura 6-21 Geometrias externas para a instância INST_SBKP ...............................129

Figura 6-22 Arquico CSV que define tipo e posição das aeronaves no sítio.................130

Figura 6-23 Aeronaves posicionadas na proximidade da RWY .............................130

Figura 6-24 Arquico CSV que define os objetos fixos a serem testados.....................131

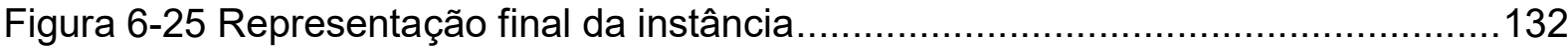

Figura 6-26 Representação final da instância após os testes de interferência ..............132

Figura 6-27 Resultados do console para os objetos fixos $X$ geometrias externas ........133

Figura 6-28 Resultados do console para os objetos móveis $X$ geometrias internas .....133

Figura 6-29 Detalhe da interferência da aeronave ID_3 ..........................................133

Figura 6-30 Teste para um sistema com 2 pistas. ............................................... 135

Figura 6-31 Teste para um sistema com 3 pistas. ................................................. 135 


\section{LISTA DE TABELAS}

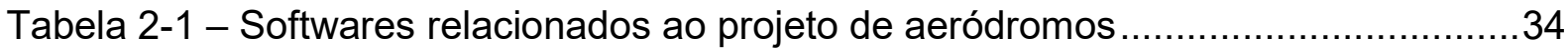

Tabela 2-2 - Características das metodologias aplicadas ao problema do layout..........39

Tabela 4-1 - Fator de ajuste em função da altura para diferentes elipsoides...............69

Tabela 4-2 - Exemplos de transformação de coordenadas UTM ................................71

Tabela 5-1 - Descrição de algumas bibliotecas (modules) utilizados ............................91

Tabela 6-1 - Testes da implementação das fórmulas de Vincenty (1975)...................114

Tabela 6-2 - Testes dos tempos computacionais: instância INST_SBKP ..................136 


\section{LISTA DE ABREVIATURAS E SIGLAS}

ALP: Airport Layout Plan

ANAC: Agência Nacional de Aviação Civil

APM: Airport Planning Manual; aircraft characteristics for airport planning

ARC: Código de referência do aeródromo/aeroporto; Airport/Aerodrome Reference Code

ASDA: Distância disponível para aceleração e parada; Accelerate Stop Distance Available

BSD: Berkeley Software Distribution

CAD: Computer Aided Design

CAE: Computer Aided Engineering

CAM: Computer Aided Manufacturing

CAT I, II ou III: Categoria de aproximação de precisão I, II ou III; Precision Approach Category

CNC: Comando Numérico Computadorizado

CRS: Coordinate Reference System

CS: Coordinate system

CSG: Constructive Solid Geometry

CWY: Zona desimpedida; Clearway

e-CFR: Electronic Code of Federal Regulations - EUA.

EPSG: European Petroleum Survey Group.

EUA: Estados Unidos da América.

FAA: Federal Aviation Administration - órgão de aviação civil dos EUA

FOD: Foreign Object Damage

GDAL: Geospatial Data Abstraction Library

GIS: Geographic Information System. SIG, na sigla em língua Portuguesa

GML: Geography Markup Language

GPL: General Public License

GPS: Global Positioning System 
HD: Horizontal Distance

IBGE: Instituto Brasileiro de Geografia e Estatística

ICAO: International Civil Aviation Organization. $\mathrm{OACl}$, na sigla em língua Portuguesa

IFR: Regras de vôo por instrumentos; Instrument Flight Rules

ILS: Instrument Landing System

IOGP: International Association of Oil and Gas Producers

ITRF: International Terrestrial Reference Frame

ITRS: International Terrestrial Reference System

KML: Keyhole Markup Language

LDA: Distância disponível para pouso; Landing Distance Available

LIDAR: Light Detection and Ranging

MDE: Modelo Digital de Elevação

MDS: Modelo Digital de Superfície

MDT: Modelo Digital de Terreno

OFZ: Zona livre de obstáculos; Obstacle Free Zone

OGC: Open Geospatial Consortium

OGR: OGR Simple Features Library

PANS-ATM: Procedures for Air Navigation Services: Air Traffic Management

PBZPA: Plano Básico de Zona de Proteção de Aeródromo

PSF: Python Software Foundation

PTL: Plano Topográfico Local

RBAC: Regulamento Brasileiro de Aviação Civil

RESA: Runway End Safety Area

RWY: Pista de pouso e/ou de decolagem; Runway

TD: Triangulação de Delaunay

TIN: Triangulated Irregular Network

SARPS: Standards and Recommended Practices

SBGR: Código ICAO para o Aeroporto Internacional de Guarulhos

SCL: Sistema Cartesiano Local

SPCS: State Plane Coordinate System

SRF: Spatial Reference Frame 
SRS: Spatial Reference System

SWY: Zona de parada da pista de pouso e/ou de decolagem; Stopway TODA: Distância disponível para decolagem; Take-Off Distance Available TORA Distância disponível para corrida de decolagem: Take-Off Run Available TWY Pista de táxi

UTM Universal Transversa de Mercator

VFR: Regras de vôo visual; Visual Flight Rules

XML: Extensible Markup Language 


\section{LISTA DE SÍMBOLOS}

a: $\quad$ Raio equatorial ou raio maior da Terra

atan: Função Inversa da tangente

$b$ : $\quad$ Raio menor da Terra.

c: $\quad$ Coeficiente de ajuste para a distorção de comprimento horizontal decorrente da elevação

$e$ : Primeira excentricidade da Terra no modelo biaxial

$E$ : Coordenada $x$ de uma projeção

$f$ : Achatamento da Terra

$h$ : $\quad$ Altura desde o elipsoide de referência

$H$ : $\quad$ Altura ortométrica

$k$ : Coeficiente de ajuste para a distorção de comprimento horizontal em uma projeção

$M$ : $\quad$ Raio de curvatura no meridiano. Radius of curvature in the meridian

$N$ : i) Raio de curvatura do primeiro vertical. Radius of curvature of the prime vertical normal section at the point of the ellipsoid. ii) Altura ou ondulação geoidal. iii) Coordenada $y$ de uma projeção

R: $\quad$ Raio da Terra

S: $\quad$ Comprimento do arco

$R_{m}$ : Raio médio da Terra

$t$ : Coordenada local equivalente a $x$

$u$ : Coordenada local equivalente a $y$

$v$ : Coordenada local equivalente a $z$

$\lambda$ : Longitude

$\varphi$ : Latitude 


\section{SUMÁRIO}

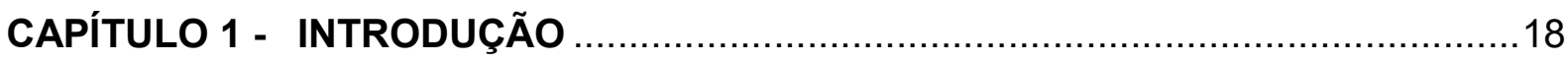

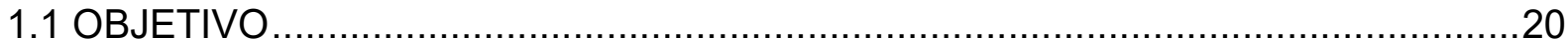

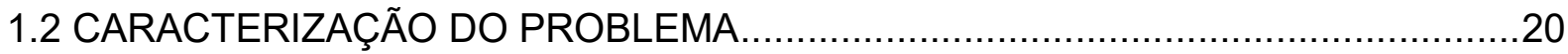

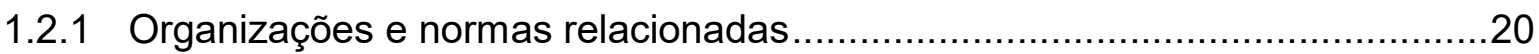

1.2.2 Descrição dos padrões e das geometrias de interesse .................................21

1.2.2.1 Pista de pouso e/ou de decolagem (RWY - runway) ................................22

1.2.2.2 Áreas de proteção em solo da pista de pouso e/ou de decolagem .............22

1.2.2.3 Superfícies de proteção ao espaço aéreo ................................................23

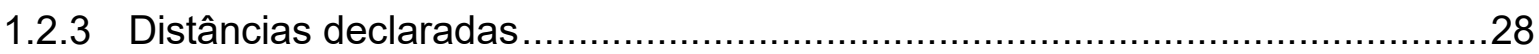

1.2.4 Síntese do problema: aspectos geométricos ...........................................29

1.2.5 Síntese do problema: aspectos espaciais ...............................................

1.3 CONCLUSÕES DO CAPÍTULO E ESTRUTURA DA PESQUISA ….......................31

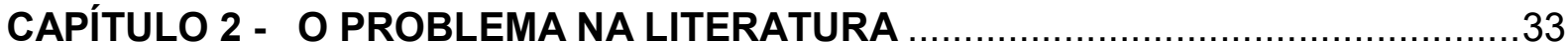

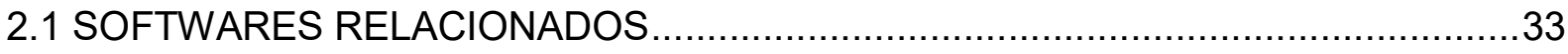

2.2 MODELAGEM GEOMÉTRICA EM AERÓDROMOS - LITERATURA ......................34

2.3 MODELAGEM GEOMÉTRICA NO LAYOUT DO CANTEIRO DE OBRAS ...............36

2.4 MODELAGEM GEOMÉTRICA NO LAYOUT DE DUTOS .......................................

2.5 MODELAGEM GEOMÉTRICA NO LAYOUT DE PLANTAS INDUSTRIAIS .............38

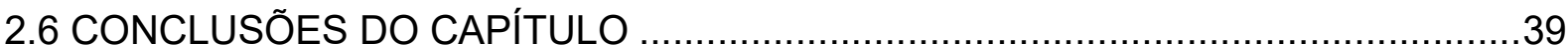

CAPÍTULO 3 - CAD E GEOMETRIA COMPUTACIONAL …................................41

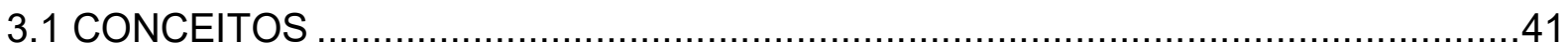

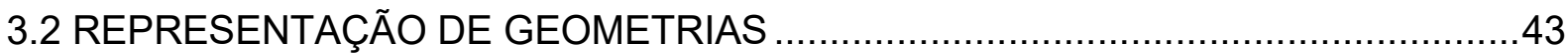

3.3 PARADIGMAS DE CONSTRUÇÃO DE UM MODELO CAD ................................46

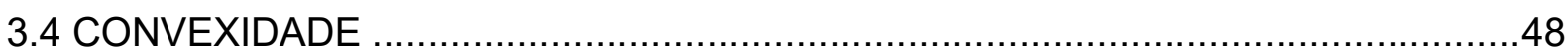

3.5 OPERAÇÕES DE TRANSLAÇÃO, ROTAÇÃO E REFLEXÃO ............................49

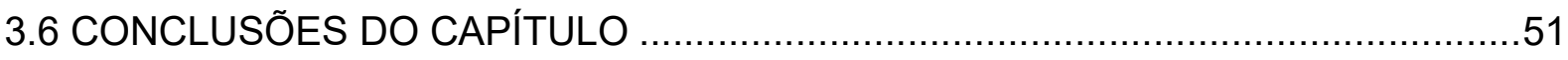

CAPÍTULO 4 - TRATAMENTO DE DADOS ESPACIAIS …....................................

4.1 GEOMETRIA DA TERRA E SISTEMAS DE COORDENADAS ............................53

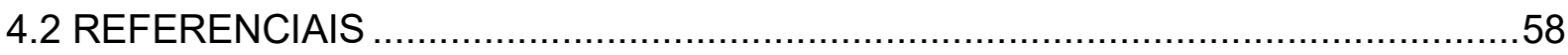

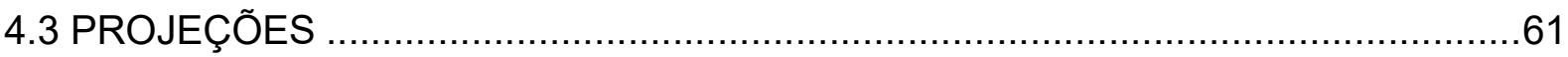




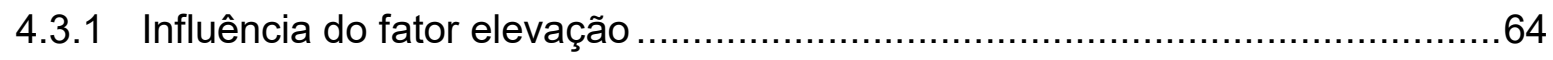

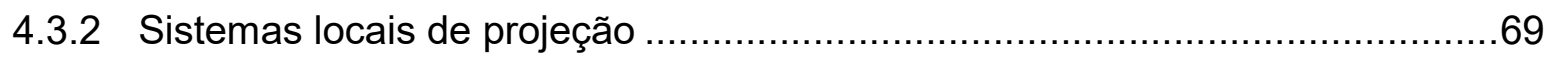

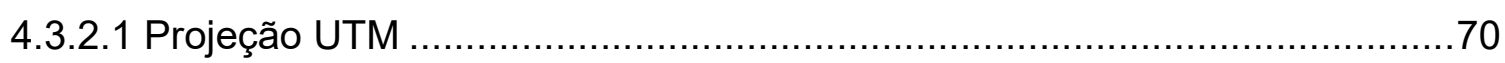

4.3.2.2 Projeção no sistema State Plane Coordinate System …………................71

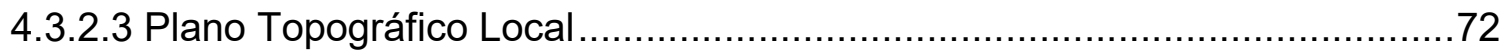

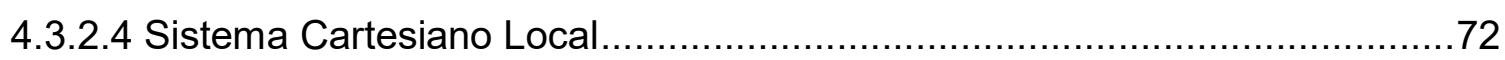

4.4 DISTÂNCIAS SOBRE A SUPERFÍCIE GEODÉSICA ............................................73

4.5 MODELOS DIGITAIS DE ELEVAÇÃO ……………....................................

4.6 SISTEMAS DE INFORMAÇÃO GEOGRÁFICA (GIS) ….................................78

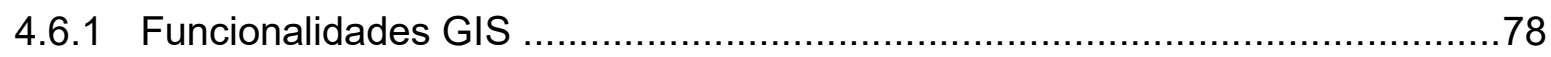

4.6.2 Padrões de arquivo e representação de dados em GIS ................................79

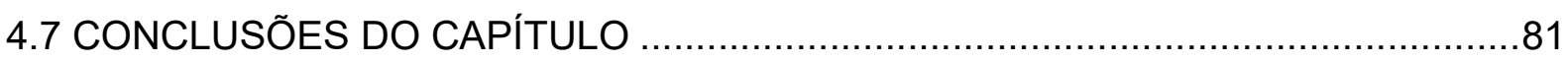

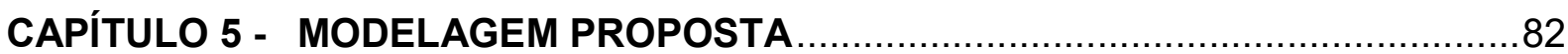

5.1 CONCEPÇÃO DO MODELO

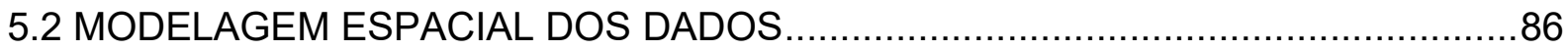

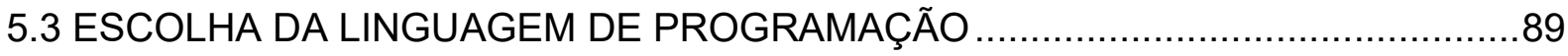

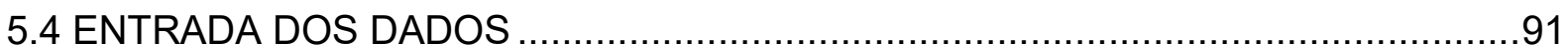

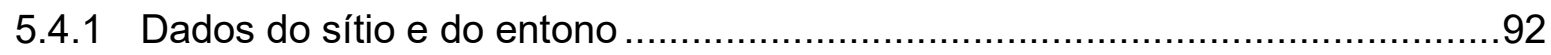

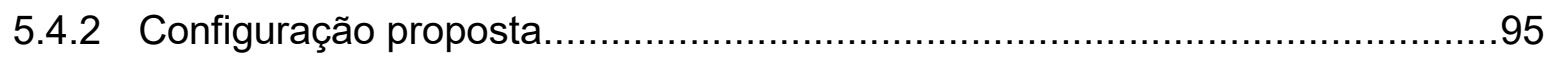

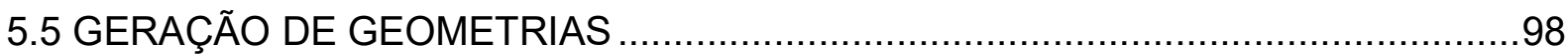

5.5.1 Geração da pista de pouso e/ou de decolagem (RWY) ................................

5.5.2 Geração da faixa de pista de pouso e decolagem .........................................99

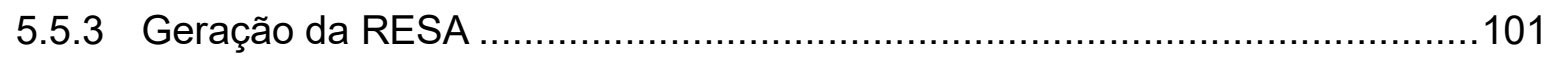

5.5.4 Geração da superfície de aproximação interna ..........................................102

5.5.5 Geração da superfície de pouso interrompido .........................................102

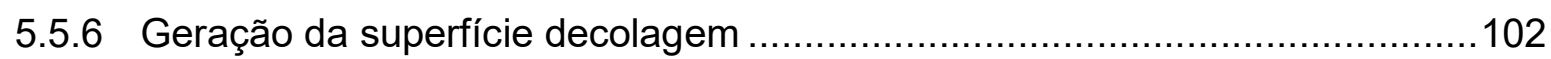

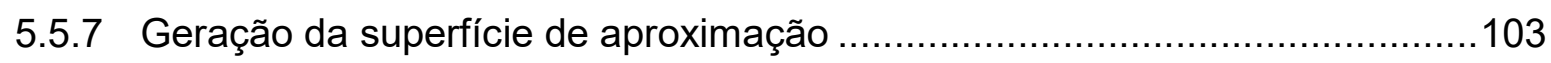

5.5.8 Geração da superfície de transição interna .................................................103

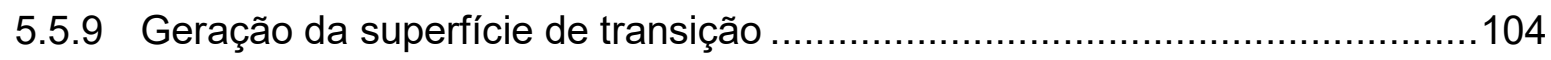

5.5.10 Geração da superfície horizontal interna .................................................104

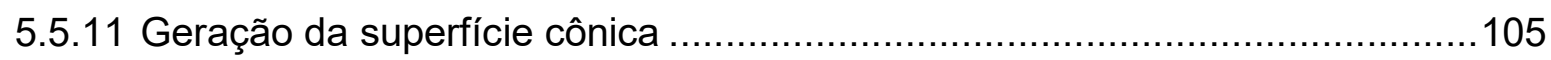

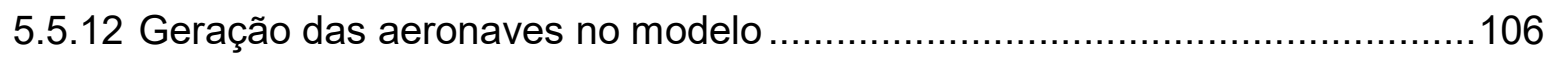

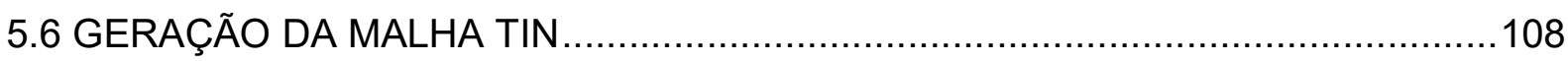

5.7 CÁLCULO DA ELEVAÇÃO EM UMA MALHA TIN …..........................................108 


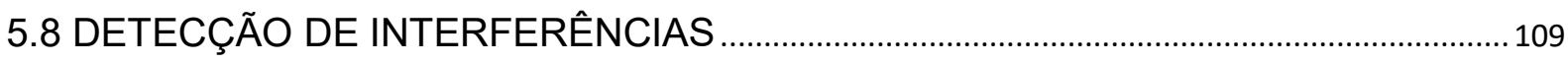

5.9 REPRESENTAÇÃO DOS DADOS EM PYTHON 2.7 …...................................................... 110

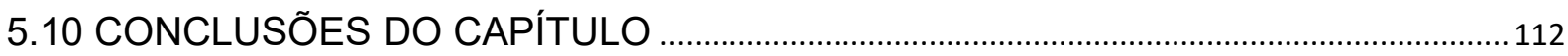

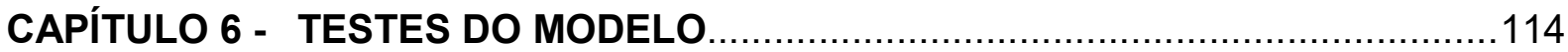

6.1 ANÁLISE DAS DISTORÇÕES NAS PROJEÇÕES SCL, PTL E UTM ……....................114

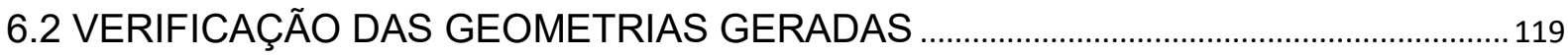

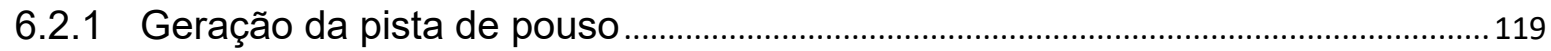

6.2.2 Geração da faixa da RWY e da faixa interna da RWY ...........................................120

6.2.3 Superfícies de aproximação interna e de pouso interrompido ................................122

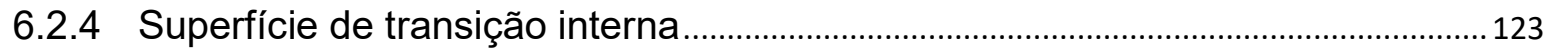

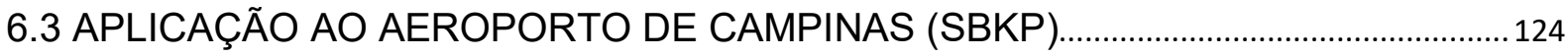

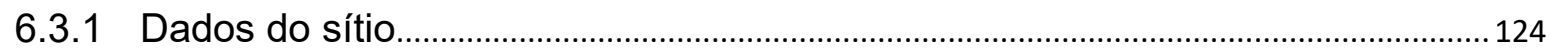

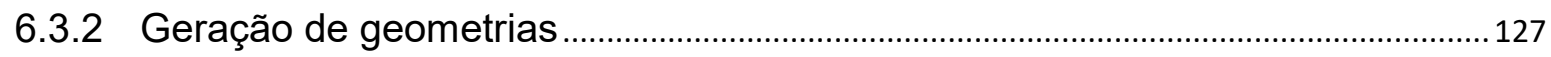

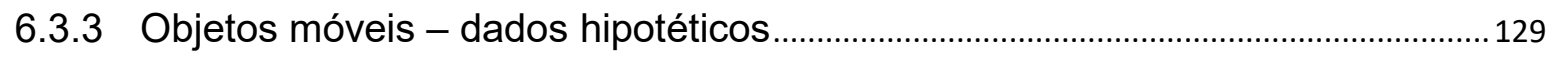

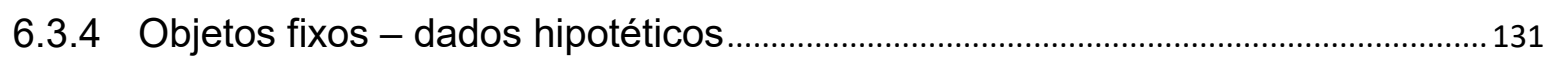

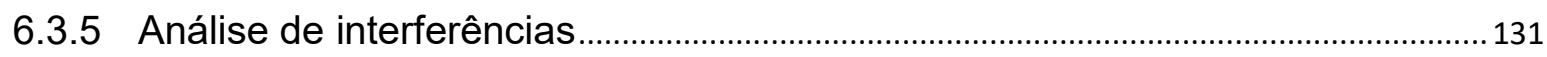

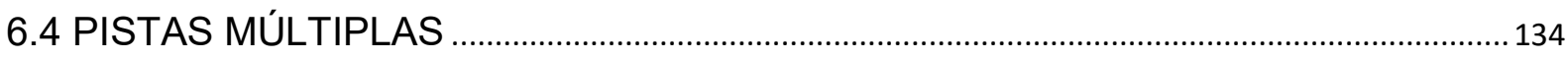

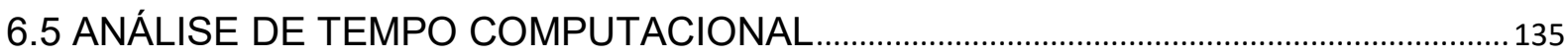

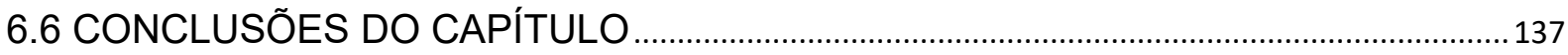

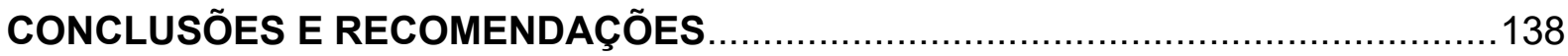

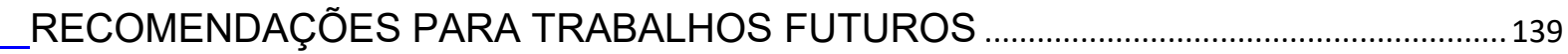

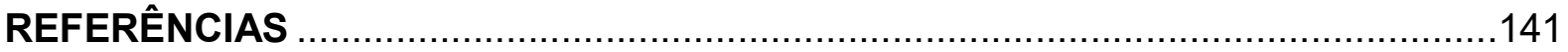

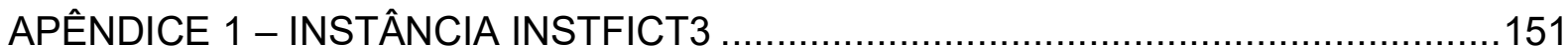

APÊNDICE 2 - DADOS PARA GERAÇÃO DO B747-8F ......................................154

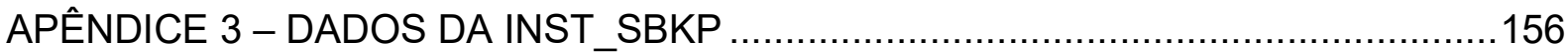

ANEXO 1 - CARTA ADC DO AEROPORTO SBKP .............................................159

ANEXO 2 - EXEMPLOS DE CÓDIGOS EPSG, PADRÃO WKT ...............................161 


\section{CAPÍTULO 1 - INTRODUÇÃO}

O projeto de um aeródromo envolve exigências em termos de separações entre pistas de pouso e decolagem, pistas de táxi, pátios e outros componentes físicos. Separações também se aplicam a objetos que se encontram fora dos limites de propriedade do aeroporto, mas que devem estar presentes em regras locais de zoneamento, protegendo o espaço aéreo para operações atuais ou planejadas. Tais separações, previstas em normas de projeto de aeródromos, são especificadas sob diversas formas, como: distâncias entre linhas de centro de pistas; folgas entre aeronaves e objetos; áreas que delimitam pistas e outros componentes do aeródromo; e superfícies tridimensionais que protegem o espaço aéreo.

O sistema de pistas de um aeródromo é protegido por um complexo conjunto de superfícies, em solo e no espaço aéreo. A Figura 1-1 apresenta uma vista do PBZPA (Plano Básico de Zona de Proteção de Aeródromo) do Aeroporto Internacional de Guarulhos, em São Paulo (SBGR). Este aeroporto possui duas pistas paralelas. Entre as superfícies de proteção, algumas servem a uma única pista, enquanto outras são combinações complexas que decorrem da geometria conjunta do sistema de pistas.

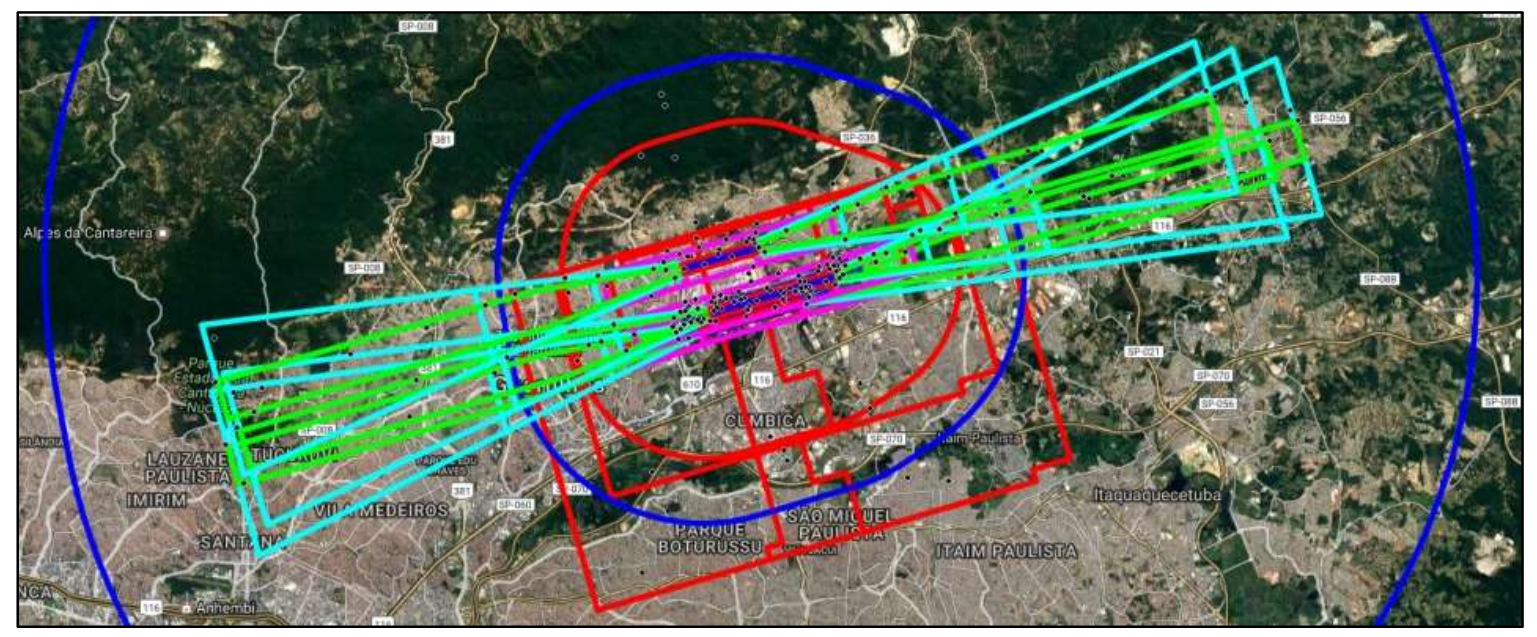

Figura 1-1 Vista das superfícies de proteção no Aeroporto Internacional de Guraulhos (SBGR). FONTE: (BRASIL, 2017)

Entre as possíveis superfícies de proteção às pistas de pouso e decolagem, algumas estão relacionadas ao horizonte de planejamento, protegendo expansões futuras do aeródromo. Outras superfícies são destinadas à proteção das operações de pouso e decolagem em condições específicas. Com isso, o projeto e a operação de aeroportos envolvem o desenho dessas superfícies imaginárias e sua comparação 
com objetos sempre que alterações surgirem, sejam elas novos procedimentos operacionais, expansão de pistas, acomodação de novas e maiores aeronaves, surgimento de novos obstáculos, mudança de padrões de projeto, entre outros.

A Figura 1-2 apresenta o Aeroporto de Chicago (código ICAO KORD), que possui um layout ainda mais complexo do que o SBGR, com múltiplas pistas sob diferentes orientações. Cada uma dessas pistas precisa ser protegida com áreas e superfícies como aquelas ilustradas na Figura 1-1, criando um conjunto de múltiplas superfícies, de forma que um único objeto, dependendo de sua posição, pode interferir sobre diversas superfícies de proteção.

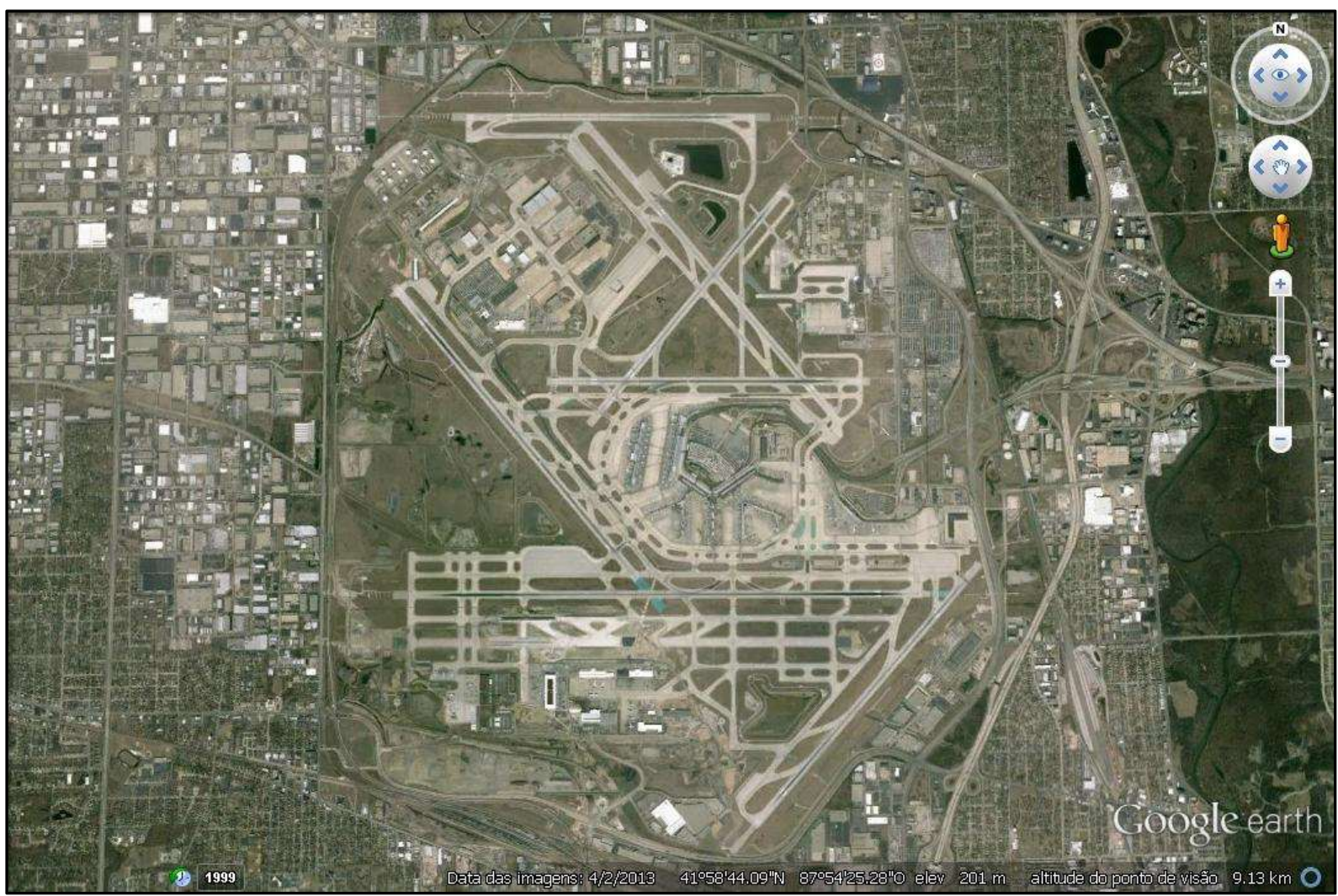

Figura 1-2 Vista de satélite do Aeroporto de Chicago, IL, EUA (ICAO KORD) em 2013. FONTE: Imagem do Google Earth

No aeródromo, as aeronaves em manobras de táxi e espera podem constituir obstáculos às superfícies de proteção, se inadequadamente posicionadas, dada a proximidade entre uma aeronave em espera/táxi e a pista. Com efeito, uma alteração do caminho de táxi em um layout complexo de pistas precisa levar em conta seus impactos sobre as superfícies de proteção.

Torres, prédios e guindastes são exemplos de objetos que, mesmo fora dos limites de propriedade do aeródromo, podem constituir violações às superfícies de 
proteção, exigindo monitoramento constante dos objetos, bem como leis de zoneamento que protejam o espaço aéreo.

A pesquisa proposta neste trabalho trata do problema da modelagem geométrica das áreas e superfícies de proteção de um sistema de pistas de acordo com os padrões de projeto do Anexo 14 da ICAO (ICAO, 2004). Para tanto, os aspectos geométricos destas áreas e superfícies imaginárias são analisados, uma modelagem é proposta e implementada em computador.

\subsection{OBJETIVO}

Este trabalho objetiva propor um modelo computacional de auxílio ao projeto geométrico de aeródromos de acordo com os padrões do Anexo 14 da ICAO (ICAO, 2004). O modelo proposto deve fornecer automaticamente a geometria georreferenciada de áreas e superfícies de proteção relacionadas ao sistema de pistas de pouso e/ou decolagem de um aeródromo e levar em conta objetos fixos e móveis existentes, apontando as eventuais interferências dos mesmos nessas superfícies.

\subsection{CARACTERIZAÇÃO DO PROBLEMA}

O projeto geométrico de aeródromos insere-se em um rigoroso ambiente normativo. $O$ estudo aqui proposto consiste em um recorte que contempla apenas componentes e critérios relacionados ao lado aéreo ${ }^{1}$, em especial às áreas e superfícies de proteção do sistema de pistas, conforme os padrões do Anexo 14 da ICAO (ICAO, 2004).

A seguir é feita uma breve exposição do contexto normativo no qual esta pesquisa se insere e, em seguida, as geometrias de interesse são expostas, em observância aos referidos padrões. É apresentada ainda uma breve revisão sobre distâncias declaradas, conceito importante para a caracterização das geometrias de interesse nesta pesquisa.

\subsubsection{ORGANIZAÇÕES E NORMAS RELACIONADAS}

A ICAO (International Civil Aviation Organization)2 ${ }^{2}$, atualmente com 191 Estados membros (ICAO, 2017), incluso o Brasil, emite padrões de projeto e operação do

\footnotetext{
1 O lado aéreo (airside) corresponde à porção de um aeródromo na qual as aeronaves decolam, pousam, taxiam e permanecem. O lado aéreo contrapõe-se ao lado terrestre (landside), porção do aeródromo que recebe e processa passageiros e cargas.

$2 \mathrm{OACl}$ (Organização da Aviação Civil Internacional), na sigla em Português.
} 
sistema internacional de transporte aéreo, incluindo os padrões de projeto de aeroportos.

Nos Estados Unidos os padrões de projeto de aeroportos encontram-se sob a autoridade da FAA (Federal Aviation Administration). Silva (2012) compara os padrões da ICAO e da FAA para o projeto de aeródromos ${ }^{3}$. Padrões de controle de obstáculos ao espaço aéreo em vigência nos EUA estão contidos na e-CFR Part 77 (EUA, 2017).

As regras vigentes no Brasil são bastante similares aos padrões da ICAO, sendo que a principal norma brasileira para o projeto de aeródromos é a RBAC 154 (ANAC, 2012), enquanto a restrição de obstáculos ao espaço aéreo é tratada no país pela Portaria 957 (BRASIL, 2015).

Esta tese e as informações doravante apresentadas nesta seção baseiam-se nos padrões da ICAO para o projeto de aeródromos, previstos no Anexo 14 (ICAO, 2004).

\subsubsection{DESCRIÇÃO DOS PADRÕES E DAS GEOMETRIAS DE INTERESSE}

Muitos dos padrões da ICAO são estabelecidos com base no chamado código de referência do aeródromo (ARC - Aerodrome Reference Code), que é composto por um número e uma letra: o número representa uma classe de aeronaves, conforme seu desempenho dinâmico, correspondente a uma faixa de comprimento de pista necessário para decolagem. Já a letra do código corresponde a um agrupamento de aeronaves baseado em duas características geométricas, predominando a mais demandante, são elas a envergadura e a largura do trem de pouso. Por exemplo, uma aeronave Boeing 747-400 é compatível com um aeródromo projetado para o ARC 4E. No entanto, nem todos os critérios de projeto são baseados no ARC, o que faz com que a compatibilidade não seja garantida para todos os componentes do aeródromo.

As disposições do Anexo 14 (ICAO, 2004) são estabelecidas na forma de SARPS (Standards and Recommended Practices), sendo os padrões (standards) requisitos obrigatórios, enquanto as recomendações (recommended practices) são opcionais, cabendo aos Estados a decisão de incorporá-las aos padrões de projeto.

Os itens seguintes introduzem as geometrias de interesse para esta pesquisa, compreendendo a pista de pouso e/ou de decolagem (RWY) e suas áreas e superfícies de proteção.

3Uma nova versão da 150/5300-13A - Airport Design (FAA, 2014) foi publicada no último quadrimestre de 2012, com uma nova alteração em 2014. 


\subsubsection{PISTA DE POUSO E/OU DE DECOLAGEM (RWY - Runway)}

Uma pista é destinada usualmente tanto ao pouso quanto à decolagem de aeronaves. No entanto, uma pista pode também ser provida exclusivamente para pouso ou para decolagem.

A orientação da pista depende: da direção dos ventos; da presença de obstáculos; da influência sobre o tráfego aéreo, especialmente em áreas de tráfego intenso; dos efeitos ambientais impostos à vizinhança, como o ruído; entre outros.

Um aeródromo pode conter mais de uma pista, que podem ser paralelas ou quase-paralelas, para aumentar a capacidade do sistema. Um aeródromo também pode apresentar pistas cruzadas, quando a distribuição de ventos é tal que uma única orientação não consegue oferecer um fator de utilização adequado (usability factor).

Enquanto pistas cruzadas não podem acomodar operações concomitantes de pouso e decolagem, em pistas paralelas ou quase-paralelas, operações simultâneas podem ser realizadas, desde que exista separação adequada entre os eixos das pistas, observados os padrões operacionais vigentes.

O comprimento da pista depende do desempenho em pouso e decolagem da aeronave crítica, considerando-se a rota a ser servida, entre outros fatores, como altitude e temperatura. A largura padrão de uma RWY depende principalmente do ARC (ICAO, 2004).

Padrões de projeto também podem impor acostamentos e blast pads, que são componentes físicos adjacentes às RWYs, destinados a proteger contra a erosão, ingestão de objetos estranhos (FOD - Foreign Object Damage), entre outras funções. Além disso, algumas pistas apresentam áreas de giro, que aumentam a área disponível para o giro de 180 graus, normalmente na extremidade da RWY.

Padrões de projeto também se aplicam às declividades transversais e longitudinais de uma RWY, atendendo a objetivos como, por exemplo, a visibilidade da pista desde a cabine de comando.

\subsubsection{2 ÁREAS DE PROTEÇÃO EM SOLO DA PISTA DE POUSO E/OU DE DECOLAGEM}

De forma a proteger as operações nas pistas de pouso e/ou decolagem (RWYs), estão previstas áreas de proteção como a faixa de pista de pouso e decolagem ${ }^{4}$ (runway strip) e a RESA (Runway End Safety Area). 
Longitudinalmente, a faixa de pista de pouso e decolagem inicia-se a uma dada distância antes da cabeceira e termina a esta mesma distância depois do final da pista ou da zona de parada (SWY $)^{5}$. Tal distância varia entre $30 \mathrm{~m}$ e $60 \mathrm{~m}$, dependendo do ARC. A largura, por sua vez, depende também do ARC e do tipo de aproximação prevista, variando entre $60 \mathrm{~m}$ e $300 \mathrm{~m}$. Padrões também se aplicam para a restrição de objetos fixos e móveis na faixa de pista de pouso e decolagem, bem como sobre as declividades e a capacidade de suporte da superfície.

Já a RESA inicia-se no final da faixa de pista de pouso e decolagem, devendo apresentar pelo menos 90m de comprimento. O Anexo 14 (ICAO, 2004) apresenta recomendações para aumentar esta distância para até $240 \mathrm{~m}$ dependendo do ARC. A largura mínima é equivalente ao dobro da largura da pista, mas também são apresentadas recomendações para aumentar a largura, dependo do ARC e do tipo de aproximação. De forma similar à faixa de pista de pouso e decolagem, padrões se aplicam para a restrição de objetos fixos e móveis na RESA, bem como sobre as declividades e a capacidade de suporte da sua superfície.

\subsubsection{SUPERFÍCIES DE PROTEÇÃO AO ESPAÇO AÉREO}

Esta subseção aborda as superfícies de proteção ao espaço aéreo previstas no Anexo 14 (ICAO, 2004). Estas superfícies são bastante similares àquelas previstas na Portaria 957 (BRASIL, 2015), referentes ao chamado PBZPA (Plano Básico de Zona de Proteção de Aeródromo).

As referidas superfícies formam um conjunto cuja geometria depende do ARC e do tipo de aproximação executada, sendo estabelecido para cada sentido de operação e considerando as distâncias declaradas ${ }^{5}$, podendo englobar uma única pista ou um conjunto. Dependendo do tipo de aproximação e do ARC, nem todas as superfícies são exigidas. A Portaria 957 (BRASIL, 2015) e ICAO (1983) dissertam sobre a função das diversas superfícies de proteção ao espaço aéreo.

Um objeto que ultrapasse os limites estabelecidos pelas áreas e superfícies de proteção será considerado um obstáculo, podendo ser necessária a sua remoção. Por outro lado, na prática, determinados obstáculos são admitidos, algumas vezes exigindo medidas mitigatórias, que podem impactar negativamente sobre a capacidade, padronização dos procedimentos e sobre economia das operações.

Conforme ICAO (1983), os planos de proteção ao espaço aéreo previstos no Anexo 14 (ICAO, 2004) destinam-se não somente à proteção das operações em um

\footnotetext{
${ }^{5}$ Para uma descrição sobre distâncias declaradas, incluindo-se zonas de parada ou stopways e zonas desimpedidas ou clearways ver subseção 1.2.3.
} 
aeródromo, mas também protegem um espaço aéreo de interesse para o seu desenvolvimento planejado, devendo estar presentes nas leis locais de zoneamento. Já os procedimentos de pouso e decolagem propriamente ditos possuem superfícies próprias a protegê-los (ICAO, 2006b).

Em relação a obstáculos, o Anexo 14 também cita o princípio de sombra (shielding), discutido em maiores detalhes em ICAO (1983) e em (BRASIL, 2015). Segundo este princípio, a existência de alguns obstáculos considerados irremovíveis pode justificar a permanência de outros obstáculos, dependendo da sua altura e posição em relação a uma pista de pouso e/ou de decolagem (RWY).

A descrição dos padrões a seguir exposta limita-se às aproximações de precisão CAT II/III para aeródromos cujo ARC é 4-F. Este caso corresponde à maior complexidade geométrica das áreas de proteção mais demandantes. Ressalta-se, que não foram tratados, no entanto, os casos que envolvem saídas e aproximações em curva.

Conforme ICAO (2004, p. 4-7), para aproximações CAT II/III, as seguintes superfícies são exigidas, conforme ilustram a Figura 1-3 (onde o pouso/decolagem ocorre da esquerda para a direita), e a Figura 1-4:

- Superfície de aproximação interna;

- Superfície de pouso interrompido (balked landing surface).

- Superfície de transição interna;

- Superfície de aproximação;

- Superfície horizontal interna;

- Superfície de transição; e

- Superfície cônica. 


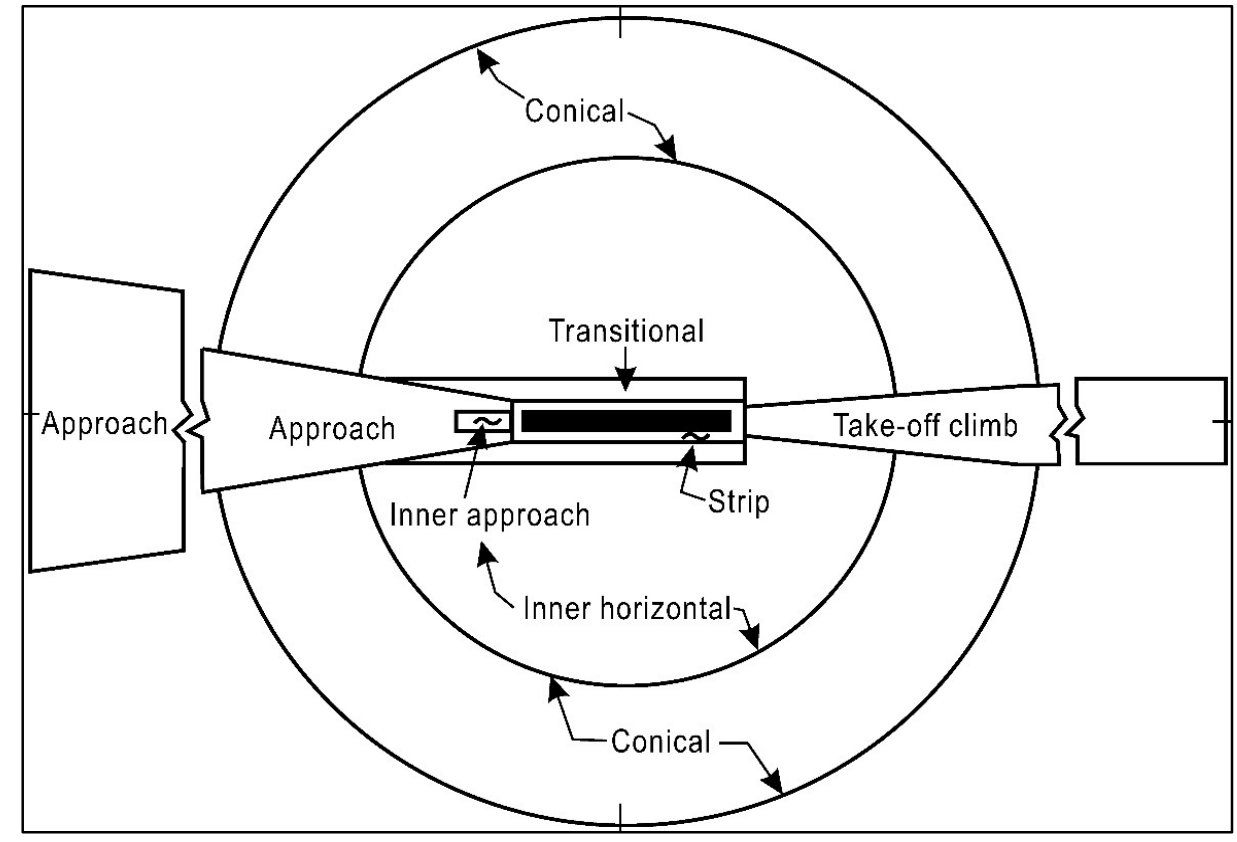

Figura 1-3 Superfícies previstas no Anexo 14 da ICAO.

FONTE: ICAO (2004)

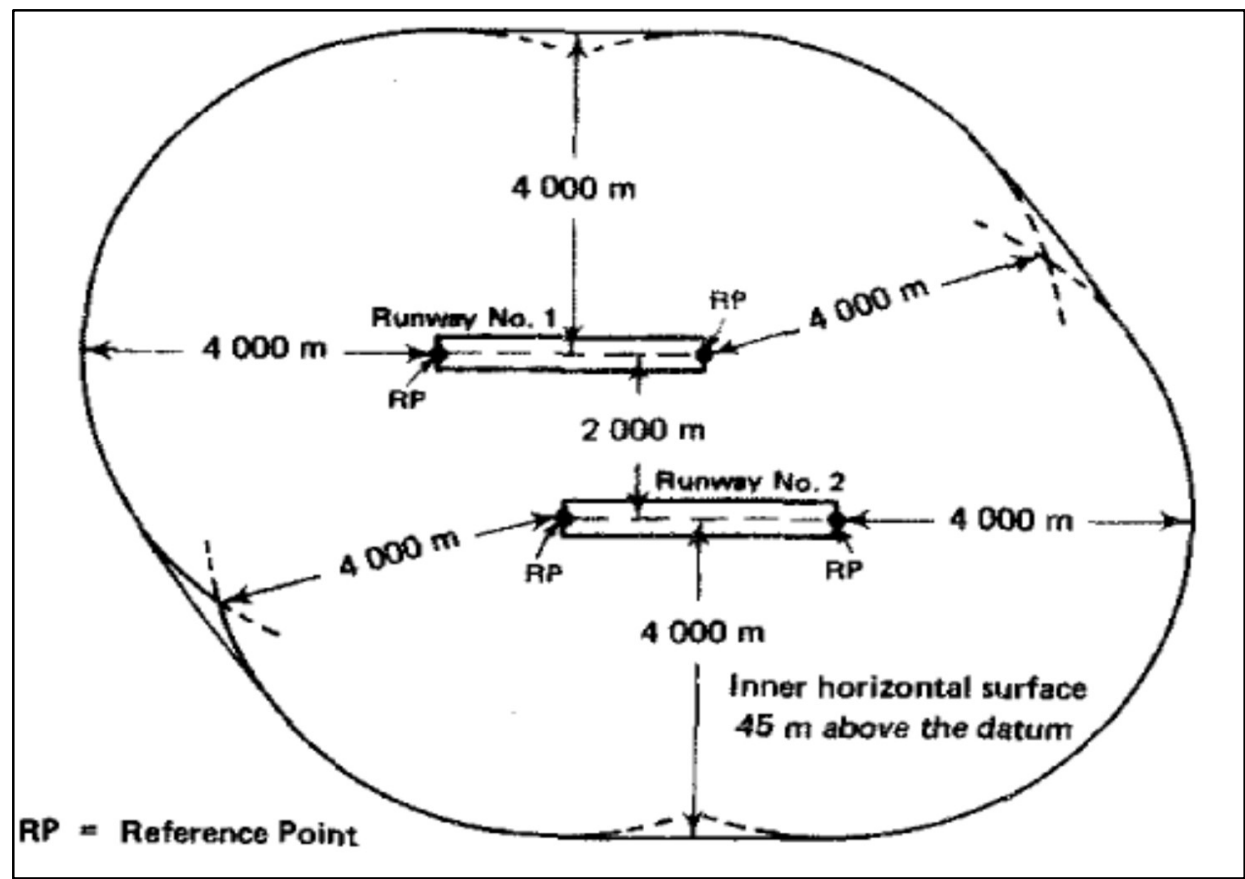

Figura 1-4 Superfície horizontal interna.

FONTE: ICAO (1983) 
A superfície de aproximação interna, a superfície de pouso interrompido e a superfície de transição interna delimitam objetos na vizinhança imediata da RWY, sendo um importante critério para avaliação de pistas de táxi paralelas e posições de espera (ver Figura 1-5).

A superfície de aproximação interna origina-se a $60 \mathrm{~m}$ da cabeceira, formando um retângulo com 900 m de comprimento, com inclinação de $2 \%$ e 155m de largura. A referência de altura para o início desta superfície é ponto médio da cabeceira. $O$ início desta superfície coincide longitudinalmente com o final da faixa de pista de pouso e decolagem.

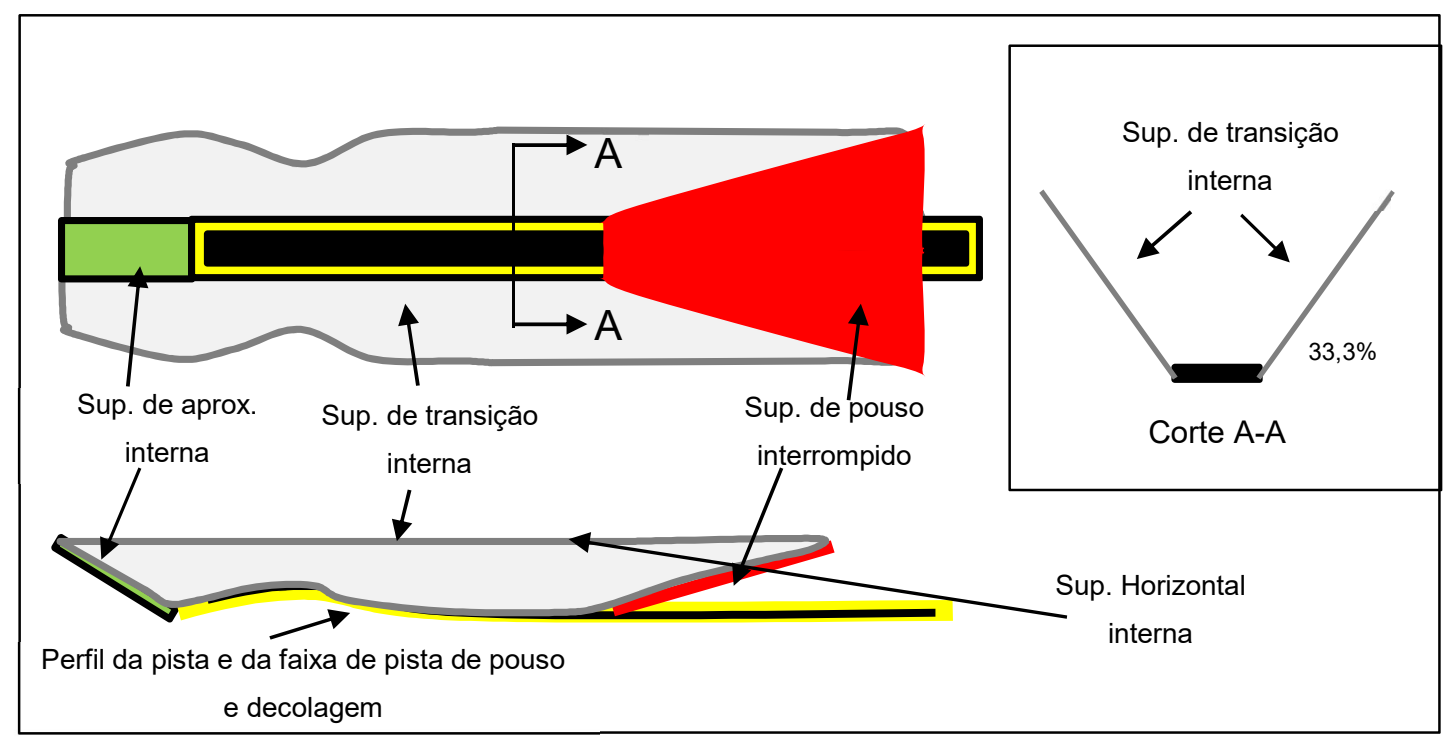

Figura 1-5 Superfícies de aproximação interna, transição interna e pouso interrompido. FONTE: Elaborado pelo autor.

A superfície de pouso interrompido inicia-se a certa distância depois da cabeceira, no sentido de pouso. Esta distância é o menor valor entre $1.800 \mathrm{~m}$ e o final da pista. A superfície de pouso interrompido é um trapézio, cuja base menor se encontra na altura da RWY e possui largura de $155 \mathrm{~m}$. A partir deste ponto a superfície sobe a uma declividade de $3,33 \%$ com divergência de $10 \%$ em cada lateral, até encontrar a base maior, na altura da superfície horizontal interna.

A superfície de transição interna possui dois limites: um superior, no plano da superfície horizontal interna e um inferior, ao longo da lateral da superfície de aproximação interna, passando pela faixa de pista de pouso e decolagem e depois subindo pela lateral da superfície de pouso interrompido. Quando o limite inferior passa pela lateral da RWY, assume a altura da sua linha de centro. A superfície de transição interna sobe lateral e ortogonalmente à RWY com uma declividade de $33,3 \%$. Como consequência da variação de altura no perfil da RWY, o limite superior 
da superfície de transição interna atinge o plano da superfície horizontal interna a diferentes distâncias desde a linha de centro da RWY, caracterizando um contorno superior irregular.

Além destas superfícies próximas à pista, outras superfícies iniciam-se na vizinhança da pista e estendem-se para fora e para cima a partir desta, delimitando a presença de objetos, de forma a proteger o espaço aéreo para seus interesses atuais e planejados. As descrições a seguir continuam admitindo o ARC 4-F e categorias de aproximação CAT II/CAT III.

A superfície de aproximação inicia-se na mesma posição da superfície de aproximação interna, mas sua largura inicial é de $300 \mathrm{~m}$, coincidindo com a largura da faixa de pista de pouso e decolagem. A partir deste ponto, esta superfície sobe na direção oposta de uma aproximação, possuindo três seções: i) na primeira seção sua declividade é de $2 \%$, possuindo esta seção 3.000 m de comprimento; ii) na segunda seção, a declividade é de $2,5 \%$ e o comprimento padrão é de $3.600 \mathrm{~m}$, podendo esta dimensão sofrer variações, dependendo da altura da $\mathrm{OCA} / \mathrm{H}$; e iii) esta seção é horizontal desde o final da segunda seção, totalizando $15.000 \mathrm{~m}$ de distância horizontal desde o início da superfície de aproximação. A superfície de aproximação possui uma forma em planta que equivale a um trapézio, com divergência de $15 \%$ em cada lateral.

A superfície horizontal interna forma um conjunto único de superfícies em um aeródromo, possuindo este uma ou mais pistas. Tal superfície possui uma forma em planta caracterizada por círculos de raio 4.000m centrados nas extremidades das pistas e unidos por tangentes. A superfície horizontal interna encontra-se em um plano situado a 45m sobre um ponto de referência do aeródromo, discutido em ICAO (1983).

Ainda, para pistas que suportam decolagens, o Anexo 14 (ICAO, 2004) exige a superfície de decolagem. Esta corresponde a um plano inclinado centrado no eixo da pista que se inicia $60 \mathrm{~m}$ depois do final da pista ou imediatamente após a zona desimpedida, se disponível, valendo a maior distância. Esta superfície inicia-se a uma dada altura e possui uma aresta interna ortogonal à pista com $180 \mathrm{~m}$ de comprimento. Esta altura inicial corresponde ao ponto mais elevado do eixo da pista desde o final da pista e o início da superfície de decolagem. Caso uma zona desimpedida seja oferecida, esta altura inicial será a maior altura encontrada sobre o eixo da zona desimpedida. A partir da aresta interna, a superfície sobe a uma dada declividade, com divergência de $12,5 \%$ em cada lateral até atingir uma largura final. A partir da largura final, a largura se mantém, sem mudança de declividade. Esta superfície estende-se até totalizar $15.000 \mathrm{~m}$ de comprimento horizontal. A largura final padrão é de $1.200 \mathrm{~m}$, podendo sofrer variações quando o procedimento de decolagem inclui 
mudanças de orientação superiores a 15 graus. A declividade padrão é de $2 \%$, podendo sofrer variação por requisitos de desempenho das aeronaves. A Figura 1-6 ilustra a superfície de decolagem, com operações em ambos os sentidos.

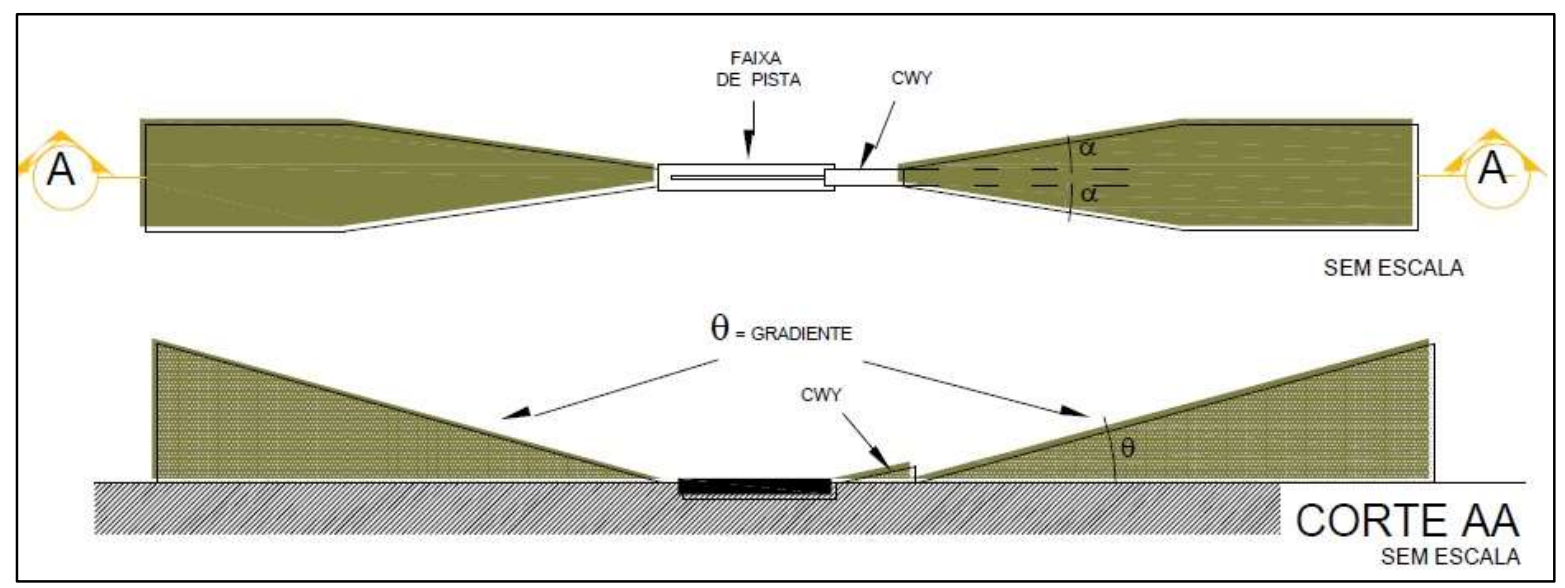

Figura 1-6 Superfície de decolagem

FONTE: (BRASIL, 2015)

\subsubsection{DISTÂNCIAS DECLARADAS}

Para cada sentido de operação em uma pista de pouso e/ou de decolagem (RWY), requisitos de desempenho das aeronaves exigem consideração de quatro distâncias:

- TORA (Take-Off Run Available): distância sobre a pista declarada disponível e adequada para a corrida de decolagem;

- TODA (Take-Off Distance Available): distância declarada disponível e adequada para a corrida de decolagem, compreendendo a pista (TORA) e a zona desimpedida (clearwy -CWY), se disponível;

- ASDA (Accelerate Stop Distance Available): distância declarada disponível e adequada para a corrida de decolagem, mais o comprimento da zona de parada (Stopway -SWY), se disponível;

- LDA (Landing Distance Available): distância declarada disponível e adequada para a corrida em solo de uma aeronave que pousa.

A zona desimpedida (CWY) é uma área livre de objetos longitudinalmente adjacente à área destinada à corrida de decolagem. Por outro lado, a zona de parada (SWY) possui preparação para a passagem eventual de uma aeronave que tenha abortado a decolagem (ICAO, 2004). 
As distâncias declaradas são discutidas em maiores detalhes em ICAO (2006a), cabendo uma série de situações, ilustradas na Figura 1-7, que considera operações da esquerda para a direita. Na situação $A$, todas as distâncias são iguais. Na situação B, a CWY está disponível, o que pode, por exemplo, permitir um maior peso de decolagem para uma aeronave que decola. No caso C, uma SWY foi adicionada, podendo também, eventualmente permitir um aumento de peso de uma aeronave que decola. No caso D, a cabeceira está deslocada, implicando em redução da distância LDA e manutenção das demais, à medida que a decolagem continua a iniciar-se no começo da pista. As situações $\mathrm{E}$ e $\mathrm{F}$ por sua vez, compreendem outras combinações.

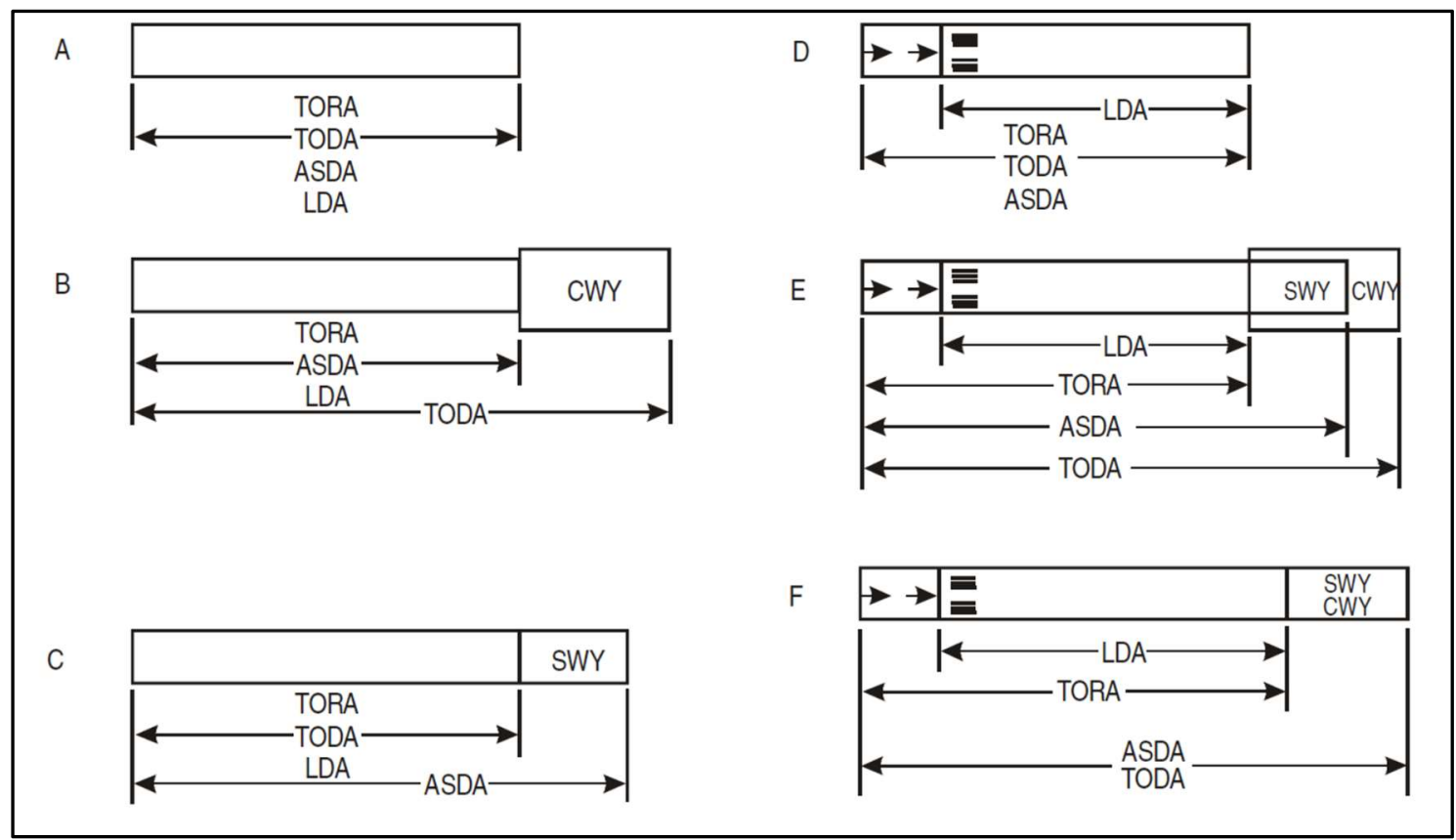

Figura 1-7 Distâncias declaradas.

FONTE: (ICAO, 2006a)

\subsubsection{SÍNTESE DO PROBLEMA: ASPECTOS GEOMÉTRICOS}

Esta subseção discute os aspectos geométricos do problema em estudo. As descrições a seguir pressupõem um sistema euclidiano de coordenadas, o mesmo sistema utilizado para a especificação dos padrões.

A pista de pouso e/ou de decolagem (RWY) situa-se no espaço tridimensional, pois seu eixo segue o perfil de altura do terreno, o que caracteriza este componente como uma superfície retangular em planta, mas sinuosa verticalmente. Esse mesmo padrão se repete para a faixa de pista de pouso e decolagem. 
As superfícies de aproximação, de aproximação interna, de pouso interrompido e de decolagem são descritas como retângulos e/ou trapézios, inclinados verticalmente ${ }^{6}$.

As superfícies de transição e de transição interna apresentam especificações geométricas mais complexas, pois, enquanto a altura máxima é fixa, a altura inicial segue a variação do perfil da pista. Logo estas duas superfícies de proteção são descritas por uma sinuosa superfície que, quando discretizada, pode ser vista como uma sequência de planos inclinados adjacentes.

Quando as superfícies de proteção atingem determinada altura, forma-se um plano paralelo ao plano $\mathrm{XY}$, com recortes laterais formados por arcos e retas tangentes. Esta é uma forma de descrever a geometria da superfície horizontal interna.

A superfície cônica compreende um plano inclinado no eixo vertical, com contornos no plano $\mathrm{XY}$ formados por arcos e retas tangentes.

Cada uma das superfícies e áreas descritas deve ser analisada isoladamente, o que leva a possíveis sobreposições e descontinuidades do conjunto de superfícies, se visto como uma geometria única. Apenas a superfície horizontal interna possui sobreposições que precisam ser "aparadas" para gerar a geometria prevista em norma.

Em nenhum caso, no entanto, as superfícies delimitam um volume interno, o que evita a necessidade de representações geométricas sólidas. Além disso, cada superfície $s$ pode ser entendida como uma função $z_{s}=f(x, y)$, de forma que no domínio da superfície, para cada ponto $x, y$, existe apenas um valor para $z$.

\subsubsection{SÍNTESE DO PROBLEMA: ASPECTOS ESPACIAIS}

Como discutido no item anterior, algumas geometrias de interesse na modelagem estão relacionadas ao perfil de altura do eixo da pista de pouso e/ou de decolagem (RWY). Uma vez que a configuração do sistema de pistas é um dado de entrada, torna-se necessário que o modelo seja capaz de associar automaticamente um perfil de pista a cada configuração proposta.

Dado tal objetivo em relação à funcionalidade do modelo e conhecidas suas implicações, cria-se a necessidade de uma modelagem digital do terreno, acessível internamente no modelo.

${ }^{6} \mathrm{~A}$ menos que estejam previstos procedimentos de saída e aproximação em curva. Ver ICAO (2006b). 
Além disso, algumas características do problema incitam preocupações em relação aos referenciais geográficos e aos sistemas de coordenadas:

- O uso combinado de técnicas de sensoriamento remoto, GPS e topografia, apesar das potenciais vantagens, leva a um conjunto de dados em diferentes referenciais e sistemas de coordenadas;

- Elevações de referência para as superfícies imaginárias costumam se basear em coordenadas geográficas;

- Dados sobre topografia e objetos fixos podem estar disponíveis em bases de dados sob mais de um referencial, geográfico ou projetado, assim como informações sobre o aeródromo e sobre as pistas; e

- O projeto das áreas e superfícies de proteção baseia-se em regras geométricas definidas conforme um sistema euclidiano.

Diante dessas características do problema, a proposição de uma metodologia baseada em um sistema de coordenadas e em um referencial pré-definido pode resultar muito restritiva, exigindo pré-processamento e/ou pós processamento, de forma a atingir-se adequada funcionalidade prática.

Além disso, existe o risco de que um tratamento inadequado dos dados espaciais leve a níveis de erro indesejáveis ou mesmo inaceitáveis.

\subsection{CONCLUSÕES DO CAPÍTULO E ESTRUTURA DA PESQUISA}

Postos os objetivos e caracterizado o problema em questão, é necessário buscar na literatura científica o atual estado da arte para a modelagem geométrica de aeródromos. Torna-se necessário avaliar ainda as metodologias que possam eventualmente ser adaptadas e incorporadas ao modelo. A revisão bibliográfica referente a estes assuntos é apresentada no Capítulo 2.

A caracterização do problema aponta também que o mesmo requer adequado tratamento em dois aspectos: aspectos geométricos; e aspectos espaciais e geográficos. Diante disso, faz-se necessário buscar os conceitos relacionados a estes dois temas, cada um com uma literatura própria. Nesse sentido, o Capítulo 3 trata conceitos e abordagens à modelagem geométrica computacional, a partir da literatura na área de CAD (Computer Aided Design). Esta é fundamental para a representação virtual das geometrias e para sua manipulação. Por sua vez, o Capítulo 4 recupera conceitos sobre referenciais, sistemas de coordenadas, projeções e sobre a tecnologia GIS (Geographic Information System). Estes dois Capítulos são importantes para fundamentar e subsidiar a modelagem proposta nesta pesquisa. 
O Capítulo 5 apresenta um modelo inédito para a modelagem geométrica das áreas e superfícies de proteção de um sistema de pistas, de acordo com os critérios da ICAO. Apresenta também aspectos relacionados à sua implementação em computador.

O Capítulo 6 apresenta os resultados do modelo geométrico após sua implementação em computador. A análise dos resultados baseia-se nas saídas gráficas do modelo e também em informações provenientes do console de execução. O modelo é avaliado em relação à sua capacidade de geração e representação das geometrias e também em relação à sua capacidade de identificar interferências geométricas, quando submetido a um conjunto de objetos fixos e móveis.

Finalmente são apresentadas as conclusões e recomendações para estudos futuros.

O texto ainda inclui um conjunto de anexos e apêndices. 


\section{CAPÍTULO 2 - O PROBLEMA NA LITERATURA}

Este capítulo tem por propósito fundamentar a presente pesquisa em relação a dois aspectos: como a pesquisa se insere na literatura de projeto geométrico de aeródromos; e, de forma mais abrangente, como a pesquisa se relaciona com a abordagem geométrica ao problema do layout. Este último é um tema mais amplo, mas considera-se que seus métodos possuem semelhanças com a presente pesquisa.

A exposição sobre o projeto geométrico de aeródromos baseia-se em softwares e na literatura técnica e científica.

A abordagem geométrica ao problema do layout engloba publicações nas áreas de planejamento do canteiro de obras, desenho das rotas de tubulações e layout em plantas industriais.

\subsection{SOFTWARES RELACIONADOS}

Buscas no portal de periódicos da Capes, no portal Science Direct e no buscador Google não apresentaram nenhum resultado que correspondesse a softwares Open Source relacionados ao projeto geométrico de aeródromos ou à análise de obstáculos ao espaço aéreo.

No entanto, foram encontrados produtos comerciais, apresentados na Tabela 2-1. Em relação aos programas comerciais relacionados à análise das superfícies de proteção ao sistema de pistas, foram encontrados o 3DAAP, o SKYSAFE e o ArcGis for Aviation: Airports. O 3DAAP aparece atualmente no site da Planning Technology (PLANNING TECHNOLOGY, 2017) apenas como um serviço, sem opções para download e sem informações técnicas sobre o produto. Os outros dois programas, conforme apurado nos websites de seus desenvolvedores, não oferecem opção de acesso via programação, portanto, não permitindo extensão das suas funções ou automatização das análises. Além disso, não existem informações sobre a modelagem utilizada, sobre as limitações dos programas ou sobre o desempenho computacional. Silva e Gualda (2015) e Silva e Gualda (2017) apresentam uma discussão mais detalhada sobre os softwares relacionados ao projeto geométrico de aeródromos. 
Tabela 2-1 - Softwares relacionados ao projeto de aeródromos

\begin{tabular}{|c|c|c|c|c|c|}
\hline Característica & 3DAAP & AeroTurn3D* & PathPlanner* & SKYSAFE & $\begin{array}{l}\text { ArcGis for } \\
\text { Aviation: } \\
\text { Airports }\end{array}$ \\
\hline Licença & $\begin{array}{l}\text { Freeware, mas } \\
\text { exige Autodesk } \\
\text { Map 3D }\end{array}$ & Proprietário & Proprietário & Proprietário & $\begin{array}{l}\text { Proprietário. } \\
\text { Exige ArcGis } \\
\text { for Desktop }\end{array}$ \\
\hline Análise de docagem & & $\boldsymbol{0}$ & 0 & & \\
\hline Análise de Jet Blast & & 0 & 0 & & \\
\hline Análise de obstáculos & $\boldsymbol{0}$ & & & 0 & 0 \\
\hline $\begin{array}{l}\text { Desenho e análise de } \\
\text { fillets }\end{array}$ & & $\boldsymbol{0}$ & 0 & & \\
\hline $\begin{array}{l}\text { Visibilidade a partir } \\
\text { da torre de controle }\end{array}$ & 0 & & & & \\
\hline $\begin{array}{l}\text { ALP (Airport Layout } \\
\text { Plan) }\end{array}$ & 0 & & & & 0 \\
\hline $\begin{array}{l}\text { Análise de } \\
\text { separações em pistas }\end{array}$ & & $\boldsymbol{0}$ & $\boldsymbol{0}$ & & \\
\hline Fonte & $\begin{array}{l}\text { (FAA e } \\
\text { PLANNING } \\
\text { TECHNOLOGY, } \\
\text { INC, 2005) }\end{array}$ & $\begin{array}{l}\text { (TRANSOFT } \\
\text { SOLUTIONS, } \\
2016)\end{array}$ & $\begin{array}{l}\text { (TRANSOFT } \\
\text { SOLUTIONS, } \\
2016)\end{array}$ & \begin{tabular}{|l|} 
(TRANSOFT \\
SOLUTIONS, \\
2017 )
\end{tabular} & (ESRI, 2016) \\
\hline
\end{tabular}

*: Substituído pelo software AviPLAN.

Fonte: Elaborado pelo autor

\subsection{MODELAGEM GEOMÉTRICA EM AERÓDROMOS - LITERATURA}

A literatura que trata a modelagem de áreas e superfícies de proteção em um aeródromo é bastante restrita, de forma que apenas dois trabalhos foram identificados. Um emprega o programa GEOPAK Site, concebido para o projeto de estradas e aterros. O outro utiliza um software GIS de propósito genérico, como o ArcGis.

Wheetley et al. (2009) apresentam uma aplicação não convencional do software proprietário GEOPAK Site, da Bentley, à análise de obstáculos no Aeroporto de Dallas/Fort Worth (KDFW), nos Estados Unidos. Este programa foi idealizado para tarefas relacionadas ao projeto de estradas e aterros. Após estudarem um conjunto de superfícies de proteção ao espaço aéreo estabelecidas pela FAA (Federal Aviation Administration), o órgão americano responsável pela aviação civil, os autores apresentam a modelagem da geometria das superfícies através da interface gráfica do programa. Uma das vantagens apresentadas é a análise digital de obstáculos. Conforme os autores, a análise de obstáculos, quando realizada por métodos convencionais, em campo, é uma tarefa de difícil execução, já que as superfícies de proteção são geometrias imaginárias, de difícil referência material. Além disso, o 
projeto virtual no GEOPAK Site pode ser exportado a outros programas, permitindo, por exemplo, que o projetista possa avaliar o efeito que a elevação de uma pista de táxi tem sobre a pista de pouso e/ou de decolagem vizinha (RWY). Quanto mais elevada uma pista de táxi adjacente a uma RWY, maior a elevação das aeronaves que a utilizam, e maior a chance de violação de uma superfície de proteção.

Entre as desvantagens da metodologia descrita por Wheetley et al. (2009), podese citar a incapacidade de deteç̧ão automática das violações, exigindo trabalho humano para a comparação de alturas, objeto a objeto. Ainda, o modelo precisa ser construído/revisado para cada pista, não respondendo automaticamente a mudanças nas variáveis de projeto.

Santos e Müller (2014) apresentam uma metodologia de análise de obstáculos à superfície de segmento visual utilizando o software ArcGis, para a pista do Aeroporto de Campo de Marte (código ICAO SBMT), em São Paulo. Os autores descrevem uma metodologia manual de entrada dos dados geométricos do aeroporto. Através de uma parametrização da referida superfície de proteção, um conjunto de objetos é analisado, através de fórmulas que permitem determinar a altura da superfície de segmento visual na posição $(x, y)$ do objeto. A comparação entre a altura da superfície e a altura do objeto permitem determinar se as violações ocorrem e também a sua magnitude, em metros.

$\mathrm{Na}$ metodologia descrita por Santos e Müller (2014), cada configuração analisada precisa ser inserida manualmente, ou seja, a metodologia utilizada não se mostra flexível para acomodar qualquer variação nos dados de entrada (ex.: posição da cabeceira) exigindo retrabalho manual.

Khalafallah e El-Rayes (2011) apresentam um modelo de otimização multiobjetivo relacionado ao layout de aeroportos, sob um ponto de vista do planejamento das atividades de construção durante projetos de expansão. $\mathrm{O}$ trabalho propõe a otimização dos impactos das atividades de construção sobre o aeroporto, através de cinco funções objetivo: 1) maximização da segurança (safety) na construção; 2) maximização de um índice de controle de resíduos (debris); 3) maximização de um índice de controle de vida selvagem; 4) maximização de um índice de segurança (security) relacionado à construção; e 5) minimização de um custo total do layout, baseado em diferentes fatores contribuintes, como custo total de transporte, custo de controle de resíduos, custo de controle da vida selvagem e custo de controle de segurança (security). O modelo se baseia em pesos e funções que relacionam variáveis de decisão representadas pela posição das diversas instalações no sítio. Após a aplicação de métodos evolucionários de otimização, além dos custos, o 
modelo gera uma visualização $2 \mathrm{D}$ em $\mathrm{CAD}$ que permite analisar as configurações resultantes.

Na metodologia proposta por Khalafallah e El-Rayes (2011), como apontado pelos próprios autores, as geometrias são representadas por retângulos bidimensionais e os limites do sítio por linhas retas.

As subseções seguintes baseiam-se em outros tipos de aplicações na área de engenharia, onde se explora de forma mais abrangente a modelagem geométrica em problemas de layout.

\subsection{MODELAGEM GEOMÉTRICA NO LAYOUT DO CANTEIRO DE OBRAS}

Sadeghpour, Moselhi e Alkass (2004) propõem um método de análise e melhoria do layout em canteiros de obras que combina o software AutoCAD com programação VBA. O AutoCAD é utilizado para a geração de geometrias que representam elementos fixos ou temporários do canteiro de obras, como o espaço necessário para equipamentos, escritórios, estacionamentos, materiais, etc. Estas geometrias são armazenadas, gerando bibliotecas, de forma que o próprio usuário alimenta uma base de dados de objetos. A automação através do VBA permite atribuir pesos entre os objetos, levando a uma caracterização funcional do canteiro, expressa em uma função que mede o custo total de transporte. As restrições, além de fórmulas que relacionam os objetos, também são tratadas com uma lógica de grade, que discretiza a área disponível para o canteiro em $\mathrm{M} X \mathrm{~N}$ células. Para tanto, a inserção e posicionamento de um objeto aloca um dado número de células, de forma temporária ou permanente. Assim, interferências geométricas são evitadas. Utilizando a interface do AutoCAD, o usuário pode fazer modificações no layout e observar o comportamento da função objetivo.

Ma, Shen e Zhang (2005) apresentam um modelo computacional (4D-ISPS) que permite gerar o que os autores apresentam como um modelo 4D: além da geometria, a dimensão tempo é adicionada. O modelo permite analisar o layout e as interferências geométricas em um canteiro de obras voltado à construção de edifícios. A ferramenta por eles proposta e implementada integra o AutoCAD com o MS Project. A partir do primeiro, são geradas as geometrias de interesse, e neste é realizada a visualização do projeto. Ainda, os autores propõem um método automatizado de construção de conjuntos a partir de partes repetitivas, como paredes, colunas e vigas. Este método foi implementado por eles e baseia-se em rotações e translações para a montagem 
dos conjuntos. O MS Project é utilizado para gerar a sequência de atividades de construção, relacionando os recursos com o tempo. O resultado da aplicação do modelo é a visualização 3D do canteiro de obras ao longo do processo de construção, permitindo ao projetista prever possíveis conflitos de recursos e, assim, alterar por exemplo o cronograma da obra.

Zhou, Abourizk e Al-Battaineh (2009) apresentam um modelo de simulaçãootimização para o problema do layout de um canteiro de obras para a construção de túneis. A parte de simulação envolve um modelo geométrico segundo o qual os recursos que requerem espaço físico no canteiro, como materiais e máquinas, são representados por retângulos. A parte de otimização é abordada através de um algoritmo genético que busca otimizar uma função objetivo baseada nos custos de transporte no canteiro. Entre as restrições consideradas estão a não sobreposição de retângulos (recursos) necessários simultaneamente no canteiro; a exigência de que todas as instalações temporárias fiquem completamente contidas no interior do canteiro; a posição relativa entre alguns recursos conflitantes entre si; e a exigência de que as rotas de circulação devam possuir uma largura mínima de $4 \mathrm{~m}$, o que exige separação entre instalações.

O trabalho de Zhou, Abourizk e Al-Battaineh (2009) é especialmente interessante para aqueles que desejam tratar os problemas de layout em um ambiente 2D onde os componentes podem ser tratados como retângulos. Essa geometria simplificada permite que a modelagem geométrica proposta possa ser aplicada diretamente na forma de equações. Geometrias mais complexas, especialmente aquelas que incorporam alturas, necessitam de um modelo geométrico mais sofisticado, e parece ser este o caso das superfícies que protegem uma pista de pouso e/ou decolagem.

\subsection{MODELAGEM GEOMÉTRICA NO LAYOUT DE DUTOS}

Ito (1999) apresenta um modelo geométrico para o desenho do layout de dutos através de uma estratégia geométrica que emprega células quadradas em um ambiente 2D. Dessa maneira, uma interferência geométrica pode ser evitada por um critério binário, de forma que células ocupadas por obstáculos não estão disponíveis para uma nova rota dos dutos. A pesquisa propõe e testa a aplicação de um algoritmo genético, tanto como método de solução, quanto como método de otimização. A função objetivo mede a adaptação de uma dada solução ao meio, no contexto do algoritmo genético. Tal adaptação ao meio é quantificada através de um índice 
potencial, de modo que obstáculos pesam negativamente e a proximidade com paredes pesa positivamente na função objetivo. De acordo com o autor, é interessante que a trajetória de um duto seja adjacente às paredes.

O trabalho apresentado por Ito (1999), além da limitação caracterizada pela sua natureza 2D, ainda possui um inconveniente que é a abordagem numérica, segundo a qual o espaço precisa ser discretizado. Isso pode não ser um problema, desde que os recursos computacionais sejam compatíveis.

\subsection{MODELAGEM GEOMÉTRICA NO LAYOUT DE PLANTAS INDUSTRIAIS}

Drira, Pierreval e Haji-Gabouj (2007) apresentam uma revisão sobre os problemas de layout no contexto das instalações industriais. Eles classificam os estudos de acordo com as seguintes categorias: 1) Formulação discreta, segundo a qual a área estudada é divida em $n$ áreas menores, e a decisão consiste em alocar os recursos a estas áreas; 2) Formulação contínua, na qual geometrias simplificadas, como retângulos, são utilizadas para modelar o problema da sobreposição de geometrias; 3) Formulação Fuzzy, na qual os dados que definem o problema não são conhecidos com precisão, razão pela qual recorre-se a métodos estocásticos; 4) Formulações multiobjetivo, nas quais busca-se melhorar mais de uma medida de desempenho ao mesmo tempo; e 5) Formulações que tratam de forma integrada o layout da planta com o layout das células produtivas.

Em suas conclusões, após a revisão de diversos trabalhos, os autores apontam a necessidade de pesquisas que levem em consideração a terceira dimensão no layout da planta industrial, permitindo estudar as questões relacionadas ao transporte vertical. Ainda em relação ao transporte interno na planta, os autores citam a falta de estudos que combinem os problemas de layout com as decisões sobre métodos de transporte de materiais, assuntos, segundo eles, relacionados entre si. Os autores citam também a falta de softwares comerciais que sejam capazes de tratar de maneira geral o problema do layout. Aeroportos, portos e supermercados são citados como áreas que podem beneficiar-se do desenvolvimento dos estudos de layout na área de manufatura.

Wu, Wang e Feng (2016) abordam o problema do layout em plantas petroquímicas, relacionando a disposição das máquinas e dos processos químicos com o comprimento da rede de dutos que transporta os materiais dentro da planta. Eles propõem um método heurístico para resolver o problema, testando diferentes regras de decisão em um conjunto de casos. Os resultados do estudo mostram as 
relações entre o conjunto de regras aplicado e o comprimento total da tubulação necessária.

No estudo de Wu, Wang e Feng (2016), a extensão da rede de dutos é determinada por um método simplificado segundo o qual os componentes são posicionados regularmente no espaço. Trata-se, portanto, de um modelo de grade regular.

A revisão de literatura, com base nas pesquisas que abordam o problema do layout desde um ponto de vista geométrico, é sistematizada na Tabela 2-2.

Tabela 2-2 - Características das metodologias aplicadas ao problema do layout

\begin{tabular}{|c|c|c|c|c|c|}
\hline \multirow[b]{2}{*}{ Trabalho } & \multicolumn{2}{|c|}{ Implementação/solução } & \multirow[b]{2}{*}{$\begin{array}{l}\text { Concepção } \\
\text { geométrica }\end{array}$} & \multirow[b]{2}{*}{ Aplicação } & \multirow[b]{2}{*}{ Dimensões } \\
\hline & $\begin{array}{c}\text { Emprega } \\
\text { softwares } \\
\text { de terceiros }\end{array}$ & $\begin{array}{c}\text { Independente } \\
\text { de softwares } \\
\text { de terceiros }\end{array}$ & & & \\
\hline (ITO, 1999) & & 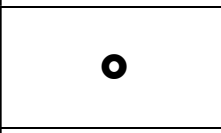 & $\begin{array}{l}\text { Emprego de grade } \\
\text { regular }\end{array}$ & $\begin{array}{l}\text { Projeto de } \\
\text { rotas de } \\
\text { dutos }\end{array}$ & $2 \mathrm{D}$ \\
\hline $\begin{array}{l}\text { (SADEGHPOUR, } \\
\text { MOSELHI e ALKASS, } \\
\text { 2004) }\end{array}$ & 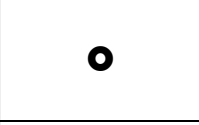 & & $\begin{array}{l}\text { Emprego de grade } \\
\text { regular }\end{array}$ & $\begin{array}{l}\text { Canteiro de } \\
\text { obras }\end{array}$ & $2 \mathrm{D}$ \\
\hline $\begin{array}{c}\text { (MA, SHEN e ZHANG, } \\
\text { 2005) }\end{array}$ & $\mathbf{0}$ & & $\begin{array}{c}\text { Geração de } \\
\text { geometrias via } \\
\text { AutoCAD, } \\
\text { transformadas via } \\
\text { programação }\end{array}$ & $\begin{array}{l}\text { Canteiro de } \\
\text { obras }\end{array}$ & $4 \mathrm{D}$ \\
\hline $\begin{array}{l}\text { (DRIRA, PIERREVAL e } \\
\text { HAJRI-GABOUJ, 2007) }\end{array}$ & - & - & $\begin{array}{l}\text { Apresenta trabalhos } \\
\text { com geometrias } \\
\text { discretas e com } \\
\text { contínuas } \\
\text { simplificadas } \\
\text { (retângulos) } \\
\end{array}$ & $\begin{array}{l}\text { Plantas } \\
\text { industriais }\end{array}$ & $2 \mathrm{D}$ \\
\hline $\begin{array}{c}\text { (ZHOU, ABOURIZK e } \\
\text { AL-BATTAINEH, 2009) }\end{array}$ & & $\mathbf{0}$ & Retângulos & $\begin{array}{c}\text { Canteiro de } \\
\text { obras }\end{array}$ & $2 \mathrm{D}$ \\
\hline $\begin{array}{l}\text { (KHALAFALLAH e EL- } \\
\text { RAYES, 2011) }\end{array}$ & 0 & & Retângulos & $\begin{array}{l}\text { Construção } \\
\text { de } \\
\text { aeroportos }\end{array}$ & $2 \mathrm{D}$ \\
\hline $\begin{array}{c}\text { (WU, WANG e FENG, } \\
\text { 2016) }\end{array}$ & & $\mathbf{0}$ & Grade regular & $\begin{array}{c}\text { Planta } \\
\text { petroquímica }\end{array}$ & $2 \mathrm{D}$ \\
\hline
\end{tabular}

Fonte: Elaborado pelo autor

\subsection{CONCLUSÕES DO CAPÍTULO}

A pesquisa não identificou nenhum software livre para o projeto de aeródromos, ao passo que os programas comerciais não oferecem informações sobre sua estratégia de modelagem. 
A literatura relacionada ao projeto geométrico de aeroportos apresenta-se bastante limitada. Os trabalhos encontrados exigem entradas manuais de dados para cada caso analisado e baseiam-se em softwares comerciais.

A literatura que aborda o problema do layout a partir de suas características geométricas é mais ampla e abrange diversos setores de atividades. Embora a revisão aqui apresentada não seja exaustiva, é possível perceber-se que:

- a maior parte dos modelos é bidimensional e distribui-se em duas vertentes: i) discretização do espaço, transformando o problema do posicionamento de recursos em um problema de alocação; ou ii) emprego de retângulos para modelagem da sobreposição de geometrias.

- Existe uma tendência de uso de softwares CAD para a geração das geometrias e para a visualização dos resultados, enquanto tarefas mais específicas são implementadas via programação.

- Modelos tridimensionais são raros nos estudos de layout, como aponta a própria literatura e o baixo número de resultados deste tema em portais científicos.

O próximo capítulo apresenta uma revisão sobre conceitos e métodos na área de CAD (Computer Aided Design) e geometria computacional. Tais conceitos fundamentam e subsidiam o modelo proposto nesta tese. 


\section{CAPÍTULO 3 - CAD E GEOMETRIA COMPUTACIONAL}

A metodologia proposta nesta tese possui muitos elementos oriundos da tecnologia CAD (Computer Aided Design). Este capítulo aborda brevemente alguns aspectos conceituais deste assunto para depois apresentar formulações empregadas na elaboração do modelo proposto.

\subsection{CONCEITOS}

O termo CAD (Computer Aided Design) é muitas vezes associado a programas de desenho, capazes de produzir plantas e visualizações bidimensionais e tridimensionais. No entanto, como a própria sigla sugere, o "auxílio computacional ao projeto" refere-se genericamente a uma gama de possíveis ferramentas nas mais diversas áreas de projeto, especialmente na engenharia (Chang, 2014; Hosseini e Moetakef-Imani, 2016 ; Zanen et al., 2013), mas também em áreas de aplicação não tão tradicionais, como, por exemplo, a medicina (Pepper et al., 2013; Telfer, 2012).

Enquanto tarefas corriqueiras da engenharia contam com softwares e usos consolidados, aplicações específicas de modelos CAD tanto em plataformas comerciais, quanto desenvolvidos via programação são encontradas na literatura. Zanen, Hartmand et al. (2013) apresentam uma proposta de visualização 4D dos impactos da construção de uma rodovia. Eles citam a utilização do software Navisworks da Autodesk para a visualização de geometrias tridimensionais representativas da zona de influência de impactos como ruído e vibrações. A quarta dimensão citada na pesquisa representa o tempo associado ao desdobramento do cronograma da obra. Já Hosseini e Moetakef-Imani (2016) apresentam uma metodologia $C A D$ para o projeto das pás de uma turbina eólica a partir de algoritmos implementados em MATLAB. Os autores destacam a capacidade apresentada pela implementação para a exportação do modelo geométrico final no padrão de arquivo IGES, compatível com programas consolidados do segmento CAD.

Além da sigla CAD (Computer Aided Design), a literatura e a indústria apresentam variações como o CAE (Computer Aided Engineering) e o CAM (Computer Aided Manufacturing). Enquanto o CAE é eventualmente utilizado de forma intercambiável com o conceito $\mathrm{CAD}$, o $\mathrm{CAM}$ é direcionado à manufatura, criando uma ponte entre um modelo computacional e a sua fabricação através de uma máquina que é capaz de reproduzi-lo, como impressoras 3D e máquinas CNC (Comando 
Numérico Computadorizado). Lee e Chang (2003) apresentam o desenvolvimento de um braço robótico a partir de um sistema integrado CAD/CAE/CAM. Na pesquisa, a expressão computer aided design refere-se a tarefas puramente geométricas de análise prévia do projeto; a expressão computer aided drawing é utilizada para a geração computacional de um modelo sólido; a expressão computer aided analysis, por sua vez, refere-se à analise mecânica realizada sobre o modelo geométrico, quando restrições físicas e propriedades dos materiais são introduzidas; e finalmente, computer aided manufacture denota a integração do modelo virtual com uma máquina CNC que o fabrica.

Do lado da indústria, a sigla CAD pode ser encontrada associada a produtos que desempenham, por exemplo, a função de análise de interferência geométrica, conforme a página web do produto SOLIDWORKS 3D CAD, desenvolvido pela Dassault Systems:

Verify that your parts and assemblies will fit, assemble, and operate correctly with SOLIDWORKS 3D CAD software before going into production. Fully integrated with CAD, you can use Interference Check while you design to accelerate your product development process, save time and development costs, and increase productivity. (SOLIDWORKS, 2017)

A partir do exposto, pode-se perceber que o termo CAD é empregado tanto para a geração de modelos geométricos em computador, quanto para análises dos modelos, em geral de natureza geométrica.

Hatvany, Newman e Sabin (1993) expandem o conceito ao afirmarem que "CAD corresponde à integração adequada de módulos de hardware e software para a criação de sistemas de projeto voltados a fins específicos ${ }^{7}$." Os mesmos autores, ao aprofundarem a relação entre o conhecimento humano e a automação do processo de projeto, apresentam uma formulação alternativa para o conceito de um sistema CAD:

CAD may be regarded as a means of optimizing design decisions and processes through a generalization of design activity studies into a synthetic theory of design whose results can be embodied in concrete programs. (HATVANY, NEWMAN e SABIN, 1993).

Como consequência da discussão apresentada por estes autores, o desenvolvimento de um software de projeto pressupõe que o desenvolvedor consiga

\footnotetext{
7 Tradução do autor.
} 
antecipar completamente o processo de projeto que deseja automatizar, fornecendo a priori um processo concreto de tomada de decisão.

Esta antecipação exige um grau de generalização compatível com a variabilidade das tarefas às quais o software se destina. Por esta razão, deve o desenvolvedor de um software CAD limitar o escopo do seu produto de uma forma que este seja capaz de cumprir um fim específico ao mesmo tempo em que não impõe esforços de desenvolvimento proibitivos.

$\mathrm{Na}$ indústria de software, uma das formas de tratar o problema da complexidade é a modularização, uma vez que é mais fácil resolver um problema de cada vez e testar sua solução separadamente através de um módulo próprio, o que exige por outro lado, precauções em termos da sincronização e das dependências entre os módulos (GHASEMI, SHARAFI e ARMAN, 2015).

De uma forma mais ampla, não existe problema em delimitar a função de um software desde que ele possa se integrar a outro para cumprir uma atividade fim. A indústria CAD possui uma série de padrões de arquivos, com diferentes níveis de compatibilidade. Isso é importante, à medida que um engenheiro que deseja analisar o comportamento estrutural de uma peça, por exemplo através de software CAE, necessita do modelo geométrico tridimensional da peça, suficientemente simples e preciso. De forma a facilitar a compatibilidade, a indústria conta com inúmeras ferramentas de validação de compatibilidade e verificação da qualidade dos modelos, como analisam González-Lluch et al. (2017).

As subseções seguintes abordam questões mais pontuais referentes à arquitetura de sistemas CAD, de especial interesse para o modelo proposto nesta tese.

\subsection{REPRESENTAÇÃO DE GEOMETRIAS}

Para a construção de geometrias, um sistema CAD emprega diversos tipos de primitivos, como planos, cilindros, cones ou superfícies (como curvas de Bézier, BSplines, NURBS) (BÉNIĖREA, et al., 2013). Podem ainda ser empregados pontos, linhas, círculos, cubos, entre outras formas. Os primitivos são as formas mais básicas de construção geométrica, sobre os quais se aplicam posteriormente uma série de operações. Um mesmo objeto geométrico pode ser representado sob diversas formas, dependendo do propósito da modelagem e da capacidade do software utilizado.

Uma das formas mais simples de representar-se um objeto é através de uma nuvem de pontos (Figura 3-1 A), porém para esta forma, a capacidade analítica será 
limitada, pois a representação guarda um número bastante limitado de informações sobre o objeto. Uma segunda alternativa de representação inclui o uso de linhas que, para serem construídas, necessitam de uma informação adicional, que é a ordem dos pontos por elas unidos, além dos pontos em si. Linhas possuem atributos como distância e direção. A união de várias linhas permite representar um objeto sob uma forma conhecida como wireframe (Figura 3-1 B). Linhas também podem unir-se de maneira a formar polígonos, seja no espaço 2D ou 3D. Por sua vez, polígonos guardam a possibilidade de cálculo de áreas e perímetros. A união de diversos polígonos forma uma malha, capaz de representar superfícies de maior complexidade (Figura 3-1 C).

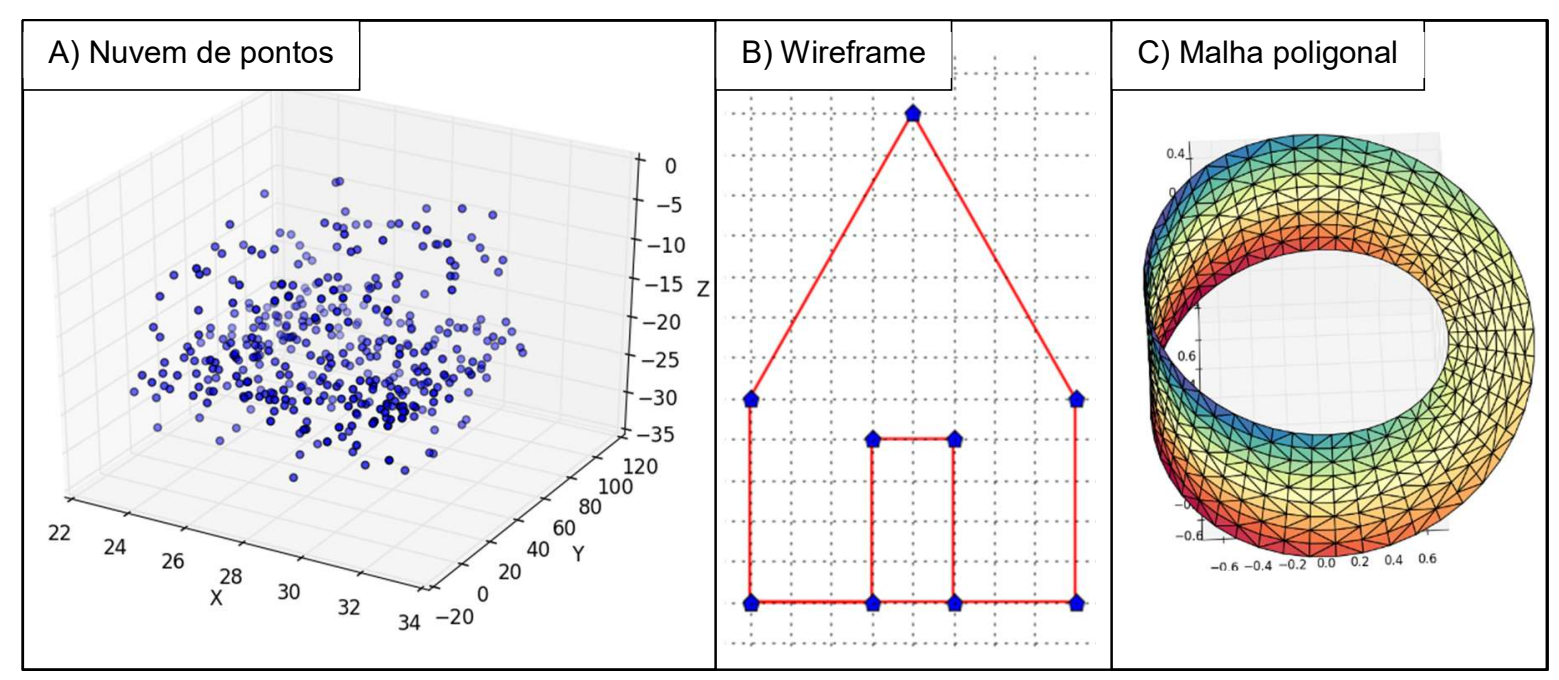

Figura 3-1 Diferentes representações de objetos geométricos em um sistema CAD.

FONTE: Elaborado pelo autor. Gráfico gerado através da biblioteca Matplotlib (MATPLOTLIB, 2017).

No exemplo do wireframe, as linhas passam exatamente pelos pontos, à medida que as arestas são por estes definidas. No entanto, existe na literatura uma vasta gama métodos de interpolação para linhas e superfícies através das quais estas são representadas por pontos de controle e equações paramétricas. Um exemplo clássico é a curva de Bézier, ilustrada na Figura 3-2A. De acordo com Motenson (1990), a curva de Bézier, aproxima um conjunto de pontos passando pelo primeiro e pelo último ponto, onde $n$ representa o grau da curva. Para superfícies, métodos de aproximação também costumam ser utilizados, especialmente quando se deseja um efeito mais suave do que aquele que decorre de uma malha poligonal simples. A Figura 3-2B ilustra um modelo de representação de superfície através da técnica NURBS (Non-Uniform Rational B-Splines), utilizada nos campos de animação, jogos, visualização científica e desenho industrial (AUTODESK, 2017). 


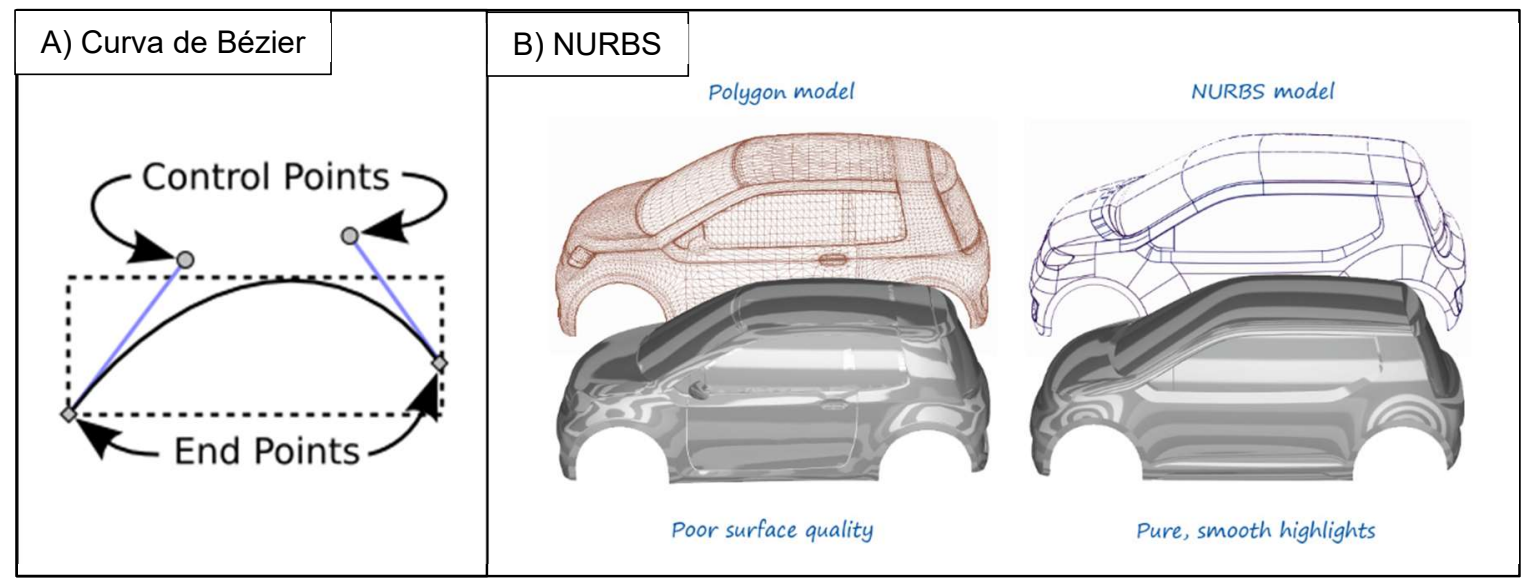

Figura 3-2 Aproximação de curvas e de superfícies

FONTE: A: (BAH, 2015) e B: (AUTODESK, 2017)

Uma malha poligonal de especial interesse nesta pesquisa é aquela obtida pela triangulação de Delaunay (TD), em 2D. Este tipo específico de triangulação é amplamente citado na literatura de geometria computacional (Cheng, Dey e Shewchuk, 2013; De Berg et al., 2000; George e Borouchaki, 1998), sendo este modelo dual a um diagrama de Voronoi. O algoritmo visa à maximização do menor ângulo interno de cada um dos triângulos da malha. Uma propriedade básica de uma TD é que, um círculo que passa pelos três nós de cada triângulo, não pode conter em seu interior nenhum outro nó. Uma segunda propriedade de uma TD é que a união de todos os triângulos forma o convex hull (ver item 3.4) dos pontos triangulados ${ }^{8}$. A Figura 3-3 ilustra estas duas propriedades. Uma TD também pode ser gerada para geometrias tridimensionais.

Outra forma de representação de um objeto geométrico é através de um sólido, dotado de propriedades como volume, por exemplo. Este tipo de representação é bastante utilizado na área mecânica, pelo tipo de análise que viabiliza, inclusive pela facilidade na extração de cortes para elaboração de plantas, o que seria mais complicado em um modelo do tipo wireframe, comparativamente. Um wireframe também não poderia suportar o cálculo de um volume, por exemplo, pois lhe faltam informações. Do ponto de vista da sua construção, uma das maneiras de obter-se um sólido é através de operações booleanas com sólidos primitivos, caracterizando um método conhecido como CSG (Constructive solid geometry).

\footnotetext{
8 Uma abordagem introdutória ao assunto pode ser encontrada em: 


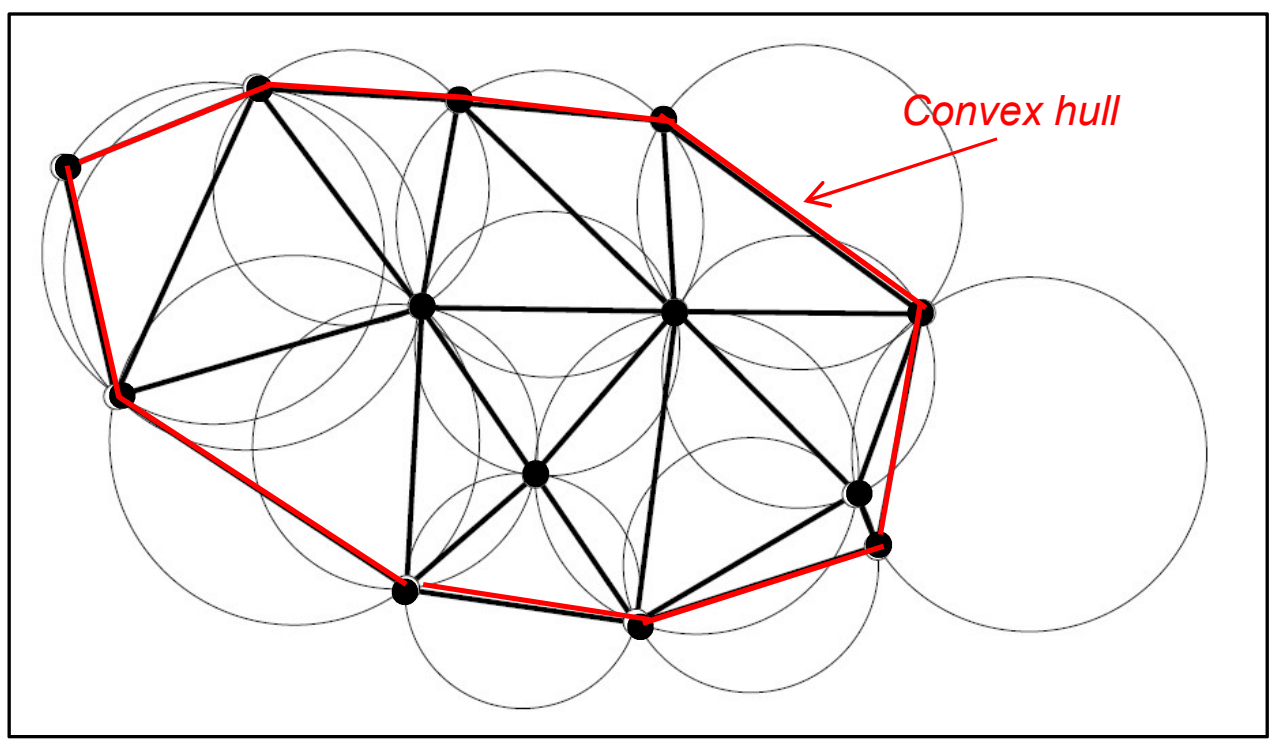

Figura 3-3 Triangulação de Delaunay.

FONTE: Adaptado a partir de (CHENG, DEY e SHEWCHUK, 2013).

\subsection{PARADIGMAS DE CONSTRUÇÃO DE UM MODELO CAD}

Um modelo CAD corresponde a uma combinação de um conjunto de primitivos transformados por uma série de operações e que obedecem a uma relação topológica, ou conforme Suzuki, Ando e Kimura (1990), um modelo geométrico compreende elementos geométricos (por exemplo, linhas e círculos) e elementos topológicos.

Como posto por Roller (1991), topologia é a relação de adjacência entre elementos geométricos. $O$ autor argumenta que em um modelo CAD, alterações dimensionais podem levar a alterações topológicas, como ilustra a Figura 3-4. Nela, uma peça que representava uma chapa com um furo em dada posição, descrita por $d 1$, passou a representar uma chapa sem furo e um círculo, após a alteração da dimensão para $d 2$.

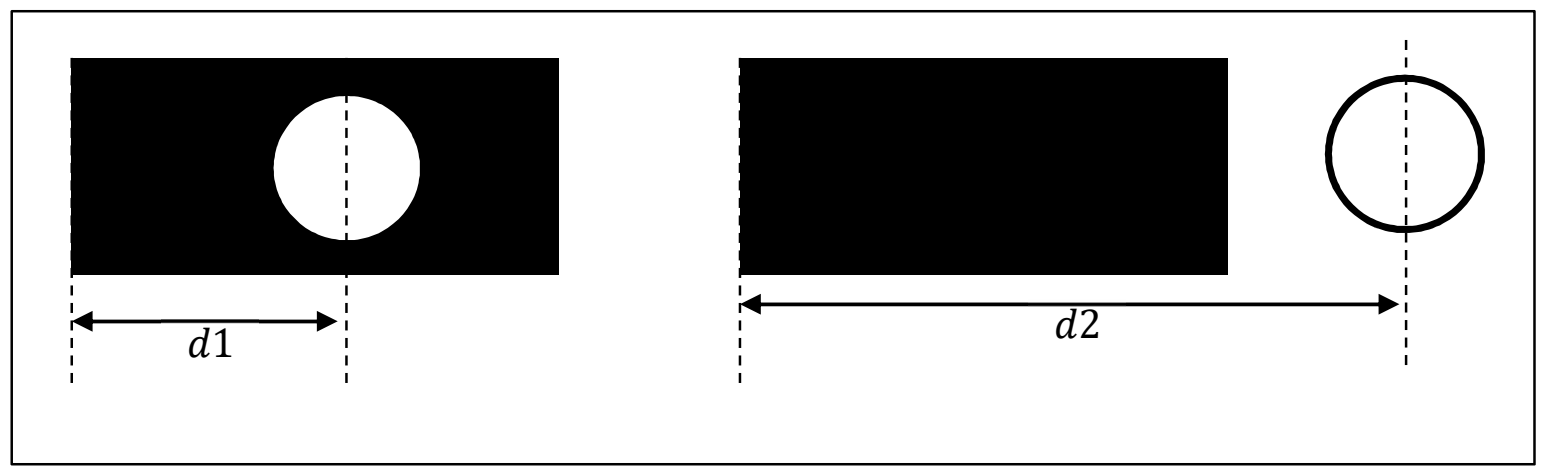

Figura 3-4 Alteração geométrica e topológica em um modelo.

FONTE: Adaptado pelo autor a partir de (ROLLER, 1991) 
Neste sentido, um CAD que permite variações topológicas é mais genérico do que um CAD que permita apenas variações dimensionais. Além disso, este último também deve assegurar a estabilidade topológica do modelo. Tal estabilidade pode ser atingida através de limitação das dimensões admissíveis, de forma prévia ou atualizada durante a construção modelo, se uma técnica interativa é empregada.

A consistência do modelo, descrita no parágrafo anterior, é apenas um exemplo de um problema geral conhecido na área de CAD como solução de restrições (constraint solving). Dependendo do paradigma de construção do modelo, o usuário repassa ao sistema um conjunto de restrições cuja solução levará à construção do modelo em si - model evaluation. As restrições podem ser geométricas com parâmetros contínuos, como a distância entre dois pontos, ou geométricas sem parâmetros, como é o caso paralelismo entre dois planos (VAN DER MEIDEN e BRONSVOORT, 2006). Além disso, Suzuki, Ando e Kimura (1990) chamam a atenção para restrições que, embora de natureza geométrica, não possuem uma relação algébrica direta. Nestes casos, pode ser necessário construir regras lógicas e, a partir delas, escrever procedimentos de teste. Poderia ser este o caso de um círculo que deve estar contido pelo perímetro de um retângulo.

A solução de restrições pode resultar inviável, dependendo do número de variáveis e do número de restrições do sistema algébrico, impedindo a construção do modelo (model evaluation). Em muitos sistemas CAD, o usuário será informado sobre a inviabilidade do projeto, e possivelmente sobre o parâmetro que levou à inviabilidade (ex.: o ângulo especificado para um plano viola outra restrição). Como notam Van der Meiden e Bronsvoort (2006), seria interessante que o usuário contasse com informação adicional sobre as faixas admissíveis para o parâmetro que levou à inviabilidade do modelo.

Já em relação ao grau de interação do usuário em um sistema CAD, Monedero (2000) identifica duas vertentes: i) Programação estática9; e ii) Método interativo.

No caso $i$, programação estática, existe um procedimento de programação definido para a geração do modelo final, sem qualquer participação do usuário qual não seja a geração do código e o fornecimento dos dados de entrada. Ainda, conforme Monedero (2000), como o usuário fornece os dados de entrada, existe a possibilidade de criação de diferentes versões do desenho dentro de uma faixa permitida. Caso alguma alteração no projeto seja necessária posteriormente, o modelo geométrico como um todo precisará ser reconstruído.

\footnotetext{
${ }^{9}$ também referida como variants programming.
} 
Já no caso $i i$, método interativo, existe interação entre o usuário e o modelo ao longo da sua construção, o que confere maior flexibilidade ao projeto. Monedero (2000) identifica diferentes abordagens aos sistemas interativos, a saber: $A$ ) modelos baseados no histórico (history-based); $B$ ) modelos paramétricos (variational design); $C$ ) modelos especialistas (expert systems); e $D$ ) modelos baseados em feições (feature-based design). A abordagem $A$ apresenta a estrutura de um grafo que guarda o histórico de construção do modelo, de maneira que as alterações introduzidas precisam ser processadas somente entre o nó atual e seus sucessores. No caso $B$, modelo paramétrico, o histórico não é importante, pois leva-se em conta somente o estado atual das restrições do modelo. A abordagem $C$ é similar ao caso $B$, porém propõe o emprego de regras de solução que diminuem o trabalho computacional, com uso de sistemas especialistas. Já o caso $D$ emprega o conceito de feição (feature), definindo uma geometria com função semântica, ou seja, que tem um significado próprio além dos aspectos geométricos. Assim, chanfros e furos, por exemplo, são feições com significado para quem elabora o desenho de uma peça mecânica. Da mesma forma, uma janela pode ser vista como uma feição para o projeto de um prédio. Bidarra e Bronsvoort (2000) discutem uma série de deficiências associadas à modelagem baseada em feições, inclusa a dificuldade em se manter a semântica de cada feição ao longo do processo de modelagem. Os autores apresentam também uma proposta metodológica para atacar os problemas por eles identificados.

\subsection{CONVEXIDADE}

A Figura 3-5 mostra como um mesmo conjunto de pontos pode delimitar polígonos diferentes entre si, caso a geometria não seja convexa. Na mesma figura, os pontos deram origem ao convex hull da geometria. Conforme, De Berg (2000), um subconjunto $S$ do plano é chamado de convex hull se e somente se, para qualquer par de pontos $p, q \in S$, o segmento de reta que liga $p$ e $q$ é completamente contido em $S$. A Figura 3-5 também permite observar que o convex hull de um conjunto de $n$ pontos pode ser completamente descrito por um número de pontos eventualmente menor do que $n$. Por esta razão, a obtenção do convex hull de um conjunto de pontos pode constituir uma operação de simplificação.

Uma área convexa é mais facilmente representada computacionalmente, pois os pontos são suficientes para caracterizar completamente a geometria, sem degenerescência. Em geometrias não convexas, é necessário indicar as arestas, o que obriga que os pontos sejam informados em pares, ou pelo menos, de uma forma sequencial. 


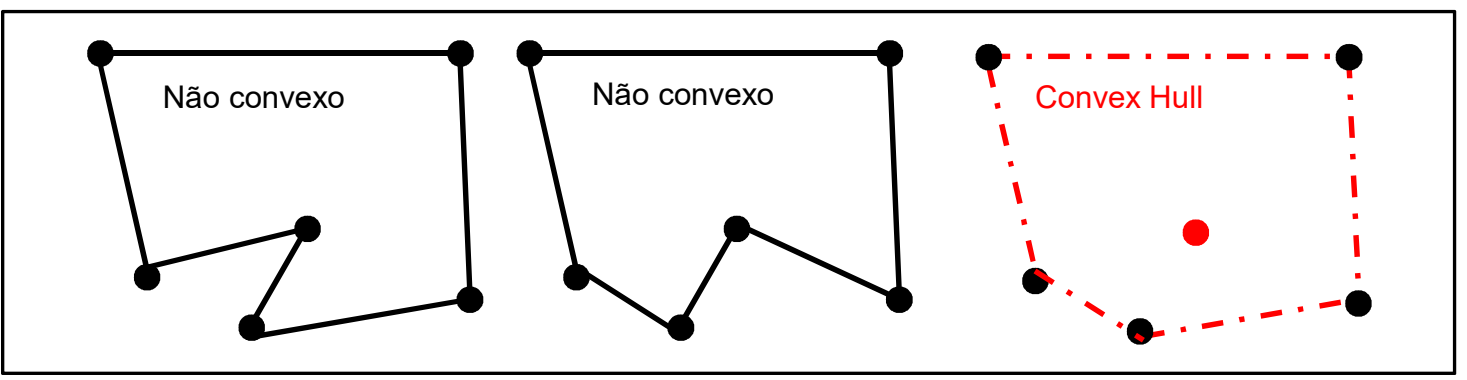

Figura 3-5 Polígonos e convexidade.

FONTE: Elaborado pelo autor

\subsection{OPERAÇÕES DE TRANSLAÇÃO, ROTAÇÃO E REFLEXÃO}

Mesmo nos softwares CAD atuais, bastante sofisticados, o usuário sente a necessidade de operações básicas como, por exemplo, translações, rotações, e espelhamento em relação a eixos e planos. Além disso, comandos mais complexos serão muitas vezes executados através de uma combinação destas e de outras operações básicas. Mortenson (1997), Hearn e Baker (1997) e Saxena e Birendra (2005) apresentam abordagens matriciais a estas operações, recuperando-se aqui somente translação, rotação e reflexão, essenciais ao desenvolvimento do modelo proposto nesta pesquisa.

Para tanto, conforme o apresentado no Capítulo 11 de Hearn e Baker (1997), a translação de um ponto $\mathrm{P}(x, y, z)$ em um sistema euclidiano de coordenadas pode ser executada pela aplicação de operações matriciais utilizando-se coordenadas homogêneas, de forma que:

$$
\left[\begin{array}{c}
x^{\prime} \\
y^{\prime} \\
z^{\prime} \\
1
\end{array}\right]=\left[\begin{array}{cccc}
1 & 0 & 0 & t_{x} \\
0 & 1 & 0 & t_{y} \\
0 & 0 & 1 & t_{z} \\
0 & 0 & 0 & 1
\end{array}\right] \cdot\left[\begin{array}{c}
x \\
y \\
z \\
1
\end{array}\right]
$$

O ponto $\left(\mathrm{x}^{\prime}, \mathrm{y}^{\prime}, \mathrm{z}^{\prime}\right)$ é a nova posição de $\mathrm{P}$, após o mesmo ser deslocado pelas distâncias $t_{x}, t_{y}$ e $t_{z}$, respectivamente em cada eixo.

Hearn e Baker (1997), de forma similar, apresentam as equações necessárias para a rotação de um ponto $\mathrm{P}(x, y, z)$ em relação ao eixo $z$ em $\theta$ graus:

$$
\left[\begin{array}{l}
x^{\prime} \\
y^{\prime} \\
z^{\prime} \\
1
\end{array}\right]=\left[\begin{array}{cccc}
\cos (\theta) & -\operatorname{sen}(\theta) & 0 & 0 \\
\operatorname{sen}(\theta) & \cos (\theta) & 0 & 0 \\
0 & 0 & 1 & 0 \\
0 & 0 & 0 & 1
\end{array}\right] \cdot\left[\begin{array}{l}
x \\
y \\
z \\
1
\end{array}\right]
$$


Em relação ao eixo $\mathrm{x}$ :

$$
\left[\begin{array}{c}
x^{\prime} \\
y^{\prime} \\
z^{\prime} \\
1
\end{array}\right]=\left[\begin{array}{cccc}
1 & 0 & 0 & 0 \\
0 & \cos (\theta) & -s \quad(\theta) & 0 \\
0 & \operatorname{sen}(\theta) & \cos (\theta) & 0 \\
0 & 0 & 0 & 1
\end{array}\right] \cdot\left[\begin{array}{l}
x \\
y \\
z \\
1
\end{array}\right]
$$

E em relação ao eixo y:

$$
\left[\begin{array}{l}
x^{\prime} \\
y^{\prime} \\
z^{\prime} \\
1
\end{array}\right]=\left[\begin{array}{cccc}
\cos (\theta) & 0 & \operatorname{sen}(\theta) & 0 \\
0 & 1 & 0 & 0 \\
-\operatorname{sen}(\theta) & 0 & \cos (\theta) & 0 \\
0 & 0 & 0 & 1
\end{array}\right] \cdot\left[\begin{array}{l}
x \\
y \\
z \\
1
\end{array}\right]
$$

Tanto nas operações de translação, quanto de rotação, a mesma operação pode ser efetuada para uma geometria inteira, descrita por $n$ pontos, repetindo-se o mesmo procedimento, que pode ganhar eficiência computacional e simplificação se x,y,e z forem tratados como vetores.

Transformações de maior complexidade podem ser atingidas pelo emprego sucessivo das matrizes de rotação e translação, no entanto, Saxena e Birendra (2005, p. 27), esclarecem que estas operações são não comutativas, ou seja, a ordem das operações influencia os resultados. No seguinte exemplo, um objeto original sofreu duas transformações sucessivas: $A$ ) rotação de $30^{\circ}$ sobre o eixo z; e $B$ ) translação de 3 unidades no eixo x. Na Figura 3-6, parte-se de um objeto original que culmina em objetos finais diferentes nas sucessões de transformação A-B e B-A, respectivamente.

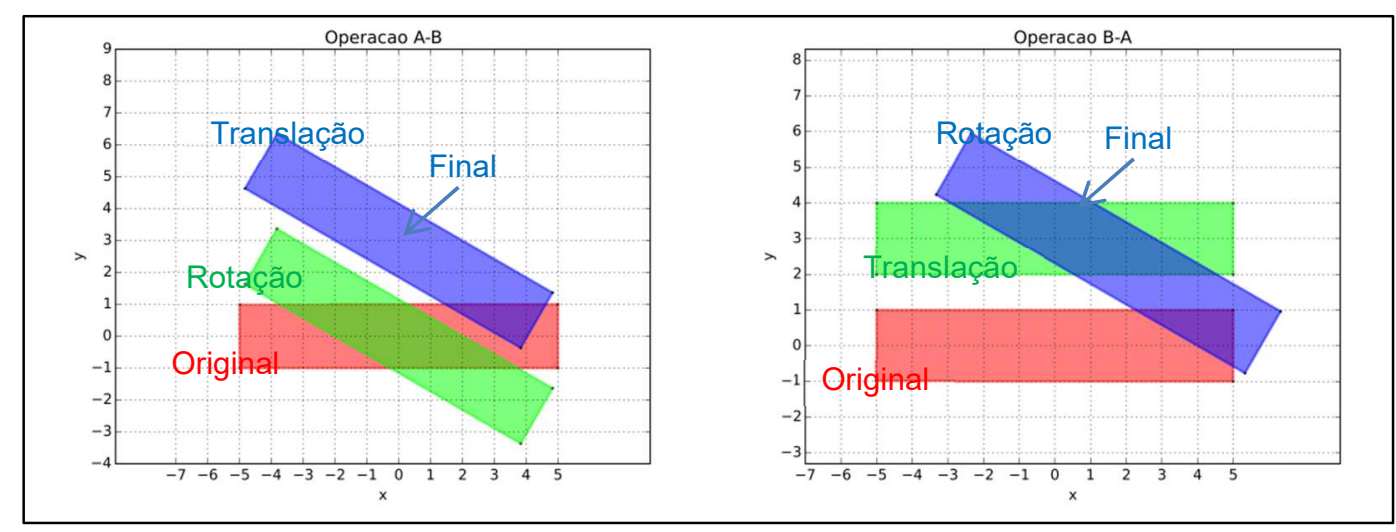

Figura 3-6 Operações não comutativas.

FONTE: Elaborado pelo autor. Gráfico gerado através da biblioteca Matplotlib (MATPLOTLIB, 2017).

As operações serão reversíveis caso a ordem correta seja mantida nas operações sucessivas. 
Outra questão importante é o efeito de rotação de uma geometria não centrada na origem. Na Figura 3-7, na imagem da esquerda, o objeto original foi rotacionado em $90^{\circ}$ em relação ao eixo z. Na imagem da direita, o objeto sofreu uma translação para a origem $\left(t_{x}=0, t_{y}=-3\right.$ e $\left.t_{z}=0\right)$, com posterior rotação de $90^{\circ}$ em relação ao eixo $z$ e reposicionamento para a posição original $\left(t_{x}=0, t_{y}=+3\right.$ e $\left.t_{z}=0\right)$. Dessa maneira, na imagem da direita, o centro geométrico não teve sua posição alterada durante a transformação. Hearn e Baker (1997) discutem como sequencias de transformações podem ser empregadas para atingir transformações mais gerais, como por exemplo, a rotação em torno de um eixo arbitrário no espaço tridimensional.

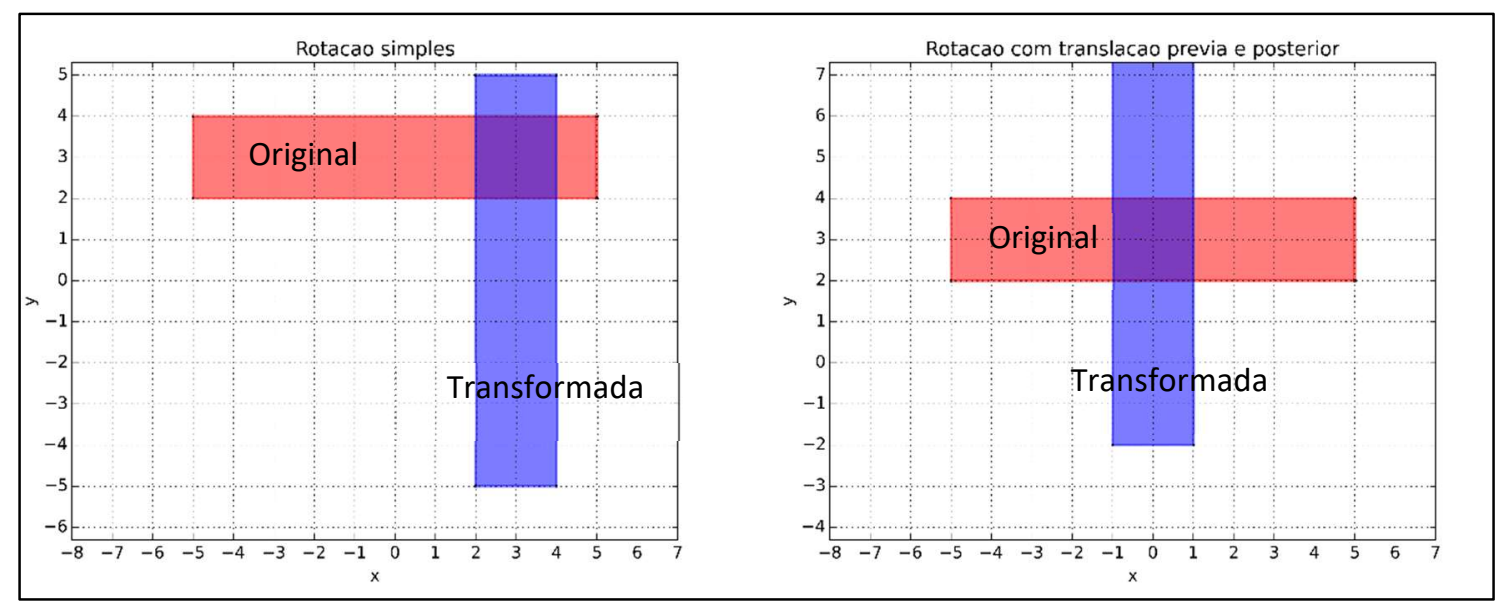

Figura 3-7 Rotação de geometrias e sua posição em relação à origem.

FONTE: Elaborado pelo autor. Gráfico gerado através da biblioteca Matplotlib (MATPLOTLIB, 2017).

Para o espelhamentos ou reflexão em torno de eixos, bastam multiplicações por -1 aplicadas sobre as coordendas. Métodos matriciais para espelhamento podem ser encontrados em Hearn e Baker (1997).

\subsection{CONCLUSÕES DO CAPÍTULO}

A tecnologia CAD (Computer Aided Design) aplica-se a esta pesquisa, de acordo com a exposição deste capítulo e com os objetivos declarados no Capítulo 1.

As geometrias podem ser representadas de maneira tão simples quanto um conjunto de pontos e evoluir para linhas e superfícies paramétricas e sólidos. Cabe ao projetista de um sistema CAD escolher as representações que ao mesmo tempo acomodem a precisão geométrica requerida e as funcionalidades desejadas. Por exemplo, um simples polígono não poderá ser mostrado em tela a partir do conjunto de pontos que o constitui, se a estrutura de vizinhança dos pontos não for conhecida. Isso contraria o senso humano de intuição, capaz de interpretar o mesmo conjunto de 
pontos desconexos como um polígono. Outro exemplo discutido é a representação wireframe, que embora sendo capaz de representar uma geometria aos olhos humanos, não dá suporte ao cálculo de volumes, por exemplo, já que lhe faltam informações para tal operação matemática.

Os primitivos são os blocos de construção de modelos CAD. Após sofrerem operações como rotações, translações e espelhamentos em torno de eixos, os primitivos podem ser unidos, gerando geometrias de maior nível de complexidade, dotadas ou não de uma natureza semântica que as caracteriza como feições (features) na terminologia CAD. No entanto, as operações de rotação, como demonstrado, não são comutativas, exigindo observância de uma ordem adequada de transformação, nas vias direta e inversa.

Modelos CAD podem ser gerados de forma estática, via programação, reproduzindo comandos prévios, incorporando ou não valores de entrada através de variáveis de projeto. Neste caso, é necessário garantir a consistência topológica do modelo pela concepção das rotinas e pela limitação da faixa de variação das variáveis de projeto.

Modelos CAD podem também ser gerados de forma interativa, neste caso, normalmente via interface gráfica. Em modelos interativos, a flexibilidade topológica poderá ser maior, já que o sistema pode deixar este tipo de decisão a cargo do usuário, durante o processo de construção da geometria.

O capítulo seguinte avança na fundamentação desta pesquisa, ao abordar as questões pertinentes a referenciais, sistemas de coordenadas, projeções e tecnologia GIS. 


\section{CAPÍTULO 4 - TRATAMENTO DE DADOS ESPACIAIS}

Conforme os padrões discutidos no Capítulo 1, a extensão territorial da área de influência de um aeródromo atinge a ordem de dezenas de quilômetros, quando consideradas as superfícies de proteção ao espaço aéreo. Estas superfícies precisam ser protegidas de objetos naturais, como o próprio relevo e de objetos construídos pelo homem. O levantamento da posição de tais objetos poderá muitas vezes ser mais convenientemente efetuado e tratado com base em um sistema de coordenadas geográficas. Técnicas diversas de coleta de dados, como a topografia convencional e o sensoriamento remoto, bem como a utilização de bases de dados podem impor a necessidade de compatibilização dos dados adquiridos sob diferentes referenciais e sistemas de coordenadas.

Por sua vez, o projeto geométrico do aeroporto, em conjunto com suas áreas e superfícies de proteção, será processado em um sistema euclidiano tridimensional, a começar pela forma como os padrões de projeto são especificados pelas normas. Além disso, do ponto de vista geométrico e computacional, o sistema cartesiano tende a ser mais vantajoso para o projeto, em tarefas como cálculos de distâncias, áreas e ângulos.

Portanto, a conversão das geometrias entre diferentes referenciais e sistemas de coordenadas é algo esperado no projeto de um aeroporto: objetos e dados levantados precisarão ser transformados para um sistema cartesiano para o projeto; e por outro lado, a transformação do projeto para um sistema de coordenadas geográficas facilitará sua sobreposição a mapas e globos virtuais, por exemplo.

Além disso, a extensão do projeto de um aeroporto traz à tona o problema da desconsideração da curvatura da Terra como uma possível fonte de erro para as análises.

Por estas razões, esta seção apresenta uma breve revisão sobre referenciais, projeções e transformações entre sistemas de coordenadas. Isso é importante também para subsidiar a posterior modelagem proposta nesta pesquisa.

\subsection{GEOMETRIA DA TERRA E SISTEMAS DE COORDENADAS}

Em geodesia, o formato da Terra precisa ser tratado sob os pontos de vista geométrico e físico, dependendo dos objetivos da análise. Um modelo geométrico 
capaz de representar com fidelidade o geoide terrestre, por exemplo, seria complexo demais para um tratamento analítico. Adota-se então o modelo biaxial para a modelagem da superfície geométrica de referência, conforme discutem Vanícek e Krakiwsky (1986, p. 107).

O modelo biaxial é definido pelo emprego de apenas dois parâmetros para definição do elipsoide de referência e se constitui como um elipsoide de revolução em torno do eixo que passa pelos polos, ou seja, o eixo Z da Figura 4-1. Assim, os planos paralelos ao equador possuem a geometria de um círculo com raio $a$. Por outro lado, os planos ortogonais ao plano do Equador, possuem a geometria de uma elipse cujo raio maior é $a$ e cujo raio menor é $b$. Normalmente, um elipsoide é especificado através de $a$ e algum outro parâmetro, que não $b$, de forma a facilitar a manipulação algébrica. Porém, de qualquer maneira, apenas dois parâmetros são suficientes para especificar completamente a geometria do elipsoide. A seguir são apresentadas as relações entre os parâmetros mais comumente empregados. Estas fórmulas são apresentadas em Torge (1991, p. 44-45).

$\mathrm{O}$ achatamento (flattening) $-f$ :

$f=\frac{a-b}{a}$

A primeira excentricidade (first eccentricity) - $e$ :

$e=\frac{\sqrt{a^{2}-b^{2}}}{a}$

E a superfície do elipsoide biaxial é descrita pela equação:

$\frac{x^{2}+y^{2}}{a^{2}}+\frac{z^{2}}{b^{2}}-1=0$ 


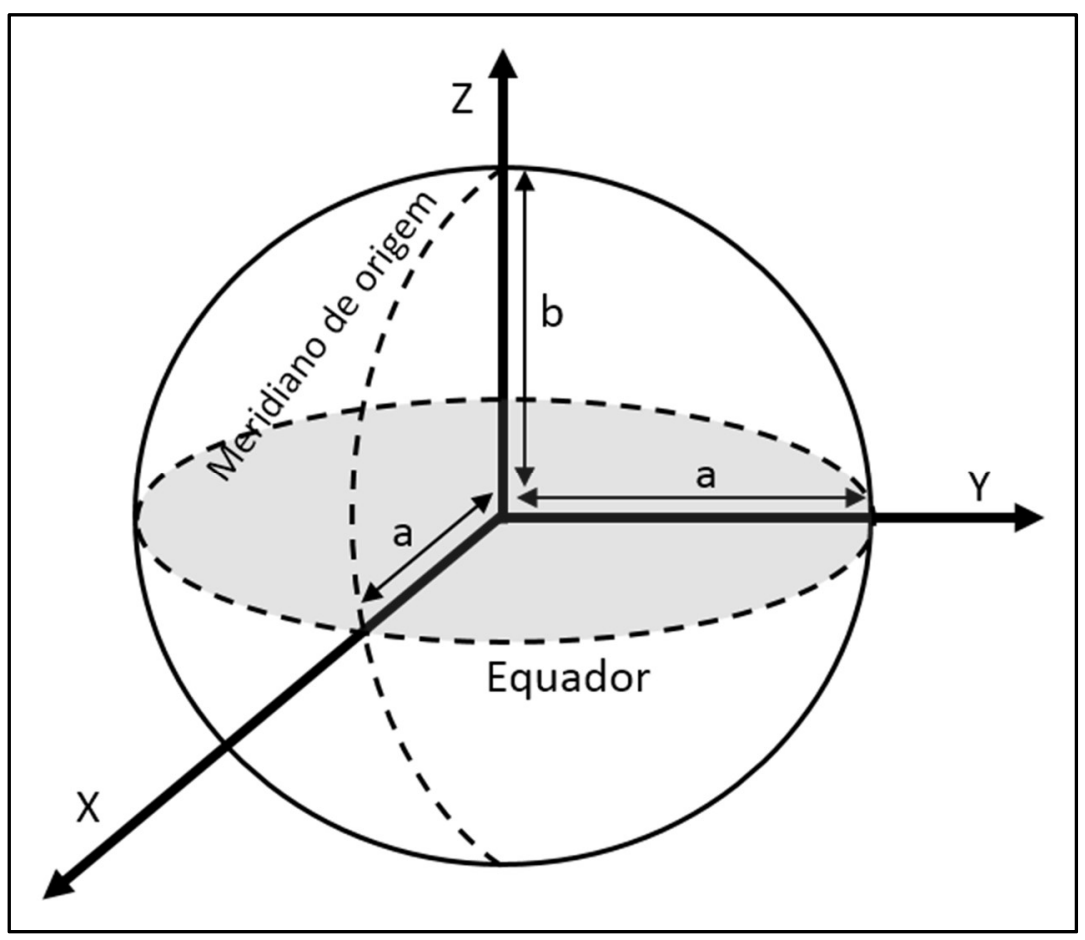

Figura 4-1- Elipsoide biaxial.

FONTE: Elaborado pelo autor.

Para representar a posição de um ponto sobre a superfície terrestre, diversos sistemas de coordenadas podem ser utilizados, tendo-se em vista o globo, parte dele ou uma projeção. Para o caso do globo, dois sistemas de coordenadas são discutidos no recorte da presente pesquisa, embora outros sistemas possam ser encontrados na literatura especializada. São eles o sistema cartesiano tridimensional e o sistema geodésico. O sistema cartesiano tridimensional tem sua origem no centro do elipsoide onde se cruzam os eixos ortogonais $\mathrm{X}, \mathrm{Y}$ e $\mathrm{Z}$ e qualquer ponto pode ser descrito por três coordenadas: $(\mathrm{x}, \mathrm{y}, \mathrm{z})$. No caso do sistema geodésico, um ponto será descrito por coordenadas $(\varphi, \lambda, \mathrm{h})$, que representam a latitude, a longitude e a altura elipsoidal, discutida na seção 4.2. A Figura 4-2 ilustra a geometria associada a estas coordenadas. Nesta figura, $\varphi$ representa a latitude, $\lambda$ representa a longitude e $\mathrm{h}$ representa a altura elipsoidal. Já N é uma distância definida em Andrade (2003, p. $73)^{10}$ como o raio de curvatura do primeiro vertical ${ }^{11}$. É costumeiro que o eixo x passe pelo meridiano inicial, mas isso depende do sistema de convenções, bem como o sinal de $\lambda$, que poderá adotar como positivo o sentido-horário ou anti-horário. A latitude por

${ }^{10} \mathrm{Ou}$ como coloca Jekeli (2012, p. 2-20): "the radius of curvature of the prime vertical normal section at the point of the ellipsoid normal".

11 Obs.: Não confundir este raio com a ondulação geoidal, muitas vezes representada também por $\mathrm{N}$. Na literatura não é incomum a utilização de 'v' para simbolizar o parâmetro aqui descrito. 
sua vez, costuma ser definida como positiva no hemisfério norte e negativa no hemisfério sul. Os valores de $\varphi$ e $\lambda$ costumam ser expressos em graus decimais ou em graus sexagesimais (graus, minutos e segundos) ${ }^{12}$.

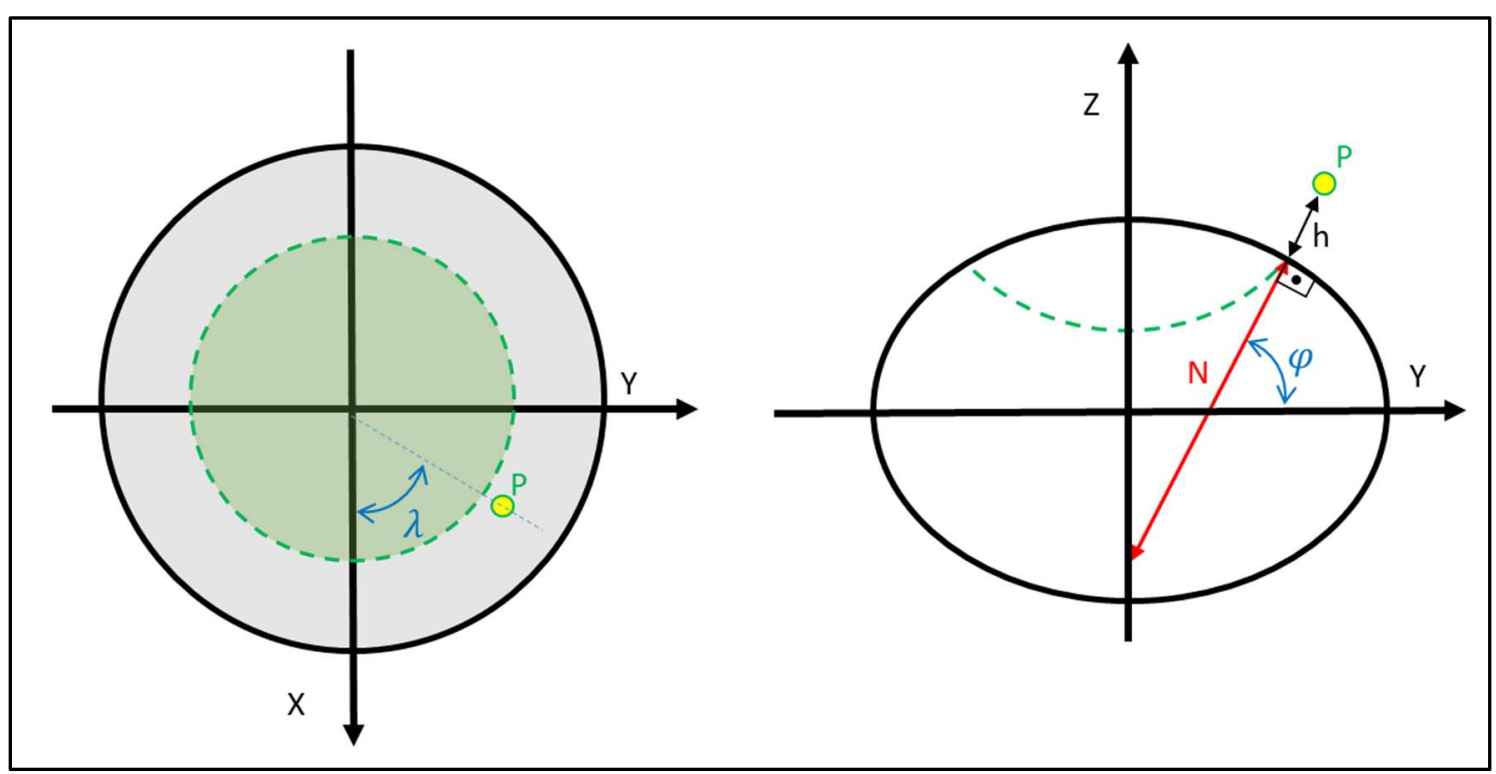

Figura 4-2- Coordenadas cartesianas e geodésicas.

FONTE: Elaborado pelo autor

As fórmulas para o cálculo das coordenadas tridimensionais a partir das coordenadas geodésicas podem ser encontradas em IOGP (2015, p. 94), Rapp (1991, p. 121), Andrade (2003, p. 72) e Jekeli (2012, p. 2-41), conforme a Equação 4-4 e a Equação 4-5.

$$
\begin{aligned}
& N=\frac{a}{\sqrt{1-e^{2} \times \operatorname{sen}^{2}(\varphi)}} \\
& {\left[\begin{array}{l}
x \\
y \\
Z
\end{array}\right]=\left[\begin{array}{c}
(N+h) \times \cos \varphi \times \cos \lambda \\
(N+h) \times \cos \varphi \times \operatorname{sen} \lambda \\
{\left[N \times\left(1-e^{2}\right)+h\right] \times \operatorname{sen} \varphi}
\end{array}\right]}
\end{aligned}
$$

Jekeli (2012, p. 2-41) lembra que as fórmulas acima não consideram mudanças nos parâmetros do elipsoide, nem na origem e orientação dos eixos durante a transformação de coordenadas.

12 Um grau sexagesimal é composto por 60 minutos, que por sua vez é composto por 60 segundos. Por exemplo, a medida sexagesimal 10²0'30" corresponde a 10,34166667 graus decimais, considerando 8 casas decimais. 
No caso da transformação inversa, conforme as quatro referências citadas, a longitude pode ser diretamente encontrada, o que é bastante intuitivo a partir da Figura 4-2:

$\lambda=\operatorname{atan}\left(\frac{y}{x}\right)$

Para o cálculo da latitude, no entanto, o processo é mais complexo, existindo fórmulas diretas ou iterativas, conforme Rapp (1991, p. 121), que apresenta diversos algoritmos e discute os respectivos tempos computacionais. Um dos métodos apresentados nesta referência e também em Jekeli (2012, p. 2-43) é o algoritmo de Hirvonen/Moritz, que pode ser sintetizado em três equações:

$\varphi^{0}=\operatorname{atan}\left(\frac{z}{\sqrt{x^{2}+y^{2}}} \times\left(1+\frac{e^{2}}{1-e^{2}}\right)\right)$

$N^{j}=\frac{a}{\sqrt{1-e^{2} \times \operatorname{sen}^{2}\left(\varphi^{j}\right)}}, j=0,1,2, \ldots$

$\varphi^{j}=\operatorname{atan}\left(\frac{z}{\sqrt{x^{2}+y^{2}}} \times\left(1+\frac{e^{2} \times N^{j-1} \times \sin \varphi^{j-1}}{z}\right)\right), j=1,2, \ldots$

Neste algoritmo, $\varphi$ será encontrado após certo número de iterações $(j)$, a começar pela Equação 4-7 e depois sucessivamente pela Equação 4-8 e pela Equação 4-9. O critério de parada deste algoritmo é $\left|\varphi_{j}-\varphi_{j-1}\right| \leq \epsilon$.

Uma vez conhecido o valor da latitude, a altura elipsoidal poderá ser encontrada pela Equação 4-10 e pela Equação 4-11, sendo que a primeira é mais estável para as regiões equatoriais e a segunda é mais estável para regiões polares, de acordo com Rapp (1991, p. 122). ${ }^{13}$

$h=\frac{\sqrt{x^{2}+y^{2}}}{\sqrt{\cos \varphi}}-N$

$h=\frac{z}{\operatorname{sen} \varphi}-N+e^{2} \times N$

13 Existem outras fórmulas que podem ser utilizadas para o cálculo dessa altura. 


\subsection{REFERENCIAIS}

Partindo-se de uma abordagem intuitiva, alguém pode ser levado a pensar que a posição de um objeto em um ambiente como uma sala pode ser completamente caracterizada por três coordenadas, considerando-se um sistema euclidiano de coordenadas. No entanto, essa informação estará incompleta se a origem do sistema e a orientação dos eixos em relação à sala não forem também definidos por um conjunto suficiente de parâmetros. O mesmo acontece com os dados geográficos: conforme By (2001, p. 208), um sistema de coordenadas de referência (tradução livre de reference coordinate system), também referido como SRS (Spatial Reference System), é um sistema de coordenadas definido por uma origem e pela orientação de três eixos ortogonais. Para os autores, o SRS é uma abstração matemática a ser materializada por meio de um SRF (Spatial Reference Frame), constituído por pontos físicos. Como exemplo de um SRS, os autores citam o International Terrestrial Reference System (ITRS), materializado através do International Terrestrial Reference Frame (ITRF).

Na mesma linha, Whitmore (1994, p. 44) define um sistema de referência (reference system) como uma visão conceitual caracterizada por uma origem e um vetor definindo escala e orientação, além de modelos, algoritmos, constantes e eventualmente um modelo cinemático. Para o mesmo autor, um reference frame é a materialização física de um sistema de referência em um dado instante, enquanto o termo datum é assim definido:

Um datum é um termo associado a redes clássicas de triangulação, consistindo de uma superfície de referência (normalmente um elipsoide) com forma e origem definidas, além das coordenadas de um número de estações na superfície. É, portanto, um reference frame, e em menor grau, um reference system. (WHITMORE, 1994, p. 44, tradução do autor)

De forma mais sucinta, o IBGE (2016) define datum como um "sistema de referência para as coordenadas geodésicas e aceleração da gravidade".

IOGP (2012, p. 10), ao apresentar os conteúdos do EPSG Geodetic Dataset, esquematiza a relação entre o que o documento chama de coordinate system (CS) e coordinate reference system (CRS), equivalentes respectivamente ao SRS e ao SRF discutidos anteriormente. Conforme IOGP (2016), o EPSG Geodetic Dataset é um conjunto estruturado de dados sobre sistemas de referência de coordenadas e suas transformações, disponíveis online e em constante atualização. Os dados e padrões 
do EPSG Geodetic Dataset são utilizados por softwares como o GRASS ( (NETELER e MITASOVA, 2004, p. 46) e (NETELER, BOWMAN, et al., 2012, p. 125)); o QGIS ( (QGIS, 2016); e o ArcGIS Desktop ( (ESRI, 2016)). Além disso, os padrões do EPSG Geodetic Dataset estão alinhados aos padrões do Open Geospatial Consortium ( (OGC, 2009, p. 4)). Esquematicamente, temos:

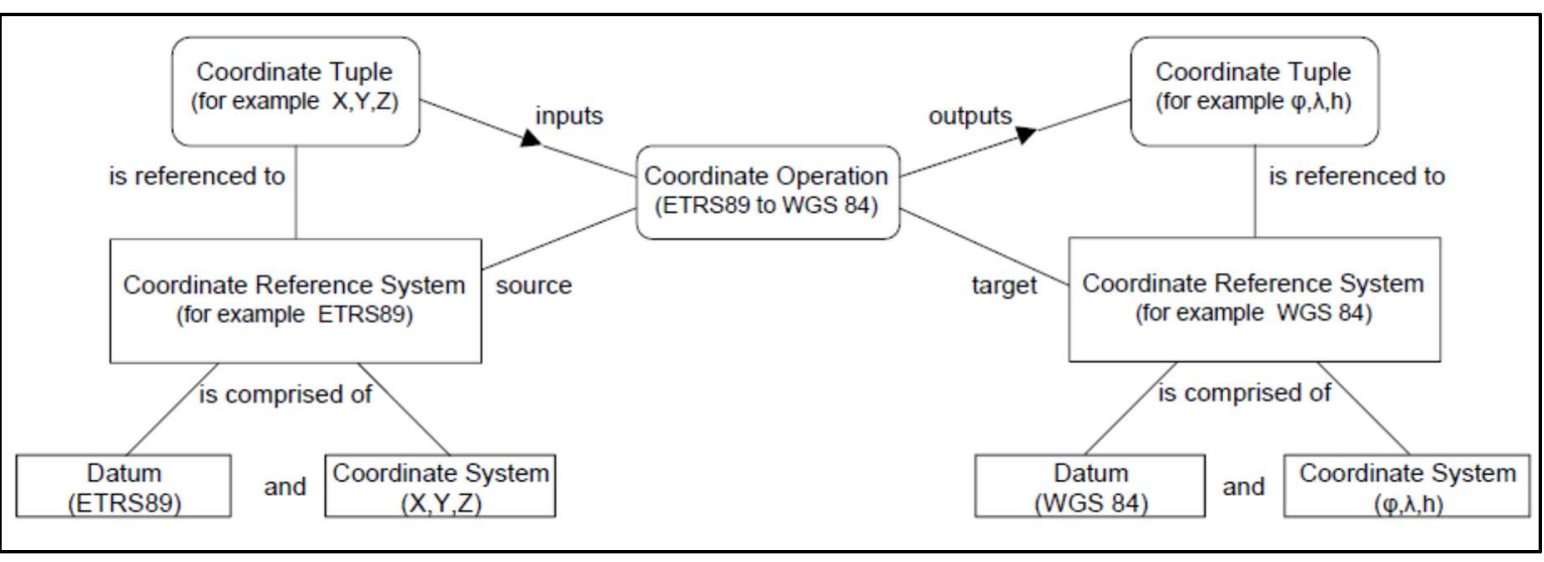

Figura 4-3 Relação entre CS, datum, e CRS. FONTE: (IOGP, 2012)

A Figura 4-3 ilustra a transformação de coordenadas cartesianas tridimensionais de um ponto associado ao datum ETRS89, para um sistema de coordenadas geodésicas sob o datum WGS84. Neste caso, há mudança tanto do datum, quanto do sistema de coordenadas (CS). Com efeito, um código EPSG representa um CRS, descrito pelo datum e pelo sistema de coordenadas (CS), podendo assumir diversos formatos: geográfico (2D ou 3D); geocêntrico, projetado, de engenharia ou composto, conforme IOGP (2012).

Torge (1991, p. 18) reforça a relevância da dimensão temporal de um referencial, em adição aos parâmetros geométricos, devido ao movimento relativo entre a Terra e outros corpos celestes e também devido às deformações da própria Terra. Isso está de acordo com as afirmações do IBGE:

[...] referencial geodésico (entende-se, sistema) moderno apresenta as seguintes características: sua definição pressupõe a adoção de um elipsoide de revolução cuja origem coincide com o centro de massa da Terra e a sua realização (materialização) se dá mediante o estabelecimento de uma rede de estações geodésicas com coordenadas tridimensionais conhecidas. $O$ referencial mais preciso existente na atualidade é o ITRS, sendo as suas realizações denominadas de ITRFyy (International Terrestrial Reference Frame, ano yy). Como as coordenadas das estações sobre a superfície terrestre variam em função do tempo, é necessário redefinir periodicamente seus valores. 
Por este motivo, a denominação dada à materialização do ITRS vem acompanhada pelo ano (yy) em que foi estabelecida. Por exemplo, ITRF94 para a realização referente ao ano de 1994. (IBGE, 2000, p. 10).

Ainda, de acordo com (SMITH, 1997, p. 83), em geodesia dois referenciais devem ser considerados: um referencial horizontal (horizontal datum) e um referencial vertical (vertical datum), podendo ambos serem unidos na forma de um único referencial (o que foi possível devido ao emprego de satélites) ou tratados separadamente, dependendo do caso. Para o autor, um referencial horizontal consiste da latitude e da longitude de um determinado ponto, chamado origem, de um azimute, de dois parâmetros para o elipsoide (raio e achatamento) e da separação geoidal na origem. Hooijberg (1997, p. 25), por sua vez, coloca que antes de 1960 era costumeiro que um datum geográfico fosse definido com base em cinco parâmetros: latitude e longitude de um ponto inicial, azimute de uma linha desde este ponto e dois parâmetros para o elipsoide. Para o mesmo autor, após 1960, o uso de satélites permitiu o estabelecimento de referenciais globais de uso prático, sendo que este tipo de referencial precisa estar baseado em pelo menos 8 constantes: três para especificar a origem do sistema de coordenadas; três para especificar a direção dos eixos; e dois para especificar os parâmetros do elipsoide.

O estabelecimento de um datum vertical, por sua vez, exige a consideração de conceitos físicos e geométricos, sendo que o termo altura pode assumir diversos significados. Para Kresse e Danko (2012, p. 192), a altura elipsoidal é definida de uma maneira puramente geométrica, representando a distância entre um ponto até o elipsoide de referência ao longo de uma linha normal ao elipsoide. O mesmo significado é dado em (NGS, 2009) para a altura geodésica (geodetic height, em tradução livre), colocada como uma coordenada geodésica. Esta altura contraria o nosso senso intuitivo:

[...] esta altura não corresponde ao nosso senso intuitivo de altura como uma medida de distância vertical com relação a uma superfície nivelada. Dois pontos com a mesma altura elipsoidal podem estar em níveis diferentes no sentido que a água iria fluir de um ponto ao outro. Alturas elipsoidais são medidas puramente geométricas sem conexão com o potencial gravitacional. (JEKELI, 2012, p. 3-31, tradução do autor)

Guimarães (2013, p. 52) coloca que a superfície de referência vertical usualmente utilizada é o geoide, que possui um potencial de gravidade constante e se aproxima do nível médio do mar. A distância entre o geoide e um ponto qualquer ao 
longo da linha de prumo (plumb line), considerando positiva a altura acima do geoide, é definida como a altura ortométrica (NGS, 2009). A altura ortométrica reflete variações locais na gravidade, além da topografia do terreno (KRESSE e DANKO, 2012, p. 193). O modelo geoidal pode ter abrangência global, como o EGM2008, ou local. Conforme Ses, Khaleef e Forsber (2009, p. 51), embora o nivelamento por GPS seja suficiente em muitas aplicações de engenharia, aplicações de alta precisão podem exigir a determinação da ondulação geoidal com uma acuracidade de poucos centímetros em uma distância de 100km. A Figura 4-4 ilustra algumas das definições apresentadas:
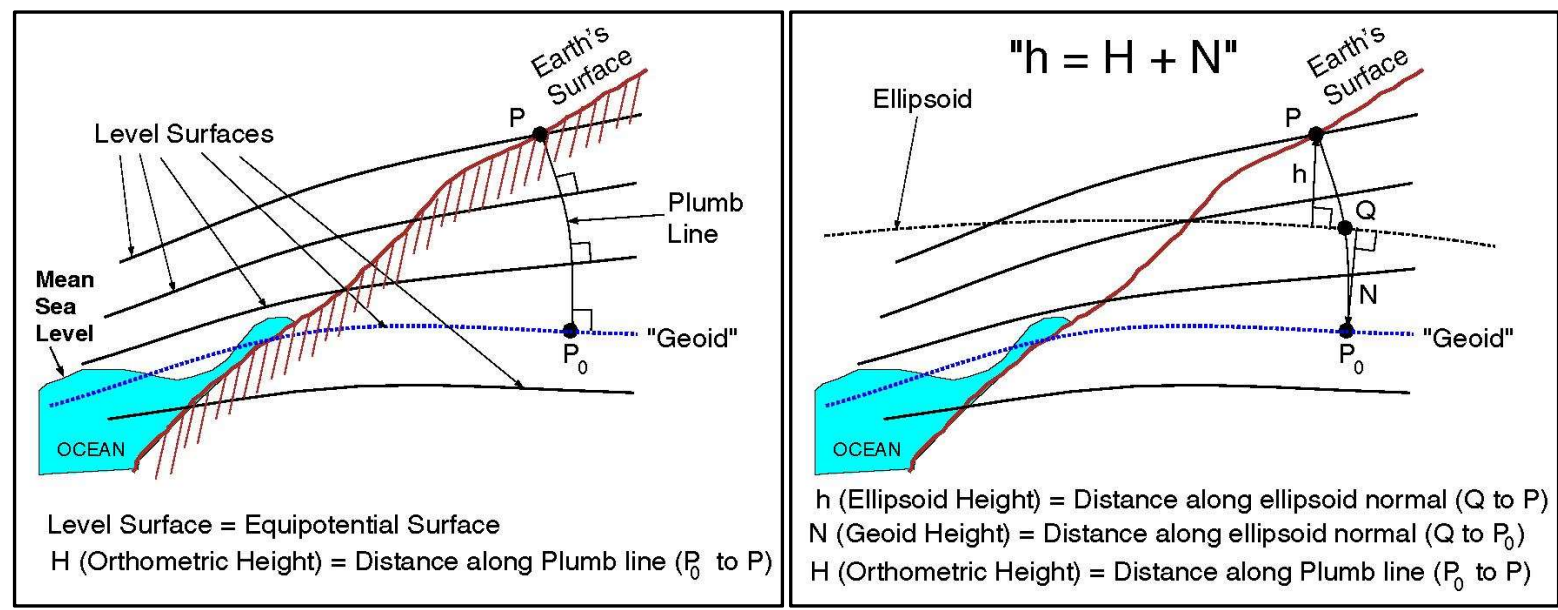

Figura 4-4 Superfícies do elipsoide e do geoide.

FONTE: (NGS, 2001)

\subsection{PROJEÇÕES}

Projeções cartográficas são necessárias, em primeiro lugar pela necessidade de representação da superfície da Terra em um plano, permitindo assim a confecção de mapas impressos. Mesmo com o advento da informática, existe a necessidade de representação dos modelos virtuais na tela do computador, o que também exige o uso de um sistema de projeção. Outra razão para o uso de projeções é o cálculo de áreas e distâncias, que pode muito mais facilmente ser executado considerando-se um sistema euclidiano de coordenadas do que seria com o uso de coordenadas geográficas. Ainda, o uso de uma projeção permite um tratamento bidimensional aos dados geográficos, o que pode ser considerado tanto vantajoso do ponto de vista do esforço computacional, quanto adequado do ponto de vista da precisão para uma gama de aplicações.

Textos como Snyder (1987) e Fenna (2007) apresentam uma série de projeções e as respectivas fórmulas de conversão, que também estão presentes em softwares 
$\mathrm{GIS}^{14}$, representadas por convenções como o código EPSG. No entanto, não existe projeção perfeita, livre de distorções, conforme Snyder (1987, p. 3-4), que cita seis características para a escolha de uma projeção, a serem preservadas, muitas vezes em detrimento das outras:

- Área: também chamada de projeção equivalente ou homolográfica, preserva a área de uma região;

- Forma: são as chamadas projeções conformes ou ortomórficas que preservam os ângulos localmente, fazendo com que os meridianos e paralelos tenham intersecções de 90 graus entre si. A preservação dos ângulos torna esta projeção adequada para navegação ${ }^{15}$, por exemplo;

- Escala: essas projeções são chamadas de equidistantes e preservam a escala ao longo de uma ou mais direções. No entanto, não é possível preservar a escala para todos os pontos do mapa;

- Direção: são as projeções azimutais ou zenitais, nas quais a direção é preservada, em geral com relação a um ponto central. Dependendo da projeção, pode preservar-se conjuntamente a área, a forma ou a distância;

- Características especiais: na projeção de Mercator, as linhas de direção constante são representadas por linhas retas. Na projeção Gnomônica, as trajetórias do grande círculo (great circle paths - rota mais curta entre dois pontos em uma esfera) são representadas como linhas retas.

Com o objetivo de avaliar o grau de distorção de uma projeção, diferentes critérios e técnicas podem ser utilizados. Mulcahy e Clarke (2001) apresentam dez técnicas gráficas para representar as distorções, incluindo a clássica indicatriz de Tissot (Tissot's Indicatrix). De forma similar, Brainerd e Pang (2001) apresentam um método gráfico que usa um anel flutuante (floating ring), o qual é apropriadamente deformado conforme o método de projeção utilizado e sobreposto ao mapa de forma interativa.

Entre os critérios para analisar as distorções de uma projeção, lliffe (2003, p. 60) apresenta o fator de escala, dado pela Equação 4-12. De acordo com o autor, a relação é válida para uma escala infinitesimal, uma vez que o fator é função da posição sobre o mapa. Por isso, a distorção verificada em uma linha que liga dois pontos será uma integral das distorções encontradas ao longo desse caminho. Ainda, a distorção 
em cada direção poderá ser diferente. $O$ resultado $k=1$ indica que no ponto analisado a distorção é nula.

$k=\frac{\text { distância na projeção }}{\text { distância no elipsóide }}$

Um segundo critério para a avaliação das distorções em uma projeção, é a convergência meridiana, também referida na literatura como grid convergence ou meridional convergence. Conforme o apresentado em Iliffe (2003, p. 59) e Maling (1991), em uma projeção costuma-se sobrepor duas malhas: uma chamada de grid e outra de graticule, conforme a ilustração da Figura 4-5. A primeira corresponde a um conjunto de linhas ortogonais entre si paralelas aos eixos x e y, quando um sistema cartesiano de coordenadas é utilizado. Já o termo graticule se refere à malha formada pelas linhas dos paralelos e dos meridianos com latitude e longitudes constantes, respectivamente. De acordo com NGS (2009), a convergência meridiana consiste no ângulo formado entre a linha do meridiano de uma graticule e o meridiano central desta graticule.

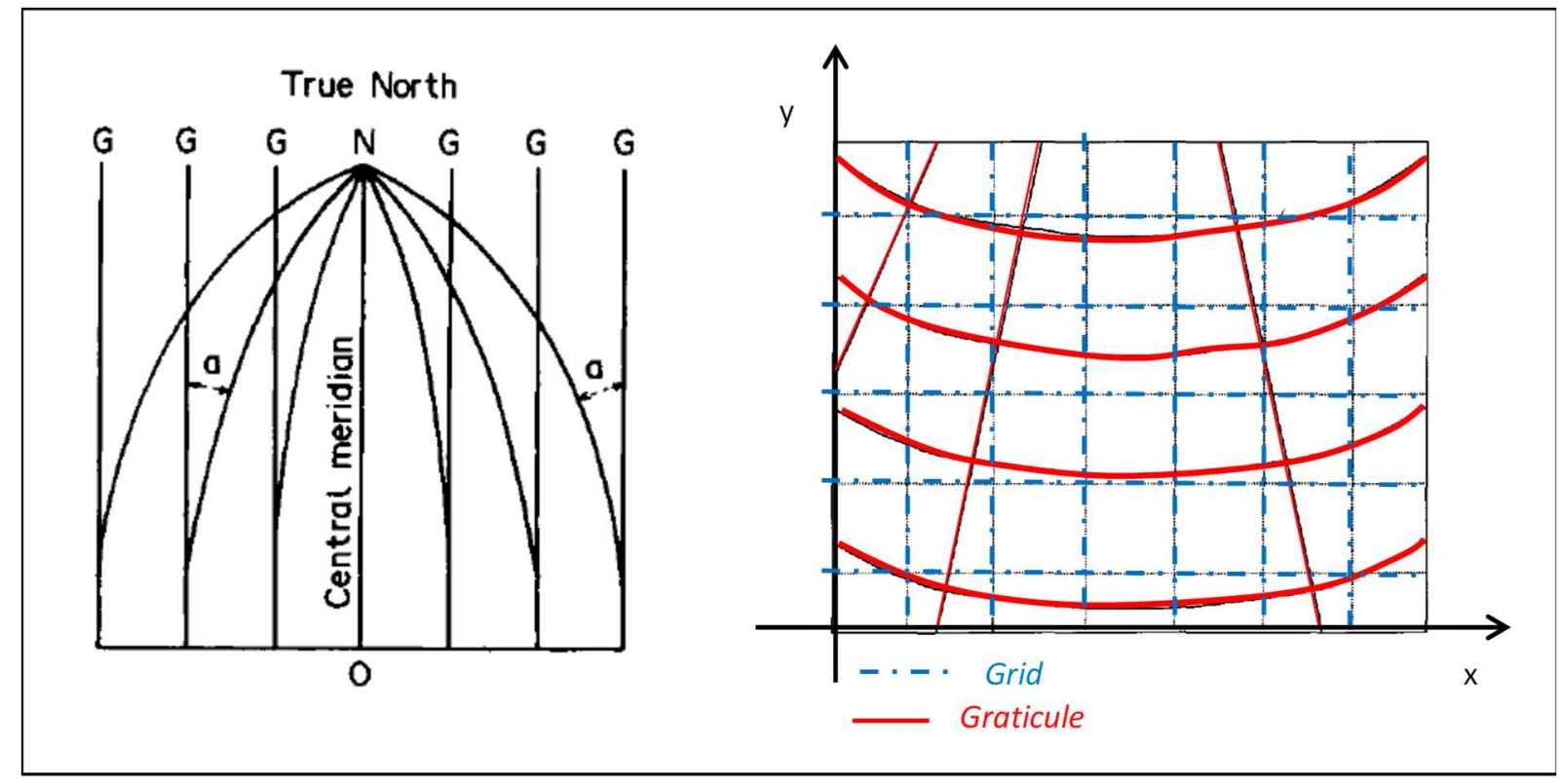

Figura 4-5 Convergência meridiana, grid e graticule.

FONTE: Figura da esquerda: (MALING, 1991). Figura da direita: Adaptado de (ILIFFE, 2003)

Além das características já mencionadas, a área de abrangência da projeção e o seu ponto de origem também são fatores importantes na escolha, o que permite a criação de projeções locais, que permitem um nível menor de distorção do que aquela verificada nas projeções globais. Como exemplos de projeções locais, pode-se citar o sistema UTM (Universal Transversa de Mercator), o sistema State Plane Coordinate 
System (SPCS); o PTL (Plano Topográfico Local) e o SCL (Sistema Cartesiano Local), discutidas a seguir. Mas antes disso, o item 4.3.1 apresenta um fator importante em uma projeção, que é a elevação da projeção sobre a superfície do elipsoide.

\subsubsection{Influência do fator elevação}

Burkholder (1991, p. 105), focando nos problemas da topografia, analisa implicações geométricas oriundas da consideração da altura no cálculo de distâncias horizontais. $O$ autor apresenta 6 maneiras diferentes de se obter a distância horizontal entre dois pontos medidos na superfície topográfica com alturas diferentes. Estes métodos são os seguintes, quando colocados em ordem crescente de precisão, segundo o autor:

- $\mathrm{HD}^{16}(1)$ : O cateto horizontal de triângulo retângulo, desconsiderando a curvatura da Terra;

- HD(2): A distância entre duas linhas de prumo (plumb lines) em um plano tangente à Terra na estação de medição;

- $\mathrm{HD}(3)$ : A corda entre duas linhas de prumo. Os dois pontos têm a mesma elevação e a corda é perpendicular à vertical somente no ponto médio da corda.

- $\mathrm{HD}(4)$ : a distância no arco entre os duas linhas de prumo em uma superfície de nivelamento;

- $\mathrm{HD}(5)$ : a distância no arco entre as duas linhas de prumo em uma superfície ao nível do mar;

- $\mathrm{HD}(6)$ : a distância ao longo da geodésica na superfície do elipsoide entre as duas linhas de prumo.

A Figura 4-6 ajuda ilustra estas distâncias. 


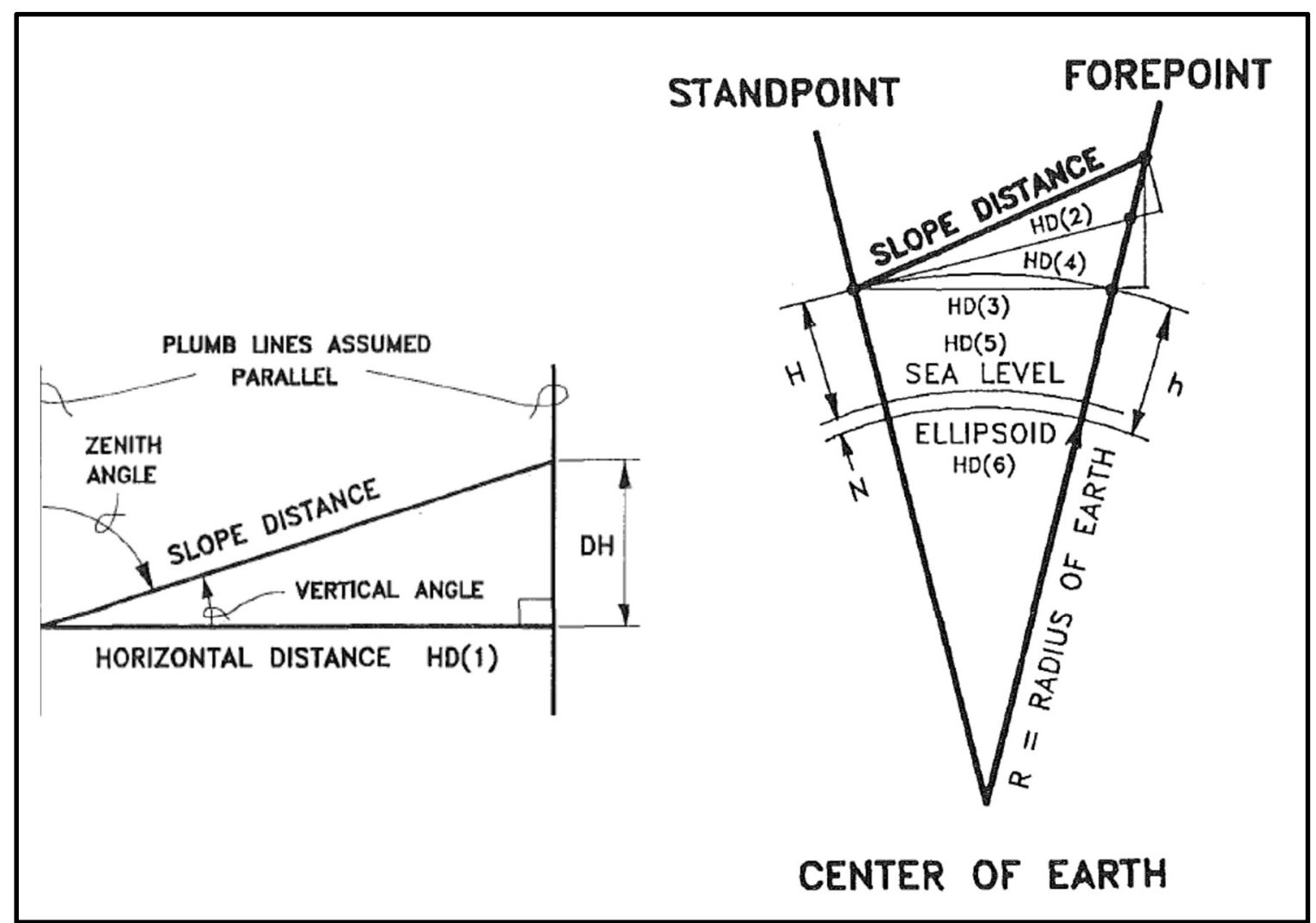

Figura 4-6 Medição de distâncias horizontais.

FONTE: (BURKHOLDER, 1991, p. 105)

A partir da discussão, fica evidente que a altura influencia em alguma medida a distância entre dois pontos na superfície projetada e, por consequência, a precisão desta projeção. Portanto, projeções que não tenham como entrada coordenadas com três dimensões encontram na altura uma fonte para distorções.

Para minimizar os efeitos das diferenças de altura, Burkholder (1991, p. 116) apresenta a seguinte fórmula de correção das distâncias, que permite escrevê-las sobre uma superfície comum, que pode ser o geoide ou o elipsoide:

$S L D=H D \times\left(\frac{R}{R+h}\right)$

SLD é a distância corrigida em uma superfície comum; HD a distância original; $\mathrm{R}$ o raio da Terra; e H a altura em relação ao geoide. Caso a superfície comum seja o elipsoide, $\mathrm{H}$ deve representar a altura elipsoidal.

De forma bastante similar, a NBR 14166:1998 (ABNT, 1998), ao apresentar as fórmulas para a projeção plano topográfico local (PTL) utiliza o coeficiente c, cuja superfície comum é o elipsoide:

$c=\frac{R_{m}+h}{R_{m}}$ 
Neste caso, $R_{m}$ é o raio da esfera de adaptação de Gauss, calculado como $\sqrt{M \times N}$. As fórmulas para $\mathrm{M}$ e $\mathrm{N}$ são mostradas na Equação 4-15 e na Equação 4-4, respectivamente.

$M=\frac{a \times\left(1-e^{2}\right)}{\left(1-e^{2} \cdot \sin (\varphi)^{2}\right)^{3 / 2}}$

Estes valores dependem dos parâmetros do elipsoide $(a$ e $e)$ e da latitude $(\varphi)$ no ponto de origem da projeção. A esfera de adaptação de Gauss é tangente ao elipsoide em um ponto escolhido $(P)$ sobre a sua superfície, buscando representar localmente o elipsoide através de uma esfera. Para tal ajuste, o centro da esfera se desloca. A Figura 4-7 ilustra estes conceitos com base em um elipsoide fictício com $a=6.378 .137 m$ e $b=2.551 .254,8 m^{17}$, e com dois pontos de tangência, nas latitudes de 0 e 90 graus. O gráfico foi preparado com o emprego do software PTC Mathcad 2014.

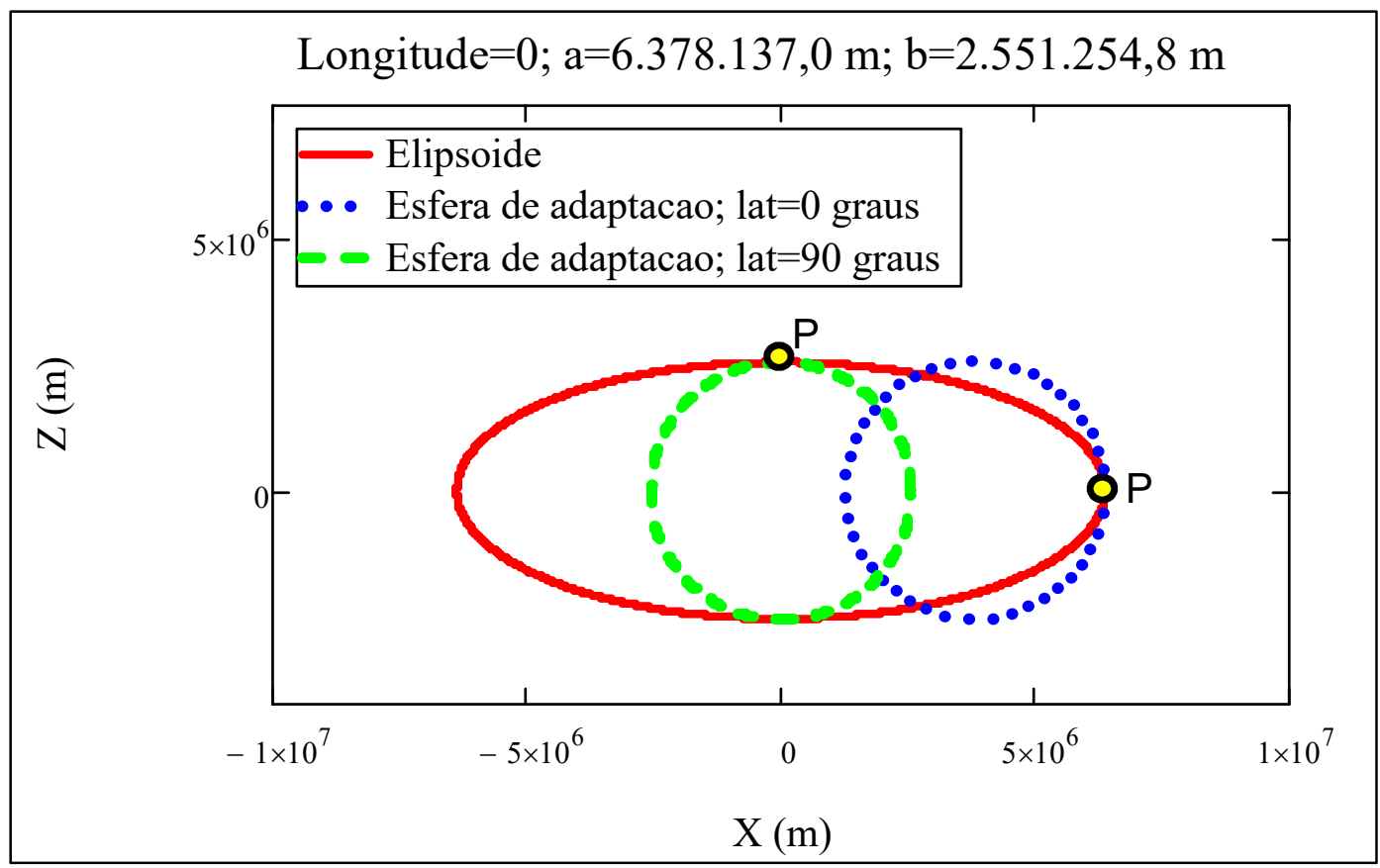

Figura 4-7 llustração da esfera de adaptação de Gauss.

FONTE: Elaborado pelo autor.

Na Figura 4-7 a elipse foi gerada com as fórmulas da Equação 4-4 e da Equação 4-5. As esferas por sua vez obedecem a:

$Z=R_{m} \times \cos \varphi+\Delta z$

$17 \mathrm{O}$ achatamento do elipsoide está exagerado para facilitar a visualização das geometrias analisadas. 
$X=R_{m} \times \operatorname{sen} \varphi+\Delta x$

Enquanto $\varphi$ denota a latitude, $\Delta x$ e $\Delta z$ precisam ser utilizados para que a esfera de adaptação seja deslocada até o ponto de tangência. Para tanto, estes acréscimos correspondem às respectivas diferenças entre as coordenadas $\mathrm{x} e$ $z$ do elipsoide e da esfera de adaptação antes do deslocamento.

A Equação 4-13, quando adaptada para uma superfície esférica, pode ser deduzida a partir da representação da Figura 4-8, com a em radianos.

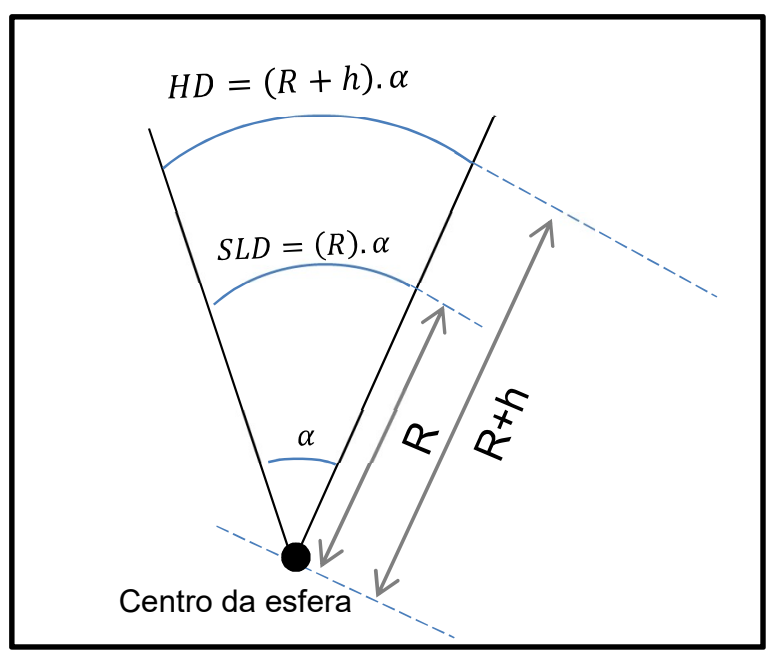

Figura 4-8 Modelagem do fator de ajuste da altura em uma projeção.

FONTE: Elaborado pelo autor.

A partir desta sucinta exploração da influência da altura, pode-se esperar uma distorção adicional na análise e representação de dados espaciais através de uma projeção construída sem a consideração da altura. Tal distorção será maior para os pontos de maior altura e será nula quando os pontos se encontram ao nível da superfície que deu origem à projeção. A seguir, apresenta-se uma análise dos limites da influência da altura na precisão de uma projeção, utilizando a Equação 4-13.

A utilização de uma projeção concebida a partir de uma superfície de referência como o elipsoide levará a uma distorção de altura caso os pontos considerados se distanciem verticalmente do elipsoide. Embora a modelagem proposta para esta pesquisa empregue uma projeção que incorpora os efeitos da altura, analisa-se aqui o impacto gerado pela desconsideração deste parâmetro. Tal análise é oportuna por delinear a ordem de grandeza das distorções introduzidas pela desconsideração da altura. 
Na Equação 4-13, para qualquer altura, a distorção será maior para os menores valores de $R_{m}$. Resta então analisar em quais condições ocorre o menor valor de $R_{m}$. Utilizando a modelagem da NBR 14166:1998 (ABNT, 1998), na qual o raio em um dado ponto da superfície do elipsoide é dado pela esfera de adaptação de Gauss, tem-se:

$R_{m}=\sqrt{\frac{a \times\left(1-e^{2}\right)}{\left(1-e^{2} \times \operatorname{sen}^{2} \varphi\right)^{3 / 2}} \times \frac{a}{\left(1-e^{2} \times \operatorname{se}^{2} \varphi\right)^{1 / 2}}}=\frac{a \times \sqrt{\left(1-e^{2}\right)}}{1-e^{2} \times \operatorname{sen}^{2} \varphi}$

Nesta equação, $a$ é o raio maior e $e$ é a primeira excentricidade, conforme o explanado na seção 4.1. Já $\varphi$ representa a latitude no ponto onde o raio $R_{m}$ é analisado. Dividindo-se a equação 4-18 por a é possível obter-se a relação entre $\left(R_{m} / a\right)$ e as variáveis $\varphi$ e $e$. A maior distorção de altura a partir da Equação 4-13 estará relacionada ao mínimo raio. A Figura 4-9 apresenta uma análise destas variáveis, demonstrando-se que $\left(R_{m} / a\right)$ é mínimo para a latitude 0 e que esta é a condição crítica para a Equação 4-13. Na mesma figura, três elipsoides são situados, para fins de exemplificação (Clarke 1880, SAD69 e WGS84).

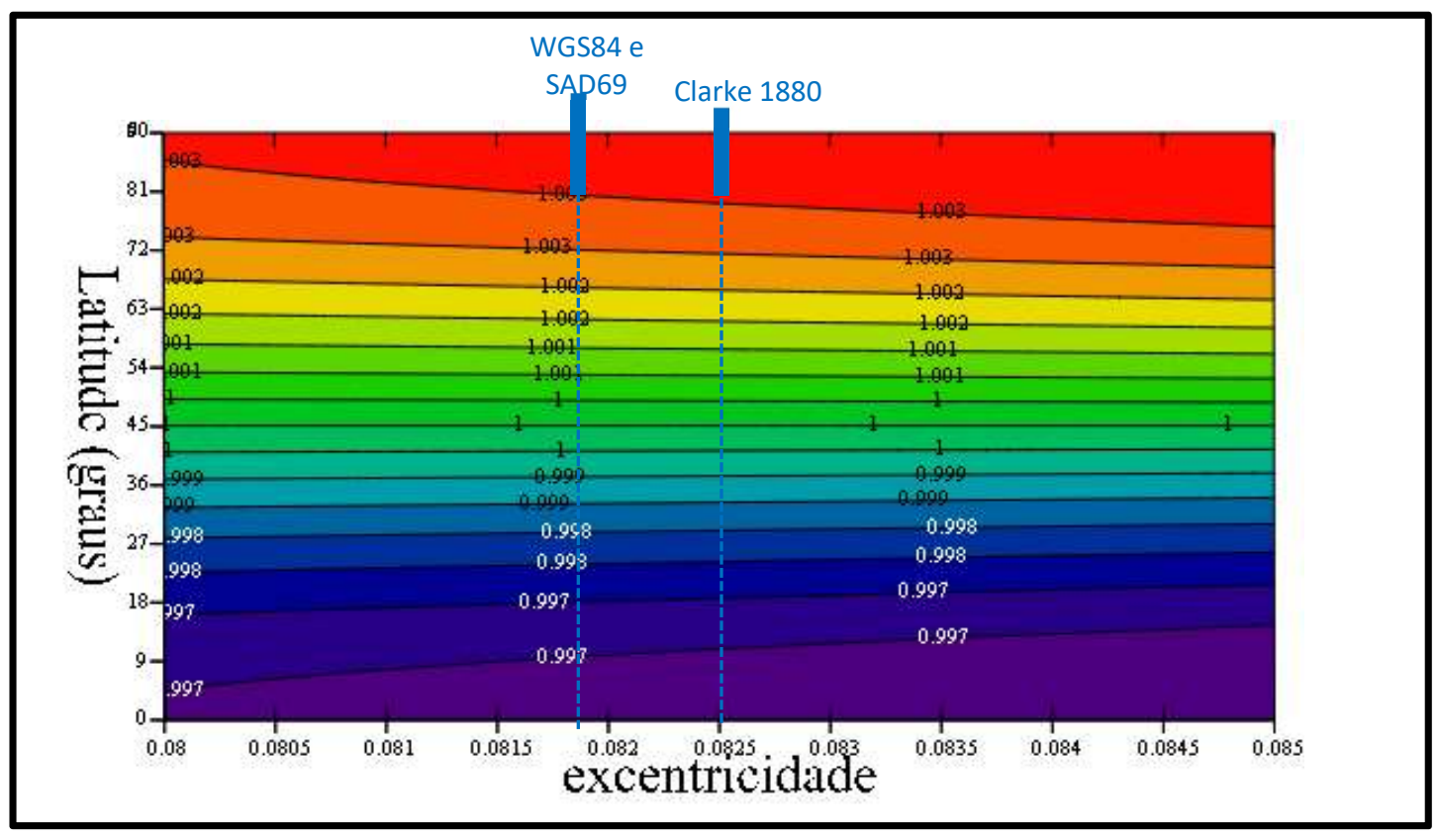

Figura 4-9 Análise das combinações críticas entre latitude e excentricidade sobre $\left(R_{m} / a\right)$.

FONTE: Elaborado pelo autor.

A Tabela 4-1 apresenta uma análise dos erros percentuais (ou fatores de conversão) esperados para as distâncias horizontais sobre uma superfície de referência para uma faixa de valores da altura $h$.

Conforme os dados, para uma altura de $1.000 \mathrm{~m}$, o fator de conversão devido à altura será de aproximadamente $0,0157 \%$ da distância horizontal, ou seja, para cada 
$100 \mathrm{~m}$ de distância horizontal existirá uma distorção de $1,57 \mathrm{~cm}$. Este valor aparece na equação simplificada do coeficiente $c$ na NBR14.166:1998 (ABNT, 1998), apresentado na Equação 4-14. Uma variação mínima pode ser verificada entre os três elipsoides analisados, o que fica ainda mais claro a partir da Figura 4-10.

Tabela 4-1 - Fator de ajuste em função da altura para diferentes elipsoides.

\begin{tabular}{c|c|c|c}
\hline \multirow{2}{*}{$\begin{array}{c}\text { Altura h } \\
(\mathbf{m})\end{array}$} & Clarke 1880 & SAD 69 & wgs84 \\
\cline { 2 - 4 } & $0,000000000 \%$ & $0,000000000 \%$ & $0,000000000 \%$ \\
\hline 0 & $0,007865327 \%$ & $0,007865005 \%$ & $0,007865033 \%$ \\
\hline 500 & $0,015729417 \%$ & $0,015728774 \%$ & $0,015728829 \%$ \\
\hline 1000 & $0,023592269 \%$ & $0,023591305 \%$ & $0,023591388 \%$ \\
\hline 1500 & $0,031453886 \%$ & $0,031452600 \%$ & $0,031452711 \%$ \\
\hline 2000 & $0,039314266 \%$ & $0,039312659 \%$ & $0,039312798 \%$ \\
\hline 2500 & $0,047173410 \%$ & $0,047171482 \%$ & $0,047171648 \%$ \\
\hline 3000 & $0,055031318 \%$ & $0,055029070 \%$ & $0,055029263 \%$ \\
\hline 3500 & $0,062887991 \%$ & $0,062885422 \%$ & $0,062885643 \%$ \\
\hline 4000 & \multicolumn{3}{|c}{} \\
\hline Latitude $=0$ & a: 6378249,145 & $1 / f: 293,465$ & \\
Parâmetros: & a: 6378160 & $1 / f: 298,25$ & \\
Clarke 1880 & a: 6378137 & $1 / f: 298,257223563$ & \\
SAD 69 & &
\end{tabular}

FONTE: Elaborado pelo autor.

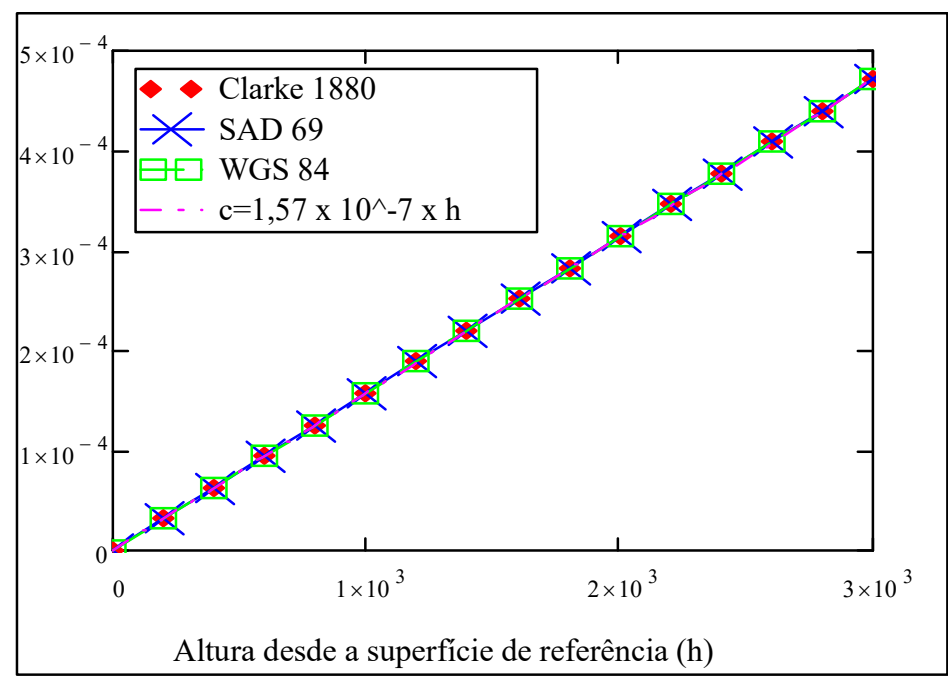

Figura 4-10 Relação entre h e (c-1) para latitude=0. Ver Equação 4-14.

FONTE: Elaborado pelo autor.

\subsubsection{Sistemas locais de projeção}

Como foi discutido anteriormente, uma projeção possui inevitavelmente algum grau de distorção, exigindo a escolha de uma projeção adequada a cada aplicação. Neste sentido, para projetos de engenharia, projeções locais serão muitas vezes selecionadas, dado que a menor abrangência espacial tende a coincidir com um 
menor nível de distorções. Uma projeção local cuja origem se localiza na altura média do terreno é uma boa estratégia para minimização da distorção associada à altura, anteriormente discutida.

A seguir, algumas projeções locais são apresentadas.

\subsubsection{Projeção UTM}

O sistema UTM divide o globo terrestre em 60 zonas, espaçadas a cada $6^{\circ}$ de longitude ao longo da linha do Equador. Estas zonas são numeradas de 1 a 60 e abrangem a porção da Terra compreendida entre latitudes $80^{\circ} \mathrm{S}$ e $84^{\circ} \mathrm{N}$.

A Figura 4-11 ilustra a divisão do globo, para a projeção UTM. Para cada um dos 60 fusos e para cada hemisfério, é criado um sistema próprio de coordenadas, originando 120 combinações possíveis. Assim, a conversão de coordenadas UTM para geodésicas exige as coordenadas $x, y$ da projeção; o hemisfério; e o fuso ou meridiano central do fuso ${ }^{18}$.

Já na transformação de coordenadas geodésicas para o sistema UTM, de forma a garantirem-se sempre valores positivos, os seguintes acréscimos são feitos às coordenadas:

$x$ (na direção leste-oeste): $+500.000 m$

$y$ (na direção norte-sul): 0m no hemisfério norte e 10.000.000m no hemisfério sul.

Tomemos alguns exemplos de transformação para exemplificação, todas baseadas no datum WGS84 (EPSG 4326), conforme a Tabela 4-2.

As transformações foram realizadas através do software QGIS, versão 2.8.3 Wien. No software, os códigos EPSG são utilizados para as transformações. Como discutido anteriormente, este código carrega informações sobre o referencial, sobre o sistema de coordenadas e sobre os parâmetros de transformação. Bibliotecas da área de GIS também costumam utilizar o sistema EPSG.

Para a projeção UTM, os cálculos serão idênticos para os 60 fusos, com a devida consideração da diferença no valor da longitude. Através da projeção UTM, qualquer ponto dentro da zona pode ser transformado em uma coordenada bidimensional do plano cartesiano, sendo a sua altura tratada como um atributo, ou seja, a altura é desconsiderada durante as transformações

\footnotetext{
18 Nesta pesquisa, $x$ é definido no eixo horizontal, correspondendo à longitude e y ao eixo vertical, correspondendo às latitudes.
} 


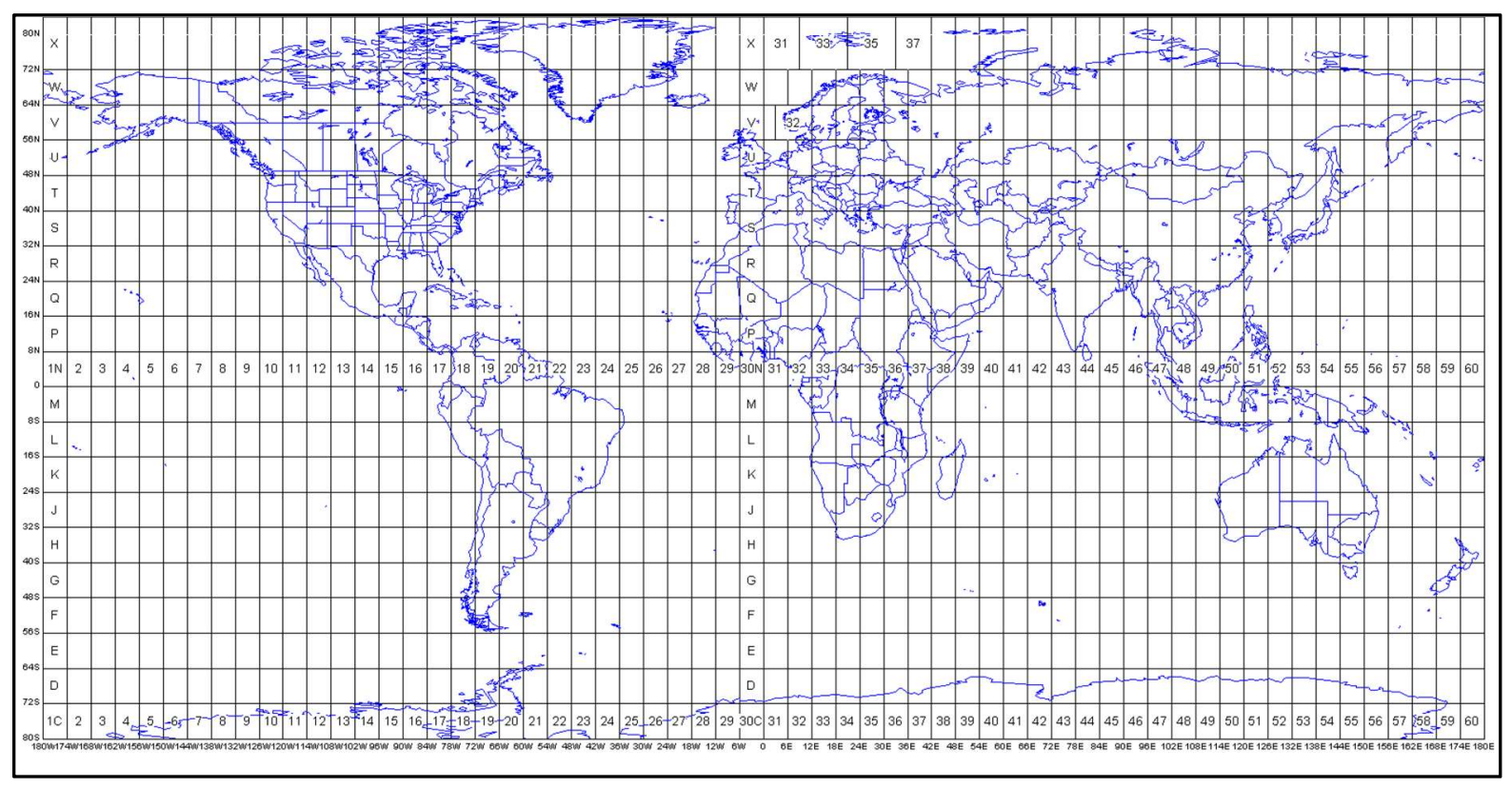

Figura 4-11 Ilustração da projeção UTM.

FONTE: (WASHINGTON STATE UNIVERSITY, 2012)

Tabela 4-2 - Exemplos de transformação de coordenadas UTM

\begin{tabular}{|c|c|c|c|c|c|}
\hline \multirow{2}{*}{$\begin{array}{l}\text { Meridiano } \\
\text { central do fuso }\end{array}$} & \multicolumn{2}{|c|}{ Coordenadas Geográficas } & \multicolumn{2}{|c|}{ Coordenadas UTM (m) } & \multirow{2}{*}{$\begin{array}{c}\text { Código } \text { EPSG }^{19} \text { para a } \\
\text { projeção UTM no WGS84 }\end{array}$} \\
\hline & Latitude & Longitude & $\mathbf{y}$ & $\mathbf{x}$ & \\
\hline $57 \mathrm{~W}$ & $0^{\circ} 0^{\prime} 0^{\prime \prime} \mathrm{N}$ & $57^{\circ} 0^{\prime} 0^{\prime \prime} \mathrm{W}$ & 0 & 500.000 & 32621 \\
\hline $51 \mathrm{~W}$ & $0^{\circ} 0^{\prime} 0^{\prime \prime} \mathrm{S}$ & $51^{\circ} 0^{\prime} 0^{\prime \prime} \mathrm{W}$ & 10.000 .000 & 500.000 & 32722 \\
\hline $51 \mathrm{E}$ & $0^{\circ} 0^{\prime} 0^{\prime \prime} \mathrm{N}$ & $51^{\circ} 0^{\prime} 0^{\prime \prime} \mathrm{E}$ & 0 & 500.000 & 32639 \\
\hline $51 \mathrm{E}$ & $0^{\circ} 0^{\prime} 0^{\prime \prime} \mathrm{S}$ & $51^{\circ} 00^{\prime} 0^{\prime \prime} \mathrm{E}$ & 10.000 .000 & 500.000 & 32739 \\
\hline $51 \mathrm{E}$ & $45^{\circ} 9^{\prime} 12.51786^{\prime \prime} \mathrm{S}$ & $51^{\circ} 0^{\prime} 0^{\prime \prime} \mathrm{E}$ & 5.000 .000 & 500.000 & 32739 \\
\hline
\end{tabular}

Obs.: No software QGIS, longitudes a oeste são consideradas negativas.

FONTE: Elaborado pelo autor

\subsubsection{Projeção no sistema State Plane Coordinate System}

O SPCS (State Plane Coordinate System) é o sistema de projeção mais utilizado no EUA e em seus territórios nas aplicações de levantamento (surveying) e mapeamento em escala regional e local (DOYLE, 2004). O sistema respeita os limites políticos, estando definido para centenas de zonas em todo o território. O SPCS utiliza mais de um sistema de projeção, dependendo da posição geográfica da zona e do seu formato. Informações detalhadas sobre este sistema podem ser encontradas em (NOAA, 2017), incluindo ferramentas de conversão online (NGS, 2017) e para download. 
Para a conversão de coordenadas, o SPCS leva em consideração a altura elipsoidal.

\subsubsection{Plano Topográfico Local}

O PTL (Plano Topográfico Local) é regulado pela NBR 14166:1998 (ABNT, 1998), constituindo-se como uma projeção local de forma que:

O plano topográfico é tangente ao elipsoide de referência no ponto de origem do Sistema Topográfico, tendo sua dimensão máxima limitada a aproximadamente $70 \mathrm{~km}$, a partir da origem do Sistema Topográfico Local, de maneira que o erro relativo, decorrente da desconsideração da curvatura terrestre, não ultrapasse 1:50 000 nesta dimensão e 1:20 000 nas imediações da extremidade desta dimensão, sendo que a dimensão máxima do plano topográfico é a metade da diagonal de um quadrado de $100 \mathrm{~km}$ de lado, correspondente à área máxima de abrangência do Sistema Topográfico Local. ${ }^{20}$ (ABNT, 1998)

O PTL tem ponto de origem do sistema $\left(P_{0}=\left(\varphi_{0}, \lambda_{0}, h_{0}\right)\right)$, situado na altura elipsoidal média do terreno $\left(h_{0}\right)$. Por questões de precisão, a norma limita a diferença de altura do terreno a $150 \mathrm{~m}$, o que pode exigir que em terrenos muitos acidentados, sistemas locais adjacentes precisem ser adotados.

As fórmulas de transformação podem ser encontradas na NBR 14166:1998 (ABNT, 1998), porém o material não apresenta as fórmulas inversas. Estas podem ser encontradas em Blitzkow et al. (2007). No entanto, após diversos testes durante o desenvolvimento desta pesquisa, percebeu-se que existe uma diferença no valor das coordenadas originais e daquelas que passaram sucessivamente pelas transformações diretas e inversas. Embora um erro contido em certo intervalo possa ser considerado aceitável para aplicações de engenharia e mapeamento, em um modelo computacional, é conveniente que os erros em transformações diretas e inversas sejam reduzidos tanto o quanto possível.

\subsubsection{Sistema Cartesiano Local}

Uma alternativa é o método descrito em Dal'Forno (2011) e Andrade (2003) ${ }^{21}$, que estabelecem as seguintes fórmulas para transformação de coordenadas para um sistema cartesiano local:

\footnotetext{
${ }^{20} \mathrm{~A}$ área de abrangência pode ser reduzida se o terreno apresentar diferenças de altura acima de um limite previsto na norma.

${ }^{21}$ Andrade (2003) utiliza a expressão referencial cartesiano local, para o que está aqui sendo chamado de SCL.
} 


$$
\left[\begin{array}{l}
t \\
u \\
v
\end{array}\right]=\left[\begin{array}{ccc}
1 & 0 & 0 \\
0 & \operatorname{sen}\left(\varphi_{0}\right) & \cos \left(\varphi_{0}\right) \\
0 & -\cos \left(\varphi_{0}\right) & \operatorname{sen}\left(\varphi_{0}\right)
\end{array}\right] \times\left[\begin{array}{ccc}
-\operatorname{sen}\left(\lambda_{0}\right) & \cos \left(\lambda_{0}\right) & 0 \\
-\cos \left(\lambda_{0}\right) & -\operatorname{sen}\left(\lambda_{0}\right) & 0 \\
0 & 0 & 1
\end{array}\right] \times\left[\begin{array}{c}
X-X_{0} \\
Y-Y_{0} \\
Z-Z_{0}
\end{array}\right]
$$

A partir deste conjunto de equações, é possível obter-se $t, u$ e $v$ que são as coordenadas em um sistema cartesiano local, aqui chamado de SCL. Por sua vez, $\mathrm{X}$, $\mathrm{Y}$ e $\mathrm{Z}$ denotam as coordenadas cartesianas globais. $\mathrm{O}$ índice 0 denota o ponto inicial do sistema local. Como se percebe, neste método, o sistema local corresponde a uma operação de rotação das coordenadas globais.

Por esta concepção matemática simples, não só o processo inverso é simples, mas também previsível computacionalmente, em termos de tempo de processamento.

Adotando-se as constantes $150.000 \mathrm{~m}$ no eixo $\mathrm{X}$ e $250.000 \mathrm{~m}$ no eixo $\mathrm{Y}$, o sistema pode ser mais facilmente comparado ao PTL.

\subsection{DISTÂNCIAS SOBRE A SUPERFÍCIE GEODÉSICA}

Quando representados em uma projeção, a distância entre dois pontos é facilmente obtida por geometria euclidiana. No entanto, como já discutido, a própria projeção contém algum grau de distorção, que pode interferir na distância calculada.

Por outro lado, quando os pontos são representados sobre a superfície do globo, a distorção associada à projeção é evitada. Se tal globo for esférico, a determinação analítica do comprimento de um arco na superfície, ou seja, a distância entre dois pontos, será trivial, pela Equação 4-20, onde R é o raio e $\Delta_{\alpha}$ a amplitude do arco.

$S=R \times \Delta_{\alpha}$

No entanto, para uma melhor adaptação à forma da Terra, o formato elipsoidal é mais comumente adotado, tornando o cálculo do comprimento de um arco na superfície mais complexo. Para algumas atividades que requerem menor precisão, poderá ser utilizado o modelo do grande círculo (great circle distance) ou da grande elipse (great elipse distance). Tseng, Guo e Liu (2013) comparam estes dois modelos utilizados na navegação com a distância geodésica, esta conforme as fórmulas apresentadas em Vincenty (1975), que apresentam erro submilimétrico.

\subsection{MODELOS DIGITAIS DE ELEVAÇÃO}

A distribuição da altura do terreno é um insumo para diversas análises nas áreas de engenharia e ciências exatas, em aplicações como hidrologia, incluindo análise de 
cheias e delineamento e análise de bacias hídricas e redes de drenagem; análise da erosão do solo e transporte de sedimentos; estudos sobre ecologia; análises geomorfológicas; modelos climáticos; aplicações militares e de engenharia civil, como análise de rotas, análise de linha de visão, análise de riscos de deslizamentos de terra; entre outros (PECKHAM e JORDAN, 2007).

Em obras de rodovias e ferrovias, a topografia do terreno é um dado importante para definição de traçado e para o cálculo do volume de terra a ser movimentado, dado o projeto geométrico da via. No caso de aeroportos, a distribuição da altura do terreno no sítio aeroportuário influencia diretamente o projeto de componentes físicos e de áreas de proteção, dados os greides estabelecidos pelas normas de projeto, além da linha de visão a partir da torre de controle. Além disso, em um aeródromo, o perfil de altura da pista de pouso e/ou de decolagem (RWY) influencia as separações necessárias entre esta e outros componentes. Isso ocorre porque superfícies imaginárias de proteção ao espaço aéreo originam-se na altura RWY: quanto menor a cota de um ponto qualquer da RWY, mais restritiva será a superfície de proteção que dela se origina.

De forma convencional, plantas ou mapas topográficos representam a altura através de curvas de nível, ou isolinhas, que permitem reconstruir o perfil do terreno em um trecho de interesse, oferecendo uma interpretação intuitiva. No entanto, novas formas de aquisição de dados e o emprego de computadores trouxeram a necessidade de uma representação digital da altura do terreno, levando ao estabelecimento do assim chamado Modelo Digital de Elevação (MDE ou DEM, na sigla em inglês). Outras siglas também costumam ser utilizadas, às vezes como sinônimos, outras vezes como forma de diferenciar o tipo de superfície que é representada. Li (1990) compara variações da sigla como DGM (Ground), DHM (Height), DTM (Terrain). Para esta tese, a sigla MDE é adotada, por simples motivo de padronização.

Oliveira; Piteri e Meneguete (2014) apresentam as fases de criação de um MDE: aquisição, manipulação e aplicação. A primeira diz respeito à obtenção dos dados. $A$ fase de manipulação se refere à geração de uma representação computacional dos dados, a qual pode ser armazenada, acessada e trocada entre programas e rotinas computacionais. A aplicação por sua vez se refere ao uso do MDE para algum propósito final, como análise de distâncias, áreas e volumes; análises de linha de visão; análise de declividades; entre outras tantas aplicações.

Florinsky (2011) indica que os dados para um MDE podem ser adquiridos a partir de fontes como: levantamentos topográficos convencionais; levantamento GPS 
cinemático (Kinematic GPS survey); abordagens fotogramétricas digitais e analógicas; técnicas baseadas em radar; técnicas baseadas em laser; técnicas baseadas em sonares a bordo de veículos aquáticos; sensoriamento óptico aéreo; altimetria radar por satélites; digitalização de contornos em mapas existentes; entre outros.

Obtidos os dados, será necessário gerar o MDE (fase de manipulação), sendo que a literatura (Li, Zhu e Gold, 2005; Petrie, 1987) apresenta diversas abordagens possíveis, a saber:

- Modelagem baseada em pontos (pointwise): uma grade (grid) de pontos é gerada e os dados levantados são utilizados para calibrar a altura de cada ponto da grade. Assim, cada ponto possui uma altura definida.

- Modelagem baseada em uma superfície global: uma única superfície tridimensional baseada em um polinômio é utilizada. Tal superfície estará definida após a calibração dos seus parâmetros, podendo incorrer em elevados erros locais e em oscilações entre os pontos levantados.

- Modelagem baseada em células (patchwise): para cada célula uma função é estabelecida e calibrada, permitindo melhor ajuste do que uma superfície global, mas com maior complexidade na estrutura de dados para armazenagem e acesso.

A utilização de células pode levar a uma superfície contínua ou descontínua, dependendo do método de interpolação utilizado. Além disso, os modelos baseados em células podem ser regulares ou irregulares. Nos modelos regulares, a geometria e as dimensões das células são fixas e os dados de altura são utilizados para calibrar os parâmetros de cada célula. Durante o posterior acesso do MDE, a altura fornecida para um dado ponto xy será dada possivelmente por uma nova interpolação. Essas características permitem que existam diferenças expressivas entre as alturas de entrada e as alturas de saída em uma dada vizinhança.

Por outro lado, nos modelos irregulares, cria-se a oportunidade aumentar a densidade dos pontos em regiões de alta declividade ou de maior resolução. Muito recorrente na literatura e nas implementações computacionais é a malha TIN (Triangulated Irregular Network), que permite a introdução de elementos de localização precisa no modelo, como estradas, rios, vales e cumes, melhorando sua precisão (Casas et al., 2006; Jones, Kidner e Ware, 1994). Na rede TIN, as interpolações ocorrem somente durante o acesso ao modelo, não durante sua construção. Isso porque qualquer ponto $x y$ de interesse, em uma malha TIN, ou coincidirá com um nó da malha (ponto levantado) ou estará entre três nós, cada um 
correspondendo a um ponto levantado. A seguir são discutidos alguns fundamentos pertinentes ao modelo TIN.

Um MDE do tipo TIN normalmente é elaborado em duas fases: i) triangulação 2D de pontos irregularmente distribuídos através de uma Triangulação de Delaunay (TD ou DT, na sigla em inglês); e ii) incorporação das alturas, gerando um conjunto de facetas triangulares adjacentes. A Figura 4-12 ajuda a entender este processo, cujas etapas são discutidas na sequência.

A etapa $\boldsymbol{i}$ - triangulação de Delaunay (TD) - consiste na elaboração de triângulos a partir dos pontos fornecidos, que são irregularmente distribuídos. Este tema é brevemente discutido no item 3.2.

Já na etapa ii, os triângulos bidimensionais são transformados em facetas triangulares adjacentes. Assim, dado um ponto $P$ de coordenadas $x_{p}$ e $y_{p}$, a altura $z_{p}$ será calculada por interpolação bilinear, considerando as coordenadas dos três nós pertencentes a uma faceta cuja projeção nos eixos $x$ e $y$ contenha $P$.

Com efeito, a determinação de $z_{p}$ a partir de uma malha TIN existente passará por duas etapas: i) determinação do triângulo cuja projeção no plano $x y$ contém $P$; e ii) interpolação da altura de $P$ a partir dos pontos adjacentes.

Uma TD pode ser bidimensional ou tridimensional. Quando o objetivo da mesma é gerar um modelo de altura, a triangulação bidimensional será muitas vezes considerada suficiente, pois a geometria em questão é uma superfície. Variações de algoritmos de triangulação de Delaunay surgem no caso restrito (constrained Delaunay triangulation), quando se deseja, por exemplo, introduzir uma linha de quebra (breakline). Li, Zhu e Gold (2005) também chamam atenção para o fato de que triangulações irregulares construídas a partir de pontos extraídos de curvas de nível podem apresentar características indesejáveis como triângulos planos, quando as curvas possuem raios diminutos. Conforme ilustra a Figura 4-13 (esquerda), isso ocorre quando o triângulo é formado por três pontos pertencentes a uma mesma curva de nível. Embora a implementação seja complexa, a ideia básica para a solução deste problema passa por uma nova triangulação das regiões afetadas, após a introdução de pontos em posições específicas. Favalli (2004) propõe o algoritmo DEST para este tipo de correção do modelo. Sofisticações da TD também podem ser encontradas em Freitas et al. (2016). 


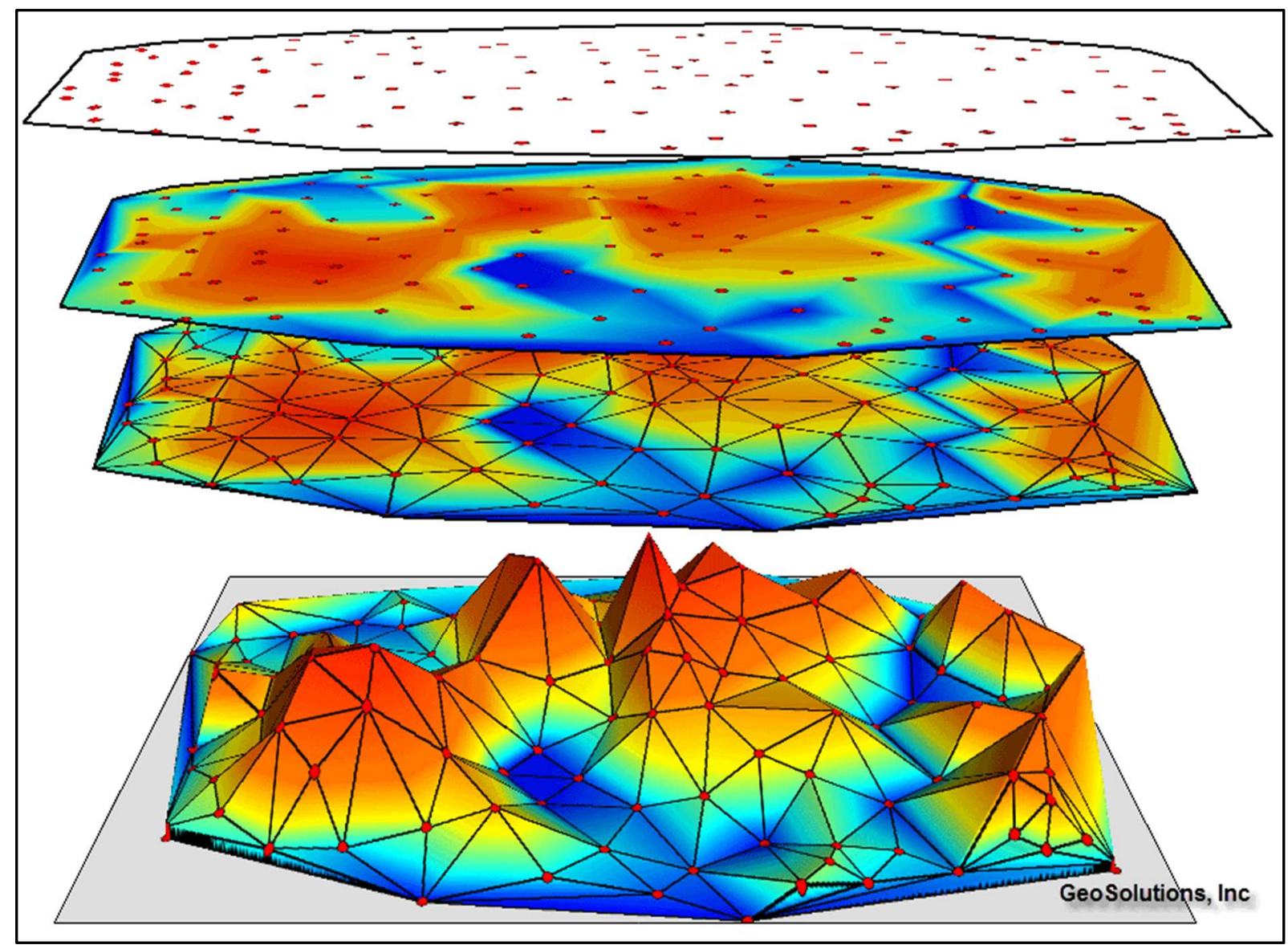

Figura 4-12 Triangulação TIN.

FONTE: (P.V. AUGUST E Y.Q. WANG, 20--)

Na Figura 4-13, a imagem da direita mostra a delimitação de uma área não convexa, conforme o traço escuro. A triangulação dos pontos que representam a elevação do terreno nesta área levará a uma figura convexa. Neste caso, à área hachurada da figura, será associado não intencionalmente um modelo de altura. Este tipo de erro, se não tratado, pode levar a leituras equivocadas sobre a altura do terreno.
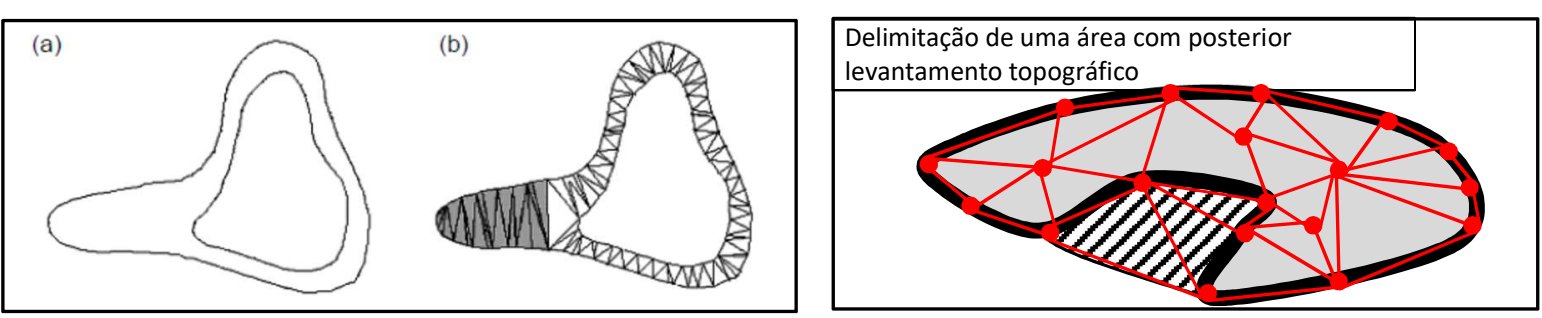

Figura 4-13 Exemplos de erros em triangulações.

FONTE: Imagem da esquerda: (LI, ZHU e GOLD, 2005, p. 81). Imagem da direta: Autor. 


\subsection{SISTEMAS DE INFORMAÇÃO GEOGRÁFICA (GIS)}

Os componentes básicos de um software GIS (Geographic Information System) ou SIG (Sistema de Informações Geográficas) incluem: “(1) um componente de entrada para a coleta e o processamento de dados espaciais; (2) um componente de armazenagem e consulta para a organização dos dados espaciais; (3) um componente de análise para a transformação de dados espaciais; e (4) um componente de saída para visualização de dados espaciais". (TAVANA, et al., 2016)22. Outras definições de softwares GIS, bem como o seu histórico podem ser encontrados em Segantine (2001).

Dados espaciais costumam ser representados em um sistema de informações geográficas (SIG ou GIS, na sigla em inglês) sob duas formas gerais: vetorial ou raster. A forma vetorial abrange pontos, linhas e polígonos ou grupos destes, dotados de um conjunto de atributos. Já dados raster compõem imagens georreferenciadas, valendose de uma rede ( $\mathrm{grid}$ ) de células ou pixels com seus respectivos atributos. Estas duas representações básicas permitem uma abrangente caracterização do terreno, à medida que mais camadas (layers) são adicionadas.

\subsubsection{FUNCIONALIDADES GIS}

Steiniger e Hunter (2013), analisando projetos FOSS4G (Free Open Source Software for Gis/Geospatial), descrevem nove categorias de softwares GIS, identificando os projetos de software livre associados a cada categoria. São elas:

- GIS Desktop: corresponde a um GIS que roda na máquina do usuário;

- Sistemas de gestão de bases de dados: para armazenar e organizar grandes volumes de infomações em uma base de dados, utilizando padrões de consultas (queries) e de representação de dados espaciais;

- Servidores GIS: Quando o servidor não só armazena os dados, mas também processa as informações, recebendo inputs e retornando dados já processados.

- GIS móvel: quando o software roda em dispositivos móveis;

- Softwares de análise exploratória de dados espaciais: utilizados para analisar e visualizar padrões em dados espaciais;

- Softwares de sensoriamento remoto: para tratamento de dados obtidos por esse método de aquisição;

- Bibliotecas para desenvolvimento de software GIS: bibliotecas capazes de cumprir diversas funções, como transformação de coordenadas, leitura e 
conversão de arquivos, etc. Estas bibliotecas podem ser utilizadas para o desenvolvimento de softwares para aplicações específicas.

- Extensões, Plug-ins e APIs: estes estendem as funções de outros softwares, não cumprindo função isoladamente.

- Softwares para aplicações web: permitem o desenvolvimento de aplicações, utilizando-se protocolos web de desenvolvimento.

De especial interesse para aqueles que desenvolvem modelos computacionais e softwares para aplicações GIS, são as bibliotecas GIS. Estas fornececem acesso via programação, o que permite alta flexibilidade e automação no processo de desenvolvimento. Dependendo do tipo de licença e das intenções do desenvolvedor, uma biblioteca de terceiros pode ser embarcada no programa desenvolvido ou ainda ser tratada como uma dependência externa, neste caso deixando ao usuário final a tarefa de instalar a biblioteca em sua máquina. No entanto, a linguagem de programação utilizada pode impor limites aos desenvolvedores, uma vez que as bibliotecas estão disponíveis para linguagens específicas, como por exemplo, $\mathrm{C} / \mathrm{C}++$, Python e Java.

Como colocam Leidig e Teew (2015), GDAL ${ }^{23}$ e OGR ${ }^{24}$, formam a base de muitos softwares GIS. GDAL (2017) apresenta uma vasta lista de softwares que utilizam esta biblioteca, incluindo ArcGIS, libLAS, MApServer, QGIS, R, TransCAD, GRASS GIS, entre outros produtos consolidados na área GIS.

\subsubsection{PADRÕES DE ARQUIVO E REPRESENTAÇÃO DE DADOS EM GIS}

Vários são os formatos disponíveis para representação de dados espaciais e geométricos, podendo estes serem classificados em abertos e fechados, sendo que, no primeiro caso, o esquema de codificação do arquivo é declarado. Isso permite que os interessados escrevam programas capazes de ler e interpretar as informações contidas nestes arquivos. Já no segundo caso, um software proprietário pode ser requerido para a simples leitura do arquivo.

Um exemplo de arquivo de formato vetorial bastante difundido é formato shapefile, que foi desenvolvido e é regulado pela empresa Esri, como um formato para interoperabilidade entre os softwares da empresa e outros disponíveis na área de GIS. Como as especificações do formato são abertas, softwares livres e de código aberto também costumam oferecer amplo suporte ao formato shapefile. Conforme ESRI (1998), shapefile é composto por um conjunto de arquivos diferentes, a citar: .shp,

\footnotetext{
23 Para dados raster.

24 Para dados vetoriais, sendo esta parte da biblioteca GDAL.
} 
contendo a geometria propriamente dita; .shx, que é um arquivo de índices; e .dbf, contendo os atributos das formas, além de uma série de outros possíveis arquivos.

Outro formato padrão para visualização de dados vetoriais é o kml (Keyhole Markup Language), desenvolvido pelo Keyhole Inc., desenvolvedora do Keyhole Earth Viewer, que mais tarde transformou-se no Google Earth, quando a empresa foi incorporada pela Google. Trata-se de uma linguagem padrão, no estilo XML (adiante descrito), cujos padrões estão publicados em Google Inc. (2014) e foram disponibilizados pela empresa ao Open Geospatial Consortium (OGC). O arquivo possui extensão. $\mathrm{kml}$ ou então. $\mathrm{kmz}$, quando compactado. Exemplos de softwares capazes de ler este formato são o QGIS (teste na versão 2.8.3) e o Google Earth.

Também derivado do formato XML, destaca-se no segmento GIS, o padrão GML, padronizado pelo OGC (Open Geospatial Consortium). Conforme OGC (2017), o padrão GML permite representar pontos, linhas e polígonos, mas os usuários definem esquemas (schemas) mais específicos, permitindo representar diretamente objetos como rodovias e pontes, por exemplo.

Para dados raster, um padrão recorrente na indústria é o GeoTIFF, que consiste em um arquivo de TIFF georreferenciado e com metadados. $O$ formato encontra suporte na biblioteca GDAL, enquanto dados geográficos neste formato podem ser encontrados para download em USGS (2017).

No âmbito da tecnologia LIDAR (Light Detection and Ranging) de sensoriamento remoto, destacam-se o padrão LAS e o LAZ (versão comprimida). Conforme ASPRS (2016), o LAS é um formato binário, cujas especificações são publicamente declaradas, destinado inicialmente à armazenagem e troca de uma nuvem de pontos XYZ obtidos por LIDAR. Além disso, este padrão de arquivo comporta uma série de outras informações importantes da tecnologia LIDAR (metadados). A manipulação destes dados pode ser feita com ferramentas como a suíte de software LAStools (RAPIDLASSO GMBH, 2016).

Para o leitor interessado, especialmente para aqueles que pretendem desenvolver aplicações GIS, é oportuno estudar uma série de outros formatos de arquivo como WKT (Well-Known Text), WKB (Well-Known Binary) e GEOJSON. Além disso, OGC (2011) apresenta especificações para dados espaciais através do padrão Simple Features, amplamente utilizado no segmento GIS.

\section{Formatos Genéricos}

O padrão CSV (Comma Separated Values) também costuma ser utilizado para armazenagem de dados espaciais, sendo este padrão de leitura intuitiva para o ser 
humano, além de ser compatível com planilhas eletrônicas e linguagens de programação. No entanto, não existe um padrão absoluto para o separador de campos. Ainda, possíveis adaptações podem ser necessárias para os separadores de números decimais e para a delimitação de texto. Este tipo de arquivo é especialmente útil para dados repetitivos, que podem ser separados por campo. Ex.: conjunto de pontos $\mathrm{x}, \mathrm{y}, \mathrm{z}$.

Por outro lado, alguns tipos de dados são carregados de informações complementares. Por exemplo, um arquivo que contenha as especificações para o plano topográfico local. Este arquivo terá possivelmente apenas um ponto $\left(\varphi_{0} \lambda_{0}, h\right)$, mas uma série de informações adicionais como datum horizontal, vertical, altura geoidal, entre outros. Para este caso, é muito útil o formato XML (Extensible Markup Language), padronizado pelo World Wide Web Consortium (W3C, 2016). Este é um formato de marcação genérica segundo o qual tags (rótulos) podem ser criados e organizados hierarquicamente, com seus valores e uma série de atributos.

\subsection{CONCLUSÕES DO CAPÍTULO}

As áreas e superfícies de proteção de um sistema de pistas são especificadas com base em um sistema euclidiano de coordenadas, ao passo que as variáveis de projeto e os dados necessários podem se encontrar sob outros sistemas de coordenadas e referenciais. Isso traz a necessidade de compatibilização dos dados e dos métodos sob um sistema único de representação.

Em relação às projeções, o sistema UTM é comumente utilizado, inclusive em um dos trabalhos discutidos no Capítulo 2 (SANTOS e MÜLLER, 2014). No entanto, existem outros sistemas de menor abrangência, que podem ser utilizados no projeto de aeródromos, como o PTL (Plano Topográfico Local) e o SCL (Sistema Cartesiano Local). O PTL é regulamentado pela NBR 14166 (ABNT, 1998), porém, após diversas tentativas de implementação, chegou-se à conclusão de que os dados sofrem alterações quando submetidos a transformações sucessivas, nos sentidos direto e inverso. Embora para muitos propósitos de engenharia essa característica do PTL possa ser irrelevante, em um modelo computacional é interessante que se disponha de uma consistência numérica mais elevada. Para tanto, foi apresentado o SCL, baseado em transformações equivalentes, nos sentidos direto e inverso, portanto consistente do ponto de vista numérico.

Declarados os objetivos da pesquisa a partir do Capítulo 1 e com os fundamentos dos Capítulos 3 e 4, no próximo Capítulo é apresentado o modelo proposto para esta tese. 


\section{CAPÍTULO 5 - MODELAGEM PROPOSTA}

Esta tese possui duas questões centrais:

- Como modelar a geometria das áreas e superfícies de proteção de um conjunto de pistas de pouso e/ou de decolagem em um aeródromo; e

- Como implementar em computador tal modelo.

A primeira questão contempla a interpretação das normas de projeto, ${ }^{25}$ bem como uma proposta de desenho parametrizado das áreas e superfícies de proteção da pista de pouso e decolagem. A segunda foca nos algoritmos, estruturas de dados, paradigmas de programação, linguagens de programação e uma série de fatores ligados ao desenvolvimento de software. Embora o foco da pesquisa esteja na modelagem, a implementação computacional é a forma mais direta de se avaliar a modelagem proposta, quanto à sua funcionalidade e desempenho. É também uma maneira conveniente de se dar utilidade prática a um modelo que, se implementado através de cálculos manuais, levaria a uma tarefa tediosa e propícia a erros de cálculo.

Um processo de modelagem costuma ser uma combinação entre técnica e criatividade, o que permite que diferentes abordagens a um mesmo problema possam existir. Por outro lado, a implementação deve considerar com fidelidade a modelagem proposta, que incorpora padrões oriundos de normas de projeto. Dessa relação espera-se um afunilamento no processo de modelagem e implementação, à medida que algumas decisões acabam influenciando as decisões subsequentes e restringindo as escolhas possíveis. Portanto, o desempenho final será uma combinação entre modelo geométrico e implementação.

Este Capítulo discute o modelo proposto desde a sua concepção, apresentando também aspectos relacionados à implementação em computador. $O$ modelo foi testado através da linguagem Python.

\subsection{CONCEPÇÃO DO MODELO}

Como discutido no Capítulo 2, a partir da lista de softwares de auxílio ao projeto de aeródromos apurados pelo autor, todos são comerciais, o que dificulta o aproveitamento da metodologia por eles utilizada, já que ela não é publicamente acessível. Além disso, a pesquisa bibliográfica não encontrou uma metodologia que pudesse ser adaptada a este trabalho, considerando-se as inúmeras diferenças de

${ }^{25}$ em especial o Anexo 14 (ICAO, 2004), no qual esta pesquisa se baseia. 
objetivos e de elementos geométricos a serem representados. Dessa maneira, é proposto um modelo inédito para a modelagem computacional em aeródromos, seguido também por uma proposta de implementação do mesmo, permitindo testar tal modelagem.

Entre os paradigmas CAD discutidos na seção 3.3, a modelagem aqui apresentada se enquadra na linha de programação estática, sem interações do usuário durante o processo de construção do modelo geométrico. Isso é possível devido à rigidez imposta pelas normas de projeto em relação à geometria das áreas e superfícies de proteção, uma vez que as decisões tomadas pelo usuário podem ser fornecidas estaticamente como dados de entrada. Ao mesmo tempo, o modelo proposto segue uma abordagem de projeto baseado em feições (feature-baseddesign), à medida que os componentes geométricos possuem uma natureza semântica (pista de pouso e/ou de decolagem, faixa de pista de pouso e decolagem, superfície de aproximação, etc.). A partir dos dados de entrada são admitidas no modelo variações dimensionais (ex.: largura da faixa de pista de pouso e decolagem) e variações topológicas (ex.: uma cabeceira deslocada pode fazer com que a pista não fique completamente envolvida pela faixa de pista de pouso e decolagem). Visto que o número de combinações e situações potenciais de conflito topológico é limitado, esta questão não é aprofundada no modelo.

O projeto de um aeroporto precisa considerar o terreno disponível, o relevo da vizinhança, a presença de objetos dentro e fora do sítio, o padrão das atividades vizinhas, os ventos, a capacidade alvo, as aeronaves esperadas a utilizá-lo, os limites de visibilidade, o tipo de solo, as condições ambientais, entre outros.

A presente modelagem propõe um recorte do problema de acordo com seus aspectos geométricos, permitindo a análise de uma configuração proposta para a pista de pouso e/ou de decolagem de acordo com os padrões de projeto previstos no Anexo 14 (ICAO, 2004) e considerando os seguintes dados de entrada:

- Sítio e entorno: delimitação externa do sítio; delimitação interna, excluindo-se áreas consideradas impróprias ou destinadas a outros fins; topografia do sítio; e posição e altura dos objetos no entorno, que possam constituir obstáculos.

- Objetos móveis: Embora alguns critérios de projeto possam ser garantidos a partir da consideração de uma aeronave crítica, a combinação entre os diferentes modelos de aeronaves, a topografia do sistema de pistas e a configuração proposta podem criar um ambiente complexo, exigindo simulação. Aeronaves são exemplos de objetos móveis complexos em termos geométricos e ainda, muito próximos às pistas. A presente modelagem se restringe à consideração das aeronaves como 
objetos móveis, mas uma sofisticação do modelo deveria incluir também veículos que trafegam na vizinhança do aeródromo, gruas, muitas vezes utilizadas em aeroportos em expansão, guindastes em terminais de cargas vizinhos, pontes móveis, entre outros objetos móveis. Felizmente, a metodologia empregada no caso das aeronaves pode ser adaptada para a extensão do modelo.

A configuração proposta refere-se aos dados mínimos necessários para representar uma proposta geométrica para o sistema de pistas: número e orientação das pistas de pouso e decolagem; procedimentos de aproximação previstos; coordenadas das extremidades das pistas e posição relativa de estruturas como stopways e cabeceiras; ARC (Aerodrome Reference Code) de projeto da pista; posição das áreas de espera e ultrapassagem.

Os padrões de projeto originam-se de normas de projeto e, a partir de uma base de especificação ${ }^{26}$, estabelecem as dimensões dos componentes físicos e das áreas e superfícies de proteção. Por exemplo, a base de especificação da largura de uma pista de pouso e/ou de decolagem (RWY), conforme os padrões da ICAO, inclui o ARC referente à aeronave crítica e o tipo de aproximação prevista (ex.: não precisão, precisão CAT I, precisão CAT II, etc.).

A Figura 5-1 apresenta um fluxograma do modelo proposto. Conforme a Figura $5-1$, as entradas do modelo são a configuração proposta, expressa em termos de variáveis de projeto; as características do sítio e do seu entorno; e os padrões de projeto, neste caso, oriundos da ICAO. Com estas entradas, o modelo deverá ser capaz de gerar a geometria da RWY e de suas áreas e superfícies de proteção.

Objetos fixos e móveis também constituem entradas do modelo. Exemplos de objetos fixos são prédios, antenas e viadutos. A incorporação de objetos fixos ao modelo geométrico é relativamente simples, bastando transportar suas coordenadas para o mesmo referencial e para o mesmo sistema local de coordenadas. Por simplificação, objetos fixos entram no modelo como pontos.

Já a consideração dos objetos móveis é mais complexa, exigindo informações detalhadas sobre a geometria e a posição dos mesmos. No caso de aeronaves, estas só podem ser posicionadas no modelo tridimensional caso a própria geometria das pistas já tenha sido gerada. Posicionar uma aeronave exige conhecimento da altura associada à posição da aeronave no sítio (via MDE), estabelecida como entrada no modelo. Exige também conhecimento sobre a orientação da mesma no plano XY.

${ }^{26} \mathrm{O} A R C$ é o principal item da base de especificação de muitos critérios de projeto, mas não o único. 


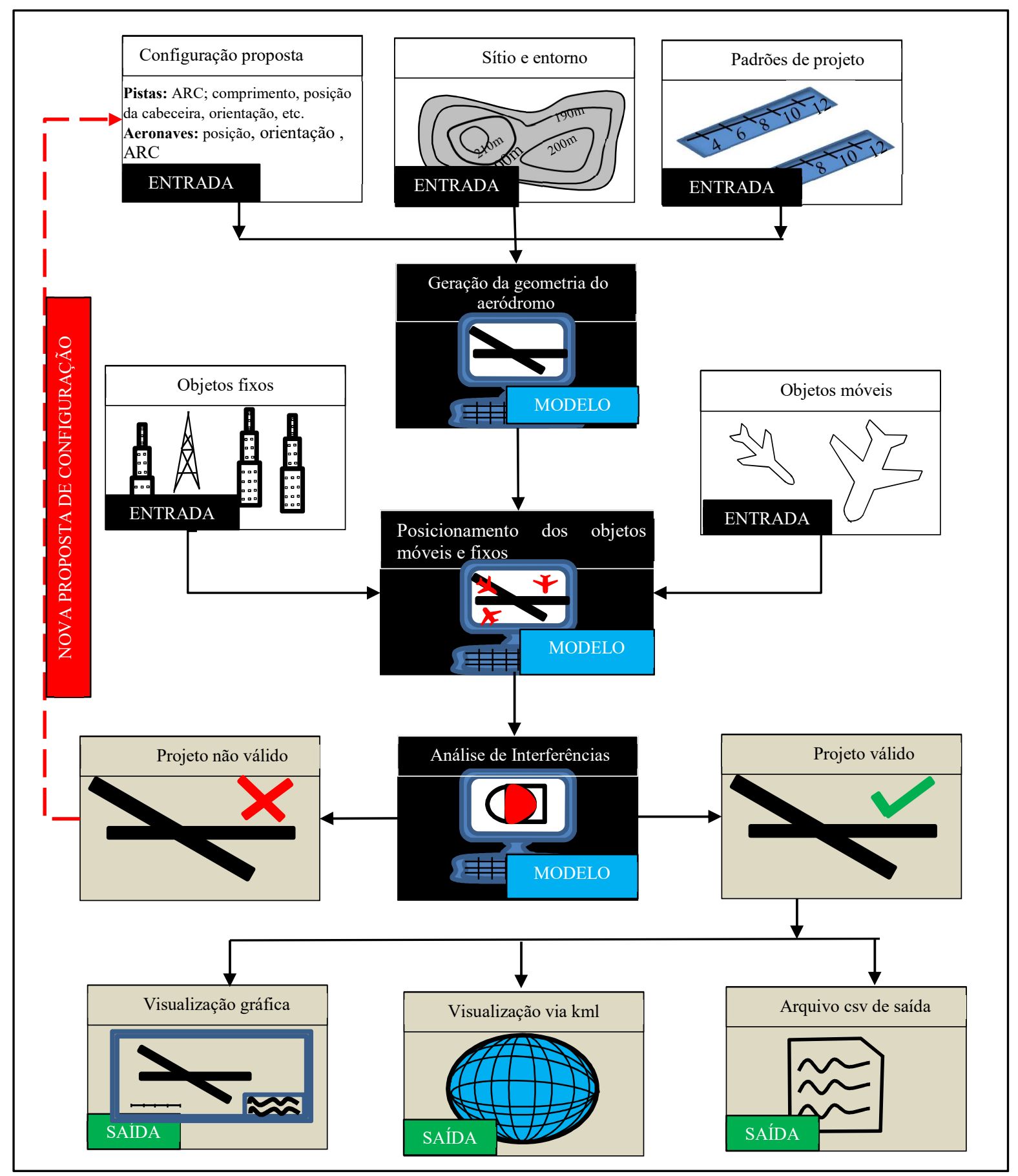

Figura 5-1 Esquema geral do modelo proposto. FONTE: Elaborado pelo autor.

Geradas as áreas e superfícies de proteção e inseridos os objetos fixos e móveis no modelo, será possível avaliar as interferências geométricas. Quando um objeto interfere com uma superfície de proteção, ele é considerado um obstáculo. Em um ambiente de projeto, este conflito pode ser resolvido de duas formas: remoção do obstáculo; ou através de mudanças na configuração proposta para o 
aeródromo. Caso o projetista decida pela segunda opção, o modelo proposto permite que diferentes configurações possam ser testadas automaticamente.

\subsection{MODELAGEM ESPACIAL DOS DADOS}

Em todo o modelo, para os dados projetados, utiliza-se o metro $(\mathrm{m})$ como unidade de comprimento. No entanto, as transformações através da biblioteca GDAL podem utilizar, eventualmente, um código EPSG de origem que comporta outras unidades, como pés, por exemplo.

Os dados de entrada no modelo são admitidos em formato geodésico, desde que o código EPSG seja informado. Os dados também são admitidos na forma de projeção, seja ela o SCL ou qualquer projeção suportada pela biblioteca GDAL, informando-se o código EPSG. A Figura 5-2 e a Figura 5-3 apresentam relações entre os elementos do modelo computacional e o formato dos dados. Caso algumas informações não sejam conhecidas, funções precisarão ser bloqueadas. O ANEXO 2 apresenta um exemplo de código EPSG com os parâmetros que o definem.

A Figura 5-2 apresenta o caso em que os dados entram no modelo sob um sistema geodésico. Neste caso, o código EPSG é indispensável. No entanto, para transformação ao plano local, o SCL, será necessário informar ainda um ponto central para este sistema. Na sequência, o modelo geométrico será gerado e a análise de interferência será realizada no SCL. Tais geometrias poderão ser salvas ou visualizadas em tela. A utilização do mesmo ponto de origem do SCL permitirá transformar todo o modelo para outro sistema de projeção ou para o formato geodésico, permitindo salvamento, inclusive no formato KML.

Já a Figura 5-3 apresenta o caso em que os dados entram no modelo já projetados. Caso esta projeção seja o $\mathrm{SCL}$, as etapas seguintes de geração de geometria e análise de conflitos poderão seguir diretamente. No entanto, em caso de outros sistemas de projeção, será necessário antes converter as coordenadas. Isso só poderá ser feito caso o código EPSG seja fornecido.

Todas as transformações entre os sistemas de coordenadas são processadas via biblioteca GDAL, com exceção das conversões que envolvem o SCL. Estas sempre ocorrem de ou para um sistema geodésico (EPSG 4326, por padrão) através do método apresentado na subseção 4.3.2.4. 


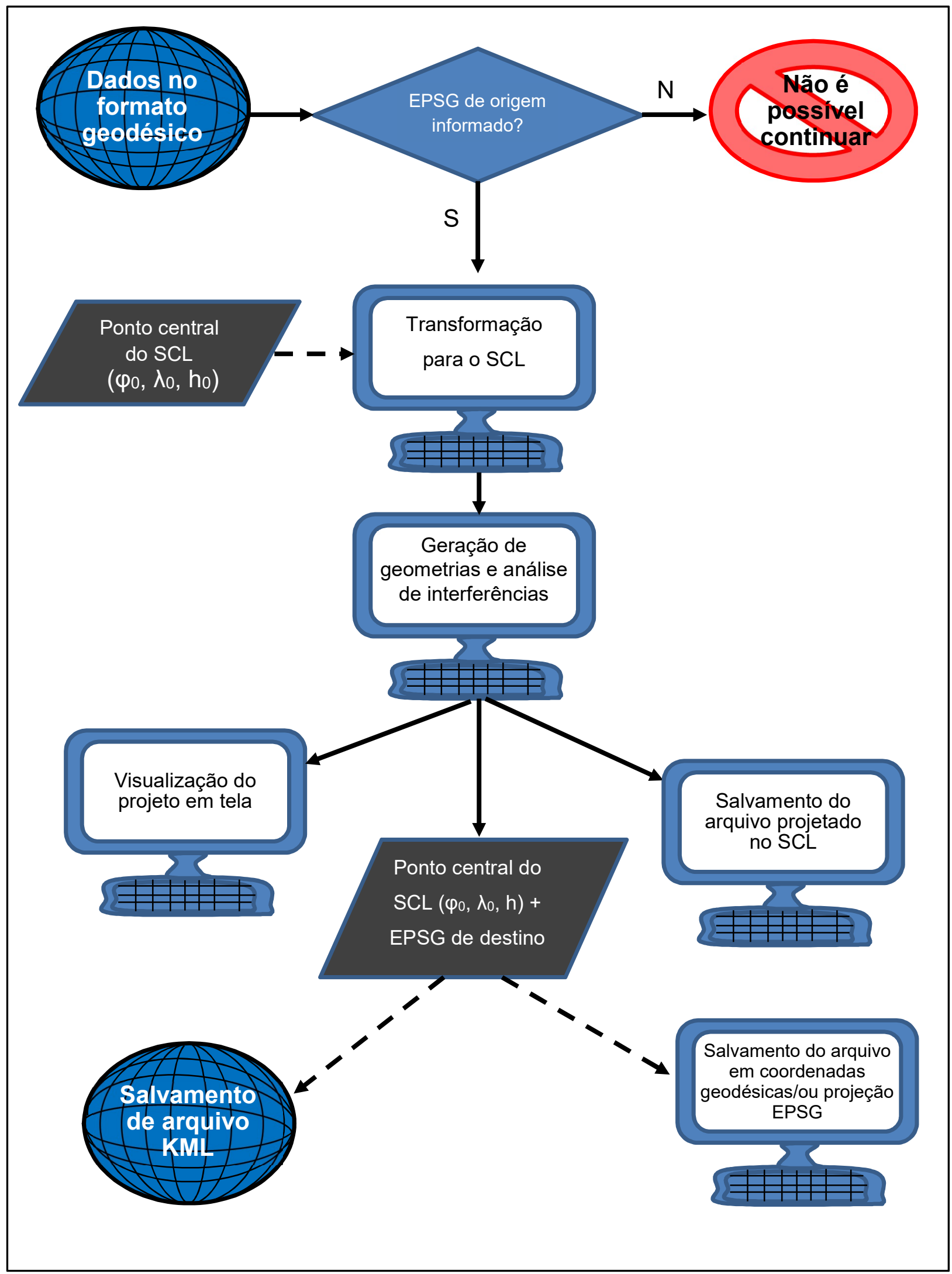

Figura 5-2 Formatos de entrada de dados em formato geodésico.

FONTE: Elaborado pelo autor. 


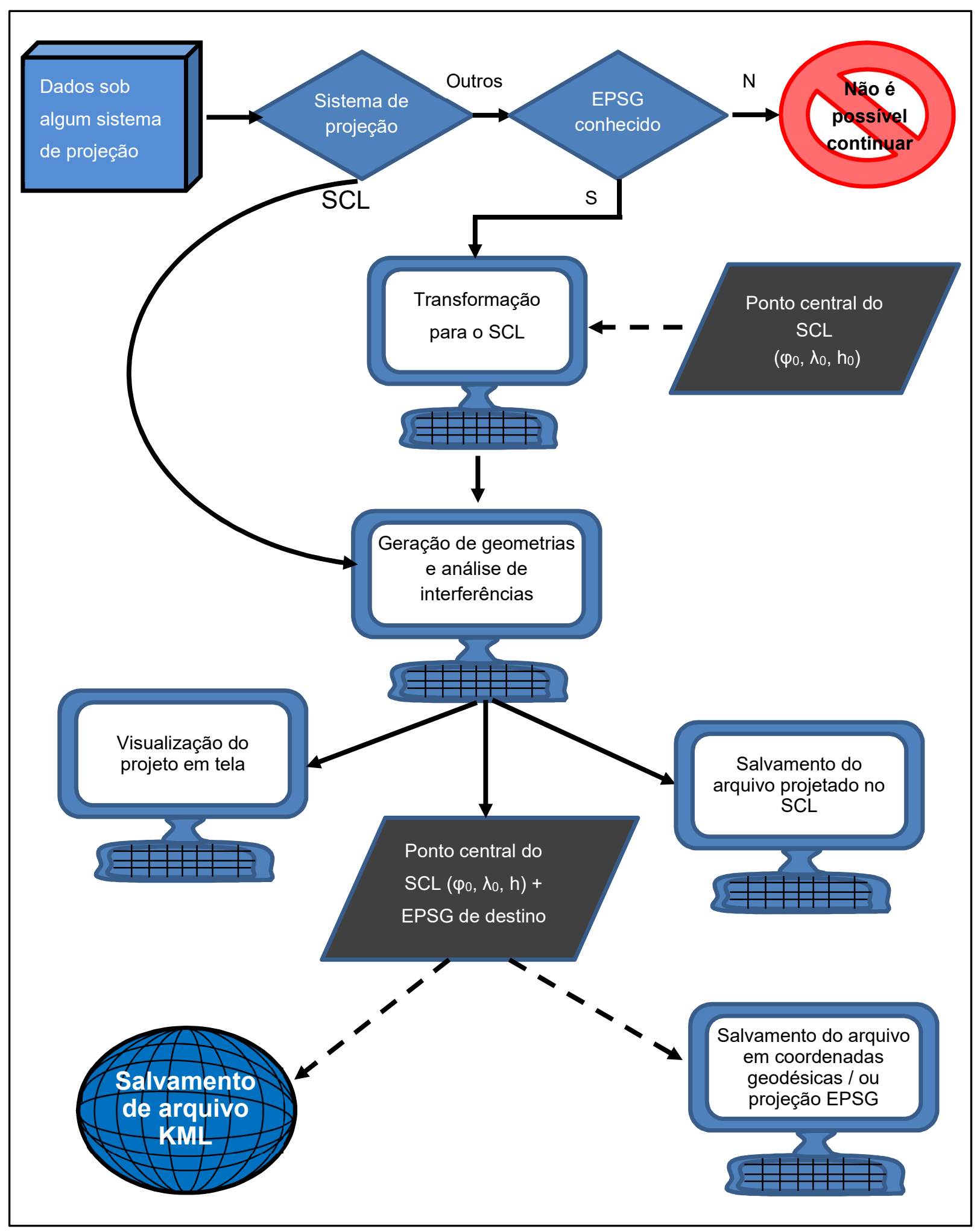

Figura 5-3 Formatos de entrada sob algum sistema de projeção.

FONTE: Elaborado pelo autor. 


\subsection{ESCOLHA DA LINGUAGEM DE PROGRAMAÇÃO}

A escolha de uma linguagem de programação é um ponto chave na concepção de um modelo computacional, não somente na sua implementação, pois estas duas fases estão relacionadas.

Algumas perguntas básicas que o processo de decisão envolve são:

a. Existem bibliotecas disponíveis para os fins pretendidos? Elas são atualizadas? Quão confiáveis elas são? Que tipos de direitos autorais a elas se aplicam?

b. É necessário algum tipo de visualização? Quais são as possibilidades gráficas da linguagem?

c. O fim pretendido é complexo em termos de processamento, como seria o caso de otimização, por exemplo? A linguagem oferece 0 desempenho computacional necessário? Ela permite programação paralela?

d. Se o projeto é esperado a ser intensivo no uso de memória, a linguagem é capaz de gerenciar memória ao nível necessário?

e. Caso se pretenda criar uma interface gráfica, a linguagem possibilita e facilita tal desenvolvimento?

f. Caso se deseje proteger o código, como isto poderá ser feito?

g. O software é esperado a ser utilizado em dispositivos móveis, como tablets, smartphones, ou ainda embarcados em circuitos eletrônicos? A linguagem permite tal uso? E nos computadores, quais os sistemas operacionais podem ser utilizados?

h. Qual o nível de complexidade de programação nesta linguagem? Existem recursos como livros, fóruns, especialistas que podem ajudar?

Todas estas decisões se aplicam à escolha de uma linguagem, mas também devem estar presentes na escolha das bibliotecas a serem utilizadas e mesmo na implementação em si, de acordo com as situações mais restritivas.

Para esta modelagem, a linguagem Python (PSF, 2017) foi selecionada. Tratase de uma linguagem de alto nível, interpretada e multiparadigma. Possui um crescente número de bibliotecas de código aberto (modules) disponibilizadas online ${ }^{27}$, além dos módulos que acompanham a distribuição, como numpy, math e matplotlib.

Conforme PSF (2017) a linguagem Python é distribuída sob licença compatível com GPL. Diferentemente de uma licença nos termos da GPL (General Public

\footnotetext{
${ }^{27}$ https://pypi.python.org/pypi/ e plataformas como o Github https://github.com/.
} 
License), as mudanças feitas por um usuário não têm a obrigatoriedade de serem repassadas a terceiros na forma de código aberto.

O trabalho feito por um usuário (script) pode ser facilmente organizado em novas bibliotecas (modules) e no final o material pode ser transformado em um arquivo executável, através de ferramentas como o pyinstaller (PYINSTALLER, 2015), cx_Freeze (CX_FREEZE, 2014) ou py2exe (PY2EXE, 2014), gerando um arquivo único ou um conjunto de arquivos que agregam as funcionalidades de todas as bibliotecas utilizadas e de outros arquivos utilizados, como arquivos de texto, por exemplo. Estes arquivos podem ser distribuídos a um usuário final contendo um programa executável, sem a necessidade de instalação de outros softwares e bibliotecas na máquina. Ainda, os arquivos podem ser distribuídos na forma convencional de um instalador, se uma ferramenta como o install creator, por exemplo, for utilizada.

Uma desvantagem da linguagem Python é a relativa dificuldade de proteção do código fonte, em comparação à linguagem $C$, que é compilada. Por se tratar de uma linguagem interpretada, o código fonte deve estar presente durante a execução. Essa pode ser considerada uma séria limitação para os autores que desejam proteger seu código. Apesar de não existir uma forma completamente segura de proteção do código, (PSF, 2014) apresenta algumas possíveis soluções como ofuscamento do código fonte, utilização de versões pré-compiladas (arquivo .pyc) e utilização de processamento via web, ficando o código armazenado na máquina remota. $O$ ofuscamento do código pode ser executado com o auxílio de programas que fazem alterações no código fonte de forma a dificultar a legibilidade pelo ser humano sem prejudicar o funcionamento computacional. Por sua vez, os arquivos pré-compilados podem ser revertidos mediante algum trabalho, inclusive feito com auxílio de ferramentas como o decompyle. Ainda, arquivos .pyc não são totalmente compatíveis entre as diversas versões da linguagem Python.

Para a proteção do código, uma quarta alternativa seria a utilização do Cython ( (CYTHON, 2014)). A ferramenta traduz o script para um arquivo em linguagem C (arquivo .c) que pode ser então compilado, o que torna a engenharia reversa muito mais complicada do aquela associada a um arquivo pré-compilado do tipo .pyc. Apesar da sua possível função de proteger o código fonte, o principal objetivo do Cython é melhorar o desempenho computacional, facilitando a interoperacionalidade entre as linguagens python e $\mathrm{C} / \mathrm{C}++$.

Para este projeto, optou-se pela versão 2.7 da linguagem, utilizando-se o sistema operacional Windows, a partir dos módulos padrões da linguagem, que 
acompanham a distribuição utilizada, bem como algumas outras bibliotecas. A Tabela 5-1 apresenta as bibliotecas utilizadas na implementação do modelo.

Tabela 5-1 - Descrição de algumas bibliotecas (modules) utilizados

\begin{tabular}{|c|c|c|c|}
\hline Nome ${ }^{* * *}$ & Site oficial & Descrição & $\begin{array}{c}\text { Tipo de } \\
\text { licença** }\end{array}$ \\
\hline $\begin{array}{l}\text { GDAL (ogr } \\
\text { e osr) }\end{array}$ & http://www.gdal.org/ & $\begin{array}{c}\text { Análise de dados } \\
\text { espaciais e } \\
\text { geométricos } \\
\end{array}$ & $\mathrm{X} 11 / \mathrm{MIT}$ \\
\hline Matplotlib* & http://matplotlib.org/ & $\begin{array}{c}\text { Produção de figuras } \\
2 \mathrm{D}, 3 \mathrm{D} \text {, interfaces } \\
\text { interativas e } \\
\text { animações }\end{array}$ & $\begin{array}{c}\text { Igual aos da PSF, } \\
\text { sendo compatível } \\
\text { com GPL }\end{array}$ \\
\hline Numpy* & http://www.numpy.org/ & $\begin{array}{l}\text { Computação } \\
\text { científica, álgebra, } \\
\text { integração com } \mathrm{C} \mathrm{e} \\
\text { Fortran }\end{array}$ & $\begin{array}{l}\text { BSD (permite } \\
\text { uso e } \\
\text { redistribuição } \\
\text { com ou sem } \\
\text { modificações) }\end{array}$ \\
\hline Scipy & www.scipy.org & $\begin{array}{c}\text { Computação } \\
\text { científica, incluindo } \\
\text { funções } \\
\text { geométricas. }\end{array}$ & BSD \\
\hline Simplekml & https://simplekml.readthedocs.io & $\begin{array}{c}\text { Escreve arquivos } \\
\text { kml ou kmz, } \\
\text { próprios para } \\
\text { visualização de } \\
\text { dados geográficos }\end{array}$ & GNU GPL v3 \\
\hline xmltodict & https://pypi.python.org/pypi/xmltodict & $\begin{array}{c}\text { Interação com } \\
\text { arquivos XML }\end{array}$ & GNU \\
\hline
\end{tabular}

${ }^{*}$ Acompanham a distribuição padrão.

${ }^{*}$ Verificar as licenças oficiais vigentes para cada biblioteca.

${ }^{* * *}$ Outras bibliotecas que acompanham a distribuição padrão foram utilizadas, como os, time, math, sys, csv, inspect, psutil

FONTE: Elaborado pelo autor

A análise de licenças envolve questões legais que não estão no escopo desta pesquisa, mas pode-se observar que as bibliotecas utilizadas são livres e de código aberto, não exigindo o pagamento por direitos de uso. Um complicador nas licenças de software é o efeito cascata eventualmente criado quando uma biblioteca utilizada faz uso, por sua vez, de outra biblioteca com licenças mais restritivas.

\subsection{ENTRADA DOS DADOS}

A avaliação dos dados de entrada tem duas preocupações: identificação dos dados necessários; e a forma de entrada dos dados no modelo, ou seja, quais os formatos de arquivos e demais requisitos, como precisão, sistemas de coordenadas, sistemas de unidades podem ser admitidos.

Considerando-se uma interoperacionalidade mínima com programas que fornecem dados importantes ao modelo, dois formatos de entrada são admitidos: CSV 
e XML, sendo o primeiro para os dados repetitivos e o segundo de acordo com esquemas próprios para o modelo, a seguir apresentados. A associação entre os dois formatos permite flexibilidade e organização dos dados e dos metadados.

\subsubsection{Dados do sítio e do entono}

Os dados necessários para caracterizar o sítio são:

- Caracterização dos limites externos: uma das formas de caracterizar os limites do sítio é o uso da poligonal topográfica, que pode ou não formar um polígono convexo. Considerando-se que o posterior tratamento computacional será mais convenientemente executado a partir de geometrias convexas, faz-se conveniente expressar os limites do sítio a partir de polígonos convexos. Na Figura 5-4 a área 1 (A1) não é convexa, exigindo a criação das áreas hachuradas $\mathrm{A} 2$ e $\mathrm{A} 3$, referidas no modelo como áreas de exclusão, onde nenhum componente físico pode ser construído. Áreas de exclusão do tipo mais geral proíbem qualquer componente físico, exigindo testes durante a construção do modelo. Portanto, a caracterização dos limites externos pode exigir um arquivo com vários polígonos, todos convexos, sendo um principal e $n$ arquivos de exclusão. Qualquer área fornecida deve ser acompanhada por dados geográficos que a caracterizem adequadamente. Por isso, os dados sobre os limites do sítio, internos e externos, são inseridos no modelo a partir de um arquivo $\mathrm{XML}$ e de um arquivo CSV, sendo que o primeiro contém os metadados do segundo.

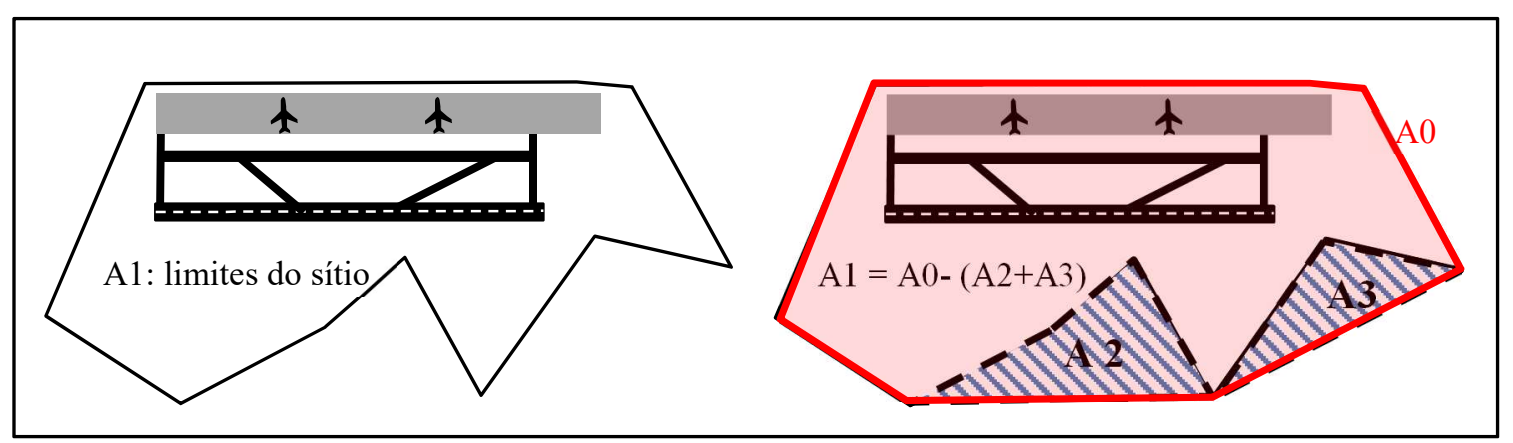

Figura 5-4 Limites externos do sítio.

FONTE: Elaborado pelo autor.

- Topografia: Os dados que descrevem a altura do terreno podem resultar em arquivos grandes, dependendo da técnica de aquisição e do tratamento dos dados. Conforme será discutido mais diante, o MDE utilizado no presente modelo adota uma malha TIN, o que encoraja a 
redução dos dados de entrada para uma densidade de pontos que possa ser comportada. Além dos dados $(N, E, h)$ ou $\left(\varphi_{0}, \lambda_{0}, h\right)$ que devem ser fornecidos ao modelo no formato CSV, é necessário fornecer informações sobre o sistema de coordenadas e sobre os referenciais geográficos, caso contrário o modelo poderá perder funcionalidades ou mesmo ficar inviável. Por essa razão, os dados de topografia ou quaisquer dados espaciais precisam ser acompanhados pelos metadados que os definam. Os dados de topografia são inseridos no modelo a partir de um arquivo XML e de um arquivo CSV, sendo que o primeiro contém os metadados do segundo.

Os dados de entrada são fornecidos através de um arquivo XML, como mostrado na Figura 5-5, onde os tipos das variáveis são inseridos em negrito. O Default_datum corresponde aos sistemas padrões do projeto, que são dois: um sistema geodésico (ellipsoid) opcional e um sistema projetado obrigatório (plan). Caso (ellipsoid $=$ EPSG), então deve-se informar este código EPSG (datumEPSG). Caso (ellipsoid = None,), o projeto existirá apenas na forma projetada. Já para o sistema projetado, que é obrigatório, pode-se informar um EPSG (planEPSG), ou pode ser informado apenas que o sistema cartesiano local será utilizado $($ plan $=S C L)$.

Caso $($ plan $=S C L)$, será necessário informar o ponto central da projeção $-\mathrm{P}_{0}$. Isto será realizado em qualquer código EPSG para formatos geodésicos (ellipsoid = $E P S G$ ) ou adotando-se o EPSG padrão do projeto (ellipsoid = Default_EPSG). ponto será caracterizado pelas coordenadas ( $p h i 0, l b d 0, S C L h e i g h t)$. O referencial vertical pode coincidir com o horizontal (vert_datum_name $=$ ellipsoid) ou não (vert_datum_name $=M S L, E G M 96$, etc.). Nesta última situação, $P 0$ terá sua elevação corrigida por $\mathrm{N}$ (vert_datum_N).

A tag $(<$ topography $>)$ pode ser repetida quantas vezes for necessário para caracterizar a topografia (type $=$ elevation) do sítio, seus limites e áreas de exclusão $(\text { type }=\text { exclusion })^{28}$, sejam estas internas (ex.: espaço destinado a terminais, lagos, etc.) ou externas (ex.: áreas convexas recortadas para criar o contorno da propriedade).

${ }^{28}$ Conforme ilustra a Figura 5-4. 


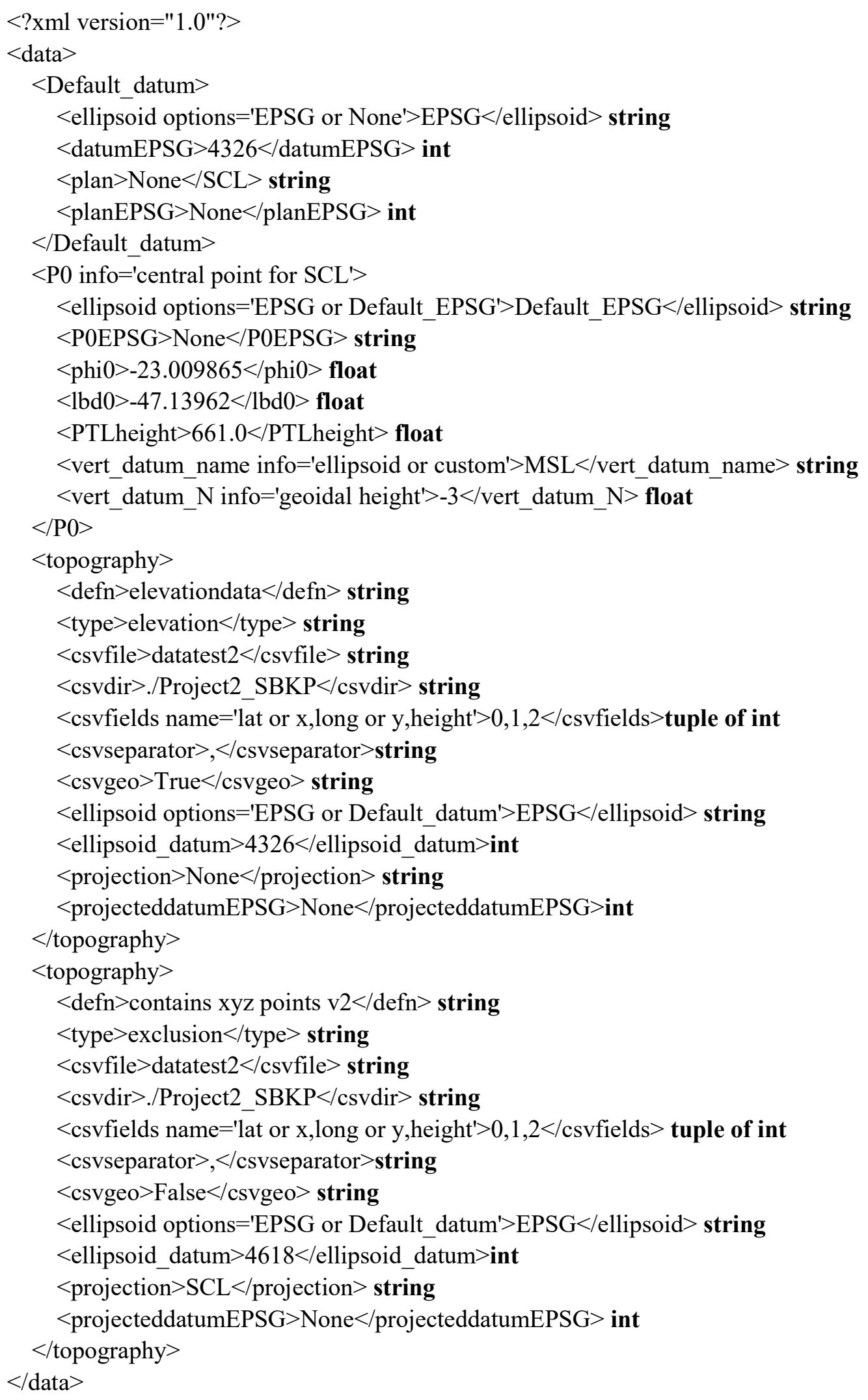

Figura 5-5 Dados de entrada para o sítio e para o projeto.

FONTE: Elaborado pelo autor. 
Um nome é associado ao conjunto de dados (defn), bem como o nome do arquivo CSV que contém seus pontos (csvfile) e o diretório do arquivo (csvdir). Para o arquivo CSV é necessário informar os campos (csvfields), a menos que o padrão $0,1,2$ possa ser utilizado. O separador de campos deve ser informado, se diferente do padrão (csvseparator $=$,).

Os dados do CSV podem se encontrar em formato geodésico $(\operatorname{csvgeo}=$ True $)$ ou projetado $($ csvgeo $=$ False $)$. Caso seja geodésico o formato, deve-se informar que eles se referem ao EPSG padrão do projeto (ellipsoid $=$ Default_datum ) ou qualquer outro EPSG em formato geodésico (ellipsoid $=E P S G$ ), informando-se este código (ellipsoid_datum). E caso ( $c s v \quad=$ False), a projeção pode ser o sistema cartesiano local $($ projection $=S C L)$ ou alguma projeção EPSG $($ projection $=E P S G)$. Para o SCL, serão assumidos os dados do projeto. Para algum código EPSG, deverá ser informado o código (projecteddatumEPSG).

\subsubsection{Configuração proposta}

A configuração proposta do lado aéreo pode ser descrita em função de um grupo de variáveis para cada um dos componentes considerados. Na presente modelagem, o componente pista e as informações importantes a esta relacionadas são informadas através de um arquivo XML como o apresentado na Figura 5-6. Em negrito são detalhados os tipos esperados para as variáveis. Um único arquivo permite a entrada de várias pistas $i d=1, i d=2, . . \mathrm{e}$, cada pista é permitida a apresentar mais de uma cabeceira (threshold), já que as superfícies e áreas de proteção devem ser estabelecidas de forma distinta para cada sentido de operação.

Uma pista não pode ser completamente definida sem informações sobre a topografia do sítio que a abrigará, pois neste caso seria impossível construir as superfícies cuja geometria depende do perfil da pista. Por isso, sitexml e sitexml_dir definem respectivamente $\mathrm{o}$ arquivo $\mathrm{XML}$ que define o sítio e seu diretório. Dependendo do padrão dos dados do ponto de vista geográfico, testes são necessários para garantir a compatibilidade dos dados das pistas. Por exemplo, se o sítio estiver representado em uma projeção desconhecida, a pista precisará ser especificada sob o mesmo sistema, pois caso contrário, não seria possível converter os dados para um sistema comum.

Cada sentido de operação terá um número da cabeceira (threshold_number). Os dados sobre as extremidades dessa pista poderão ser informados sob um sistema geodésico $($ csvge $=$ True $)$ ou projetado $($ csvge $=$ False $)$. 
No primeiro caso, será necessário informar se a pista adota o referencial padrão do projeto (ellipsoid $=$ Default_datum) ou se ela possui um código EPSG próprio (ellipsoid $=E P S G)$. Neste último caso, será necessário informar qual é este código (ellipsoid_datum).

Mas, caso os dados da pista obedeçam a um sistema de projeção (csvgeo $=$ False), será necessário informar se esta projeção é o sistema cartesiano local (projection $=S C L)$, ou se ela está baseada em algum código EPSG (projection = EPSG). No primeiro caso, estará subentendido que valem para este SCL os mesmos dados que se aplicam ao sítio. No segundo caso, será necessário informar o código EPSG (projecteddatumEPSG) da projeção. Ainda, os dados da pista podem estar definidos em um referencial vertical que coincide com o horizontal (vert_datum = Default), ou em um referencial vertical próprio $\left(\right.$ vert $_{\text {datum }}=M S L, E G 96$, etc.). Neste último caso, deve-se fornecer o valor de $\mathrm{N}$ (vert_datum_ $N$ ).

O início da pista será dado por (phi,lbd,height) e seu final por (phi2,lbd2, height2). Caso coordenadas projetadas sejam utilizadas, observar a equivalência ( $p h i:=x, l b d:=y$, height $:=z$ ). Caso a cabeceira seja deslocada, informar um valor maior do que zero para (main_thr_displ).

O ARC (ARCNumber e ARCLetter) e a categoria de aproximação (aprox) precisam estar definidos para cada cabeceira. Ainda, para cada sentido de operação é necessário informar o comprimento da zona desimpedida (main_CWY) e da zona de parada (main_swy).

Como a superfície horizontal se encontra a $45 \mathrm{~m}$ de uma altura de referência, que não necessariamente é a elevação da cabeceira, é necessário especificar tal altura (inner_surf_datum_height).

O modelo XML apresentado é bastante flexível. O uso de tags permite alterar o modelo XML e incluir novas informações para a extensão do modelo computacional. Em linguagem Python, este arquivo pode facilmente ser transformado em uma estrutura de dados nativa, que também utiliza tags, o dicionário. A biblioteca xmltodict facilita estas transformações. 


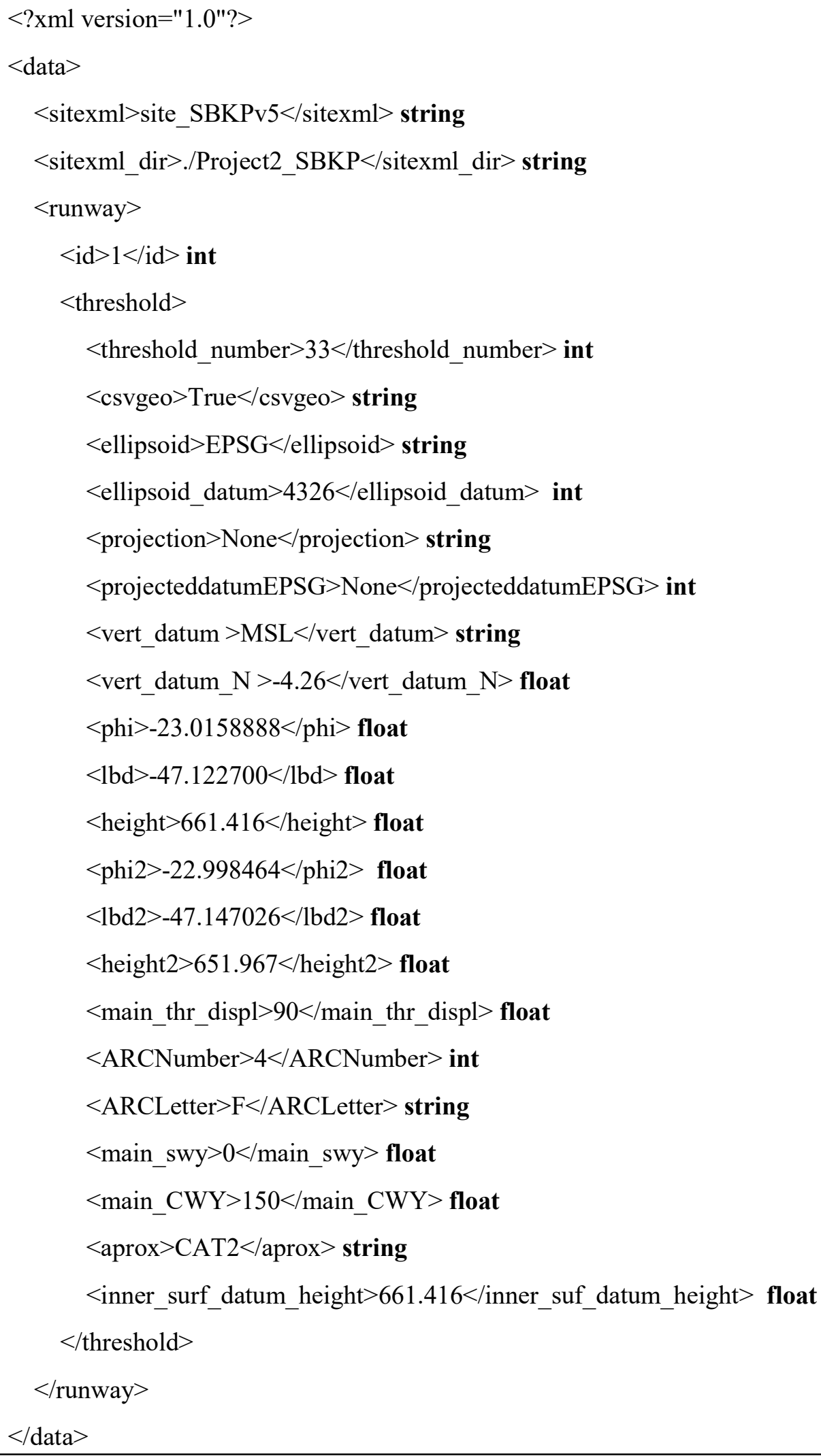

Figura 5-6 Dados de entrada para o sistema de pistas de pouso e decolagem.

FONTE: Elaborado pelo autor. 


\subsection{GERAÇÃO DE GEOMETRIAS}

Esta subseção apresenta a metodologia utilizada para a geração das geometrias, a partir da intepretação das normas e da utilização das variáveis de projeto, conforme os dados fornecidos ao modelo.

\subsubsection{Geração da pista de pouso e/ou de decolagem (RWY)}

Dado o recorte do sítio, sua topografia, e as áreas internas de restrição, será inserido um traçado no plano $X Y$, a ser especificado por um ponto xy de origem e um ponto $x y$ final. Uma vez inserido o traçado, este será testado, de forma que esteja tanto contido pelos limites externos, quanto livre das zonas de exclusão. Com o modelo digital de elevação (MDE), o traçado será transformado em perfil com coordenadas tridimensionais, dado um incremento longitudinal (ex: inc. $=20 \mathrm{~m}$ ). Quanto menor o incremento, maior será o número de pontos de uma pista.

A RWY, por sua vez, será gerada inserindo-se a informação de largura da pista. A construção será tal que para cada ponto do perfil haverá um ponto correspondente em cada margem da pista. Dessa maneira, uma RWY será formada por um polígono que pode ser descrito por um número de pontos igual ao dobro do número de pontos que define o perfil da pista. A Figura 5-7 ilustra o método de geração da geometria da pista.

A necessidade de caracterizar a geometria da pista em função do perfil de altura de sua linha de centro obriga que pelo menos o seu perfil seja construído in situ. Uma alternativa, não adotada no presente modelo, seria construir a geometria da pista e incorporar as alturas durante o posicionamento da mesma no terreno.

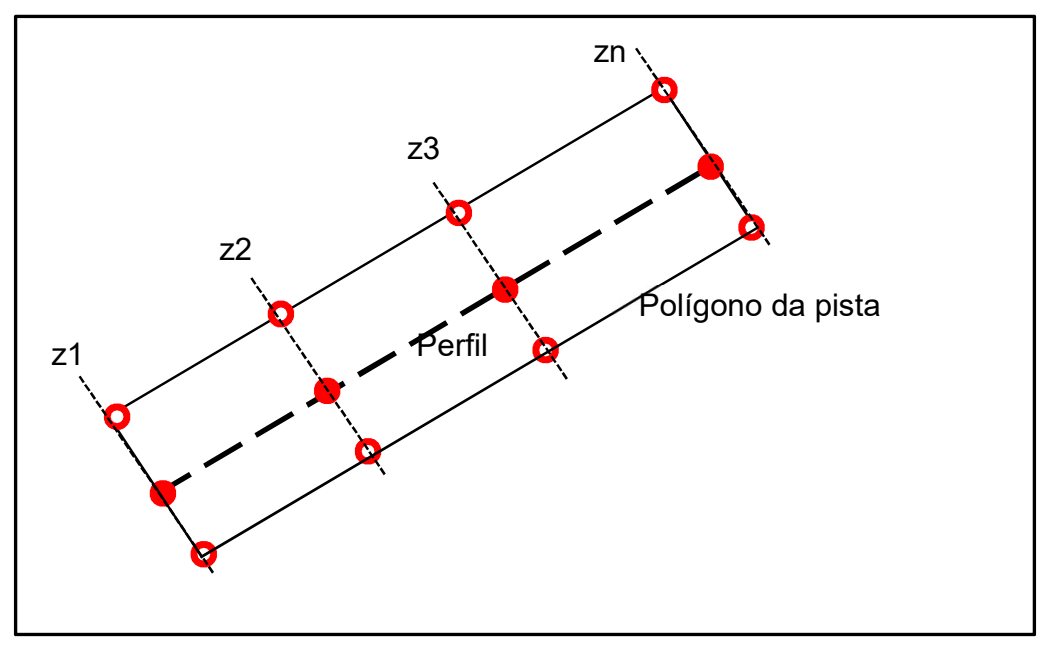

Figura 5-7 Representação da geometria da RWY.

FONTE: Elaborado pelo autor. 


\subsubsection{Geração da faixa de pista de pouso e decolagem}

A faixa de pista de pouso e decolagem é um retângulo que envolve a pista de pouso e/ou de decolagem (RWY), a uma determinada largura. Como discutido em Silva (2012), critérios diferentes de preparação e de exclusão de objetos se aplicam dentro da faixa, dependo de uma distância desde a linha de centro da pista de pouso e decolagem à qual a faixa se destina. Para a modelagem geométrica proposta nesta pesquisa interessam a área aqui chamada de faixa de pista de pouso e decolagem ${ }^{29}$ e a área aqui chamada de área interna da faixa da RWY. A Figura 5-8 ilustra estas áreas, apresentando, para fins de exemplificação, dimensões equivalentes ao ARC 4F, em condições CAT II/III. Por basear-se em distâncias declaradas, a faixa precisa ser estabelecida para cada sentido de operação, para efeito da análise de obstáculos. Do ponto de vista construtivo, no entanto, deve ser estabelecida a configuração que atenda aos requisitos oriundos de diferentes condições de operação.

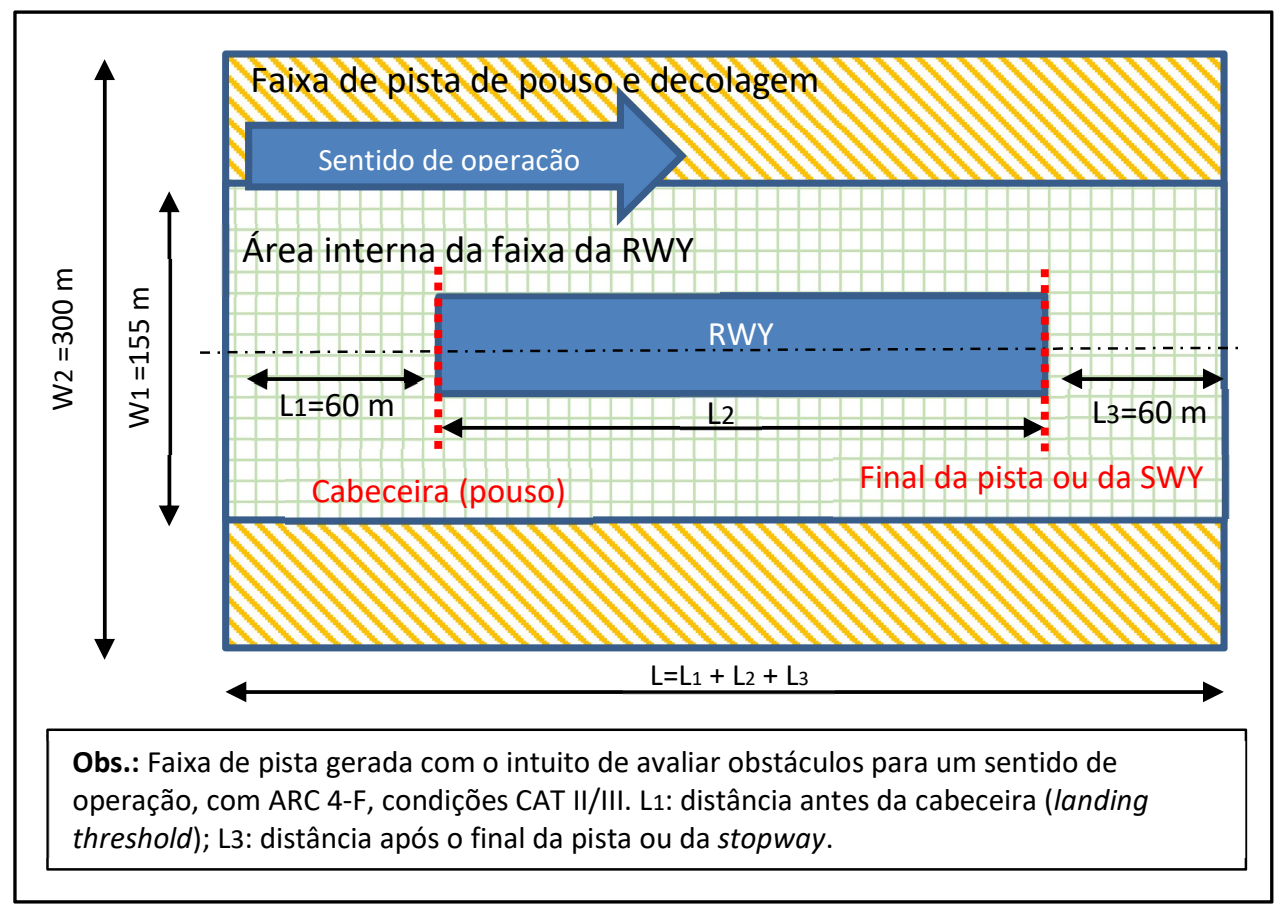

Figura 5-8 Divisão da faixa de pista de pouso e decolagem em duas áreas.

FONTE: Elaborado pelo autor com as informações de ICAO (2004).

Cada uma das duas áreas discutidas serve como limite para a construção de outras superfícies, a saber:

Área interna da faixa da RWY: superfície de aproximação interna; superfície de transição interna.

${ }^{29}$ Faixa de pista de pouso e decolagem, como utilizado em ANAC (2012). 
Faixa de pista de pouso e decolagem: superfície de aproximação; superfície de transição.

Além disso, a RESA (Runway End Safety Area) se inicia em ambas as extremidades da faixa de pista de pouso e decolagem ${ }^{30}$, possuindo largura própria.

As geometrias adjacentes a outras superfícies podem ser construídas de duas formas: a) ou se utilizam os pontos já calculados da respectiva superfície; ou b) os pontos podem ser recalculados. Neste caso, existirá um trade-off entre o custo computacional em se recalcular os pontos, e a complexidade de acesso à estrutura de dados que contém os pontos anteriormente calculados. No presente modelo, enquanto a RESA e as superfícies de aproximação utilizam a estratégia $b$, as superfícies de transição utilizam os pontos da respectiva lateral da faixa (estratégia a).

Uma complexidade adicional da faixa de pista de pouso e decolagem é a consideração das distâncias declaradas, que influenciam seus limites longitudinais, conforme ilustra a Figura 5-9. Nesta figura, apresenta-se o caso mais simples e o caso mais geral, com cabeceira deslocada e com presença de zona de parada. Ressaltase que esta representação reflete o dimensionamento da faixa de pista de pouso e decolagem para propósitos de avaliação de obstáculos e construção de superfícies imaginárias. O projeto para fins construtivos deve considerar a operação em ambos os sentidos.

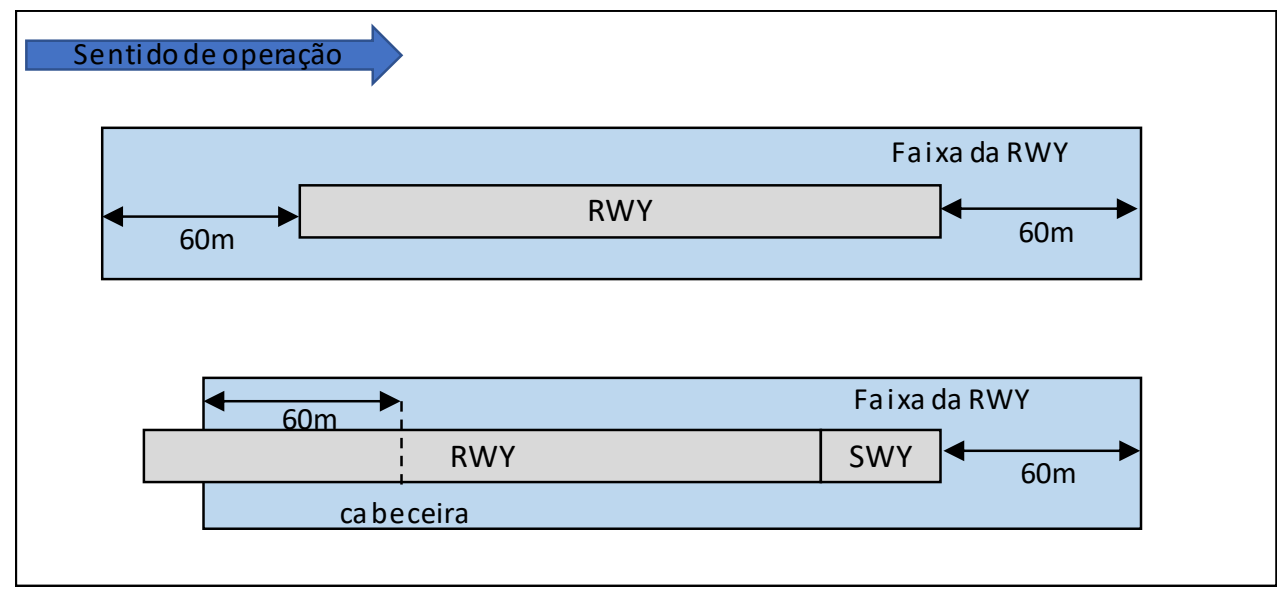

Figura 5-9 Distâncias declaradas que influenciam a faixa de pista (letras 3 e 4 do ARC) FONTE: Elaborado pelo autor.

A faixa de pista de pouso e decolagem e a área interna da faixa da RWY são construídas através da seguinte sequência, ilustrada na Figura 5-10:

30 Conforme (ICAO, 2004), a RESA protege as aeronaves que acidentalmente pousem antes do início da pista (undershooting) ou depois dela (overruning). 
1) Construção de um perfil longitudinal $Y Z$, observando-se o MDE, conforme a posição da RWY no plano XY;

2) Translação deste perfil para o eixo $X$, de modo que o início da pista seja transportado para a coordenada $(x=0, y=0)$ e o final para $(x=0, y=$ comprimento da pista ;

3) Adição e subtração de pontos das duas extremidades para consideração das distâncias declaradas e dos $60 \mathrm{~m}$, em cada extremidade;

4) Construção de uma geometria retangular, centrada no eixo $X$, representando a faixa de pista de pouso e decolagem, considerando-se o perfil $Y Z$ de altura;

5) Translação para o início da pista na projeção local; e

6) Rotação da geometria para o ângulo de orientação da RWY.
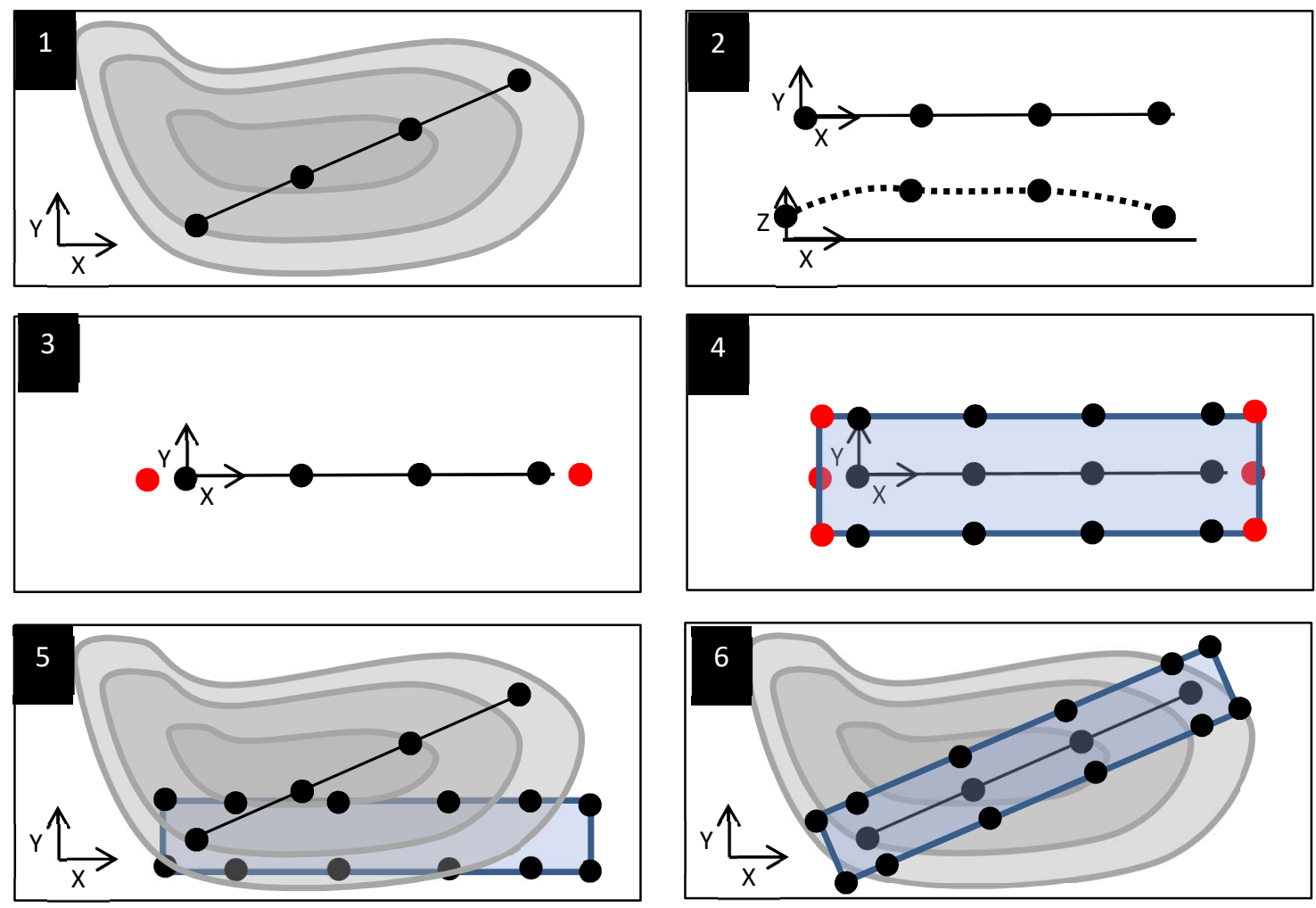

Figura 5-10 Etapas para a geração da faixa de pista de pouso e decolagem. FONTE: Elaborado pelo autor.

\subsubsection{Geração da RESA}

A RESA é retangular em planta e se situa nos finais de pista, longitudinalmente adjacente à faixa de pista de pouso e decolagem. Para o controle de obstáculos como aeronaves e veículos, a altura desta área pode ser considerada como ao nível do solo. Esta foi a abordagem adotada nesta modelagem, dados seus objetivos. Para propósitos mais sofisticados, como análise de declividades e posição de equipamentos de navegação, uma modelagem mais complexa pode ser necessária. 
A RESA pode ser construída com o auxílio de um primitivo retangular ou mesmo inserindo-se os seus pontos através de fórmulas. Apenas quatro pontos são suficientes para descrever sua geometria.

\subsubsection{Geração da superfície de aproximação interna}

A geração da superfície de aproximação interna emprega um primitivo retangular, submetido à sequência:

1) Geração na origem, com o ponto médio da base centrado na origem $(0,0,0)$ e com a linha de centro alinhada com o eixo $X$;

2) Rotação em torno do eixo $Y$, conferindo a orientação vertical;

3) Rotação em torno do eixo $Z$, de acordo com a orientação da pista no plano $\mathrm{XY}$; e

4) Translação para o seu ponto de origem na proximidade da cabeceira.

\subsubsection{Geração da superfície de pouso interrompido}

A superfície de pouso interrompido é similar à superfície de aproximação, porém com parâmetros próprios de inclinação, comprimento e larguras. Além disso, esta superfície se encontra rotacionada em 180 graus em relação às superfícies de aproximação. A superfície de pouso interrompido utiliza um trapézio como primitivo.

\subsubsection{Geração da superfície decolagem}

A superfície de decolagem inicia-se no final da pista (ou zona desimpedida), após certa distância obedecendo a um perfil de subida e de divergência lateral. Se comporta como um trapézio inicialmente e depois se transforma em um retângulo. Trata-se, portanto, de uma geometria complexa, se comparada às anteriores. Como solução para este problema, propõe-se aqui a utilização de um perfil (yprofile) com três pontos: um ponto inicial, um ponto intermediário e um ponto final, estando o perfil centrado no eixo Y. O ponto intermediário é calculado de forma que ocorre nele a mudança de trapézio para retângulo. A seguir é apresentado o pseudocódigo que permite gerar as coordenadas $x, y$ e $z$ de cada lateral: 


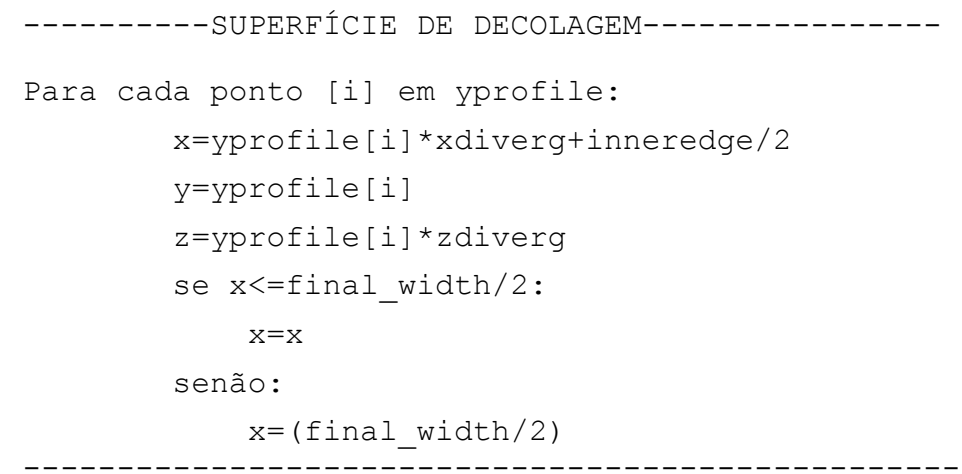

No código, xdiverg indica a divergência lateral, zdive indica a divergência vertical, inneredge a largura do base menor do trapézio e final_width simboliza a base maior. Gerada uma lateral da geometria, será necessário aplicar um espelhamento para formar a geometria completa. Os passos seguintes envolvem rotações e translações para posicionamento no aeródromo.

\subsubsection{Geração da superfície de aproximação}

A superfície de aproximação é trapezoidal em planta, porém possui inclinação variável, à media que a superfície se distancia da cabeceira. Inicia-se a determinada distância antes da cabeceira, portanto, varia com as distâncias declaradas.

Para tanto, de forma similar à superfície de decolagem, foi criado um perfil centrado no eixo y (yprofile $=[y 0, y 1, y 2, y 3]$ ) representando os pontos de mudança de declividade da superfície. Dessa forma, as coordenadas $x_{i}$ e $z_{i}$ podem ser calculadas com base nas divergências lateral e vertical previstas em norma, para cada ponto do perfil em Y. A geometria pode ser completada por espelhamento em relação ao eixo y.

$\mathrm{Na}$ sequência, estes pontos sofrem rotações e translações para seu posicionamento no conjunto.

\subsubsection{Geração da superfície de transição interna}

A superfície de transição interna é adjacente a outras três superfícies: área interna da faixa da RWY; superfície de pouso interrompido; superfície de aproximação interna; e superfície horizontal interna. A geração da geometria desta superfície envolve a identificação e extração dos pontos que a delimitam, em cada uma das outras superfícies, com exceção da superfície horizontal interna. Para a aresta interna, os pontos foram gerados a partir dos pontos da área interna da faixa da RWY. Estas colocações ficam mais claras a partir da Figura 5-11. 


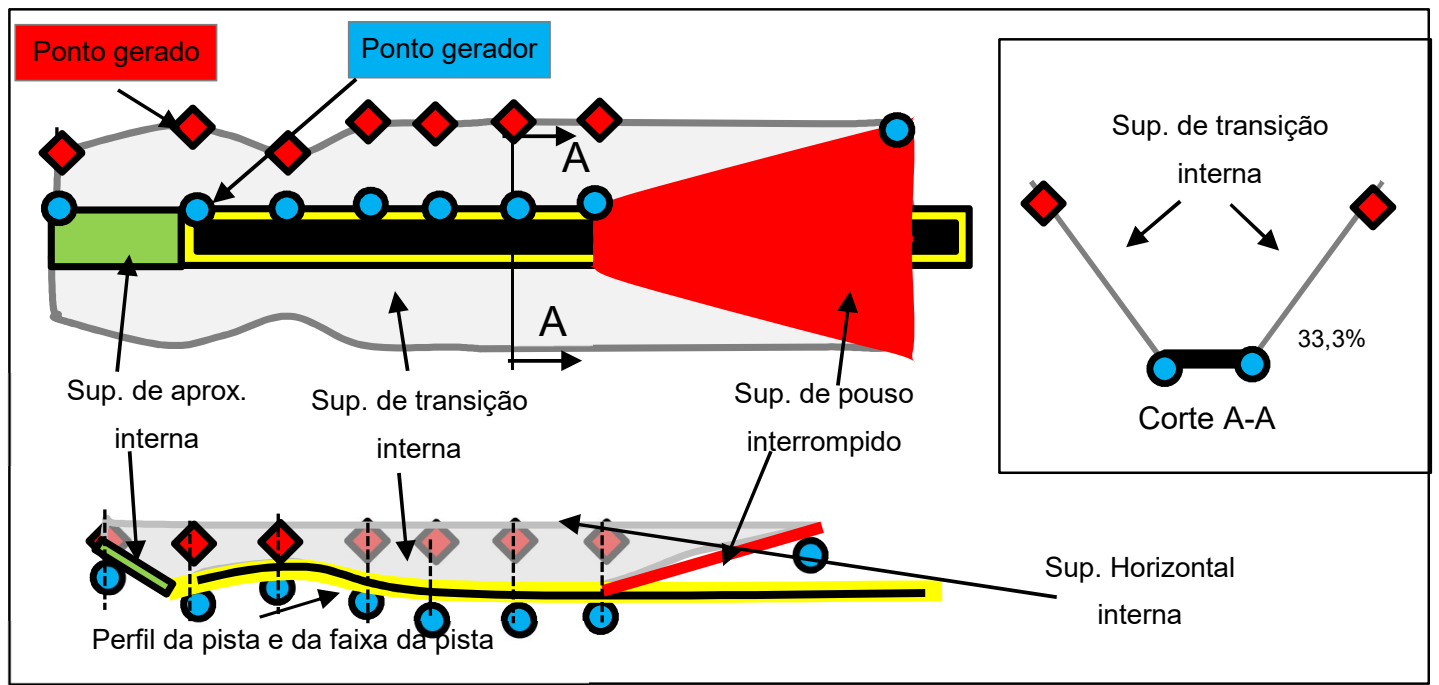

Figura 5-11 Geração da superfície de transição interna.

FONTE: Elaborado pelo autor.

Na figura, os pontos representados por círculos foram retirados das superfícies adjacentes e os pontos representados por losangos foram calculados com base na declividade estabelecida em norma e na diferença de altura entre o ponto inferior que o originou e a superfície horizontal interna.

\subsubsection{Geração da superfície de transição}

A superfície de transição é bastante similar à superfície de transição interna, atingindo também seu limite superior na superfície horizontal interna. Já seus limites inferiores compreendem a superfície de aproximação e a borda da faixa de pista de pouso e decolagem. Para a sua geração, foram extraídos destas duas superfícies:

Da superfície de aproximação: um ponto da superfície de aproximação, na elevação da superfície horizontal interna; e um ponto no início da superfície de aproximação.

Da faixa de pista de pouso e decolagem: $n$ pontos ao longo da lateral faixa de pista de pouso e decolagem até seu final.

Os pontos superiores foram gerados a partir da diferença de altura entre seu ponto gerador e a superfície horizontal interna.

\subsubsection{Geração da superfície horizontal interna}

Conforme ilustra a Figura 1-3, o contorno desta superfície poderá ser mais complexo no caso de um aeródromo com um sistema de múltiplas pistas. Porém, a criação da geometria é bastante simples, a partir do seguinte procedimento: 
1) Criação de círculos centrados nos finais de cada pista, cada círculo sendo formado por $n$ pontos, de forma que, quanto maior $n$, maior a aproximação da geometria a se representar; e

2) União dos pontos em uma geometria única, na forma de uma nuvem de pontos, com posterior extração do Convex Hull da nuvem de pontos.
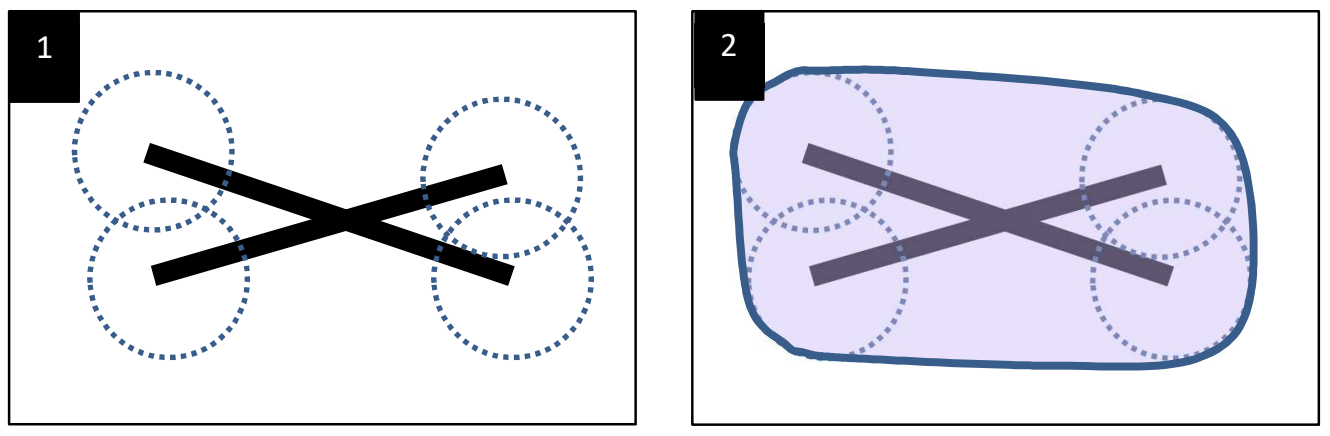

Figura 5-12 Geração da superfície de horizontal interna.

FONTE: Elaborado pelo autor.

A criação dos círculos foi, nesta modelagem, executada com a utilização de primitivos circulares (representados por $n$ pontos), posteriormente transladados para os finais de pistas. A modelagem emprega uma altitude única para todos os círculos. No entanto, ICAO (ICAO, 1983) coloca que quando a elevação das cabeceiras difere em mais de $6 \mathrm{~m}$, pode-se empregar diferentes alturas para o desenho da superfície horizontal interna. Em caso de sobreposição, a superfície mais baixa deve ser considerada dominate.

\subsubsection{Geração da superfície cônica}

A superfície cônica pode ser gerada empregando-se a mesma técnica aplicada às superfícies de transição: um ponto gerador é utilizado para calcular outro ponto, uma vez que basta a aplicação de uma declividade e uma altura previstas em norma. A Figura 5-13 ilustra a geração dos pontos que descrevem os limites da superfície cônica. O limite inferior é composto pelos pontos da própria superfície horizontal interna, enquanto os pontos superiores delimitam a superfície cônica em um plano superior. A área hachurada da figura representa a superfície cônica, que obedece a uma declividade vertical prevista em norma. 


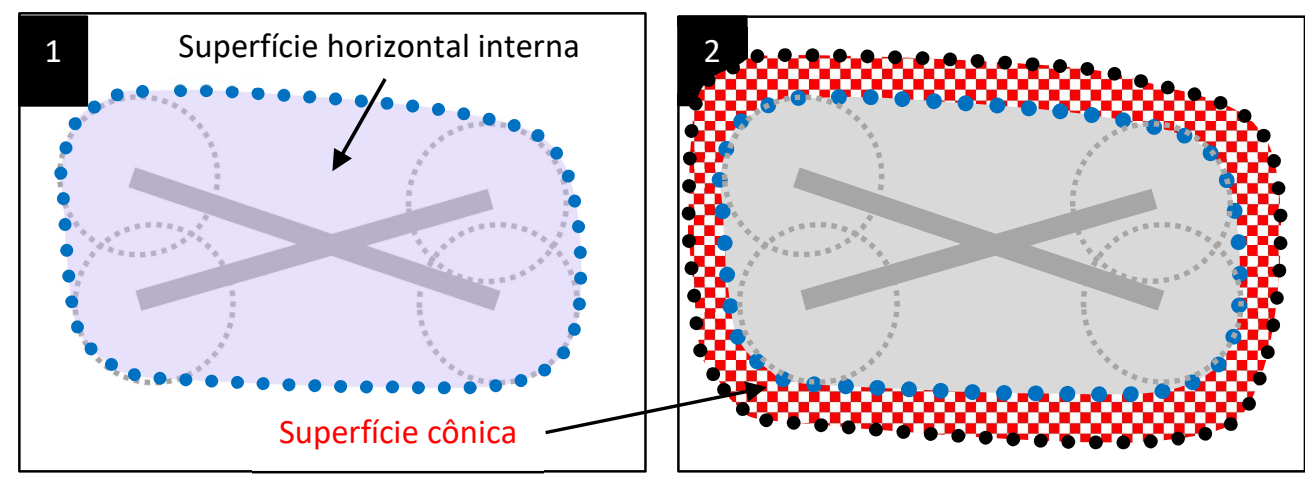

Figura 5-13 Geração da superfície cônica.

FONTE: Elaborado pelo autor.

O seguinte pseudocódigo apresenta o algoritmo utilizado para a geração do contorno externo da superfície cônica:

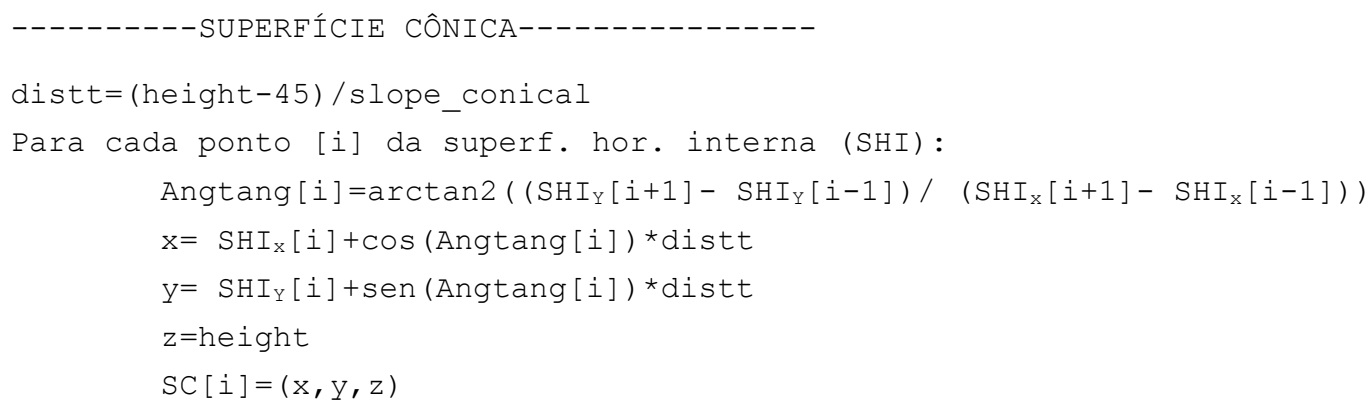

Neste código, distt se refere à distância horizontal que separa o ponto gerador $(S H I)$ do ponto gerado $(S C)$. Esta distância é calculada com base na diferença de altura entre os planos da superfície horizontal e do plano superior da superfície cônica. A declividade (slope_conical) é prevista em norma.

Para cada um dos pontos da superfície horizontal interna, o ângulo normal à curvatura desta é estimado numericamente pelas coordenadas dos seus dois pontos vizinhos $(S H I[i-1]$ e $S H I[i+1])$.

\subsubsection{Geração das aeronaves no modelo}

Foram levantadas duas alternativas para a geração de aeronaves: modelo paramétrico e digitalização.

A primeira estratégia consistiria na geração de geometrias a partir de parâmetros como a letra do ARC, a altura do estabilizador, configuração (cauda convencional e em $\mathrm{T}$, asa baixa, asa alta, etc.). Verificou-se que esta alternativa levaria a representações não realistas das aeronaves, talvez permitindo explorar efeitos de um conjunto diverso, mas nunca permitindo analisar os efeitos de um modelo 
específico. Além disso, a variabilidade esperada nos desenhos levaria à necessidade de um complexo método de controle topológico.

Por esta razão, a alternativa de digitalização se mostra mais realista e simples e é a seguir descrita.

As dimensões da aeronave B747-8F foram introduzidas no modelo, a partir da digitalização das plantas contidas em seu APM (Airport Planning Manual). Esta aeronave é representada através de um wireframe. Tal representação é esperada suficiente para os propósitos de visualização, permitindo detectar visualmente as interferências. A estrutura é formada por duas categorias de pontos que formam o wireframe: pontos estéticos e pontos críticos. Os pontos críticos são utilizados para analisar interferências geométricas via modelo e guardam rótulos como nose, wingtip1, wingtip 2 , horizontal_stab_tip1, horizontal_stab_tip2 e vertical_stab.

O APÊNDICE 2 apresenta o arquivo CSV completo que caracteriza um B747$8 \mathrm{~F}$. Além das coordenadas $\mathrm{x}, \mathrm{y}, \mathrm{z}$ dos pontos críticos, o arquivo contém: 10 conjuntos convexos de pontos que caracterizam fuselagem, asas, estabilizadores; o ponto de referência da aeronave (bequilha); o centro de geométrico de giro da aeronave; a posição $(\mathrm{x}, \mathrm{y}, \mathrm{z})$, diâmetro e rótulo (bequilha, trem central, etc.) de cada roda. A inserção de outros modelos de aeronaves poderia ser feita por procedimento idêntico, criandose arquivos CSV equivalentes na pasta aircraft_data.

Um script Python gera automaticamente a aeronave, formada por primitivos circulares (rodas); polígonos convexos; e pontos (para os pontos críticos). Uma vez gerada a aeronave, seu ponto de referência será ajustado à coordenada $(0,0,0)$. Um Python dictionary é utilizado para representar a aeronave, o que permite recuperar os dados de maneira direta.

O posicionamento da aeronave no sítio precisa considerar o ângulo da mesma no plano $X Y(\theta)$. Por sua vez, a altura de referência pode ser especificada diretamente, resultando em uma simples translação. Pode também utilizar o algoritmo apresentado no seguinte pseudocódigo, que posiciona a aeronave respeitando a altura do MDE local: 
ENTRADAS :

MDE; aeronave ACF[i]; ponto de referência da aeronave REF[i];

centro de giro da aeronave $\mathrm{CGEO}^{31}[\mathrm{i}]$; ponto de destino no aeródromo (x', $\left.\mathrm{Y}^{\prime}\right)$; ângulo. ALGORITMO :

Transladar ACF[i] para que REF[i] encontre $\left(\mathrm{x}^{\prime}, \mathrm{Y}^{\prime}\right)$

Rotacionar ACF[i] em $\theta$ graus em torno de REF[i]

Ler no MDE as alturas CGEOHEIGHT $[i]$ e REF HEIGHT [i];

Height=max $\left(\right.$ CGEO HEIGHT $_{\text {Hi }}$; REF HEIGHT $\left.[i]\right)$

Transladar ACF[i] conforme Height

SAÍDAS:

ACF [i] posicionada em $\left(x^{\prime}, y^{\prime}\right)$ a $\theta$ graus $e$

na máxima elevação do MDE no local

\subsection{GERAÇÃO DA MALHA TIN}

A malha TIN é formada a partir de um conjunto de pontos, conforme discutido na subseção 4.5. Nesta modelagem, tanto o MDE é tratado como uma malha TIN, quanto as áreas e superfícies de proteção. Em ambas, o objetivo é determinar a altura da malha em um ponto $\mathrm{P}$ com coordenadas $\mathrm{x}, \mathrm{y}$ conhecidas.

A geração da malha é realizada através da biblioteca $S c i P y^{32}$, que gera um objeto na memória. Este objeto pode ser repassado como argumento nas funções, garantindo que a triangulação seja realizada apenas uma vez e que seus resultados possam ser acessados a qualquer momento.

A geração da geometria da pista, por exemplo, precisa acessar a malha TIN para cada ponto ao longo do seu eixo. O próximo tópico discute como a altura de uma malha TIN pode ser acessada.

\subsection{CÁLCULO DA ELEVAÇÃO EM UMA MALHA TIN}

Uma das funcionalidades essenciais ao modelo é o cálculo da altura de um ponto $P$ com coordenadas $x, y$ conhecidas. Tal cálculo é executado em relação a uma malha TIN previamente gerada, que na modelagem proposta, corresponde a um objeto na memória. Este objeto é acessado utilizando métodos da biblioteca Scipy. A mesma utilizada para gerar o objeto na memória.

O pseudocódigo a seguir mostra o cálculo da elevação para um único ponto:

\footnotetext{
${ }^{31}$ Admitido como centro geométrico do trem central.

${ }^{32}$ A biblioteca Scipy (www.scipy.org) utiliza para a triangulação a biblioteca Qhull (http://www.qhull.org/). Esta é uma consolidada biblioteca open source na área de geometria computacional.
} 


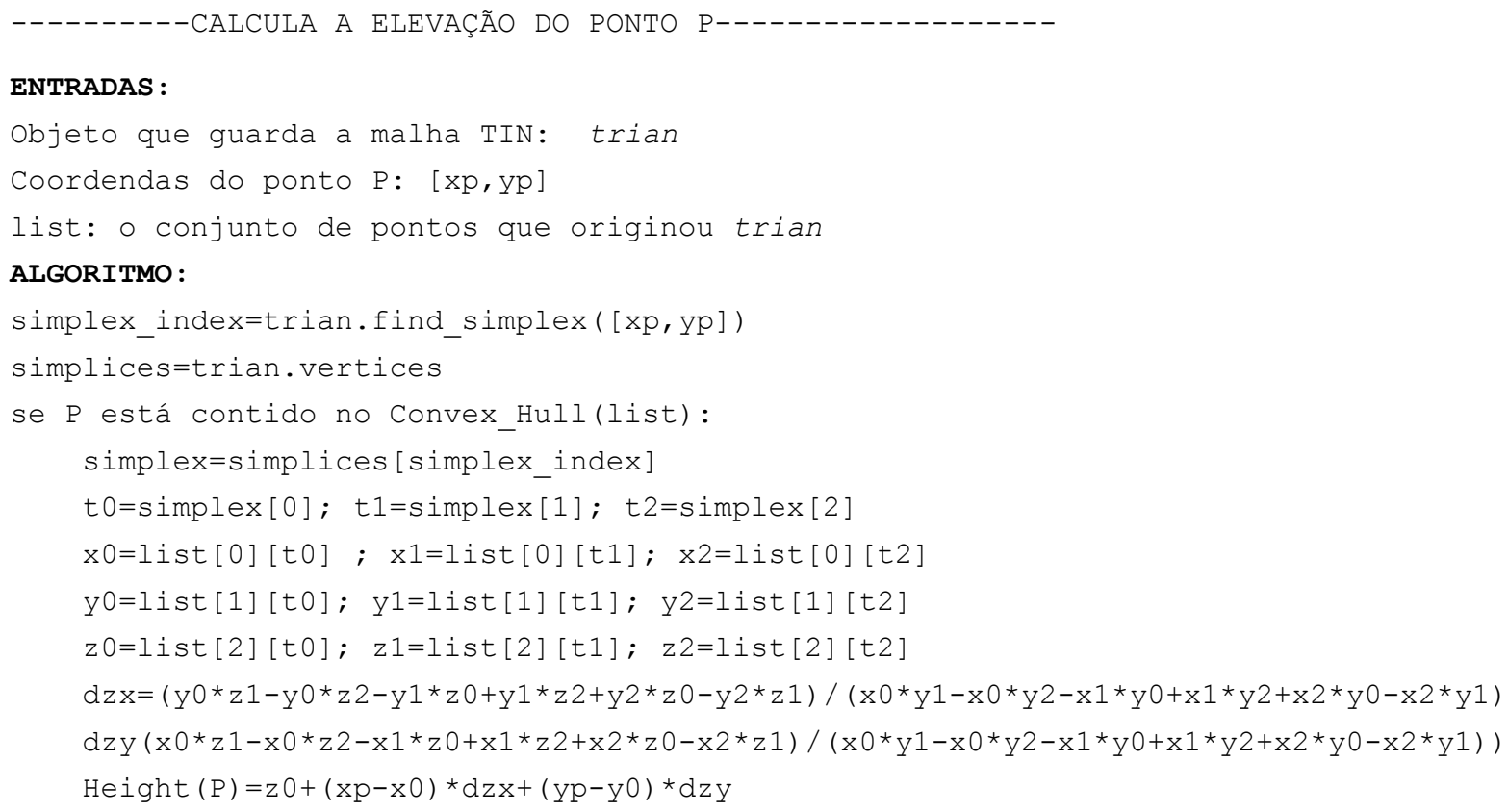

O algoritmo baseia-se no objeto trian, que já deve se encontrar disponível na memória. O método find_simplex( ), disponível pela biblioteca Scipy, é capaz de detectar em qual triângulo da malha se encontra o ponto $P$. Os triângulos são indexados $e$ armazenados em simplices. Cada triângulo pode ser descrito pelos índices dos três pontos que o constituem $(t 0, t 1, t 2)$. A partir de list, é possível obter as coordenadas $\mathrm{x}, \mathrm{y}, \mathrm{e} \mathrm{z}$ destes pontos. Por exemplo, list $[0][t 0]$, retorna a coordenada $\mathrm{x}$ - [0] - do primeiro ponto - $[t 0]$ - do triângulo que contém $\mathrm{P}$. A inclinação do triângulo no sentido do eixo $\mathrm{x}(d z x)$ e no eixo y $(d z y)$ permitem calcular a elevação de um ponto $[x p, y p]$, situado no interior do triângulo. Trata-se, portanto, de uma interpolação bilinear.

\subsection{DETECÇÃO DE INTERFERÊNCIAS}

O método de detecção de interferências permite verificar automaticamente quais objetos fixos ou móveis interferem com as superfícies de proteção. Este procedimento permite que as análises possam ser executadas sem a necessidade de saídas gráficas. Tal funcionalidade é importante para automatização do modelo: caso se deseje analisar múltiplas configurações, não seria viável verificar graficamente as interferências. Além disso, a verificação gráfica pode exigir a preparação de imagens detalhadas, com o emprego de rotações e cortes. No caso de sobreposição de superfícies, este processo precisaria ainda ser repetido.

A detecção de conflitos via algoritmo tem ainda outra funcionalidade: alterar a cor do objeto analisado para vermelho, permitindo a visualização gráfica da 
interferência sem a necessidade de gráficos detalhados. Este padrão de cor é utilizado tanto nas saídas gráficas em tela, quanto no arquivo KML criado. A seguir, apresentase o pseudocódigo do algoritmo que compara a interferência de um objeto móvel, neste caso, uma aeronave, com um conjunto de superfícies de proteção:

\section{ENTRADAS :}

Conjunto de Áreas e Superfícies de Proteção S

Conjunto de aeronaves posicionadas no aeródromo ACF

ALGORITMO:

Para cada aeronave [i] de $\mathrm{ACF}$ :

Para cada superfície [j] de $\mathrm{S}$ :

Se:

Convex_hull(S[j]). Intersects (Convex_hull (ACF[i])) ou

Convex hull $(\mathrm{S}[j])$. Contains (Convex hull (ACF[i])) :

Para cada ponto crítico [k] em ACF[i]:

Se Height (ACF[i] $[k])>\operatorname{Height~}(\mathrm{S}[j])$ :

INTERF[[j] [i] $[k]<-$ True

SAÍDAS :

INTERF[[j][i][k]: o ponto crítico k da aeronave i interfere na superfície j

O mesmo algoritmo pode ser utilizado para os objetos fixos, que são representados por um único ponto no modelo. Neste caso, a função convex_hull () do objeto não precisa ser utilizada.

Aliás, a função convex_hulı() simplifica as geometrias para compará-las mais facilmente, de forma que a função Intersects () analisa se os dois polígonos convexos se interseccionam. A função contains() é análoga para verificar se a aeronave $A C F$ está contida no polígono convexo de $S$. Estas três funções pertencem à biblioteca GDAL osgeo/ogr.

A função Height () é descrita no item 5.7.

\subsection{REPRESENTAÇÃO DOS DADOS EM PYTHON 2.7}

A seguir são apresentadas as codificações de representação dos dados do modelo durante a implementação em linguagem Python. Estas codificações foram propostas para este trabalho, utilizando apenas duas estruturas de dados da linguagem Python: listas (lists) e dicionários (dictionaries). São elas:

- Obgeo: um objeto geométrico no formato de uma list em Python onde as três primeiras linhas representam pontos $\mathrm{x}, \mathrm{y}$ e $\mathrm{z}$, cada uma também no formato list, podendo conter ainda uma quarta linha no formato de um Python 
dictionary, contendo atributos, entre os quais, rótulos, cores, etc. Um Obgeo pode formar um conjunto de pontos, linhas ou polígonos, sendo a ordem dos pontos relevante para construção de geometrias baseadas em linhas, à medida que cada segmento de linha une dois pontos adjacentes. Esta também é a razão pela qual o último ponto da sequência deve ser igual ao primeiro. Já em geometrias baseadas em pontos, a ordem não é importante, nem é importante a repetição do primeiro ponto. No entanto, por padronização, todos os Obgeos preveem representação como linhas. Tal característica aumenta a quantidade necessária de pontos, mas tende a facilitar a conversão para outros formatos, facilitando principalmente a visualização. Ver OGC (2011) para a discussão de padrões relacionados a este aspecto.

- Setobgeo: um conjunto de Obgeos que guardam relação entre si, formando uma entidade com valor semântico ou apenas geométrico. A pista de pouso e as suas superfícies de proteção formam um Setobgeo. Também é exemplo de um Setobgeo uma única aeronave, formada por várias linhas, pontos e polígonos. O Setobgeo possui $n+1$ linhas, representando $n$ Obgeos e um dicionário de atributos na última linha. A estrutura de dados segue o padrão list.

- Nestset: um conjunto de $n$ Setobgeos no padrão list. Um Nestset pode representar a totalidade da geometria de um aeródromo, permitindo que os gráficos sejam gerados diretamente, por exemplo.

- Objeto geométrico: um conjunto de geometrias com valor semântico. Pode ser um Obgeo, Setobgeo ou Nestset.

As operações de rotação, translação e espelhamento podem ser aplicadas a um objeto geométrico em qualquer dos níveis apresentados de agregação (Obgeo, Setobgeo ou Nestset). A conversão entre sistemas de coordenadas também pode ser realizada para cada um dos formatos. Em qualquer uma das operações os dicionários são mantidos.

Além disso, a visualização em tela e o salvamento em KML podem ser obtidos para qualquer Nestset. Um Obgeo pode ser transformado em um Setobgeo e um Setobgeo em um Nestset, conforme:

$$
\begin{aligned}
& \text { Set }_{\text {Obgeo }}=[\text { Obgeo }] \\
& \text { Nest }_{\text {Set }}=\left[\text { Set }_{\text {obgeo }}\right]
\end{aligned}
$$


Estes formatos permitem, para as necessidades do modelo em questão, uma representação organizada de objetos baseados em combinações entre nuvens de pontos, linhas e polígonos. A união de polígonos não preenchidos e linhas permite representações wireframe em $2 \mathrm{D}$ e em $3 \mathrm{D}$. A união de polígonos permite também a criação de malhas poligonais, como a malha TIN por exemplo.

Através da implementação de scripts de tradução entre estes formatos e os formatos WKT e numpy array, foi possível utilizar as funções geométricas da biblioteca GDAL, bem como as funções gráficas da biblioteca gráfica matplotlib, que acompanha a distribuição.

A leitura de arquivos CSV é executada através do módulo $c s v$, que acompanha a distribuição. Os arquivos XML são lidos a partir da biblioteca xm/todict. Já as saídas de arquivos da implementação compreendem: módulo csv para arquivos CSV; a biblioteca simplekml, para os arquivos $\mathrm{KML}$; e a biblioteca matplotlib, para o salvamento de figuras em diferentes formatos.

\subsection{CONCLUSÕES DO CAPÍTULO}

A modelagem proposta leva em conta, de forma precisa, as especificações do Anexo 14 da ICAO para as áreas e superfícies de proteção da pista de pouso e decolagem, sendo capaz, inclusive, de representar a complexa intersecção entre as superfícies de transição e a superfície horizontal interna.

Para a representação de todas as geometrias, conforme o modelo proposto, são suficientes pontos, linhas, polígonos, e combinações destes. Tal característica é conveniente para o tratamento computacional das geometrias, à medida que estas estruturas podem ser interpretadas por diferentes bibliotecas, mediante tradução dos dados para estruturas simplificadas. Por exemplo, para utilização da biblioteca GDAL, o padrão WKT foi utilizado. Caso a modelagem empregasse representações mais complexas, a tradução poderia até mesmo ser inviabilizada. Isso traria a necessidade de implementação de funções que podem ser desempenhadas por bibliotecas disponíveis, muitas vezes já testadas e otimizadas.

Além disso, as representações propostas Obgeo, Setobgeo e Nestset são suficientes para armazenar de forma organizada todas as informações do modelo geométrico, baseando-se nas estruturas list e dictionary, nativas da linguagem Python.

O algoritmo para a detecção de interferências geométricas entre os objetos e as áreas e superfícies de proteção aproveita a metodologia utilizada para a modelagem digital do terreno. Isso é possível, uma vez que as áreas e superfícies de proteção 
podem ser representadas conforme uma malha TIN (Triangulated Irregular Network). Esta modelagem é essencial para a interpolação bilinear da elevação destas superfícies, de forma a compará-las com objetos.

Aeronaves podem ser representadas no modelo de forma precisa, utilizando-se uma técnica de digitalização que se baseia em conjuntos de pontos convexos a partir do APM da aeronave (Airport Planning Manual).

O processo de implementação computacional da referida modelagem em linguagem Python demonstra que é possível modelar o problema com o emprego de bibliotecas que acompanham a distribuição padrão, além de bibliotecas livres e de código aberto, a saber: GDAL, Scipy, xmltodict e simplekml. 


\section{CAPÍTULO 6 - TESTES DO MODELO}

Este capítulo apresenta os testes realizados para com a implementação e tem por objetivo verificar a validade da metodologia proposta. Para tanto, verifica-se: a projeção local SCL em termos das distorções dela resultantes; a geração de geometrias, com emprego de instâncias fictícias; a geração de geometrias, com uso de dados de um caso real associado ao Aeroporto de Viracopos em Campinas (SBKP); a deteç̧ão de obstáculos fixos e móveis, também para o caso do SBKP; a geração de geometrias para sistemas de pistas múltiplas; e o tempo computacional do modelo, tomando-se por base a aplicação relacionada ao Aeroporto de Viracopos.

\subsection{ANÁLISE DAS DISTORÇÕES NAS PROJEÇÕES SCL, PTL E UTM}

Um dos indicadores de qualidade de uma projeção é a distorção associada à distância entre dois pontos. Este indicador é comparativo, ou seja, parte-se de uma distância de referência a ser comparada com a distância verificada na projeção. De forma a viabilizar esta comparação, optou-se pela implementação das equações apresentadas em Vincenty (1975), que oferecem uma precisão submilimétrica para o cálculo da distância geodésica entre dois pontos. O primeiro passo é avaliar a qualidade da implementação destas equações, que recorrem a processos iterativos nas conversões direta e inversa.

Para tanto, foram utilizados os dados de testes que constam no próprio artigo original, a partir de cinco arcos, conforme a Tabela 6-1.

Tabela 6-1 - Testes da implementação das fórmulas de Vincenty (1975)

\begin{tabular}{|c|c|c|c|c|c|}
\hline Arco & phil & phi2 & $\begin{array}{c}\mathrm{L} \\
\text { (diferença de } \\
\text { longitude) }\end{array}$ & $\begin{array}{c}\text { Comprimento } \\
\text { do arco } \\
\text { apresentado por } \\
\text { Vincenty } \\
(1975) \\
\text { (em metros) }\end{array}$ & $\begin{array}{c}\text { Comprimento } \\
\text { do arco a partir } \\
\text { da } \\
\text { implementação } \\
\text { do autor } \\
\text { (em metros) }\end{array}$ \\
\hline (a) & 55,75000000000 & $-33,43333333330$ & 108,21666666700 & 14110526,1696 & 14110526,1696 \\
\hline (b) & 37,33193157500 & 26,12856651670 & 41,47652980280 & 4085966,7026 & 4085966,7026 \\
\hline (c) & 35,26979128330 & 67,37077121670 & 137,79119843100 & 8084823,8383 & 8084823,8383 \\
\hline (d) & 1,00000000000 & $-0,99828632222$ & 179,29667499200 & 19959999,9998 & 19959999,9998 \\
\hline (e) & 1,00000000000 & 1,02088597778 & 179,77162290000 & 19780006,5588 & 19780006,5588 \\
\hline \multicolumn{6}{|c|}{$* 1:$ Bessel: $a=6377397.155 m, 1 / f=299.1528128$} \\
\hline
\end{tabular}


A partir da comparação do comprimento dos 5 arcos analisados, percebe-se que até a casa dos décimos de milímetros não existe diferença entre os dados do trabalho original e a implementação realizada nesta pesquisa.

Aceitando-se a qualidade da implementação do modelo de referência, testou-se a precisão da projeção local, aqui referida como Sistema Cartesiano Local (SCL). Foi avaliada também a projeção prevista na NBR 141666, o PTL (Plano Topográfico Local). Para tanto, foi comparada a distância entre o ponto central da projeção $\left(\varphi_{0}, \lambda_{0}, h_{0}\right)$, tangente ao elipsoide, e quatro pontos extremos, distantes $\pm 50.000 \mathrm{~m}$ no eixo $x(E$ ou $\lambda$ ) e $\pm 50.000 \mathrm{~m}$ no eixo y $(\mathrm{N}$ ou $\varphi$ ). Enquanto a distância no elipsoide foi calculada com base em Vincenty (1975), a distância na projeção foi obtida por geometria cartesiana. A seguir, a comparação mencionada é apresentada de forma gráfica para a projeção SCL - Figura 6-1 - e para o PTL- Figura 6-2. O ponto central foi variado formando uma grade com resolução de 0,5 graus para a latitude e 10 graus para a longitude, cobrindo $360^{\circ}$ de leste a oeste, enquanto a latitude é analisada de $70^{\circ} \mathrm{S}$ a $70^{\circ} \mathrm{N}^{33}$. A altura do plano foi mantida em $0 \mathrm{~m}$, e a altura do outro ponto também vale $0 \mathrm{~m}$. Os parâmetros do elipsoide WGS84 foram utilizados (a=6378160,0m; e= $0,081820180369054)^{34}$.

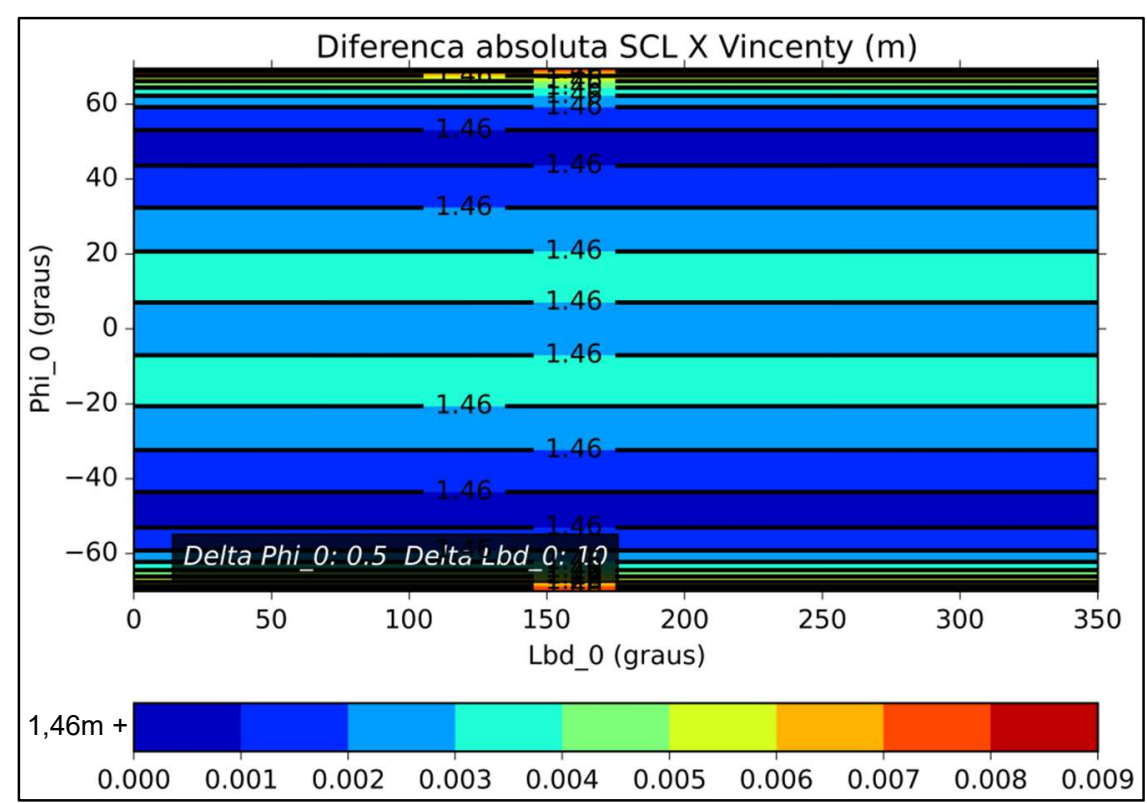

Figura 6-1 Distorção absoluta de distância: SCL X Vincenty (m). FONTE: Elaborado pelo autor.

\footnotetext{
33 Para latitudes mais elevadas as distorções aumentam.

34 Para efeitos práticos o referencial WGS84 coincide com o SIRGAS 2000.
} 


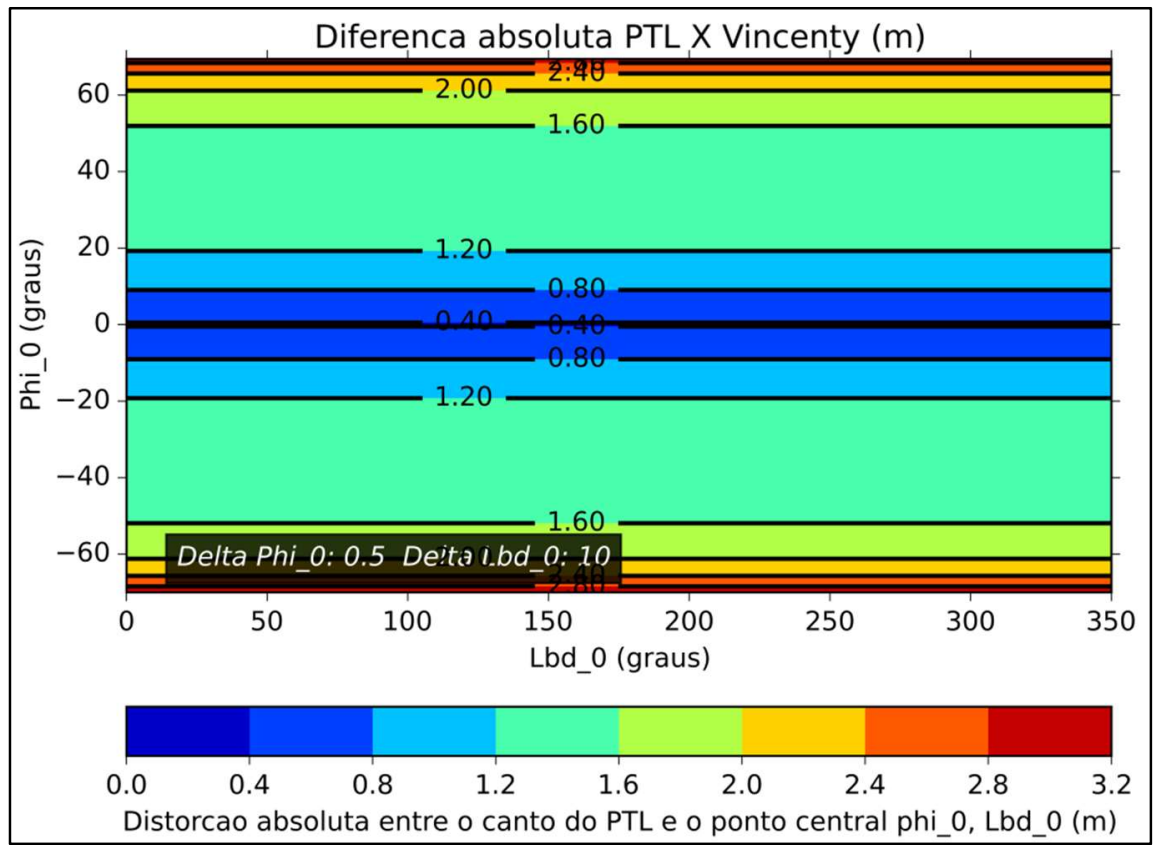

Figura 6-2 Distorção absoluta de distância: Projeção estabelecida pela NBR 14.166 X Vincenty.

FONTE: Elaborado pelo autor.

Para o SCL, a distorção absoluta é estável em 1,46m. O PTL apresenta distorções variáveis em relação à latitude, chegando na casa dos $3 \mathrm{~m}$ para as latitudes mais elevadas que foram analisadas. Em ambas as projeções, percebe-se que a longitude não altera a distorção.

Ainda em uma escala global, foi comparada a distância entre os pontos periféricos das duas projeções, o que permite avaliar indiretamente a máxima distorção angular entre as mesmas nestes pontos extremos. A diferença variou de $1,14 \mathrm{~m}$ a $4,78 \mathrm{~m}$. Para este caso, descrito por catetos de $50.000 \mathrm{~m}$ cada, a diferença de azimute para as hipotenusas é de 13,9" ${ }^{35}$. Estas comparações são apresentadas na Figura 6-3. Os pontos periféricos possuem altura de $0 \mathrm{~m}$ e o ponto central também.

Realizadas as análises em uma escala global, percebe-se que as maiores latitudes são mais críticas (somente para o PTL) e que a longitude não exerce efeito sobre as distorções.

O SCL e o PTL são agora analisados para duas latitudes: $5^{\circ}$ e $70^{\circ}$, com a longitude fixa em $10^{\circ}$. Tal análise compara a distância entre o ponto de origem da projeção $\left(\varphi_{0}, \lambda_{0}, h_{0}\right)$ e um ponto qualquer $(\varphi, \lambda, h)$ com a distância geodésica, obtida por Vincenty (1975). A área considerada tem largura de $100 \mathrm{~km} \times 100 \mathrm{~km}$ e a diferença de altura entre o ponto central e as extremidades é de $0 \mathrm{~m}$.

${ }^{35}$ diferença máxima $=\left(\tan ^{-1}\left(\frac{4,78}{\sqrt{50.000^{2}+50.000^{2}}}\right)\right) \times 3600$ 


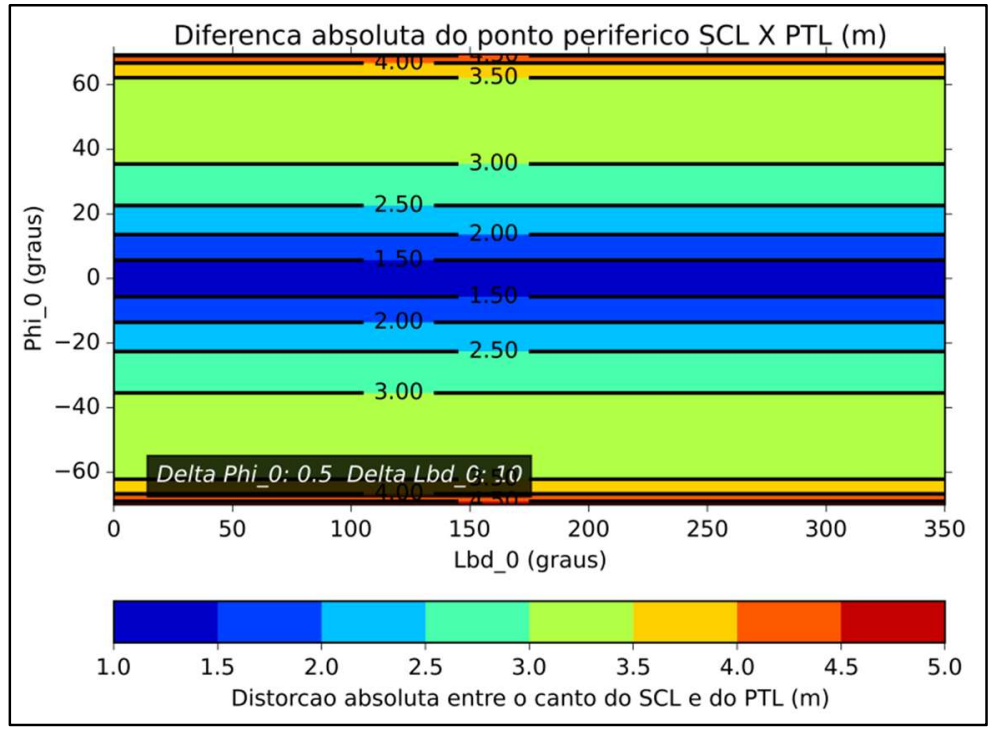

Figura 6-3 Distância entre pontos periféricos: SCL X PTL. FONTE: Elaborado pelo autor.
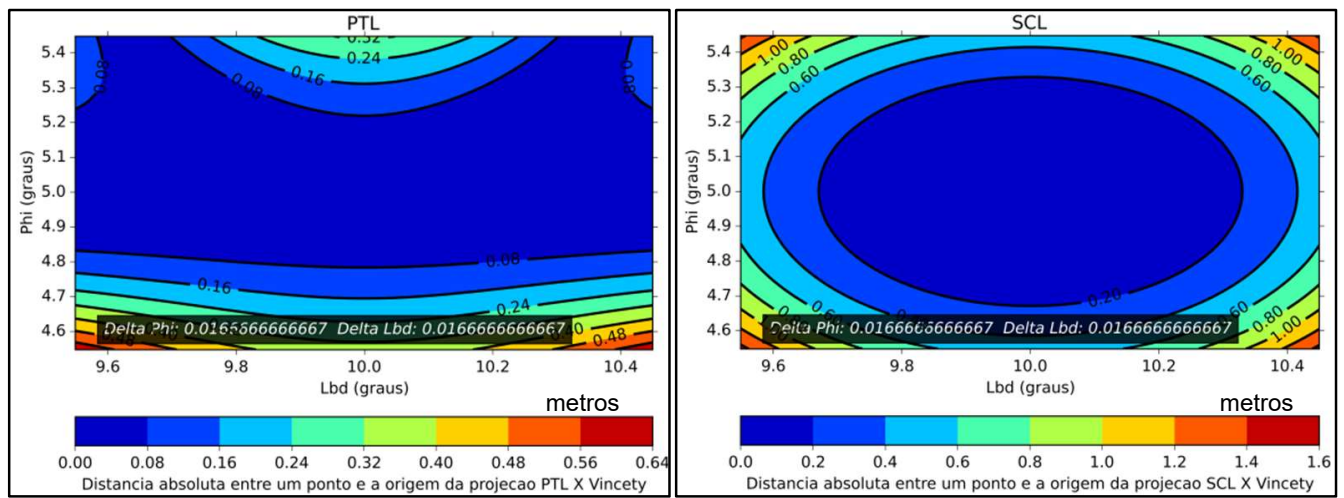

Figura 6-4 Diferença absoluta SCL, PTL e Vincenty em uma área local. Ponto central $5^{\circ} \mathrm{N} 10^{\circ} \mathrm{W}$. FONTE: Elaborado pelo autor.
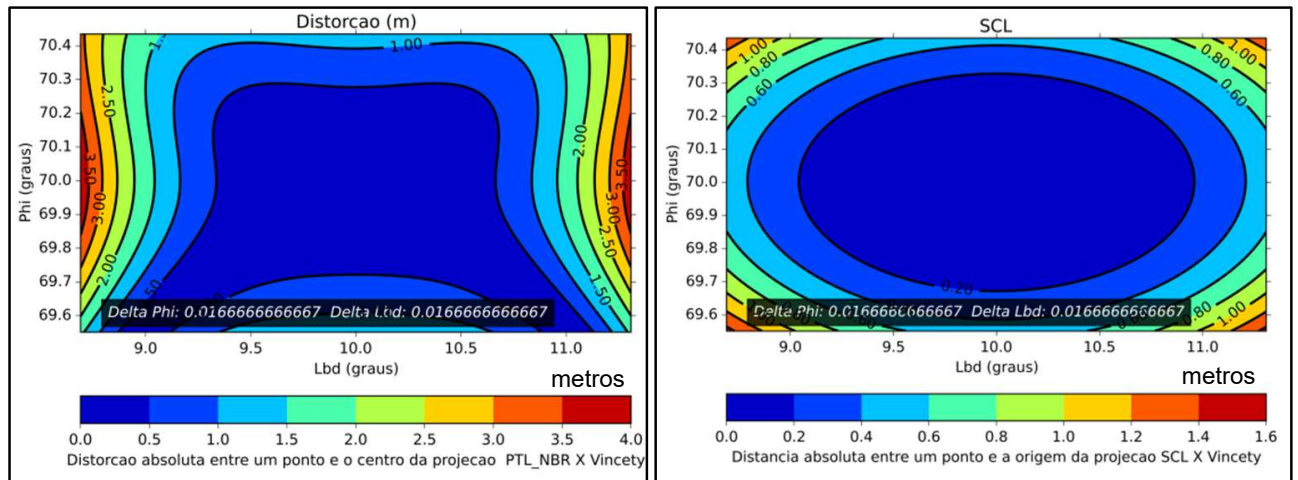

Figura 6-5 Diferença absoluta SCL, PTL e Vincenty em uma área local. Ponto central $70^{\circ} \mathrm{N} 10^{\circ} \mathrm{W}$. FONTE: Elaborado pelo autor.

Pode-se notar que o SCL possui um perfil radial de distorção, enquanto o PTL exibe um padrão mais complexo. A distorção no SCL é praticamente estável em relação à faixa de variação de latitude testada. Enquanto isso, o PTL é bastante dependente deste parâmetro. 
Para fins de comparação, escolheu-se a projeção UTM em uma escala local. A análise é realizada para a zona $32 \mathrm{~N}$, que se estende de $6^{\circ} \mathrm{E}$ a $12^{\circ} \mathrm{E}$ do hemisfério norte, representada pelo código EPSG $32632^{36}$. Foram realizados testes para o ponto central localizado em duas longitudes: $9^{\circ}$, no centro da zona, e $12^{\circ}$, na sua extremidade. A latitude foi avaliada em $5^{\circ} \mathrm{N}$ e em $70^{\circ} \mathrm{N}$. A altura é mantida em zero. A projeção possui uma extensão idêntica àquelas anteriormente analisadas, ou seja, $100 \mathrm{~km}$ em cada eixo. Os resultados são apresentados na Figura 6-6 e na Figura 6-7.
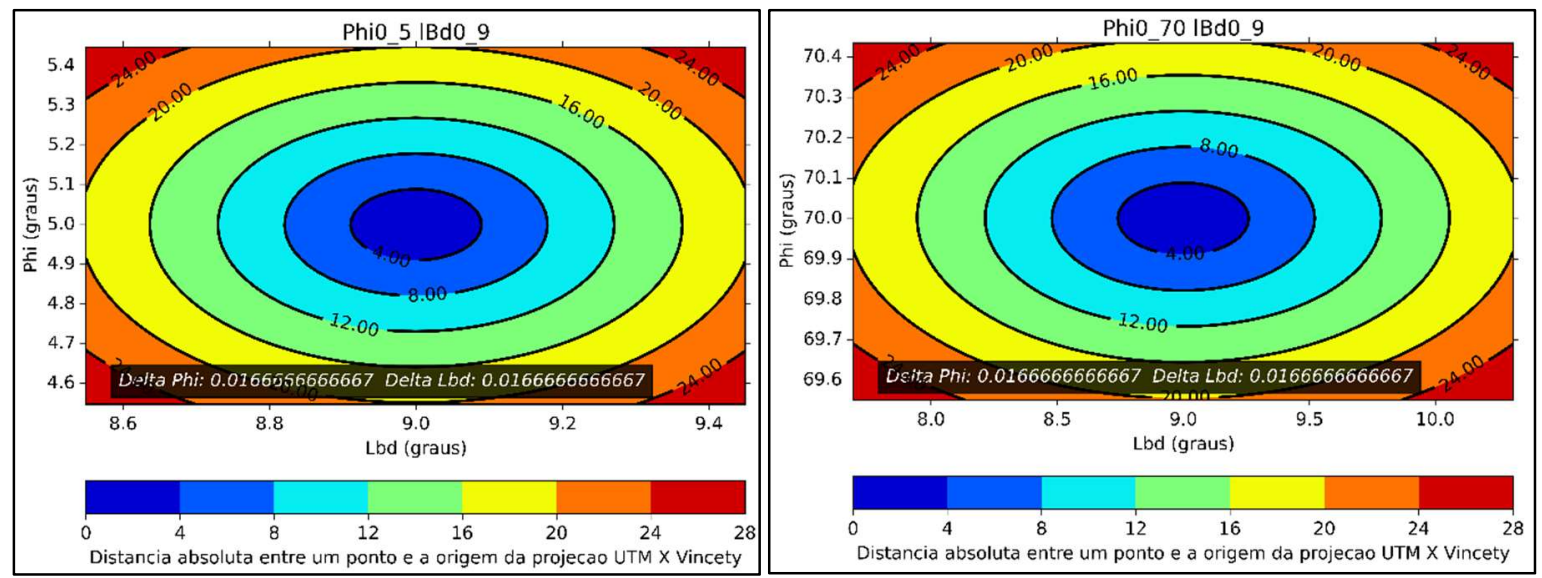

Figura 6-6 Projeção UTM zona 32N X Vincenty. Pontos centrais coincidentes. FONTE: Elaborado pelo autor.
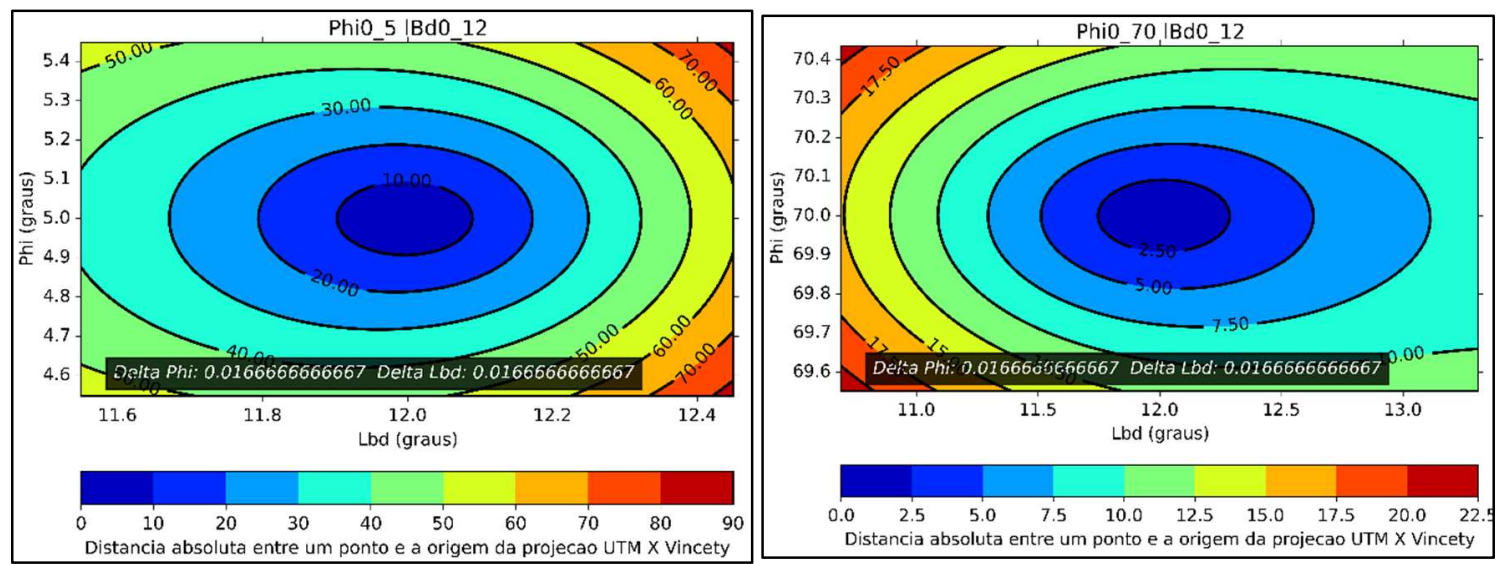

Figura 6-7 Projeção UTM zona 32N X Vincenty. Pontos centrais não coincidentes. FONTE: Elaborado pelo autor.

A Figura 6-6 apresenta o caso em que uma projeção de interesse coincide exatamente com o centro do fuso. Já Figura 6-7 apresenta o caso em que a projeção de interesse se encontra no limite entre duas zonas UTM. A distorção máxima verificada nos casos analisados foi de $83,56 \mathrm{~m}$. Nos demais casos, a distorção ficou na casa dos $20 m$. 
Logo, para os casos analisados, a projeção $S C L$ é a que apresenta as menores distorções, não sendo influenciada pela latitude ou pela longitude. Além disso, como discutido na subseção 4.3.2, esta projeção é consistente numericamente, quando consideradas as transformações direta e inversa.

\subsection{VERIFICAÇÃO DAS GEOMETRIAS GERADAS}

Esta seção analisa a geração de geometrias no modelo implementado. Para tanto, utiliza-se um conjunto de dados aqui referido como InstFICT1, ou seja, uma instância fictícia de teste. Os limites do sítio para esta instância são mostrados na Figura 6-8. O sítio é formado por duas geometrias convexas, uma maior com os dados de topografia (na cor mais clara) e uma segunda como área de exclusão (em vermelho), de maneira a permitir uma delimitação não convexa do sítio.

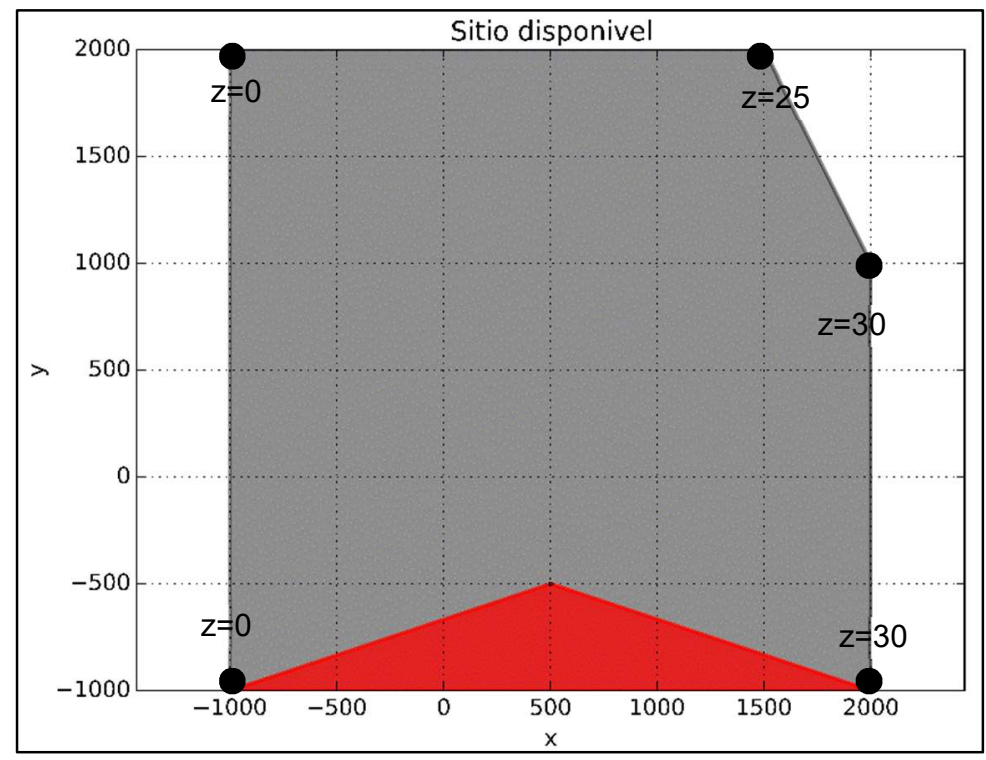

Figura 6-8 Sítio para a instância fictícia 1 -InstFICT1.

FONTE: Elaborado pelo autor.

\subsubsection{GERAÇÃO DA PISTA DE POUSO}

A pista fictícia é construída a partir de suas duas extremidades: $(0,0)$ e $(0,1500)$ com o parâmetro incremento inc $=10 \mathrm{~m}$ para um ARC 4-F. Caso a pista se encontre totalmente nos limites do sítio e ainda sem passar por nenhuma área de exclusão, ela é construída e considerada válida no modelo (caso A). Quando o início da pista é deslocado para a área de exclusão (caso B), a mesma é construída para fins de visualização, mas despreza-se o MDE e retorna uma mensagem caraterística via console. O mesmo ocorre quando um de seus pontos intermediários se sobrepõe a 
uma área de exclusão (caso C). A Figura 6-9 ilustra estes casos, mostrando as saídas do modelo, via janela gráfica ${ }^{37}$ e via console.

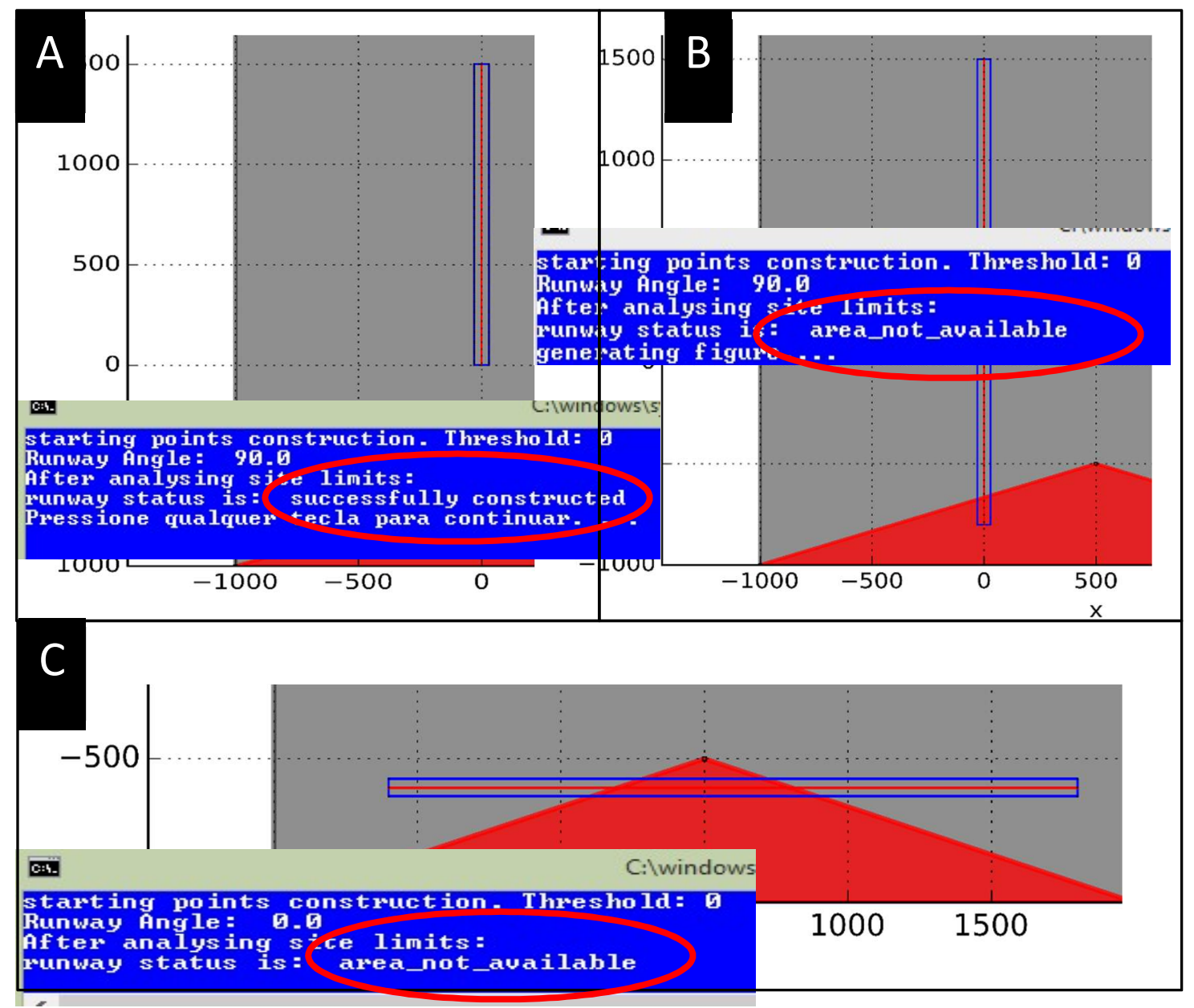

Figura 6-9 Construção da pista para diferentes disponibilidades do sítio. FONTE: Elaborado pelo autor.

\subsubsection{GERAÇÃO DA FAIXA DA RWY E DA FAIXA INTERNA DA RWY}

A Figura 6-10 apresenta a geometria gerada para faixa de pista de pouso e decolagem e para a área interna da faixa da RWY. Caso a cabeceira fosse deslocada em $200 \mathrm{~m}$ e a pista fosse provida com uma zona de parada de $100 \mathrm{~m}$, seria criada a geometria mostrada na Figura 6-11. Em ambos os casos, a geometria gerada representa as adequadamente as normas da ICAO.

37 Gerada na biblioteca matplotlib. 


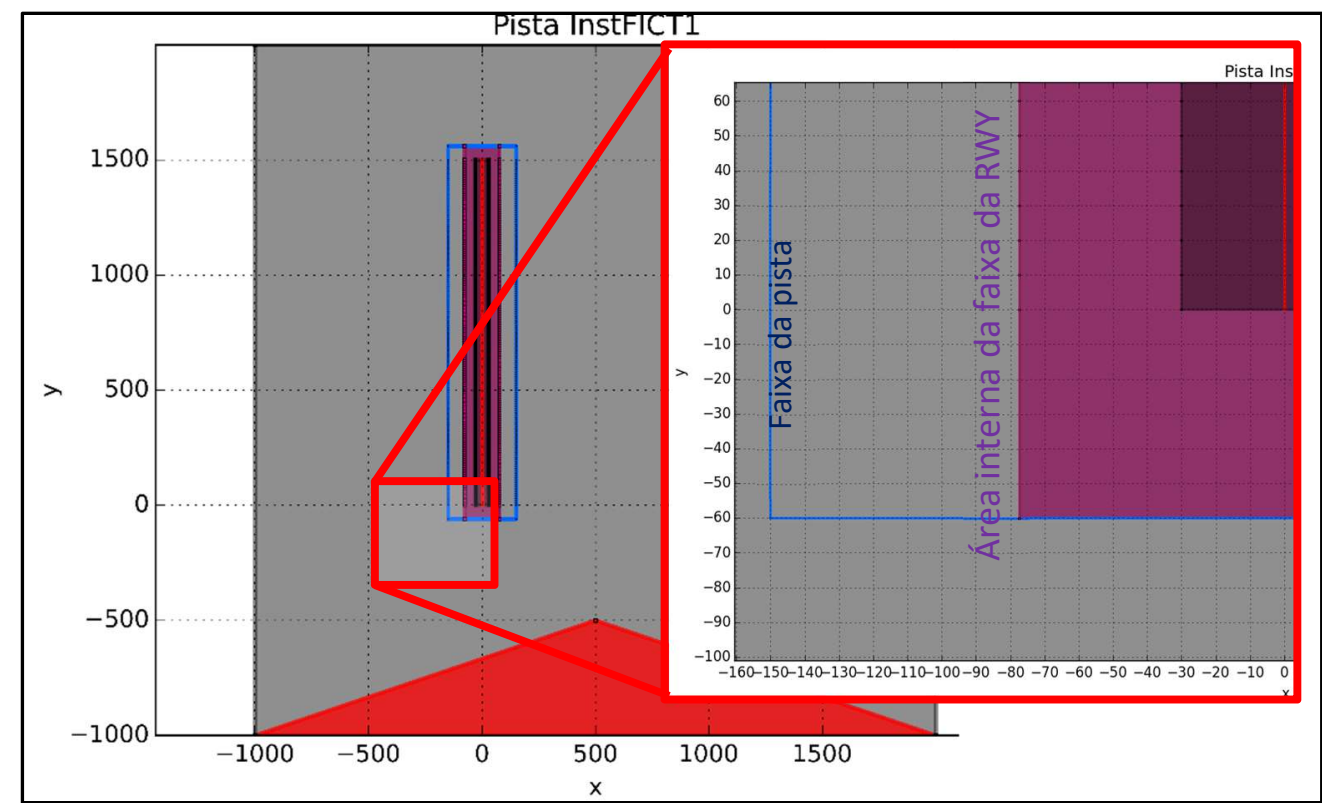

Figura 6-10 Faixa de pista de pouso e decolagem e área interna da faixa da RWY FONTE: Elaborado pelo autor.

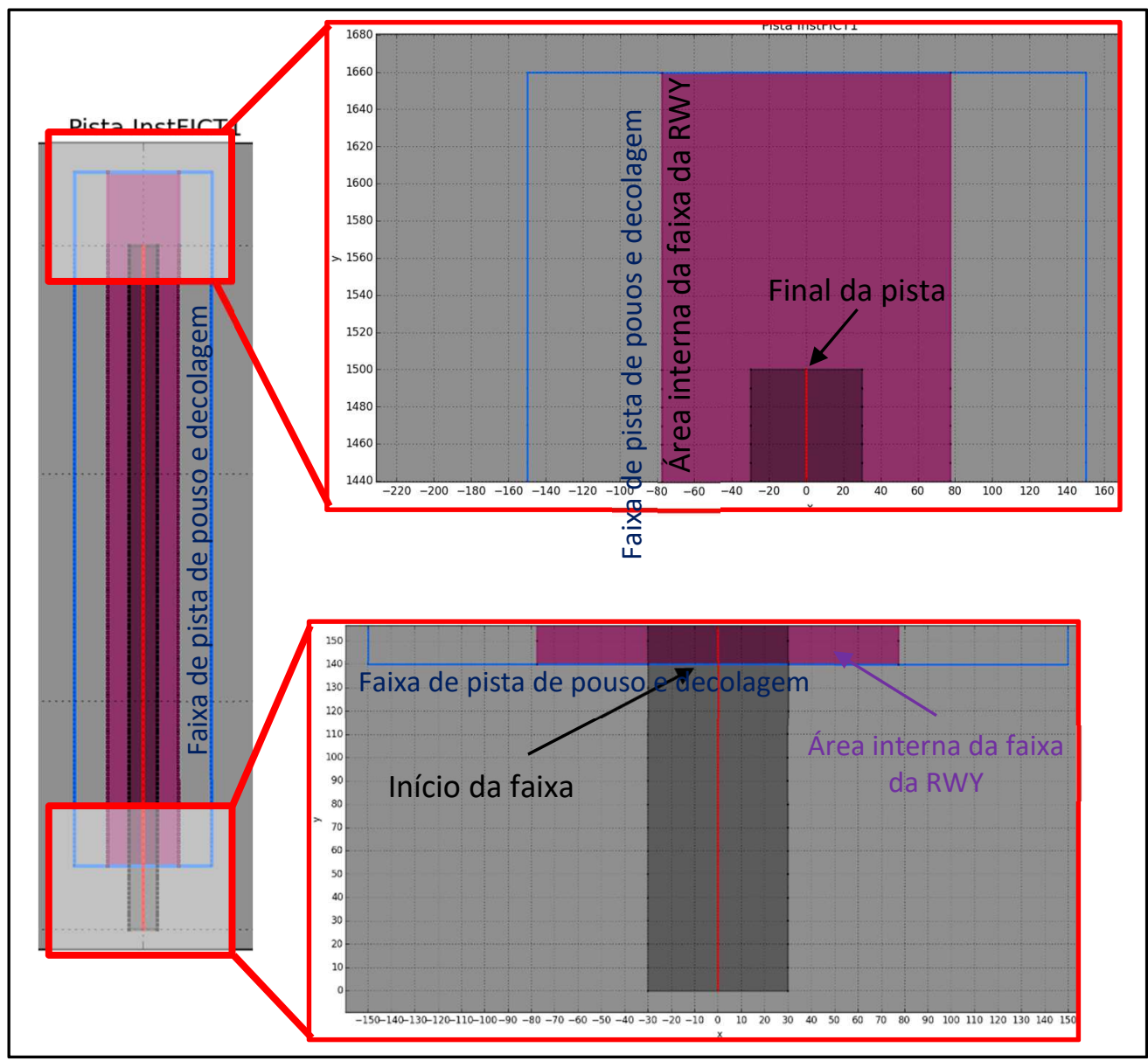

Figura 6-11 Distâncias declaradas na geração da faixa de pista de pouso e decolagem. FONTE: Elaborado pelo autor. 


\subsubsection{SUPERFÍCIES DE APROXIMAÇÃO INTERNA E DE POUSO INTERROMPIDO}

Para verificar a superfície de aproximação interna e a superfície de pouso interrompido, foi criada instância INSTFICT2. Esta assume o mesmo sítio da InstFICT1, porém suas extremidades são descritas por $(-900,0)$ e $(1500,0)$ com o parâmetro incremento inc $=10 \mathrm{~m}$ e um ARC 4-F. Ainda, a cabeceira está deslocada em $200 \mathrm{~m}$ e a zona desimpedida possui $100 \mathrm{~m}$. Dessa forma, como mostra a Figura $6-12$, a superfície de aproximação interna inicia-se na posição $x=-760 m^{38}$, coincidindo com o início da faixa de pista de pouso e decolagem. A partir deste ponto, a faixa de pista de pouso e decolagem e a RWY seguem o perfil do terreno (ver Figura 6-8). A superfície de pouso interrompido inicia-se na elevação da pista e sobe até $45 \mathrm{~m}$ em relação ao referencial de altura fornecido, que vale zero. Longitudinalmente, a superfície de pouso interrompido inicia-se em $x=1.100 \mathrm{~m}{ }^{39}$. Nota-se ainda que a faixa de pista de pouso e decolagem segue a elevação do último ponto da própria RWY.

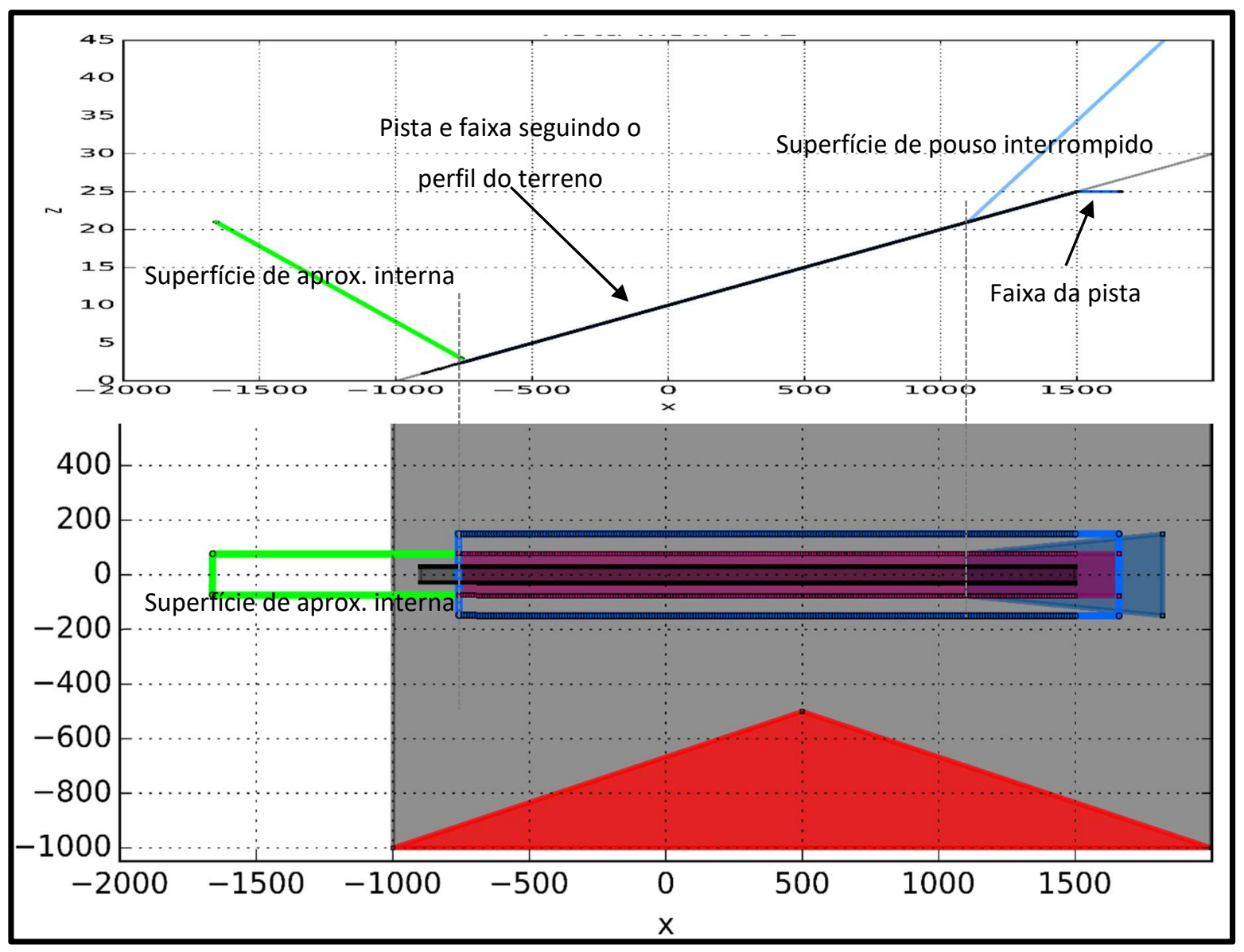

Figura 6-12 Superfícies de pouso interrompido e de aproximação interna para InstFICT2 FONTE: Elaborado pelo autor. 


\subsubsection{SUPERFÍCIE DE TRANSIÇÃO INTERNA}

Para verificar a superfície de transição interna graficamente com mais conveniência, a instância anterior é transformada em InstFICT3, alterando-se apenas o incremento inc para $100 \mathrm{~m}$.

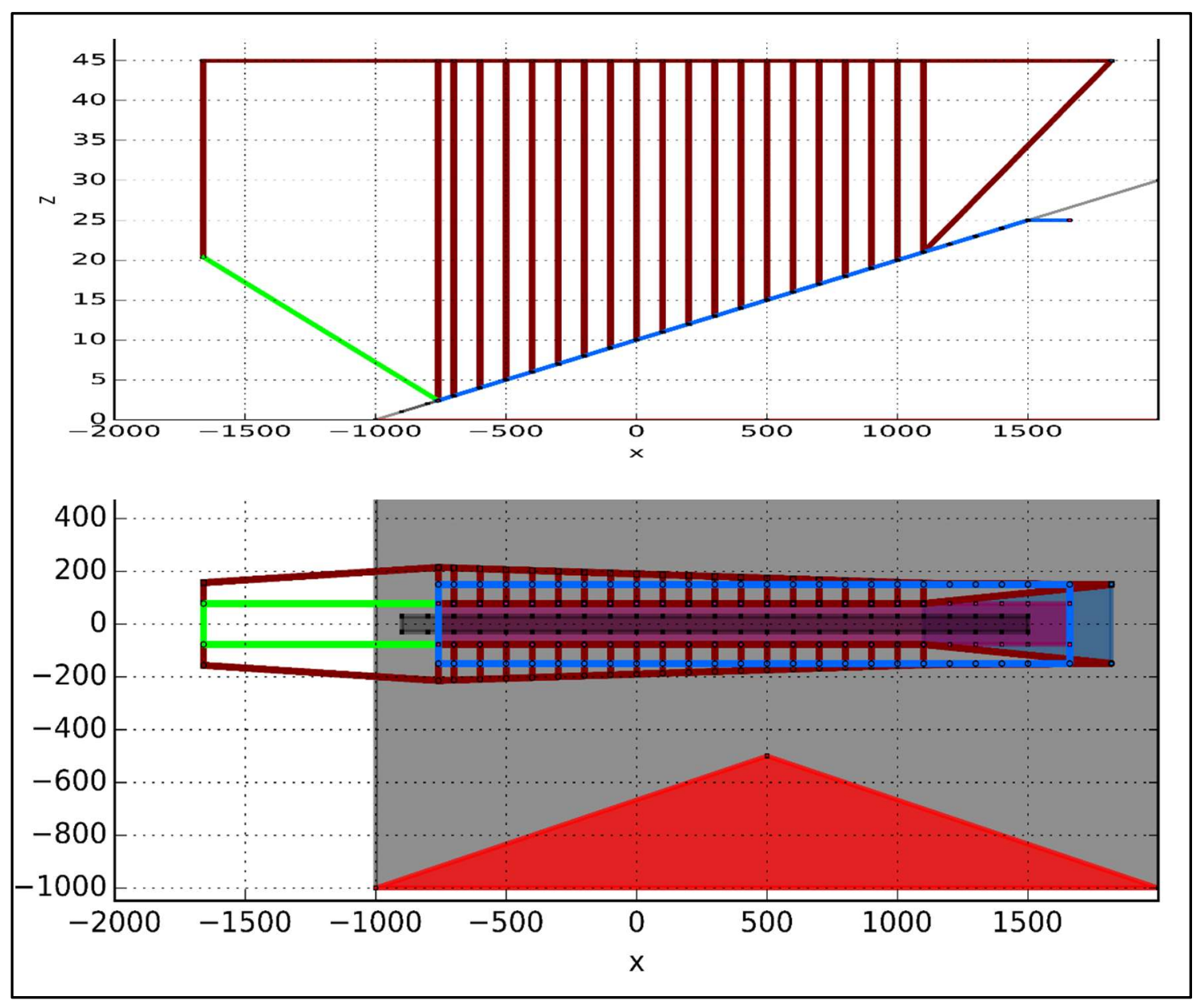

Figura 6-13 Conjunto de superfícies para InstFICT3

FONTE: Elaborado pelo autor.

É possível perceber que a superfície de transição interna se comporta exatamente como o estabelecido pela ICAO. Ela sobe desde a superfície de aproximação até uma altura de $45 \mathrm{~m}$ em relação a um ponto de referência vertical, que vale $0 \mathrm{~m}$. Já na extremidade oposta à cabeceira, é a própria superfície de pouso interrompido que sobe até a elevação de $45 \mathrm{~m}$.

O APÊNDICE 1 apresenta figuras contendo todas as superfícies verificadas até aqui, incluindo ainda a RESA. Tais gráficos baseiam-se na instância InstFICT3.

As demais superfícies são verificadas na instância real que segue. 


\subsection{APLICAÇÃO AO AEROPORTO DE CAMPINAS (SBKP)}

Esta seção tem por objetivo apresentar uma aplicação do modelo a um caso real. Cabe salientar que esta aplicação tem por único objetivo verificar a funcionalidade do modelo, de modo que várias simplificações foram realizadas em relação aos dados de entrada.

O referido teste é realizado com dados do Aeroporto Internacional de Viracopos (SBKP), em Campinas-SP.

Este aeroporto possui uma única pista de pouso e decolagem, com $45 \mathrm{~m}$ de largura e 3.240m de comprimento. A Figura 6-14 apresenta as distâncias declaradas para as duas cabeceiras da única pista do aeroporto. O ANEXO 1 apresenta maiores detalhes sobre o aeródromo.

\begin{tabular}{|c|c|c|c|c|}
\hline RWY & TORA(m) & TODA(m) & ASDA(m) & LDA(m) \\
\hline 15 & 3150 & 3390 & 3150 & 3150 \\
33 & 3240 & 3390 & 3240 & 3150 \\
\hline
\end{tabular}

Figura 6-14 Distâncias declaradas para o Aeroporto de Campinas (SBKP) FONTE: (BRASIL, 2014)

Como as áreas e superfícies de proteção precisam ser construídas para cada sentido de operação, escolhe-se o sentido 33 para as verificações. Este possui a cabeceira deslocada em 90m. Além disso, a partir da tabela, deduz-se que o sentido 33 conta com uma zona desimpedida de $150 \mathrm{~m}$.

\subsubsection{DADOS DO SÍTIO}

Como discutido anteriormente, fez-se uma série de simplificações em relação aos dados do sítio $^{40}$, para que o esforço de aquisição de dados seja mínimo e, mesmo assim, o modelo ainda possa ser adequadamente testado.

Utilizando-se o software QGIS ${ }^{41}$, foi obtido o recorte aproximado do sítio a partir de um arquivo shapefile. O recorte foi baseado em uma delimitação arbitrária, executando-se o recorte sobre uma imagem de satélite do OpenLayers Plugin, conforme a Figura 6-15.

\footnotetext{
40 Para aeroportos em fase de planejamento, este modelo permite a utilização de dados de altura que cubram uma grande área do sítio. Em aeroportos existentes, dados sobre o perfil da pista podem ser obtidos de forma muito mais precisa, o que obriga que estese sobrescrevam o modelo obtido pelo MDE.

41 Versão 2.8 .2
} 
Os dados de entrada que descrevem o sítio são parcialmente apresentados no APÊNDICE 3, através de um arquivo XML. A instância de teste do Aeroporto de Campinas é aqui referida como INST_SBKP e consta no APÊNDICE 3.

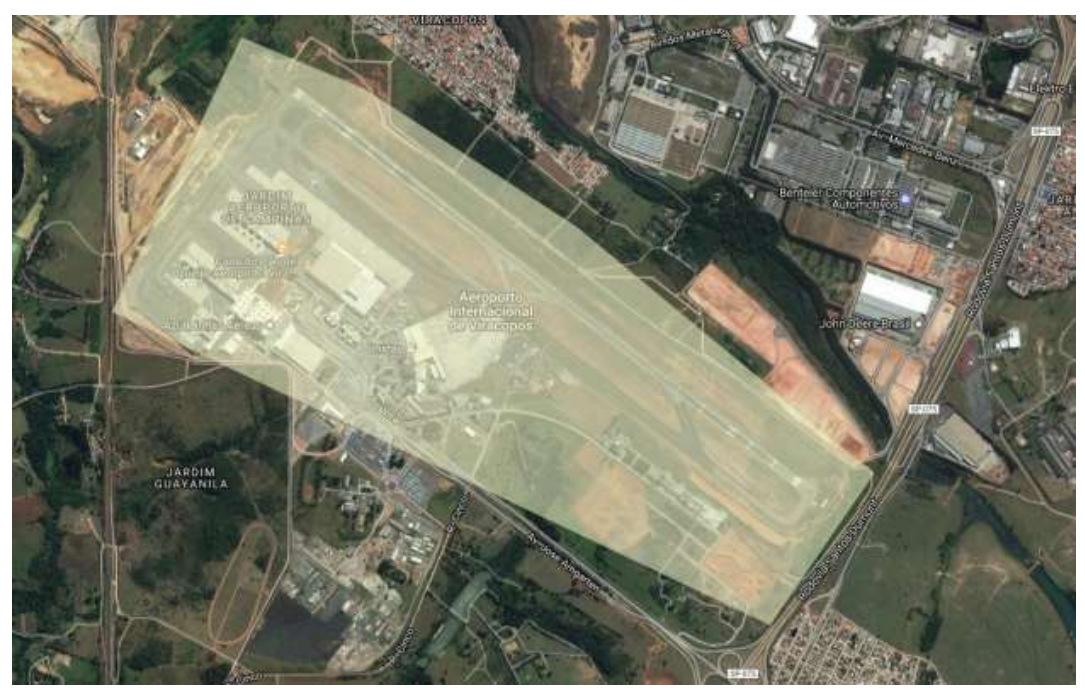

Figura 6-15 Recorte arbitrário para o sítio do Aeroporto de Campinas (SBKP) FONTE: Elaborado pelo autor no software QGIS com imagem Google Maps.

O próximo passo foi encontrar uma fonte para os dados de elevação do sítio. Como a verificação prioriza os desafios computacionais e não a precisão dos dados de entrada, foram utilizados dados do SRTM (Shuttle Radar Topography Mission), fornecido pelo aplicativo web Earth Explorer (USGS, 2017). A resolução do mesmo é de 1 arco de segundo (aproximadamente $30 \mathrm{~m}$ ). Os dados do SRTM encontram-se no formato raster GeoTiff, tendo o WGS84 como referencial horizontal e o EGM96 como referencial vertical. Devido à posição da pista, foi necessário unir duas imagens (tiles) para compor uma imagem que cobre a totalidade do sítio. Esta imagem foi então recortada no software QGIS, utilizando o recorte da Figura 6-15 como máscara.

Para gerar um arquivo CSV que pudesse ser lido pelo modelo, foram seguidos estes passos no QGIS: a) poligonização; b) extração de nós; e c) exportação para o formato CSV. A Figura 6-16 ilustra as imagens relacionadas aos passos A e B. Este processo gerou 16.028 nós.

Como os dados se apresentam no referencial vertical EGM96, seria necessário ainda fazer a devida correção, de forma que a elevação dos pontos fosse dada através do WGS84. Na falta de uma biblioteca que pudesse fazer a conversão automaticamente, aplicou-se um valor fixo de $N=-4,5 m^{42}$ para corrigir a altura dos pontos.

42 Esta é apenas uma forma aproximada de corrigir o referencial vertical. Modelos mais sofisticados devem ser empregados para fins que não sejam a mera demonstração. Este fator de correção está de acordo com o programa EGM96 geoid program for Windows 95/NT, disponível no site http://earthinfo.nga.mil/GandG/wgs84/gravitymod/egm96/egm96.html. Através do programa foram calculadas as alturas geoidais de alguns pontos aleatórios selecionados no perímetro do sítio. 

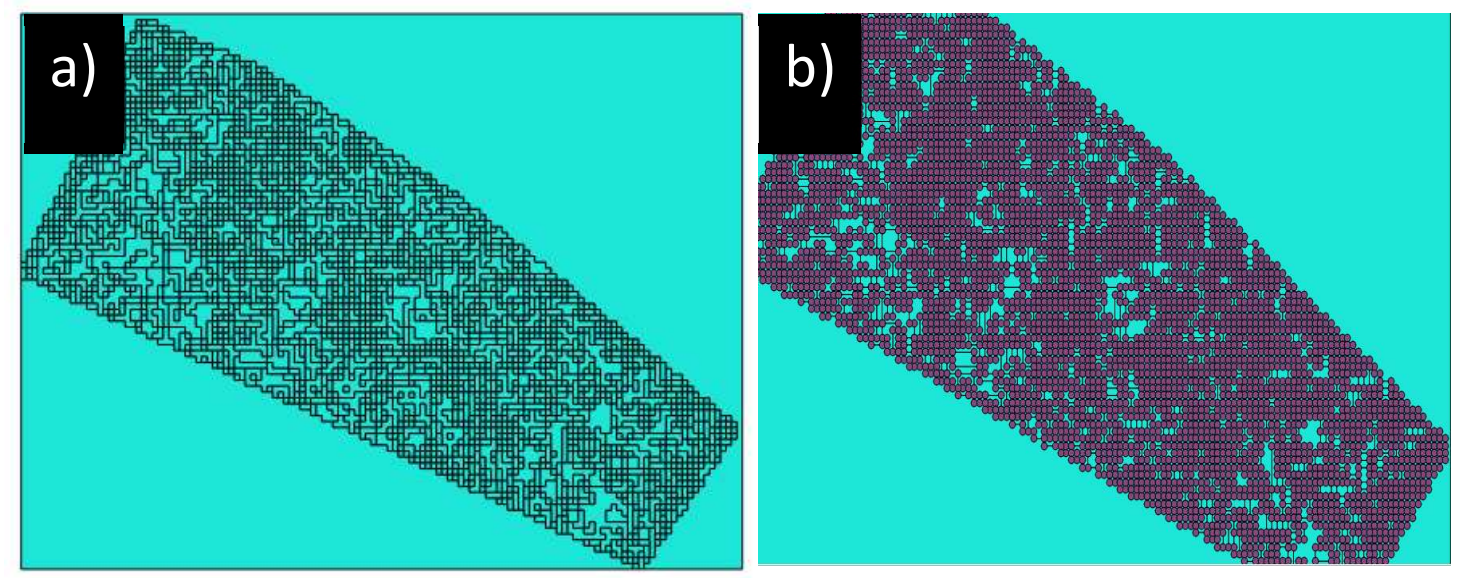

Figura 6-16 Tratamento dos dados raster do sítio do Aeroporto de Campinas (SBKP) FONTE: Elaborado pelo autor no software QGIS.

O referido arquivo CSV foi então importado pelo modelo. Um último ajuste nos dados foi realizado para remover outliers situados fora de uma faixa de elevação situada entre os $500 \mathrm{~m}$ e os $700 \mathrm{~m}$. Dos 16.027 pontos, 321 foram removidos.

Também foi gerada uma área de exclusão interna simulando uma área fictícia para terminais, estacionamentos, etc. O polígono que descreve esta área foi gerado da mesma maneira do que aquele que descreve o sítio. Porém ele é identificado no modelo como uma área de exclusão (ver APÊNDICE 3). A Figura 6-17 apresenta estes dois polígonos já tratados e carregados no modelo e representados no SCL.

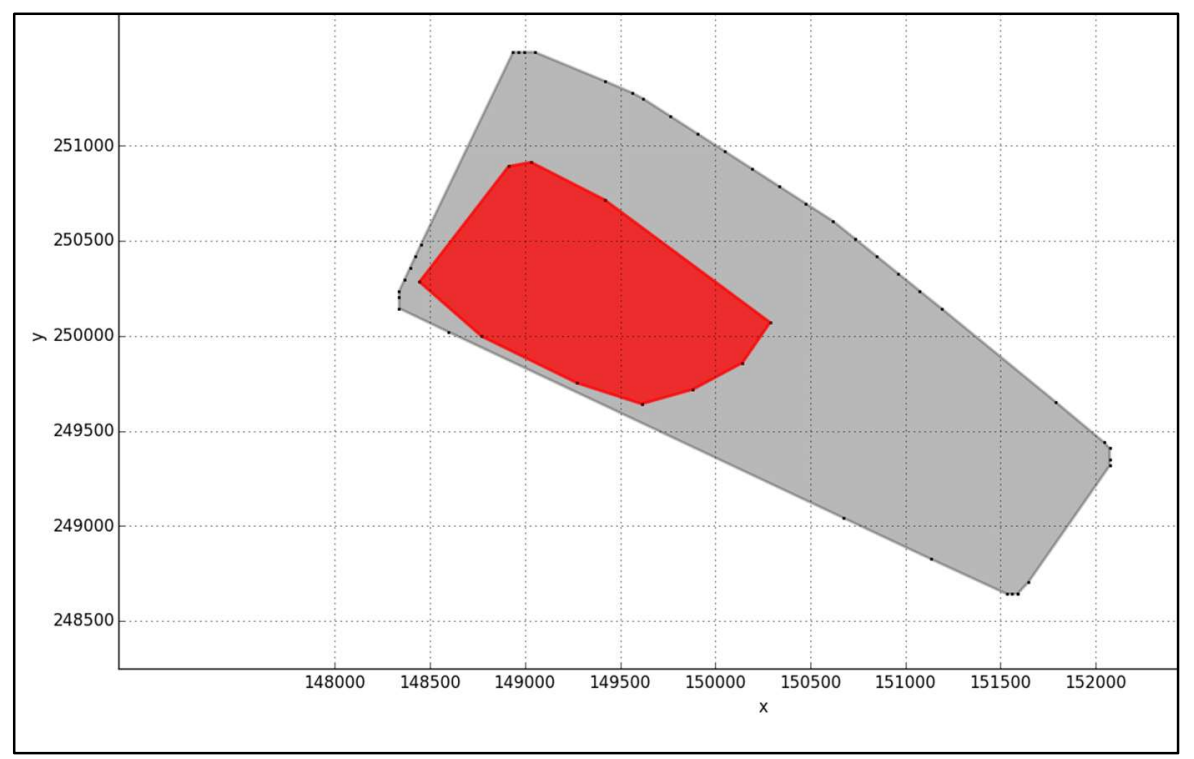

Figura 6-17 Dados do sítio (SBKP) carregados no modelo FONTE: Elaborado pelo autor 


\subsubsection{GERAÇÃO DE GEOMETRIAS}

Para facilitar a referência às áreas e superfícies de proteção, elas são aqui divididas em dois grupos: geometrias internas e geometrias externas.

Geometrias internas: pista de pouso e/ou de decolagem (RWY); faixa de pista de pouso e decolagem; área interna da faixa da RWY; RESA; superfície de aproximação interna; superfície de transição interna; e superfície de pouso interrompido.

Geometrias externas: superfície de aproximação; superfície de decolagem; superfície de transição; superfície horizontal interna; e superfície cônica.

Juntas, as geometrias internas e externas formam o conjunto de áreas e superfícies de proteção estabelecidas pelo Anexo 14 da ICAO (ICAO, 2004).

Para a verificação da modelagem, utilizam-se os dados que constam no APÊNDICE 3, que descrevem a instância INST_SBKP. Algumas figuras geradas também podem ser encontradas no mesmo apêndice.

A Figura 6-18 apresenta as geometrias internas geradas pelo modelo, através de visualização no Google Earth. Já a Figura 6-19 apresenta o mesmo conjunto de superfícies vistas na tela gráfica, que é gerada através da biblioteca matplotlib.

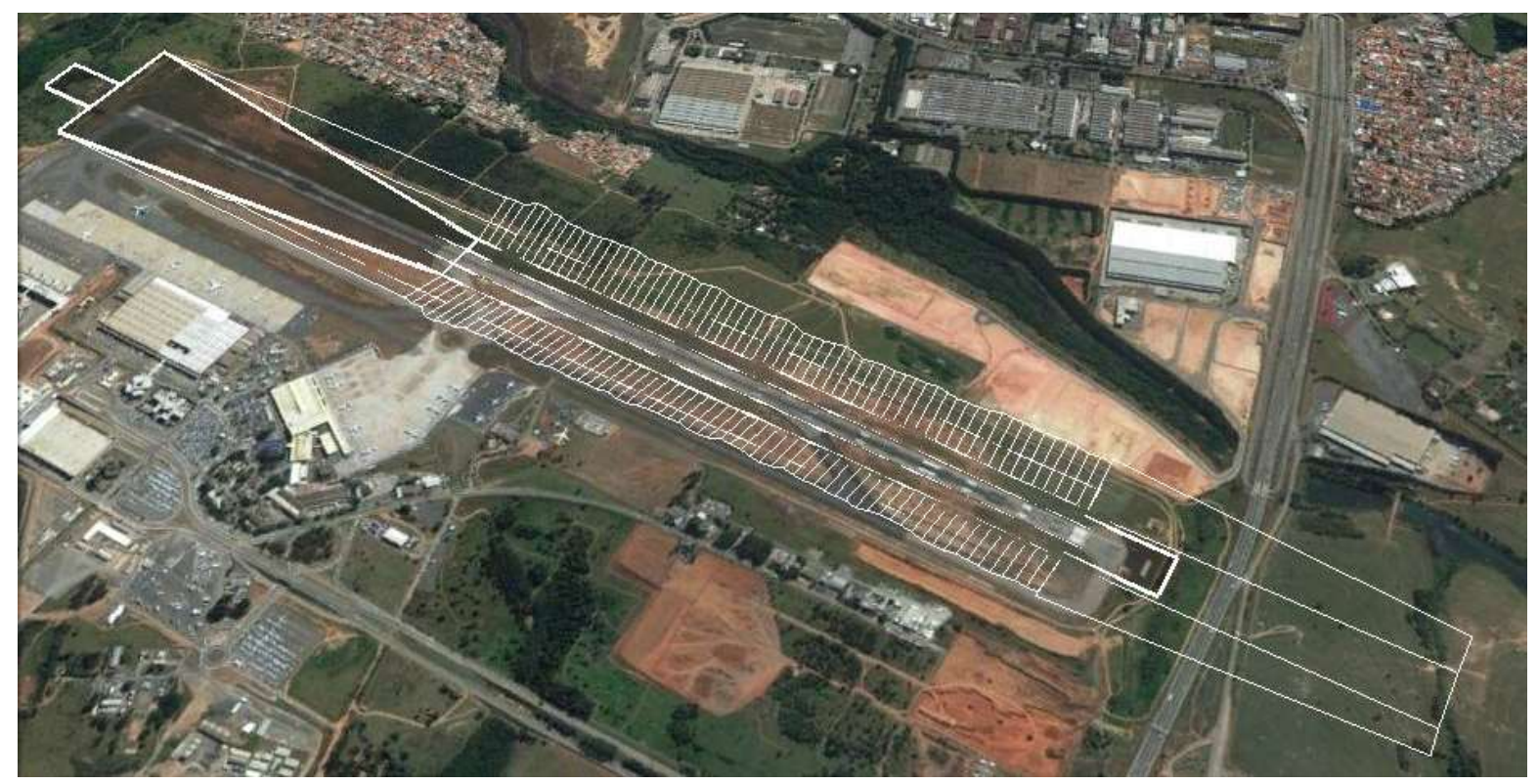

Figura 6-18 Geometrias internas para a instância INST_SBKP vistas no Google Earth FONTE: Elaborado pelo autor com imagens do Google Earth

Na imagem da Figura 6-18 pode-se perceber a diferença do modelo de altura do Google Earth em relação aos dados utilizados, uma vez que algumas arestas das geometrias de menor elevação encontram-se abaixo da linha da superfície. Verificase também o contorno superior irregular da superfície de transição interna, 
apresentando, portanto, o padrão esperado. O mesmo pode ser verificado na imagem da Figura 6-19, que também apresenta as geometrias internas. Além disso, tal imagem mostra que as rotações e translações aplicadas sobre as geometrias geradas comportam-se como o esperado, sem introduzir aparentes distorções. Para cada ponto da RWY, gerado sob um incremento longitudinal de $30 \mathrm{~m}$, existe um ponto gerado na faixa de pista de pouso e decolagem, na área interna da faixa da RWY e na superfície de transição interna.

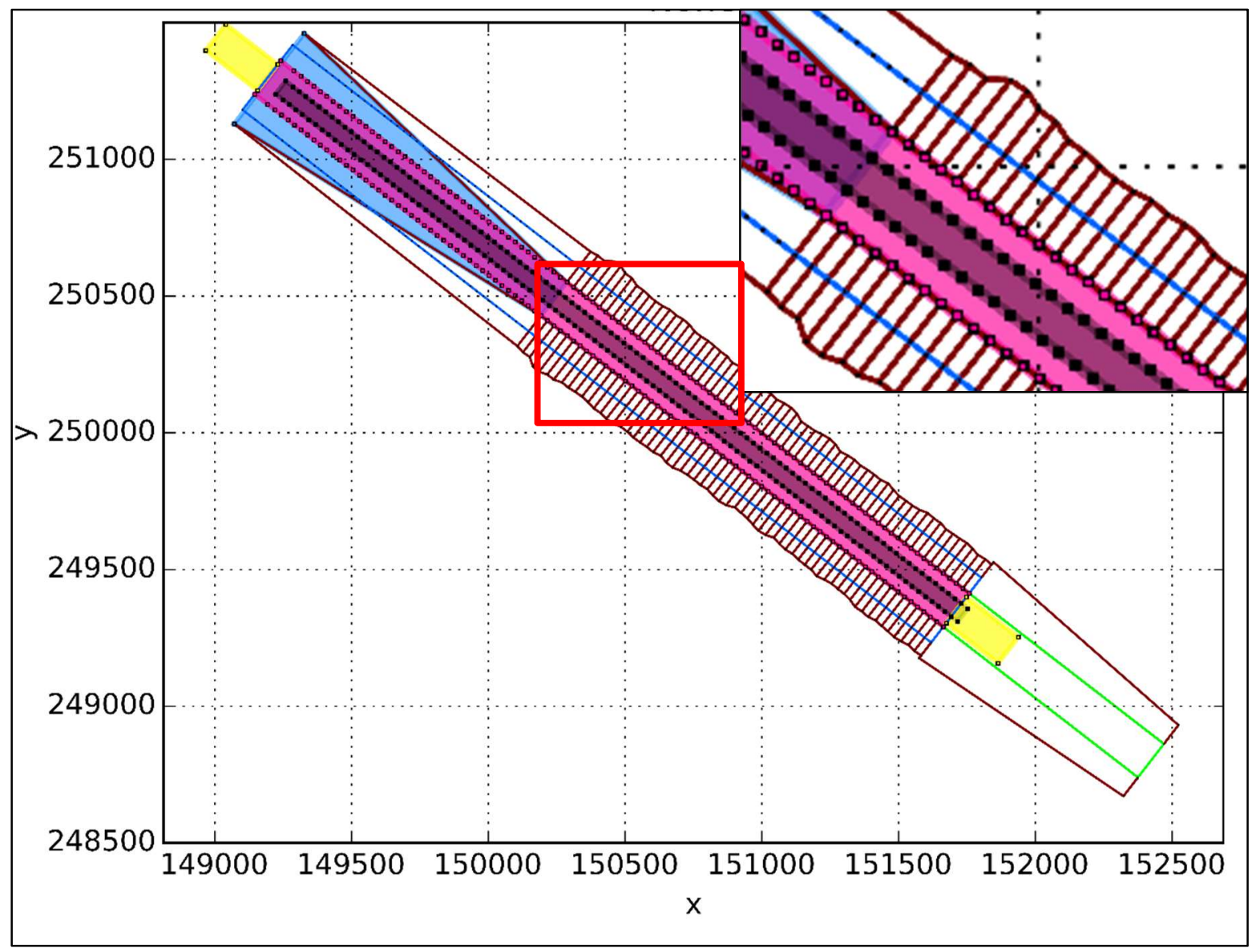

Figura 6-19 Geometrias internas para a instância INST_SBKP

FONTE: Elaborado pelo autor.

Foram geradas também para a instância INST_SBKP as geometrias externas. A Figura 6-20 permite uma visualização das mesmas no Google Earth. E a Figura 6-21 apresenta uma visualização em tela das mesmas superfícies. Para esta última, vê-se que a superfície horizontal interna apresenta retângulos de tamanho variável: no prolongamento do eixo da pista, esta superfície é formada por círculos e na lateral, por arcos tangentes aos círculos. Esta visualização foi gerada com base em um modelo de malha que liga pontos adjacentes de uma mesma geometria. 


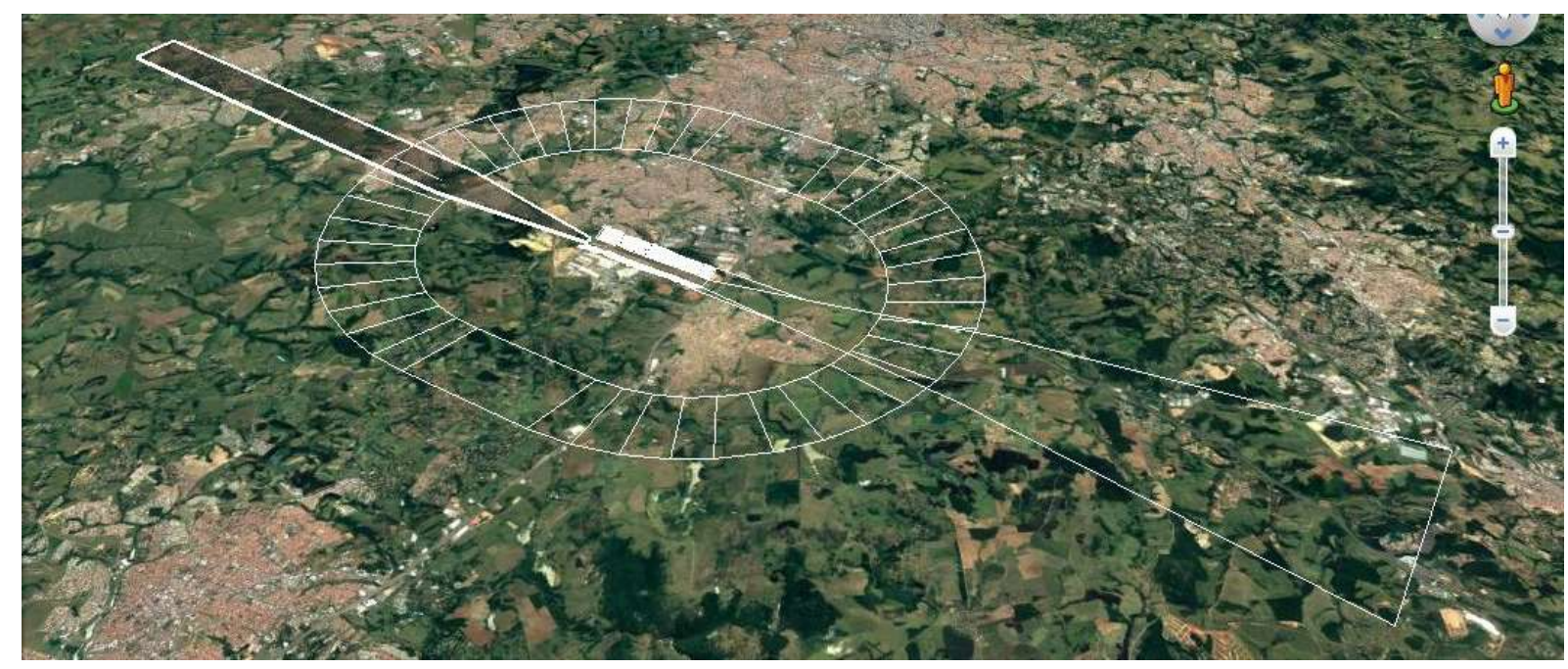

Figura 6-20 Geometrias externas para a instância INST_SBKP vistas no Google Earth FONTE: Elaborado pelo autor com imagens do Google Earth

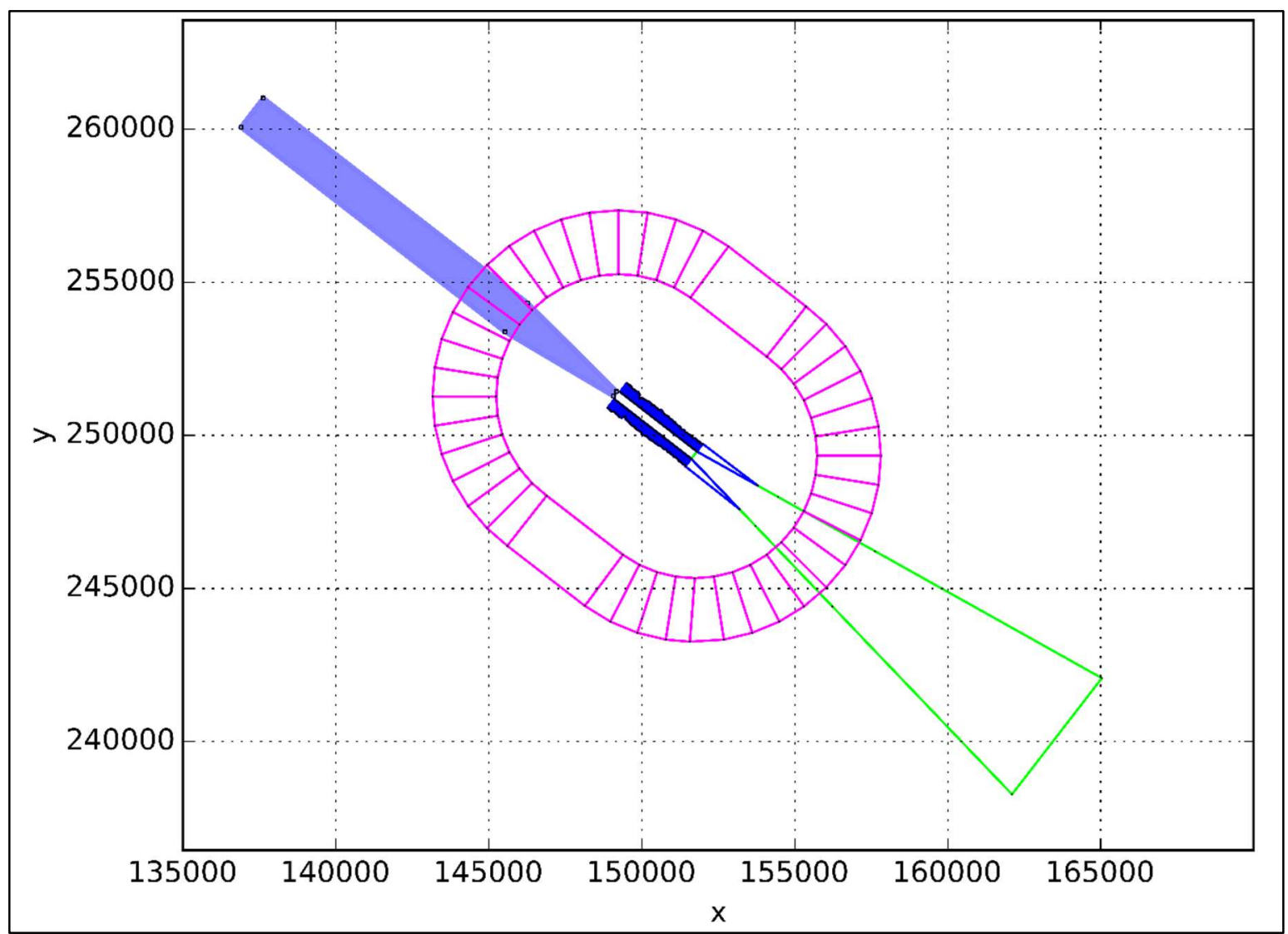

Figura 6-21 Geometrias externas para a instância INST_SBKP FONTE: Elaborado pelo autor.

\subsubsection{OBJETOS MÓVEIS - DADOS HIPOTÉTICOS}

Aeronaves são exemplos de objetos móveis complexos. Analisa-se aqui a geração de aeronaves e seu posicionamento no sítio, conforme os dados apresentados na Figura 6-22. 


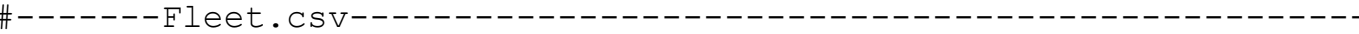

\#ID, model, collor, angx, angy, angz, dx, dy epsg4326

$1, \mathrm{~B} 747$ 8F, 0,1,0,0,0,60.,-23.01697,-47.122623

2,B747_8F, 0,1,0,0,0,60.,-23.01597,-47.152623

$3, \mathrm{~B} 747 \_8 \mathrm{~F}, 0,1,0,0,0,140.0,-23.01335,-47.128138$

\#, END

Figura 6-22 Arquico CSV que define tipo e posição das aeronaves no sítio.

FONTE: Elaborado pelo autor.

A Figura 6-23 apresenta um zoom para as duas aeronaves que foram posicionadas na proximidade da pista de pouso e decolagem.

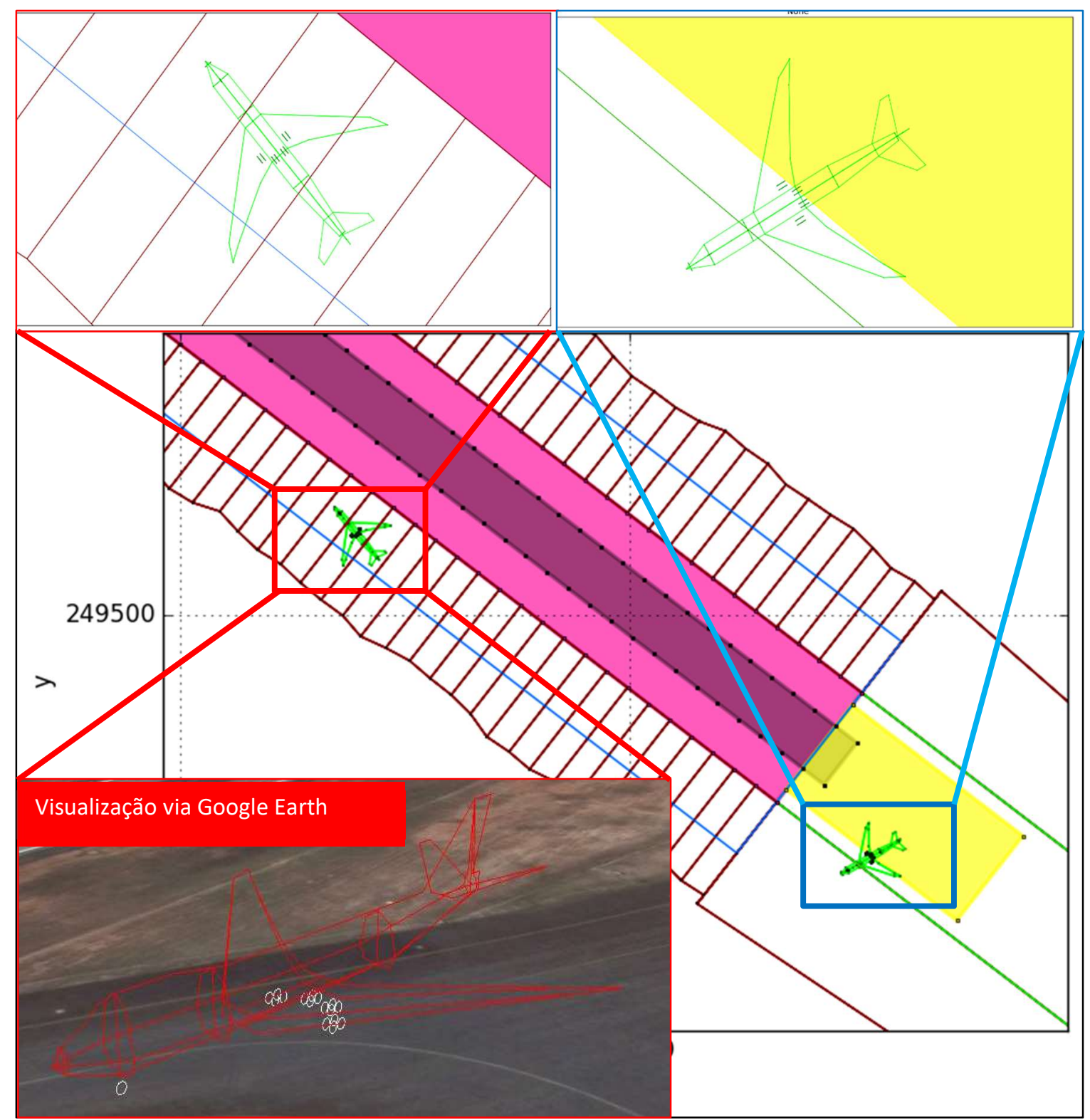

Figura 6-23 Aeronaves posicionadas na proximidade da RWY.

FONTE: Elaborado pelo autor. 
As imagens da Figura 6-23 foram geradas em tela e também no Google Earth. Testes demonstraram que é possível posicionar a aeronave tridimensionalmente inserindo-se apenas informações relativas ao plano $\mathrm{XY}$, pois a coordenada $\mathrm{z}$ da base do trem de pouso é lida no MDE.

\subsubsection{OBJETOS FIXOS - DADOS HIPOTÉTICOS}

Objetos fixos são tratados no modelo como pontos. A Figura 6-24 apresenta os dados dos obstáculos inseridos na instância para testes.

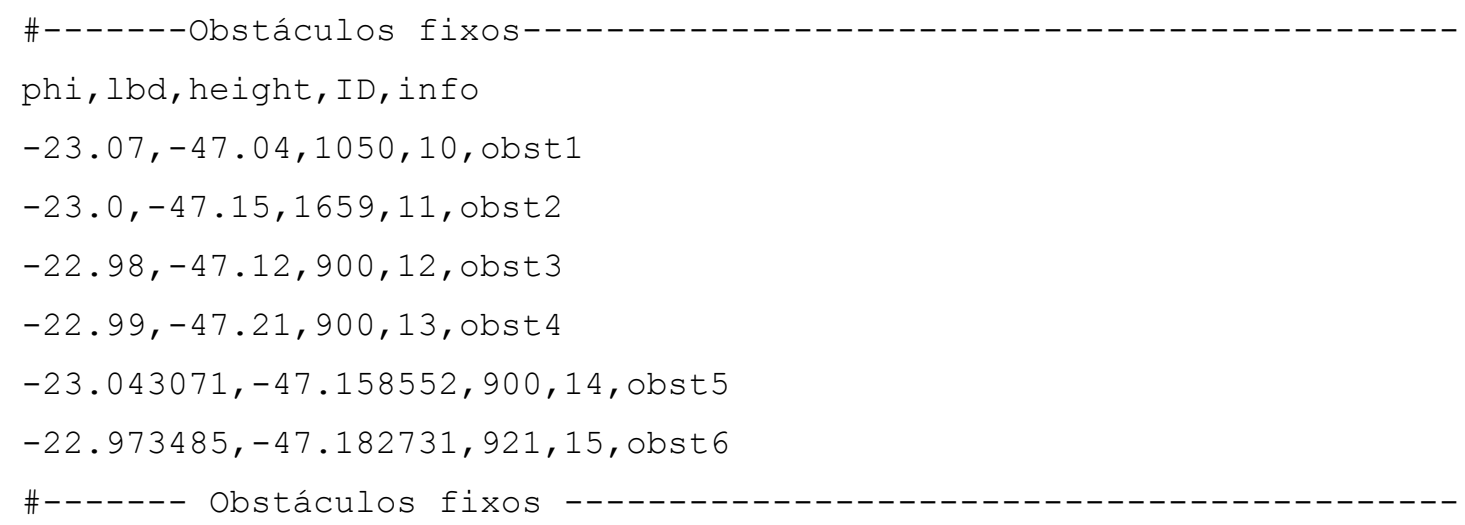

Figura 6-24 Arquico CSV que define os objetos fixos a serem testados FONTE: Elaborado pelo autor.

A Figura 6-25 apresenta o conjunto formado pelas seguintes geometrias: geometrias internas, geometrias externas, contorno do sítio, contorno da área de exclusão, objetos móveis e objetos fixos. Os objetos fixos aparecem na forma de 5 pontos verdes.

\subsubsection{ANÁLISE DE INTERFERÊNCIAS}

Para avaliação da capacidade de detecção de conflitos, os objetos móveis são aqui comparados com as geometrias internas e o os objetos fixos são comparados com as geometrias externas. A Figura 6-25 permite ver a situação geral da instância antes na análise de conflitos. Após a aplicação do algoritmo de detecção de interferência, verifica-se o padrão apresentado na Figura 6-26. Nesta, os objetos fixos e móveis que apresentam a cor vermelha apresentam interferência com pelo menos uma superfície de proteção. Detalhes sobre as relações de interferência podem ser visualizados via console de execução, como demonstram a Figura 6-27 (objetos fixos) e a Figura 6-28 (objetos móveis). 


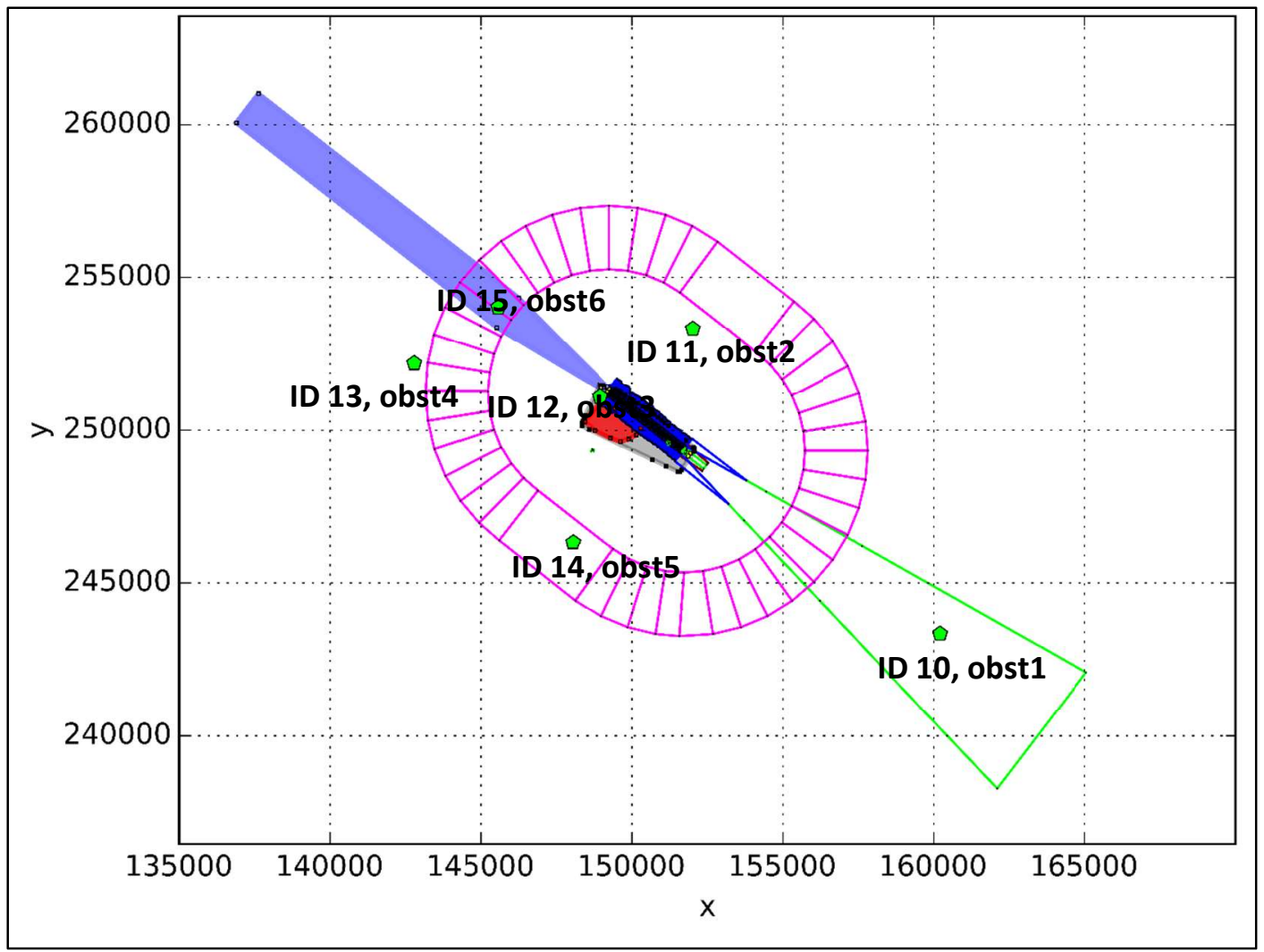

Figura 6-25 Representação final da instância FONTE: Elaborado pelo autor.

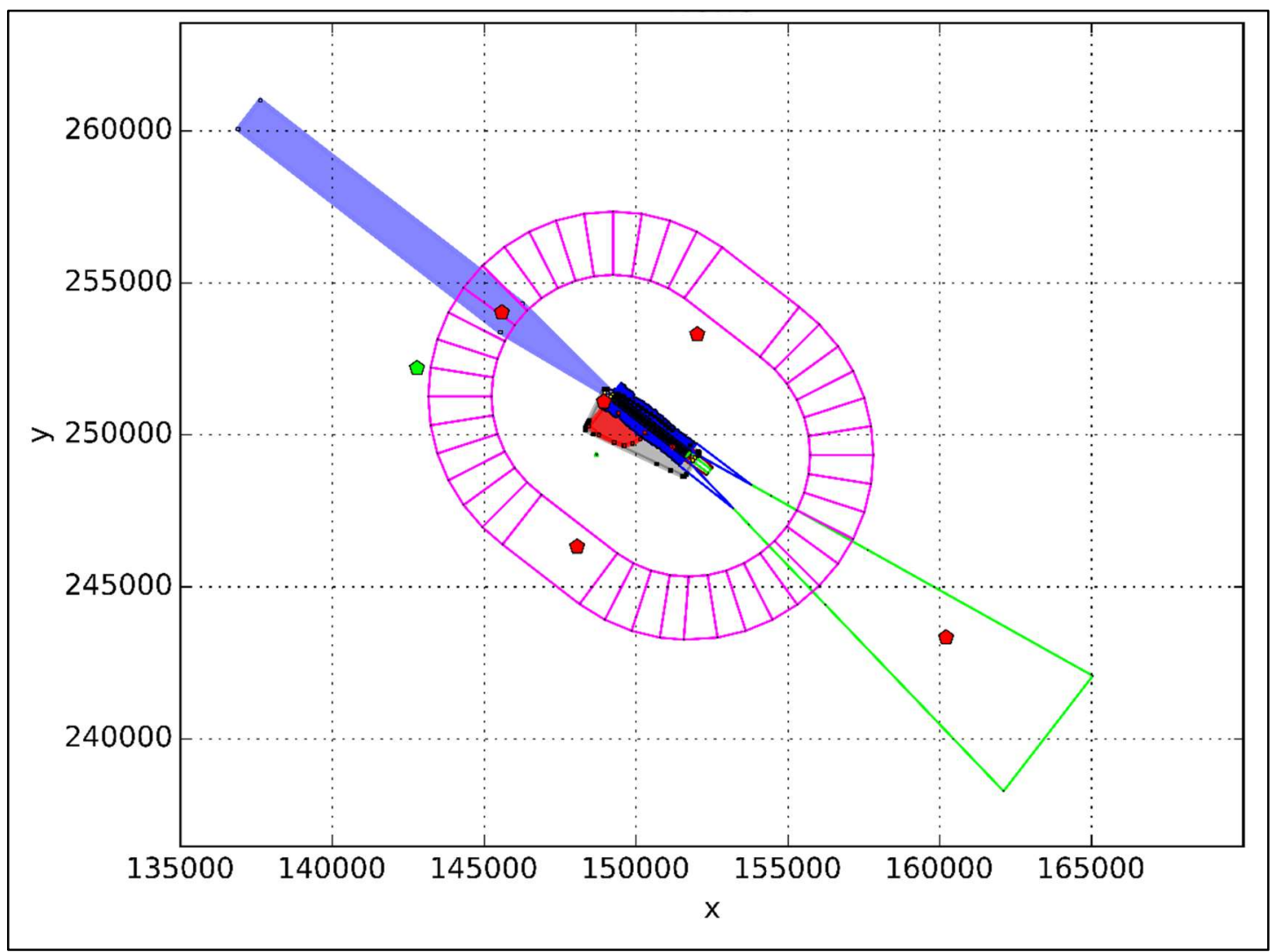

Figura 6-26 Representação final da instância após os testes de interferência FONTE: Elaborado pelo autor. 


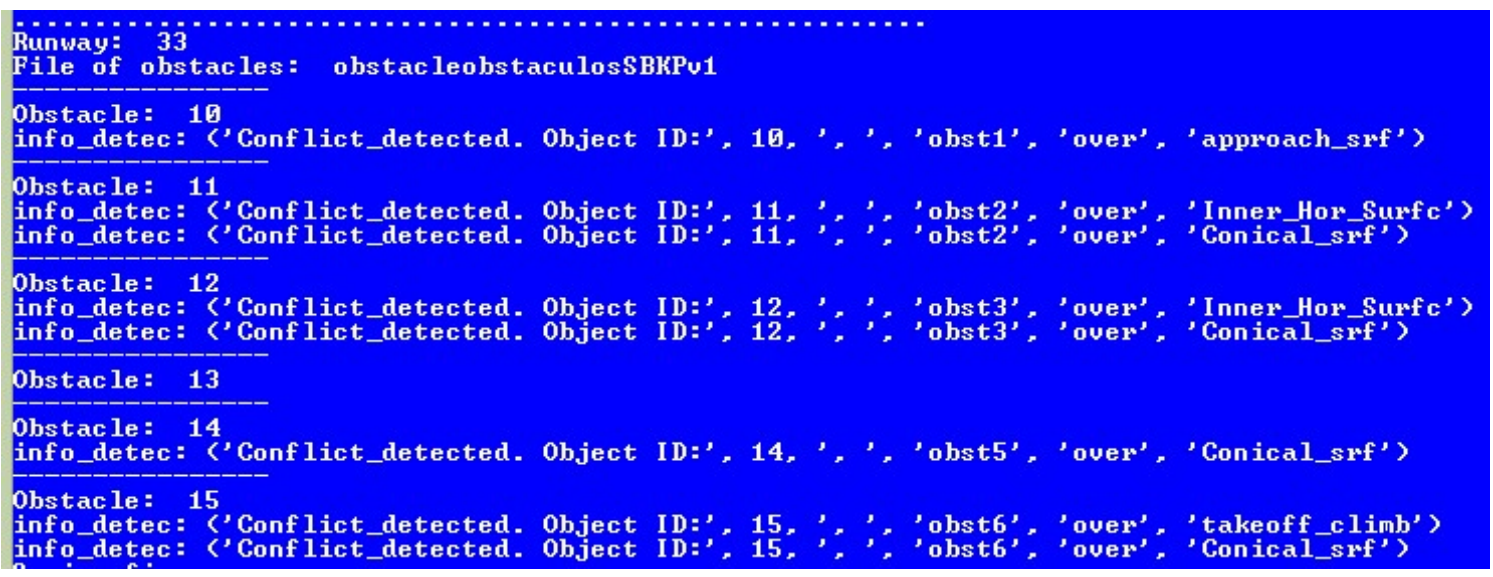

Figura 6-27 Resultados do console para os objetos fixos VERSUS geometrias externas FONTE: Elaborado pelo autor.

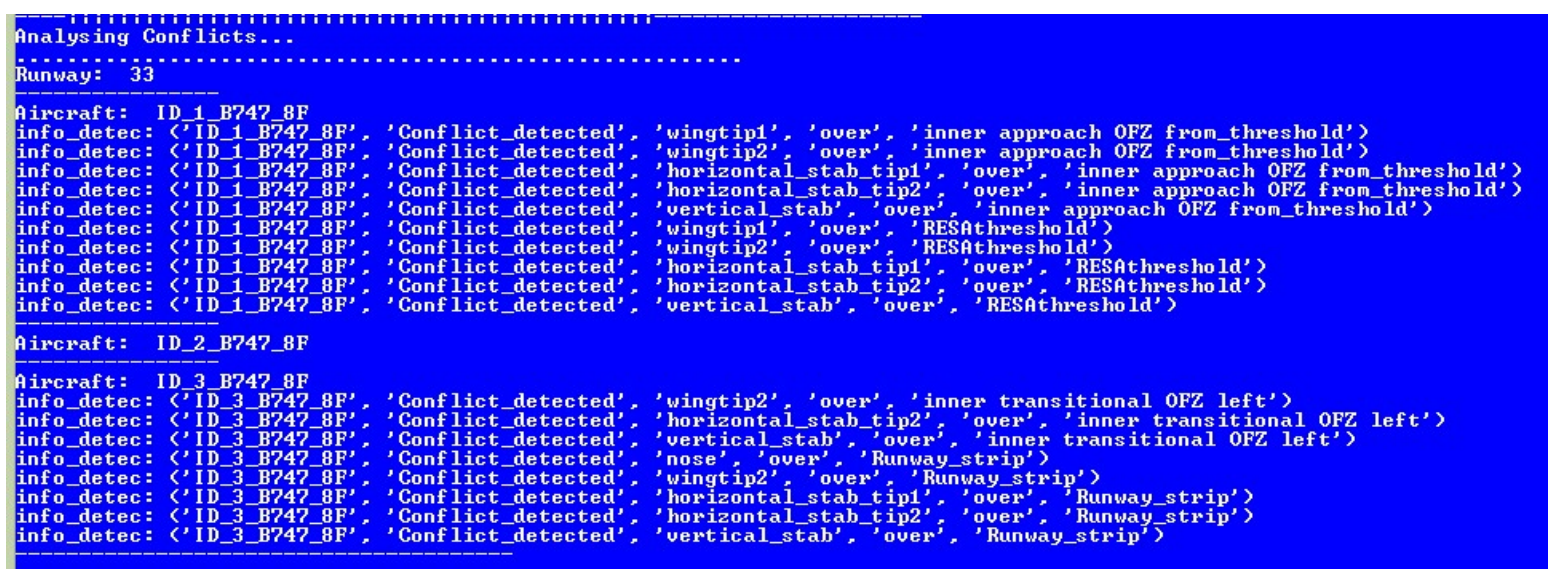

Figura 6-28 Resultados do console para os objetos móveis VERSUS geometrias internas Obs.: Ver Apêndice 3 para uma visualização ampliada da figura.

FONTE: Elaborado pelo autor.

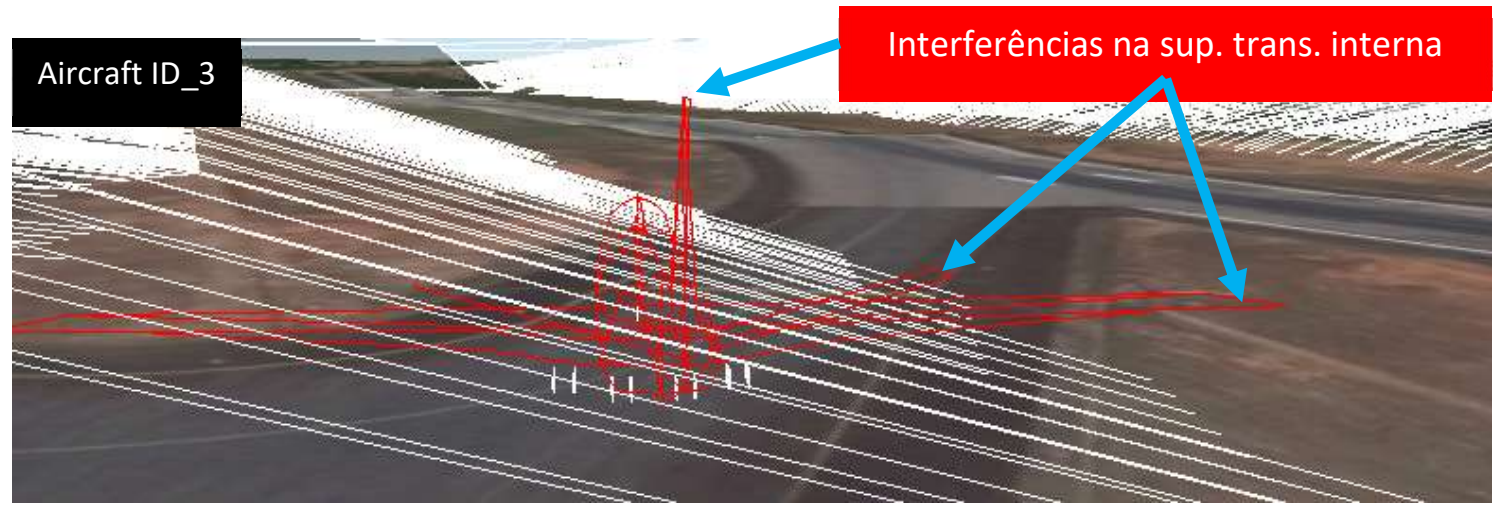

Figura 6-29 Detalhe da interferência da aeronave ID_3

FONTE: Elaborado pelo autor com imagens do Goolge Earth. 


\section{Objetos fixos:}

Conforme a Figura 6-26 e a Figura 6-27, o obst4 ID 13 não interfere com nenhuma das superfícies externas. Isso é totalmente esperado, pois o objeto encontra-se fora do Convex hull dessas superfícies.

O obst1 ID 10 interfere com a superfície de aproximação.

O obst2 ID 11 interfere com a superfície horizontal interna: sua altura é de $1.659 \mathrm{~m}$, contra os $45 \mathrm{~m}$ de elevação da referida superfície sobre um ponto de referência. O obst2 ID 11 também aparece no console interferindo com a superfície cônica. Isso se deve ao fato de que o algoritmo gera uma malha TIN para esta superfície de uma forma que o limite interno não pode ser excluído. Tal característica do modelo não o compromete, pois a elevação da superfície cônica é maior do que a elevação da superfície horizontal interna. Assim, um objeto que interfira com esta última, já tem razões para ser considerado um obstáculo.

O obst3 ID 12 é um caso similar ao obst2 ID 11.

O obst5 ID 14 interfere apenas com a superfície cônica.

O obst6 ID 15 interfere com a superfície de decolagem e com a superfície cônica.

\section{Objetos móveis:}

Conforme a Figura 6-28, as aeronaves com IDs 1 e 3 interferem com as geometrias internas. Tomando-se por exemplo o caso da aeronave de ID3, esta interfere com a superfície horizontal interna em três dos seus pontos críticos: ponta da asa direita; ponta do estabilizador vertical e ponta direita do estabilizador horizontal. Além disso, o nariz da mesma se encontra sobre a área interna da faixa da RWY, bem como a ponta da asa direita, e as pontas dos estabilizadores.

\subsection{PISTAS MÚLTIPLAS}

No caso de um aeródromo que seja caracterizado por pistas múltiplas, as geometrias internas e externas serão geradas de forma separada para cada pista e para sentido de operação, com exceção da superfície horizontal interna e da superfície cônica. As geometrias destas duas respondem pelos inputs conjuntos das pistas, conforme apresentado na Figura 1-4.

De forma a avaliar-se o comportamento do modelo neste caso mais geral, foram geradas duas instâncias de teste, com base na própria INST_SBKP. A alteração consistiu em adicionar pista(s) ao aeródromo, conforme mostram a Figura 6-30 e a Figura 6-31. 


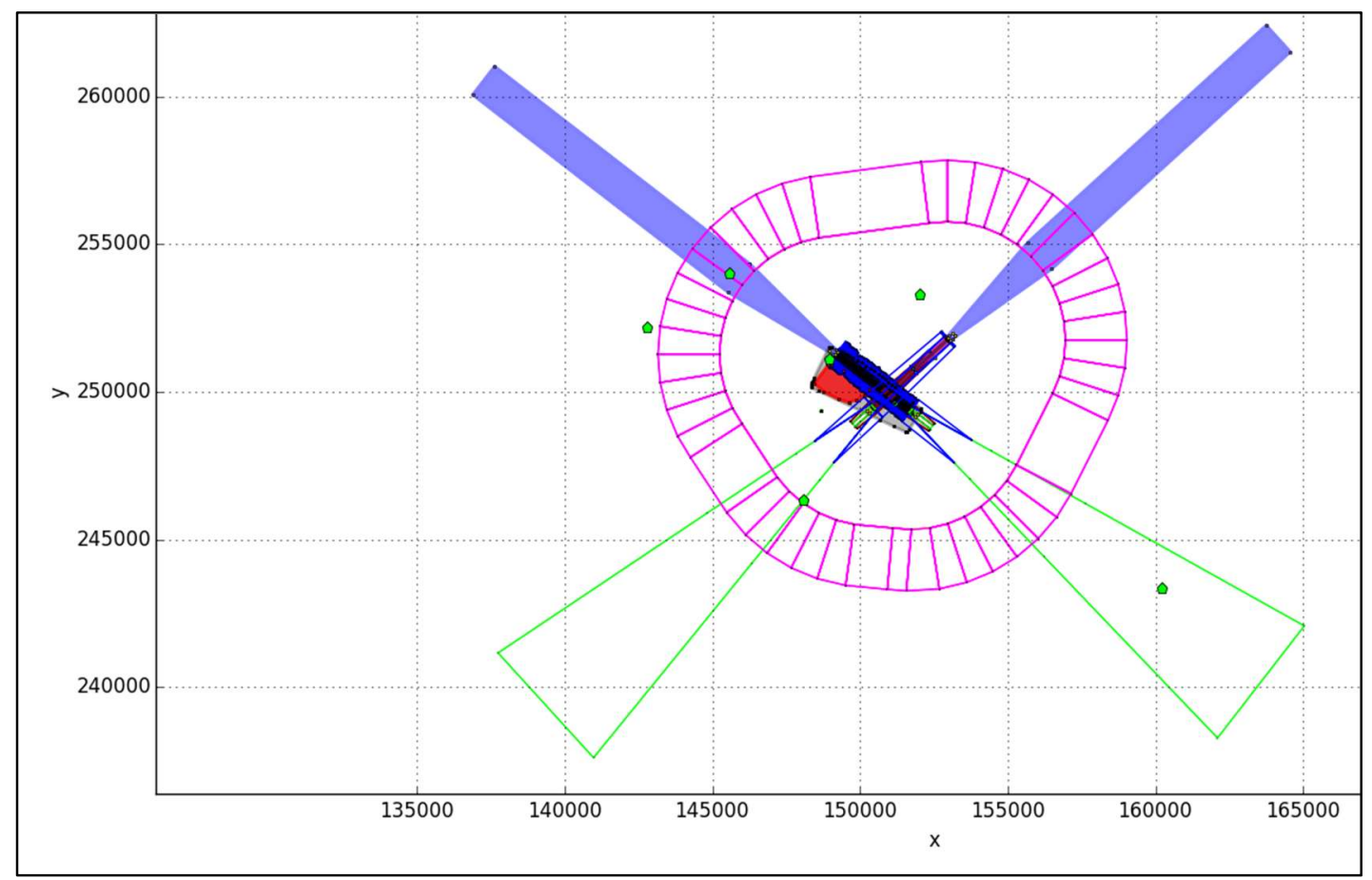

Figura 6-30 Teste para um sistema com 2 pistas.

FONTE: Elaborado pelo autor

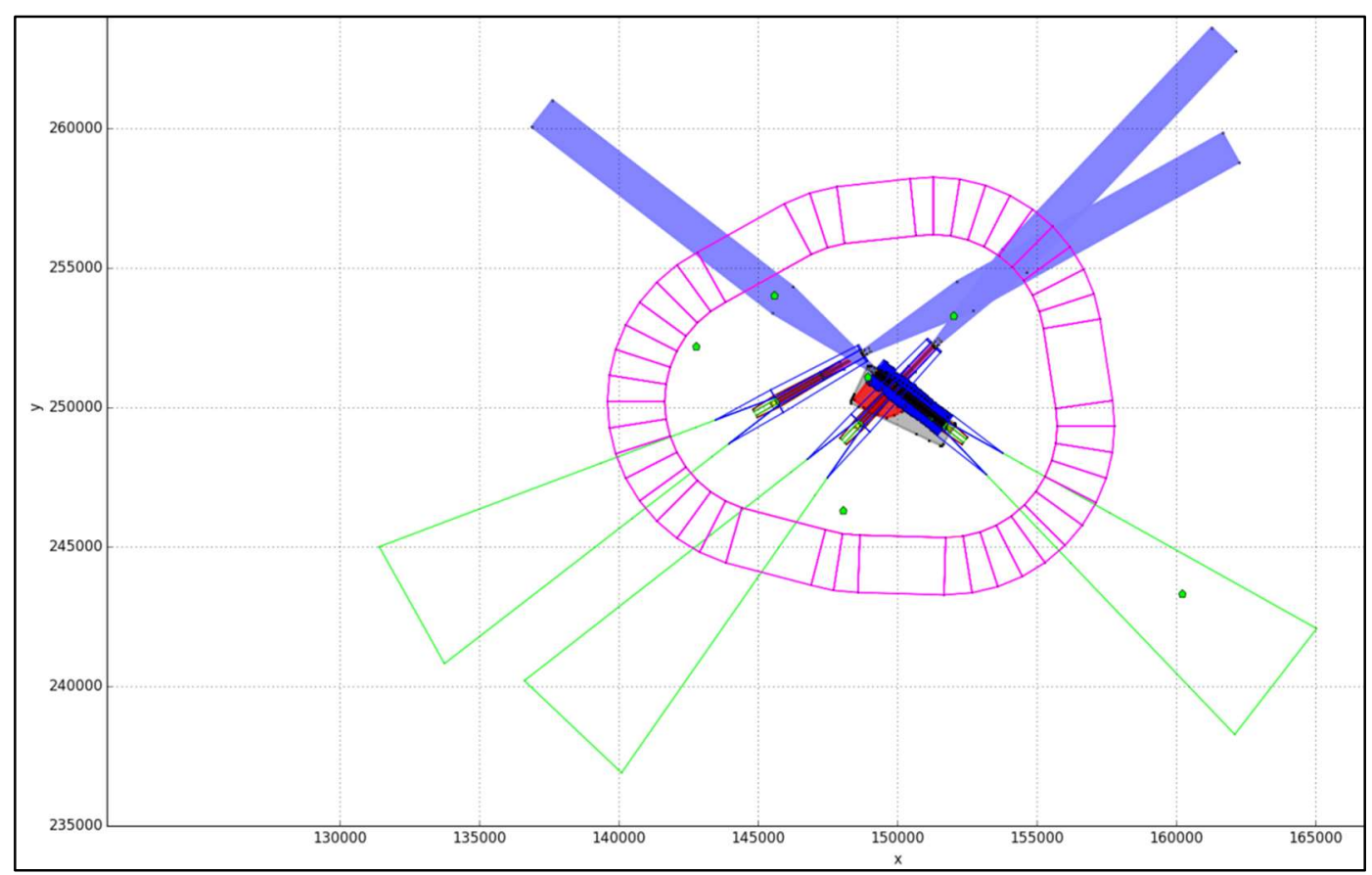

Figura 6-31 Teste para um sistema com 3 pistas.

FONTE: Elaborado pelo autor

\subsection{ANÁLISE DE TEMPO COMPUTACIONAL}

A análise dos tempos de execução foi realizada para a instância INST_SBKP com três variações para o parâmetro incremento (inc). A Tabela 6-2 apresenta os 
resultados das análises de tempo de execução, na qual os valores são apresentados em segundos. O computador no qual os testes foram executados possui as seguintes configurações: sistema operacional Windows 8.1; 8,0 GB de memória RAM; e processador Intel Core i5-4210U.

Tabela 6-2 - Testes dos tempos computacionais: instância INST_SBKP

\begin{tabular}{c|c|c|c|c|c|c}
\hline \multirow{2}{*}{ Atividade } & \multicolumn{2}{|c|}{ Incremento=1 m } & \multicolumn{2}{c|}{ Incremento=10m } & \multicolumn{2}{c}{ Incremento=100m } \\
\cline { 2 - 7 } & Duração & Total & Duração & Total & Duração & Total \\
\hline Início & 0,0000 & 0,0000 & 0,0000 & 0,0000 & 0,0000 & 0,0000 \\
\hline Carregar nomes dos arquivos & 0,0130 & 0,0130 & 0,0140 & 0,0140 & 0,0190 & 0,0190 \\
\hline Ler dados do sítio e pista(s) & 1,0020 & 1,0150 & 0,9960 & 1,0100 & 0,9960 & 1,0150 \\
\hline Gerar MDE & 0,3310 & 1,3460 & 0,3050 & 1,3150 & 0,3120 & 1,3270 \\
\hline Carregar áreas de exclusão & 0,0010 & 1,3470 & 0,0000 & 1,3150 & 0,0000 & 1,3270 \\
\hline $\begin{array}{c}\text { Gerar áreas e superfícies de proteção } \\
\text { Convex hull do sítio para imagem }\end{array}$ & 5,4050 & 6,7520 & 0,4020 & 1,7170 & 0,1060 & 1,4330 \\
\hline Convex hull das exclusões para & 0,0000 & 6,7520 & 0,0000 & 1,7170 & 0,0000 & 1,4330 \\
\hline imagem & 6,7520 & 0,0000 & 1,7170 & 0,0000 & 1,4330 \\
\hline Gerar e posicionar aeronaves & 0,5400 & 7,2920 & 0,5070 & 2,2240 & 0,4810 & 1,9140 \\
\hline Carregar objetos fixos & 0,0030 & 7,2950 & 0,0040 & 2,2280 & 0,0040 & 1,9180 \\
\hline Analisar interferência com & 22,3140 & 29,6090 & 0,4710 & 2,6990 & 0,1220 & 2,0400 \\
\hline aeronaves & 1,3620 & 30,9710 & 0,2370 & 2,9360 & 0,1030 & 2,1430 \\
\hline fixos & 0,0000 & $\mathbf{3 0 , 9 7 1 0}$ & 0,0000 & $\mathbf{2 , 9 3 6 0}$ & 0,0000 & $\mathbf{2 , 1 4 3 0}$ \\
\hline
\end{tabular}

Unidades: Tempos em segundos (s)

Fonte: Elaborado pelo autor

Verifica-se que utilizando incrementos de $1 \mathrm{~m}$ sobre o eixo da pista, o modelo precisa de cerca de 30s para executar as tarefas de carregamento dos dados, geração do MDE, geração das geometrias internas e externas e análise de interferência, de acordo com os objetos fixos e móveis apresentados na seção 6.3.

No entanto, a utilização de um incremento mais grosseiro influencia bastante o tempo de execução, que diminui para cerca de $3 \mathrm{~s}$ e $2 \mathrm{~s}$, respectivamente para incrementos de $10 \mathrm{~m}$ e de $100 \mathrm{~m}$.

Quanto mais refinado o parâmetro incremento, maior o número de pontos para representar a geometria das áreas: RWY; faixa de pista de pouso e decolagem; área interna da faixa da RWY; superfície de transição e superfície de transição interna. Isso leva a uma maior carga de processamento para a geração das geometrias, e também para as análises de interferência, principalmente das aeronaves. 
Aeronaves exigem testes em relação a cada um dos seus pontos críticos, o que as torna mais complexas do que os objetos fixos.

\subsection{CONCLUSÕES DO CAPÍTULO}

A funcionalidade do modelo foi validada através de instâncias reais e fictícias. Através de instâncias fictícias foi verificado que o modelo é capaz de reconhecer adequadamente as áreas disponíveis do sítio. A geração das geometrias mostrou-se correta, sendo capaz de responder automaticamente às variáveis de projeto e reconhecer o MDE.

A aplicação ao Aeroporto de Campinas (SBKP) demonstra que o modelo é capaz de responder a um caso real, no qual a topografia do sítio é descrita por um conjunto de 15.706 nós. Nesta instância, o processo de geração das geometrias das áreas e superfícies de proteção levou entre $0,1 \mathrm{~s}$ e 5,4s, dependendo do incremento de distância sobre o eixo da pista, único parâmetro numérico do modelo.

A esta instância real foram adicionados 6 objetos fixos hipotéticos e 3 objetos móveis, também hipotéticos, permitindo avaliar a função de avaliação de interferências. Esta função se comportou como o esperado, apontando os obstáculos existentes. Dependendo do parâmetro de incremento adotado, o tempo de análise de interferências para o conjunto de objetos fixos variou entre $0,1 \mathrm{~s}$ e $1,3 \mathrm{~s}$. Já para o conjunto de aeronaves, este tempo variou entre 0,12 s e 22,3 s.

O modelo também foi capaz de gerar adequadamente as áreas e superfícies de proteção no caso de sistemas de pistas formadas por pistas múltiplas.

A projeção SCL foi testada para uma área de abrangência igual àquela estabelecida para o PTL na NBR 14166 (ABNT, 1998). De forma a medir o nível das distorções no SCL, comparou-se uma distância medida sobre a projeção com a distância geodésica, obtida conforme Vincenty (1975). Tal distância liga o ponto central da projeção a um de seus vértices $(50 \mathrm{~km}, 50 \mathrm{~km})$. Verificou-se que a posição geográfica do ponto central exerce uma influência muito pequena sobre tal indicador de distorção, estável na faixa dos $1,46 \mathrm{~m}$, para o ponto limite da área de abrangência da projeção. 


\section{CONCLUSÕES E RECOMENDAÇÕES}

Esta tese tem como objetivo a proposição de um modelo computacional para análise de conformidade das áreas e superfícies de proteção relacionadas ao sistema de pistas de pouso e/ou decolagem de um aeródromo de acordo com os critérios da ICAO. Ainda conforme o objetivo proposto, o modelo deve ser capaz de fornecer a geometria georreferenciada das áreas e superfícies de proteção do sistema de pistas de pouso e/ou de decolagem e verificar a interferência de objetos fixos e móveis com estas áreas e superfícies.

As áreas e superfícies de proteção de interesse foram analisadas, de forma a caracterizar o problema, permitindo que o mesmo fosse submetido à pesquisa bibliográfica.

A revisão de literatura realizada não identificou softwares open source relacionados ao problema. Além disso, não foram identificadas modelagens compatíveis, que por adaptação ou extensão, pudessem ser empregadas.

A solução metodológica adotada foi a concepção de um modelo computacional que mescla aspectos das tecnologias CAD (Computer Aided Design) e GIS (Geographic Information System). O modelo proposto baseia-se em um paradigma CAD (programação estática ou variants programming) que dispensa a interação com o usuário durante sua execução. Dessa forma, o modelo é concebido para um funcionamento automático, a partir dos dados de entrada. A compatibilização entre dados sob diferentes referenciais geográficos e projetados é atingida através do emprego da biblioteca GDAL, ao passo que a projeção padrão do projeto é o SCL (Sistema Cartesiano Local).

A topografia do terreno, essencial para a construção de algumas das geometrias de interesse, é abordada digitalmente através de um MDE (Modelo Digital de Elevação) baseado em uma malha TIN (Triangulated Irregular Network). O modelo TIN também é utilizado para representar as áreas e superfícies de proteção na função de análise de interferências.

Métodos de geração de cada uma das geometrias foram propostos. Para a representação das aeronaves, em especial, foi proposto um método de digitalização, com base no APM (Airport Planning Manual) da aeronave.

A linguagem Python, na versão 2.7, foi selecionada para a implementação do modelo e é proposta uma estrutura de agrupamento de dados (Obgeo, Setobgeo e 
Nestset), baseada na estrutura nativa list. Tal agrupamento mostrou-se um facilitador em diversas operações, como transformações de coordenadas, geração de gráficos em tela e salvamento de arquivos. As geometrias são representadas no modelo como pontos, linhas e polígonos, que observam a estrutura proposta de agrupamento de dados.

Testes foram realizados para validar o modelo utilizando-se instâncias fictícias e uma instância real, associada ao Aeroporto de Viracopos, em Campinas. As geometrias foram geradas adequadamente.

Os testes também validaram a metodologia de detecção de obstáculos, que compara as áreas e superfícies de proteção com objetos fixos e móveis.

Variações introduzidas nas instâncias de testes também permitiram verificar que o modelo é capaz de fornecer as geometrias esperadas em casos de sistemas formados por pistas múltiplas. Nestes casos, a superfície horizontal interna e superfície cônica formam uma geometria única para o conjunto de pistas de pouso e/ou decolagem.

Pode-se concluir que a presente pesquisa propõe um modelo computacional inédito e válido, capaz de cumprir os objetivos aos quais se destina.

\section{RECOMENDAÇÕES PARA TRABALHOS FUTUROS}

Esta pesquisa propõe e testa uma metodologia relacionada à geração de geometrias e análise de interferências com foco nas áreas e superfícies de proteção da pista de pouso e/ou decolagem de acordo com os critérios de projeto do Anexo 14 da ICAO.

Adaptações em partes do modelo podem fazer com que o mesmo responda a outras áreas e superfícies de proteção, como aquelas relacionadas às pistas de táxi e pátios. De forma alternativa, o modelo também pode eventualmente ser adaptado a outros sistemas de normas, ou ainda, para avaliar áreas e superfícies de proteção relacionadas a procedimentos operacionais específicos.

No caso de outros sistemas de normas ou de superfícies que protegem procedimentos específicos, será necessário também avaliar outros métodos de geração das geometrias de interesse. Além disso, é necessário avaliar se a atual representação de geometrias absorve a geometria de interesse. Áreas e superfícies que possam ser representadas por uma malha TIN 2D, possuindo ou não atributos de altura, podem ser entendidas como facilmente acomodáveis no modelo. 
O modelo proposto, base para uma biblioteca acessível em linguagem de programação, pode ser automatizado, viabilizando análises de múltiplas configurações para um mesmo sítio, sem qualquer interferência humana. Se pensado desta forma, o modelo proposto pode passar de uma ferramenta de auxílio ao projeto em computador para um método de projeto, capaz de sugerir automaticamente configurações que atendam às restrições impostas.

De uma forma mais ampla, o modelo também pode ser adaptado a outros setores de atividade que empreguem critérios de separação. Como discutido na revisão de literatura, o problema tratado nesta tese é um caso em uma classe de estudos que aborda o layout a partir dos seus aspectos geométricos. Por exemplo, o método de detecção de interferências pode ser adaptado para estudar a disposição de objetos convexos que não podem se sobrepor. 


\section{REFERÊNCIAS}

ABNT. NBR 14166 - Rede de Referência Cadastral Municipal - Procedimento. ABNT Associação Brasileira de Normas Técnicas. Rio de Janeiro. 1998.

ALI, T.; MEHRABIAN, A. A novel computational paradigm for creating a Triangular Irregular Network (TIN) from LiDAR data. Nonlinear Analysis: Theory, Methods \& Applications , v. 71, n. 12, p. e624 - e629, 2009.

ANAC. Agência Nacional de Aviação Civil. RBAC 154 - Projeto de Aeródromos. Inclui Emenda 01. ed. Brasília: [s.n.], 2012.

ANDRADE, J. B. D. Fotogrametria. 2ed. Curitiba: SBEE, 2003. 274 p.

ASPRS - THE IMAGING AND GEOSPATIAL INFORMATION SOCIETY. LASer (LAS) File Format Exchange Activities, 2016. Disponivel em: <https://www.asprs.org/committeegeneral/laser-las-file-format-exchange-activities.html>. Acesso em: 31 Outubro 2016.

AUTODESK. Autodesk Knowledge Network, 2017. Disponivel em: $<$ https://knowledge.autodesk.com/support/alias-products/gettingstarted/caas/CloudHelp/cloudhelp/2016/ENU/Alias-Tutorials-Legacy/files/GUID-366304CB16FF-46F9-9F64-D7385358D855-htm.html>. Acesso em: 2017 Janeiro 2017.

$\mathrm{BAH}, \mathrm{T}$. Inkscape: Guide to a Vector Drawing Program, 2015. Disponivel em: <http://tavmjong.free.fr/INKSCAPE/MANUAL/html/Paths-Bezier-Curves.html>. Acesso em: 29 Janeiro 2017.

BÉNIÈREA, R. et al. A comprehensive process of reverse engineering from 3D meshes to CAD models. Computer-Aided Design, v. 45, n. 11, p. 1382-1393, 2013.

BIDARRA, R.; BRONSVOORT, W. F. Semantic feature modelling. Computer-Aided Design , v. 32, n. 3, p. 201-225, 2000.

BLITZKOW, D. et al. Informações espaciais II: PTR 2202: Notas de Aulas. São Paulo: Escola Politécnica da USP, 2007.

BRAINERD, J.; PANG, A. Interactive map projections and distortion. Computers \& Geosciences, v. 27, n. 3, p. 299-314, 2001. ISSN 0098-3004.

BRASIL. COMAER.Departamento de Controle do Espaço Aéreo. Serviço de Informação Aeronáutica. Brasília, p. Disponível em: http://www.aisweb.aer.mil.br/. 2014.

BRASIL. Portaria n 957/GC3. Ministério da Defesa. Comando da Aeronáutica. Brasília. 2015.

BRASIL. AGA Portal Aeródromos. DECEA. Ministério da Defesa. PBZPA Aeródromo Guarulhos - Governador André Franco Montoro, 2017. Disponivel em: <http://servicos.decea.gov.br/aga>. Acesso em: 2017 Fevereiro 2017.

BURKHOLDER, E. F. Computation of Horizontal/Level Distances. Journal of Surveying Engineering, v. 117, n. 3, p. 104-116, Agosto 1991. ISSN 0733-9453.

BY, R. A. D. Principles of geographic information systems. [S.I.]: International Institute for Aerospace Survey and Earth Sciences, 2001. 
BY, R. A. D. E. A. Principles of Geographic Information Systems: an Introductory Textbook. Enschede: ITC, 2001.

CASAS, A. et al. The topographic data source of digital terrain models as a key element in the accuracy of hydraulic flood modelling. Earth Surface Processes and Landforms, v. 31 , n. 4, p. 444-456, 2006. ISSN DOI: 10.1002/esp.1278.

CHANG, K.-H. Design Theory and Methods using CAD/CAE: The Computer Aided Engineering Design Series. 1. ed. [S.I.]: Academic Press, 2014.

CHENG, S.-W.; DEY, T. K.; SHEWCHUK, J. Delaunay mesh generation. [S.I.]: CRC Press, 2013.

CX_FREEZE. cx_Freeze website, 26 Dez 2014. Disponivel em: <http://cxfreeze.sourceforge.net/>. Acesso em: 1 Jan 2016.

CYTHON. Cython: C Extensions for Python, 2014. Disponivel em: <http://cython.org/>. Acesso em: 10 Janeiro 2015.

DAL'FORNO, G. L. et al. Transformação de coordenadas geodésicas em coordenadas no plano topográfico local pelos métodos da norma nbr 14166/1998 e o de rotações I translações. A Mira: Agrimensura e Cartografia, 2011.

DE BERG, M. et al. Computational geometry: algorithms and applications. 2nd rev. ed. ed. [S.I.]: Springer, 2000. ISBN ISBN: 3540656200,9783540656203.

DOYLE, D. R. NGS Geodetic Toolkit, Part 7: Computing State Plane Coordinates. Professional Surveyor magazine, v. 24, n. 1, 2004.

DRIRA, A.; PIERREVAL, H.; HAJRI-GABOUJ, S. Facility layout problems: A survey. Annual Reviews in Control , v. 31, n. 2, p. 255-267, 2007.

ESRI. ESRI Shapefile Technical Description. An ESRI White Paper-July 1998, 1998. Disponivel em: <http://www.esri.com/library/whitepapers/pdfs/shapefile.pdf>. Acesso em: 10 Novembro 2014.

ESRI. ArcGIS for Desktop Extensions. ArcGIS for Aviation: Airports, 2016. Disponivel em: <http://www.esri.com/software/arcgis/extensions/aviation/airports/features>. Acesso em: 26 Jul 2016.

ESRI. Support. Knowledge Base - Technical Articles, 2016. Disponivel em: <http://support.esri.com/en/knowledgebase/techarticles/detail/38711>. Acesso em: 26 Janeiro 2016.

EUA. Electronic Code of Federal Regulations. Title 14: Aeronautics and Space. PART 77safe, efficient use, and preservation of the navigable airspace, 2017. Disponivel em: $<$ http://www.ecfr.gov/cgi-bin/text-

idx?c=ecfr\&sid=fab9bfa191e740463dbdb9acc14b6e2a\&rgn=div5\&view=text\&node=14:2.0.1. 2.9\&idno=14>. Acesso em: 25 Janeiro 2017.

FAA. Federal Aviation Administration. AC 150/5300-13A. Airport Design. Includes Change 1, Washington, 2014. 
FAA, T. C. A. F. T. I. L.; PLANNING TECHNOLOGY, INC. Three-Dimensional Airspace Analysis Programs. User Manual: Program Installation and Menu Commands: AutoCAD Map 3D 2005. [S.I.]. 2005.

FARR, T. G. et al. The Shuttle Radar Topography Mission. Rev. Geophys., v. 45, n. 2, 2007. ISSN DOI: 10.1029/2005rg000183.

FAVALLI, M. Digital elevation model construction from structured topographic data: The DEST algorithm. Journal of Geophysical Research, v. 109, n. F4, 2004. ISSN DOI: 10.1029/2004jf000150.

FENNA, D. Cartographic Science: a Compendium of Map Projections with Derivations. Boca Raton: CRC Press, 2007.

FLORINSKY, I. V. Digital terrain analysis in soil science and geology. [S.I.]: Academic Press, 2011.

FREITAS, H. R. D. A. et al. Drainage networks and watersheds delineation derived from TIN-based digital elevation models. Computers \& Geosciences, v. 92, p. 21-37, 2016.

GDAL. Software Using GDAL, 2017. Disponivel em: <https://trac.osgeo.org/gdal/wiki/SoftwareUsingGdal>. Acesso em: 2 Fevereiro 2017.

GEO COMMUNITY. GISDataDepot - GIS Data Formats, 2014. Disponivel em: <http://data.geocomm.com/helpdesk/formats.html>. Acesso em: 5 Abril 2016.

GEORGE, P. L.; BOROUCHAKI, H. Delaunay triangulation and meshing. [S.I.]: Herme's, 1998.

GHASEMI, M.; SHARAFI, S. M.; ARMAN, A. Towards an Analytical Approach to Measure Modularity in Software Architecture Design. Journal of Software, v. 10, n. 4, p. 465 - 479, 2015.

GNU OPERATING SYSTEM. Disponivel em: <http://www.gnu.org/licenses/gpl.html>. Acesso em: 5 janeiro 2015.

GONZÁLEZ-LLUCH, C. et al. A survey on 3D CAD model quality assurance and testing tools. Computer-Aided Design, v. 83, p. 64-79, 2017

GOOGLE INC. Google Developers. Keyhole Markup Language, 2014. Disponivel em: <https://developers.google.com/kml/documentation/>. Acesso em: 2015 Janeiro 2.

GUIMARÃES, G. D. N. A geoid model in the state of São Paulo: an attempt for the evaluation of different methodologies. Tese (Doutorado) - Escola Politécnica, Universidade de São Paulo. São paulo, p. 144. 2013. (Disponível em: http://www.teses.usp.br/teses/disponiveis/3/3138/tde-30072013-234021/. Acesso em: 27 jan. 2016.).

HATVANY, J.; NEWMAN, W. M.; SABIN, M. A. World survey of computer-aided design. Computer-Aided Design , v. 25, n. 12, p. 776-798, 1993.

HEARN, D.; BAKER, M. P. Computer Graphics: C version. Segunda. ed. [S.I.]: Pearson, 1997.

HOOIJBERG, M. Practical geodesy: using computers. Berlin: Springer, 1997. 
HOOIJBERG, M. Geometrical geodesy: using information and computer technology. Berlin: Springer, 2008.

HORONJEFF, R. et al. Planning and design of airports. 5 ${ }^{\text {a }}$. ed. [S.I.]: McGraw-Hill, 2010.

HOSSEINI, S. F.; MOETAKEF-IMANI, B. Innovative approach to computer-aided design of horizontal axis wind turbine blades. Journal of Computational Design and Engineering , p. - , 2016.

HSU, M.-C. et al. An interactive geometry modeling and parametric design platform for isogeometric analysis. Computers \& Mathematics with Applications , v. 70, n. 7, p. 14811500, 2015.

IAOG. EPSG Geodetic Parameter Registry. International Association of Oil and Gas, 201? Disponivel em: <http://www.epsg-registry.org/>. Acesso em: 15 Janeiro 2015.

IBGE. Instituto Brasileiro de Geografia e Estatística. Proposta Preliminar para a Adoção de um Referencial Geocêntrico no Brasil. Rio de Janeiro: Documento preliminar - texto para discussão, 2000.

IBGE. Instituto Brasileiro de Geografia e Estatística. Glossário Cartográfico, 2016. Disponivel em: <http://www.ibge.gov.br/home/geociencias/cartografia/glossario/glossario_cartografico.shtm> . Acesso em: 22 Janeiro 2016.

ICAO. International Civil Aviation Organization. Airport Services Manual: Part 6 Control of Obstacles. Doc 9137, 2nd Ed 1983.

ICAO. International Civil Aviation Organization. Annex 14 to the Convention on International Civil Aviation. Volume I. Aerodrome Design and Operations, 2004.

ICAO. International Civil Aviation Organization. Aerodrome Design Manual. Part 1: Runways. Doc 9157. 3rd edition, 2006a.

ICAO. International Civil Aviation Organization. Procedures for Air Navigation Services. Doc 8168, 2006b.

ICAO. International Civil Aviation Organization. ICAO, 2017. Disponivel em: <http://www.icao.int>. Acesso em: 25 Janeiro 2017.

ILIFFE, J. Datums and map projections for remote sensing, GIS, and surveying. Glasgow: Whittles Publishing, 2003.

IOGP. International Association of Oil and Gas Producers. Geomatics Guidance Note number 7, part 1. EPSG Geodetic Parameter Dataset. [S.I.], p. 41. 2012. (OGP Publication 373-7-1).

IOGP. International Association of Oil and Gas Producers.Geomatics Guidance Note number 7, part 2. Coordinate Conversions and Transformations including Formulas. [S.I.], p. 145. 2015. (OGP Publication 373-7-2 ).

IOGP. International Association of Oil and Gas Producers. EPSG Geodetic Parameter Registry, 2016. Disponivel em: <http://www.epsg-registry.org/>. Acesso em: 25 Janeiro 2016. 
ITO, T. A genetic algorithm approach to piping route path planning. Journal of Intelligent Manufacturing, DOI: 10.1023/A:1008924832167, v. 10, n. 1, p. 103-114, Março 1999. ISSN $1572-8145$.

JEKELI, C. Geometric Reference Systems in Geodesy. Notas de Aula. Division of Geodetic Science School of Earth Sciences - Ohio State University. Ohio. 2012.

JONES, C. B.; KIDNER, D. B.; WARE, J. M. The Implicit Triangulated Irregular Network and Multiscale Spatial Databases. The Computer Journal, v. 37, n. 1, p. 43-57, 1994. ISSN DOI: $10.1093 /$ comjnl/37.1.43.

JUNG, S. Facility siting and plant layout optimization for chemical process safety. Korean Journal of Chemical Engineering, v. 33, n. 1, p. 1-7, 2016.

KAZDA, A.; CAVES, R. E. Airport design and operation. [S.I.]: Elsevier, 2007.

KHALAFALLAH, A.; EL-RAYES, K. Automated multi-objective optimization system for airport site layouts. Automation in Construction , v. 20, n. 4, p. 313-320, 2011.

KIENZLE, S. The Effect of DEM Raster Resolution on First Order, Second Order and Compound Terrain Derivatives. Transactions in GIS, v. 8, n. 1, p. 83-111, 2004.

KNIPPERS, R. Geometric Aspects of Mapping. Department of Ge-information Processing. University of $\quad$ Twente, 2009.2 Disponivel em: <http://kartoweb.itc.nl/geometrics/Map\%20projections/mappro.html>. Acesso em: 11 Janeiro 2015.

KRESSE, W.; DANKO, D. M. (. ). Springer handbook of geographic information. [S.I.]: Springer, 2012.

LEE, H. S.; CHANG, S. L. Development of a CAD CAE CAM system for a robot manipulator. Journal of Materials Processing Technology, v. 140, n. 1-3, p. 100-104, 2003.

LEIDIG, M.; TEEUW, R. Free software: A review, in the context of disaster management. International Journal of Applied Earth Observation and Geoinformation , v. 42, p. 49-56, 2015.

LI, Z. Sampling strategy and accuracy assessment. University of Glasgow. Glasgow, p. 299 (Tese de Doutorado). 1990.

LI, Z.; ZHU, Q.; GOLD, C. Digital terrain modeling. [S.I.]: CRC Press, 2005.

MA, Z.; SHEN, Q.; ZHANG, J. Application of 4D for dynamic site layout and management of construction projects. Automation in Construction , v. 14, n. 3, p. 369-381, 2005.

MALING, D. H. Coordinate systems and map projections. 2nd. ed. Oxford: Pergamon Press, 1991.

MATPLOTLIB, 2017. Disponivel em: <http://matplotlib.org/index.html>. Acesso em: 29 Janeiro 2017.

MICROSOFT CORPORATION. Bing Mapas. 2014 Digital Globe. Acessado pelo plugin OpenLayers do QGIS, 2014. Disponivel em: <http://www.bing.com/maps/>. Acesso em: 17 Janeiro 2015. 
MONEDERO, J. Parametric design: a review and some experiences. Automation in Construction , v. 9, n. 4, p. 369-377, 2000.

MORTENSON, M. E. Computer Graphics Handbook: Geometry and Mathematics. Nova Iorque: Industrial Press Inc, 1990.

MORTENSON, M. E. Geometric Modeling. Segunda. ed. [S.I.]: John Wiley and Sons, 1997.

MULCAHY, K. A.; CLARKE, K. C. Symbolization of Map Projection Distortion: A Review. Cartography and Geographic Information Science, v. 28, n. 3, p. 167-181, 2001. ISSN 15450465.

NABAIS, R. J. D. S. (Organizador). Manual básico de engenharia ferroviária. ISSN: 97885-7975-131-8. ed. São Paulo: Oficina de Textos, 2014.

NETELER, M. et al. GIS: A multi-purpose open source. Environmental Modelling \& Software, v. 31, p. 124-130, 2012.

NETELER, M.; MITASOVA, H. Open Source GIS: A GRASS GIS Approach. 2nd. ed. Boston: Kluwer Academic, 2004.

NGS. National Geodetic Survey. What is the geoid?, 2001. Disponivel em: <http://www.ngs.noaa.gov/GEOID/geoid_def.html>. Acesso em: 28 Janeiro 2016.

NGS. National Geodetic Survey. Geodetic Glossary, 2009. Disponivel em: <http://www.ngs.noaa.gov/CORS-Proxy/Glossary/xml/>. Acesso em: 27 Janeiro 2016.

NGS. National Geodetic Survey. Geodetic Glossary, 2009. Disponivel em: <http://www.ngs.noaa.gov/CORS-Proxy/Glossary/xml/NGS_Glossary.xml>. Acesso em: 05 Abril 2016.

NGS. National Geodetic Survey. NOAA. Coordinate Conversion - Beta Version, 2017. Disponivel em: <https://beta.ngs.noaa.gov/gtkweb/>. Acesso em: 1 Fevereiro 2017.

NOAA. National Oceanic and Atmospheric Administration. U.S. Department Of Commerce, 2017. Disponivel em: <http://www.noaa.gov/>. Acesso em: 1 Fevereiro 2017.

OGC. Open Geospatial Consortium Inc. Definition identifier URNs in OGC namespace. [S.I.], p. 40. 2009. (07-092r3).

OGC. Open Geospatial Consortium Inc. OpenGIS ${ }^{\circledR}$ Implementation Standard for Geographic information - Simple feature access - Part 1: Common architecture. [S.I.], p. 92. 2011. (OGC 06-103r4).

OGC. Open Geospatial Consortium Inc. Geography Markup Language, 2017. Disponivel em: <http://www.opengeospatial.org/standards/gml>. Acesso em: 2 Fevereiro 2017.

OLIVEIRA, F. F.; PITERI, M. A.; MENEGUETTE, M. Desenvolvimento de uma plataforma de software para a modelagem digital de terrenos baseada em TIN. Boletim de Ciências Geodésicas, v. 20, n. 1, p. 117-131, 2014.

P.V. AUGUST E Y.Q. WANG. NRS 409/509 Concepts in GIS and Remote Sensing. Environmental Data Center. The University of Rhode Island, 20--. Disponivel em: <http://www.edc.uri.edu/nrs/classes/nrs409509/Lectures2014.htm>. Acesso em: 14 Janeiro 2015. 
PARISHER, R. A.; RHEA, R. A. Pipe Drafting and Design. 2. ed. [S.I.]: Gulf Professional Pub, 2002.

PECKHAM, R.; JORDAN, G. (Eds.). Digital terrain modelling. Berlin: Springer, 2007.

PEPPER, J. et al. Implantation of an individually computer-designed and manufactured external support for the Marfan aortic root. Multimedia Manual of Cardio-Thoracic Surgery, v. 2013, 2013.

PETER H. DANA. The Geographer's Craft Project, Department of Geography, The University of Colorado at Boulder., 2014. Disponivel em: <http://www.colorado.edu/geography/gcraft/notes/mapproj/mapproj_f.html>. Acesso em: 11 Janeiro 2015.

PETRIE, G. K. T. J. M. Terrain modelling in surveying and civil engineering. ComputerAided Design, v. 19, n. 4, p. 171-187, 1987.

PING HUANG, Y. Triangular irregular network generation and topographical modeling. Computers in Industry, v. 12, n. 3, p. 203-213, 1989.

PLANNING TECHNOLOGY, 2017. Disponivel em: <http://www.plantech.com/\#!/page_home>. Acesso em: 08 Fevereiro 2017.

PSF. Python Software Foundation. Python: asking for help, 15 Mar 2014. Disponivel em: <https://wiki.python.org/moin/Asking\%20for\%20Help/How\%20do\%20you\%20protect\%20Pyt hon\%20source\%20code\%3F>. Acesso em: 7 Jan 2016.

PSF. Python Software Foundation, 2015. Disponivel em: <https://www.python.org/>. Acesso em: 2 Janeiro 2015.

PY2EXE. py2exe website, 2 Set 2014. Disponivel em: <http://www.py2exe.org/>. Acesso em: 7 Jan 2016.

PYINSTALLER. Pyinstaller Official Website, 2015. Disponivel em: <http://www.pyinstaller.org/>. Acesso em: 7 Jan 2016.

QGIS. A Free and Open Source Geographic Information System. Documentation QGIS 2.8, $2016 . \quad$ Disponivel em: <http://docs.qgis.org/2.8/en/docs/pyqgis_developer_cookbook/crs.html?highlight=proj4>. Acesso em: 25 Janeiro 2016.

RAPIDLASSO GMBH. LAStools, 2016. Disponivel em: <https://rapidlasso.com/lastools/>. Acesso em: 15 Novembro 2016.

RAPP, R. H. Geometric Geodesy: Part I. Department of Geodetic Science and SurveyingThe Ohio State University. Columbus. 1991.

RAPP, R. H. Geometric Geodesy: Part II. Department of Geodetic Science and SurveyingThe Ohio State University. Columbus. 1993.

ROLLER, D. An approach to computer-aided parametric design. Computer-Aided Design , v. 23, n. 5, p. 385-391, 1991. ISSN ISSN: 0010-4485 DOI: http://dx.doi.org/10.1016/00104485(91)90033-S.

Disponivel

em:

<//www.sciencedirect.com/science/article/pii/001044859190033S>. 
SADEGHPOUR, F.; MOSELHI, O.; ALKASS, S. A CAD-based model for site planning. Automation in Construction , v. 13, n. 6, p. 701-715, 2004.

SANTOS, F. A. B. D.; MÜLLER, C. Sistema de Informações Geográficas no apoio ao gerenciamento de obstáculos à superfície de segmento visual. Boletim de Ciências Geodésicas, v. 20, n. 3, 2014.

SAXENA, A.; BIRENDRA, S. Computer aided engineering design. 1. ed. Nova lorque: Springer, 2005.

SEGANTINE, P. C. L. Estudo do sinergismo entre os sistemas de informação geográfica e o de posicionamento global. Tese de Livre-Docência. Escola de Engenharia de São Carlos. Universidade de São Paulo. São Carlos, p. 224. 2001.

SES, S.; KHALEEF, A.; FORSBER, R. Refined Geoid for the United Arab Emirates. Geoinformation Science Journal, v. 9, n. 1, p. 51-61, Junho 2009.

SILVA, E. J. Análise dos Padrões e Recomendações da ICAO e da FAA para o Projeto Geométrico de Aeródromos. Dissertação (Mestrado). Escola Politécnica da Universidade de São Paulo. São Paulo, p. 254. 2012.

SILVA, E. J.; GUALDA, N. D. F. Modelagem Computacional em Aeródromos. Sitraer 2015 - Air Transportation Symposium. São José dos Campos: SBTA. 2015. p. 1-14.

SILVA, E. J.; GUALDA, N. D. F. Computational Model to conform aerodrome geometry to ICAO design standards. Transport Infrastructure and Systems. Proceedings of the Aiit International Congress on Transport Infrastructure and Systems (Tis 2017), Rome, Italy. 169176. ISBN: 978-1-315-28188-9. Doi: 10.1201/9781315281896-24.

SMITH, J. R. Introduction to Geodesy. Nova Iorque: Wiley, 1997.

SNYDER, J. P. Map Projections: A Working Manual. Geological Survey (U.S.). [S.I.], p. 385. 1987. (1395).

SOLIDWORKS. SOLIDWORKS 3D CAD, 2017. Disponivel em: <http://www.solidworks.com/sw/products/3d-cad/interference-check.htm>. Acesso em: 29 Janeiro 2017.

STEINIGER, S.; HUNTER, A. J. S. The 2012 free and open source GIS software map - A guide to facilitate research, development, and adoption. Computers, Environment and Urban Systems, v. 39, p. 136-150, 2013.

SUZUKI, H.; ANDO, H.; KIMURA, F. Geometric constraints and reasoning for geometrical CAD systems. Computers \& Graphics, v. 14, n. 2, p. 211-224, 1990.

TAVANA, M. et al. A practical taxonomy of methods and literature for managing uncertain spatial data in geographic information systems. Measurement, v. 81, p. 123162, 2016.

TELFER, S. et al. Computer-Aided Design of Customized Foot Orthoses: Reproducibility and Effect of Method Used to Obtain Foot Shape. Archives of Physical Medicine and Rehabilitation , v. 93, n. 5, p. 863-870, 2012. 
TORGE, W. Geodesy. 2rd. ed. Berlin, New York: Walter de Gruyter, 1991.

TRANSOFT SOLUTIONS. Transoft Solutions, 18 Agosto 2016. Disponivel em: <http://www.simtra.com/>. Acesso em: 26 jul 2016.

TRANSOFT SOLUTIONS, 2017. SKYSAFE. Disponivel em: <http://www.transoftsolutions.com/obstacle-limitation-analysis/skysafe/>. Acesso em: 8 Fevereiro 2017.

TSENG, W.-K.; GUO, J.-L.; LIU, C.-P. A comparison of Great Circle, Great Ellipse and Geodesic Sailing. Journal of Marine Science and Technology, v. 21, n. 3, p. 287-299, 2013.

UFRGS. Transformação de coordenadas Planas a Geodésicas. Instituto de Geociências. Departamento de Geodésia. Engenharia Cartográfica. Universidade Federal do Rio Grande do Sul, 201-? Disponivel em: <http://www.ufrgs.br/engcart/Teste/transf_coord_4.php>. Acesso em: 12 Janeiro 2015.

USGS. USGS Earth Explorer. United States Geological Survey, 2014. Disponivel em: <http://earthexplorer.usgs.gov/>. Acesso em: 15 Janeiro 2014.

USGS. USGS Earth Explorer. United States Geologial Survey, 2016. Disponivel em: <http://earthexplorer.usgs.gov/>. Acesso em: 30 Outubro 2016.

USGS. USGS Earth Explorer. United States Geologial Survey, 2017. Disponivel em: $<$ http://earthexplorer.usgs.gov/>. Acesso em: 2 Fevereiro 2017.

VAN DER MEIDEN, H. A.; BRONSVOORT, W. F. A constructive approach to calculate parameter ranges for systems of geometric constraints. Computer-Aided Design , v. 38, n. 4, p. 275-283, 2006.

VANÍCEK, P.; KRAKIWSKY, E. J. Geodesy: the concepts. 2nd. ed. Amsterdam: North Holland, 1986.

VINCENTY, T. Direct and inverse solutions of geodesics on the ellipsoid with application of nested equations. Survey Review, v. 23 , n. 176, p. 88-93, 1975. ISSN DOI: 10.1179/sre.1975.23.176.88.

W3C. World Wide Web Consortium, 2016. Disponivel em: <https://www.w3.org/XML/>. Acesso em: 11 Dezembro 2016.

WASHINGTON STATE UNIVERSITY. GIS Technology at RTI, 2012. Disponivel em: <http://www.ruraltech.org/gis/>. Acesso em: 6 Janeiro 2015.

WHEETLEY, L. E. I. T.; HELMBERGER, K. P. E. On Modeling FAA Surfaces for Airspace Analysis Using Geopak. Freese and Nichols Consulting. [S.I.], p. 11. 2009. (Disponível em: https://www.freese.com/sites/default/files/On\%20Modeling $\% 20 F A A \% 20$ Surfaces $\% 20$ for $\% 20$ Airpace\%20Analysis\%20Using\%20Geopak.pdf).

WHITMORE, G. M. Coordinate reference systems for high precision geodesy. Tese (doutorado). Universidade de Nottingham. Disponível em: http://eprints.nottingham.ac.uk/29037/1/260666.pdf. Acesso em 22 jan. 2016, p. 223. 1994. 
WU, Y.; WANG, Y.; FENG, X. A heuristic approach for petrochemical plant layout considering steam pipeline length. Chinese Journal of Chemical Engineering , v. 24, n. 8, p. 1032-1037, 2016.

XIAOMING, Z. A. P. D. A model-based approach to assembly sequence planning. The International Journal of Advanced Manufacturing Technology, v. 39, n. 9, p. 983-994, 2008.

YILDIRIM, F.; KAYA, A. Selecting Map Projections in Minimizing Area Distortions in GIS Applications. Sensors, v. 8, n. 12, p. 7809-7817, 2008.

YU, J. A. W. C. Method for discriminating geometric feasibility in assembly planning based on extended and turning interference matrix. The International Journal of Advanced Manufacturing Technology, v. 67, n. 5, p. 1867-1882, 2013

ZANEN, P. P. A. et al. Using 4D CAD to visualize the impacts of highway construction on the public. Automation in Construction, v. 32, p. 136-144, 2013.

ZANETTI, M. A. Z. Implicaçőes atuais no relacionamento entre sistemas terrestres de referência de origem local e geocêntrica. 97 p. Tese (doutorado) - Programa de PósGraduaçăo em Ciencias Geodésicas da Universidade Federal do Paraná, Curitiba, 2006. Disponível em: http://hdl.handle.net/1884/6291. Acesso em 24 Jan. 2016.

ZHOU, F.; ABOURIZK, S. M.; AL-BATTAINEH, H. Optimisation of construction site layout using a hybrid simulation-based system. Simulation Modelling Practice and Theory , v. 17, n. 2, p. 348-363, 2009. 


\section{APÊNDICE 1 - INSTÂNCIA INSTFICT3}

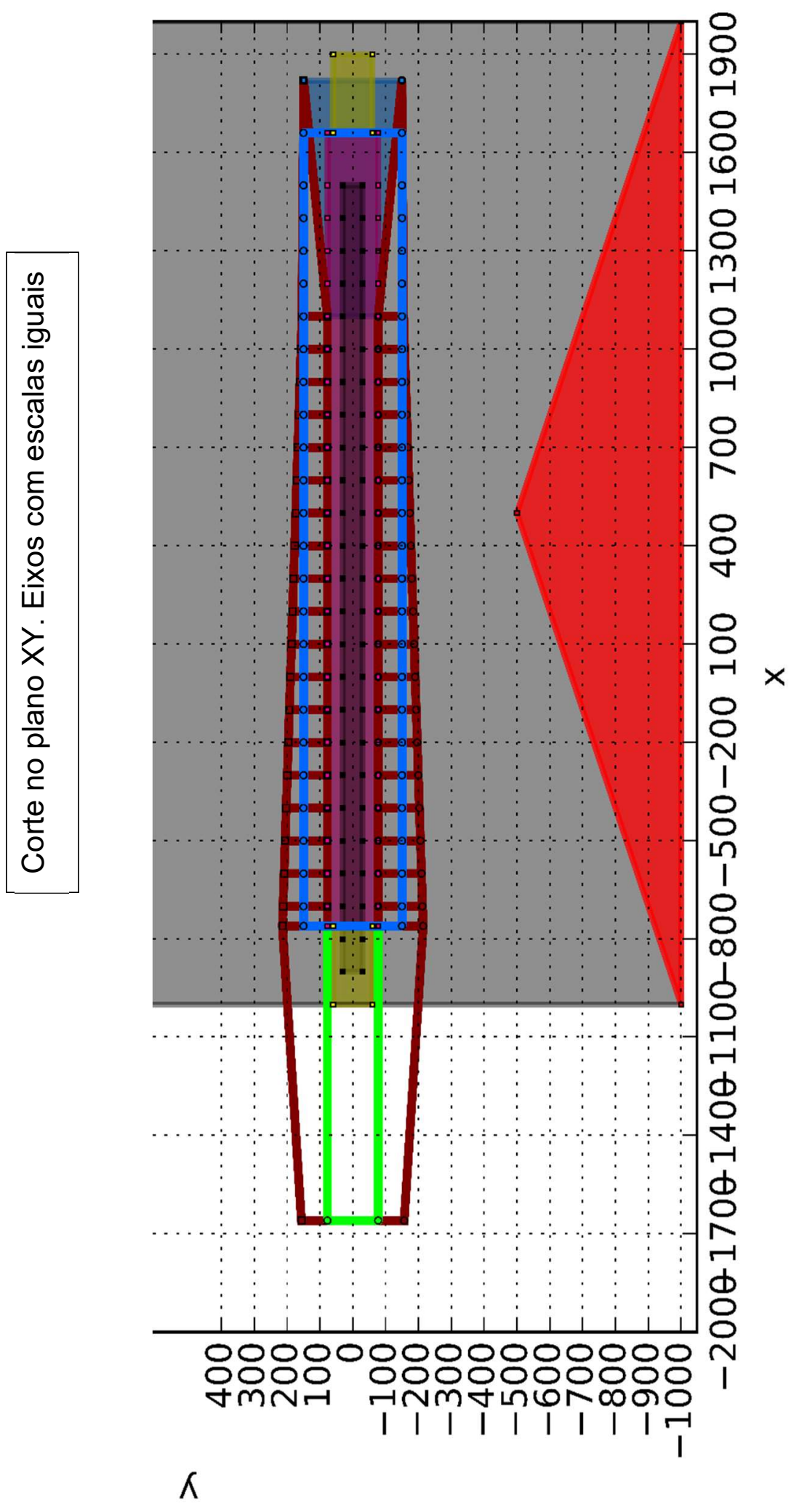




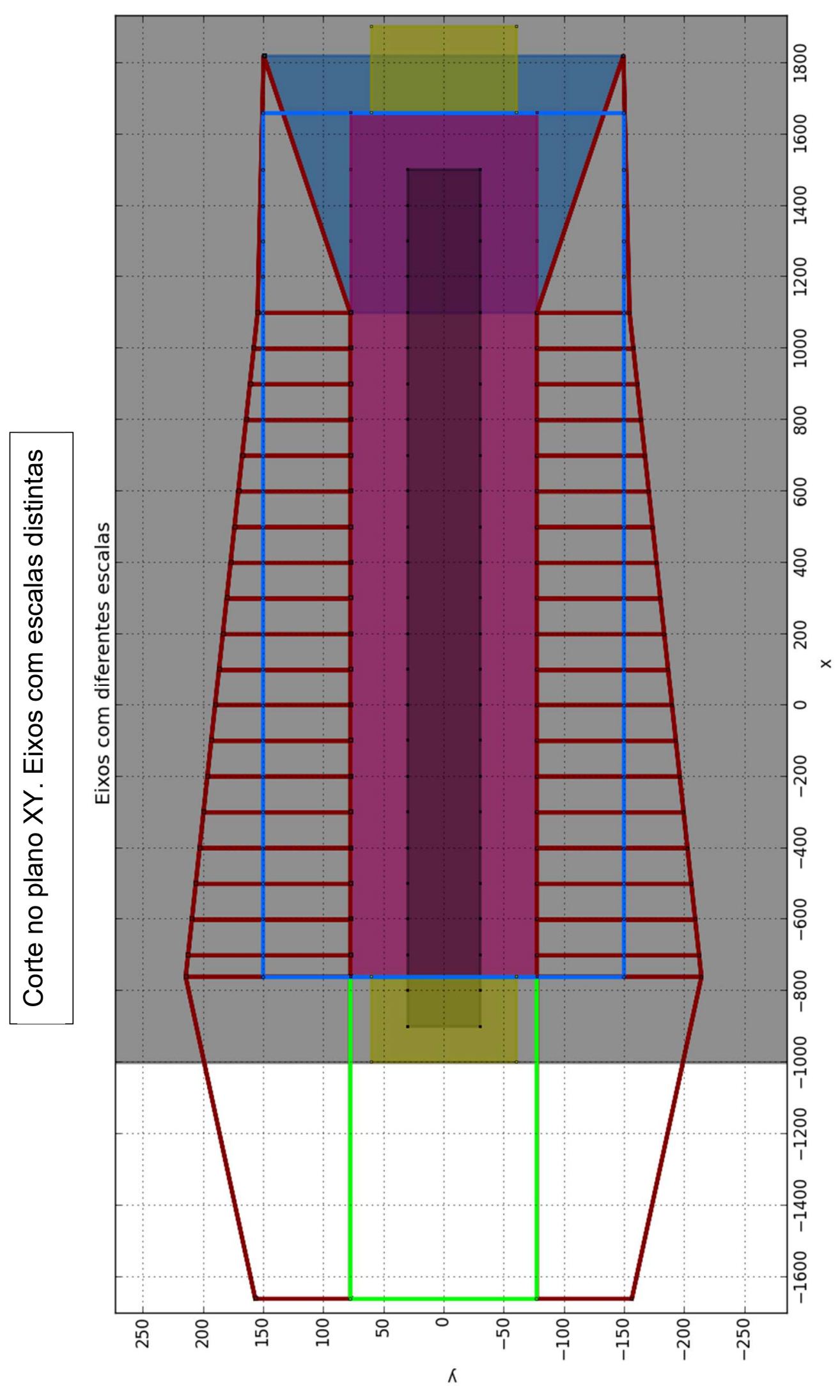




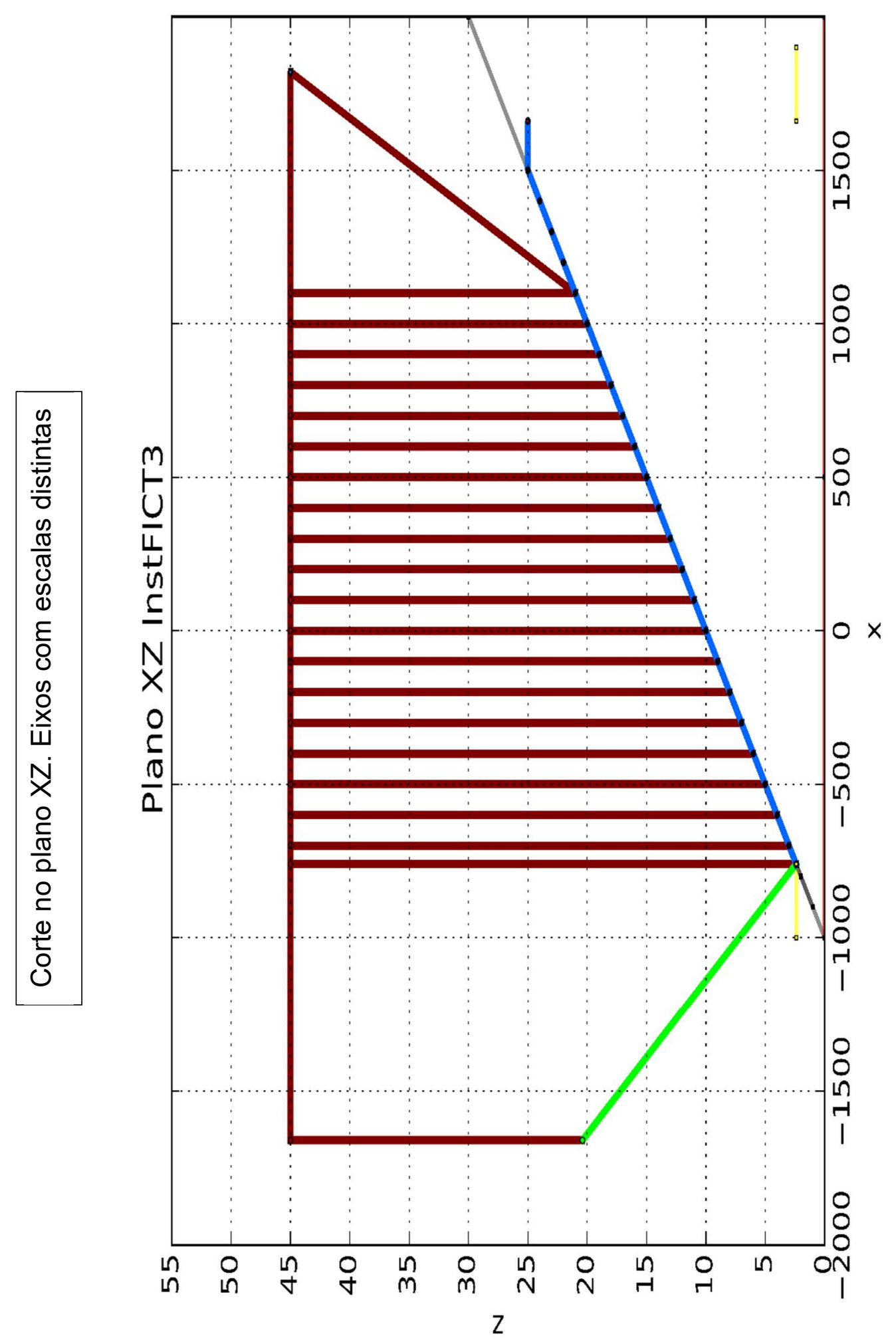




\title{
APÊNDICE 2 - DADOS PARA GERAÇÃO DO B747-8F
}

\author{
\#B747-8F according to Boeing APM D6-58326-3 2012 \\ \$,CRTPTS \\ $\# \mathrm{x}, \mathrm{y}, \mathrm{z}$,label \\ $0,0,5.29$, nose \\ $34.2,55.19,6.48$, wingtip 1 \\ $-34.2,55.19,6.48$, wingtip2 \\ $11,75.24,9.16$,horizontal_stab_tip1 \\ -11,75.24,9.16,horizontal_stab_tip2 \\ $0,75.24,19.56$,vertical_stab \\ $\$, N O N C V X 1, y z$ platform of fuselage \\ \#x,y,z points, label, number \\ $0.0,0.0,5.31$, nose, 1 \\ $0.0,1.29,4.17$,upradarlow, 1.1 \\ $0.0,3.42,3.33$, None, 2 \\ $0.0,7.88,1.93$,fus beq, 3 \\ $0.0,24.74,1.85$,ini_wng_low, 4 \\ $0.0,53.73,2.58$, None, 5 \\ $0.0,74.22,7.345$,apu_low, 6 \\ $0.0,74.22,9.67$,apu_hig, 7 \\ $0.0,72.42,9.67$, vtaillow, 8 \\ $0.0,76.25,19.44$,vtailhigh, 9 \\ $0.0,72.03,19.44$, vtailhigh2,10 \\ $0.0,59.99,9.43$,vtailfront, 11 \\ $0.0,22.88,8.91$,ini_wng_high, 12 \\ $0.0,15.306,9.93$,aft_cab, 13 \\ $0.0,7.72,9.93$,front_cab, 14 \\ $0.0,5.64,9.38$,front_cab1,141 \\ $0.0,3.98,8.0$, windshield, 15 \\ $0.0,1.29,6.7$, upradar, 16 \\ $0.0,0.0,5.31$, nose, 1 \\ $\$$,NONCVX2,upper part of the wing \\ $\# x, y, z$,label,seq, upper wing surface \\ $34.2,55.19,7.34$, wingtip, 1 \\ $31.27,49.59,7.34$, None, 2 \\ $3.49,24.96,3.69$, wingrootfront, 3 \\ $0,24.96,3.69$, wingcentrefront, 4 \\ $0,39.16,3.69$, wingcentrerear, 5 \\ $3.49,39.16,3.69$, wingrooterear, 6 \\ $10.74,41.74,4.84$, None, 7 \\ 28.1,51.38,6.69,ailerontip, 8 \\ $34.2,55.19,7.34$, wingtip, 1 \\ \#,NONCVX3,lower part of the wing \\ $\# x, y, z$,label,seq, upper wing surface \\ $34.2,55.19,7.34$, wingtip, 1 \\ $31.27,49.59,7.34$, None, 2 \\ $3.49,24.96,2.1$, wingrootfront, 3 \\ $0,24.96,2.1$, wingcentrefront, 4 \\ $0,39.16,2.1$, wingcentrerear, 5 \\ $3.49,39.16,2.1$, wingrooterear, 6 \\ 10.74,41.74,3.74, None, 7 \\ 28.1,51.38,6.69,ailerontip, 8 \\ $34.2,55.19,7.34$, wingtip, 1 \\ \$,NONCVX4,horizontal stabilizer \\ $\# \mathrm{x}, \mathrm{y}, \mathrm{z}$,label,seq \\ $0,64.77,8.23$,frontcentrehest, 1 \\ $2.06,64.77,8.23$,frontroothest, 2 \\ $11,72.76,11.97$,frontiphest, 3 \\ $11,75.64,11.97$,reartiphest, 4 \\ $0,72.39,8.23$,rearcentrehest, 5 \\ $0,64.77,8.23$,frontcentrehest, 1 \\ $\$$,NONCVX5,fuselage section1 nose \\ $\# x, y, z$,label,seq \\ $0,1.29,6.7,1$ \\ $0.74,1.29,6.44,2$ \\ $1.08,1.29,6.0,3$
}




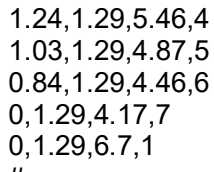

$\$, N O N C V X 6$,fuselage section2 nosegear $\# x, y, z$,label,seq

$0.0,7.88,9.93$,fus_beqhigh, 1

1.17,7.88,9.38,None, 2

2.13,7.88,8.58,None, 3

3.19,7.88,4.44,None, 4

2.79,7.88,3.26,None, 5

$1.61,7.88,2.34$,None, 6

$0.0,7.88,1.93$,fus_beqlow, 7

$0.0,7.88,9.93$,fus beqhigh, 1

$\$, N O N C V X 7, f u s e l a g e$ section3 init wing

$\# \mathrm{x}, \mathrm{y}, \mathrm{z}$,label,seq

$0.0,21.06,9.16$, high, 1

2.3,21.06,7.91,None, 2

3.36,21.06,4.27, None, 3

2.5,21.06,2.2,None, 4

$0,21.06,1.93$,None, 5

$0.0,21.06,9.16$,high, 1

\$,NONCVX8,fuselage section4 None

$\# x, y, z$,label,seq

$0.0,50.3,9.16$, high, 1

2.3,50.3,7.91, None, 2

3.36,50.3,4.27, None, 3

2.5,50.3,2.7, None, 4

$0,50.3,2.43$, None, 5

$0.0,50.3,9.16$, high, 1

\#--

$\$, N O N C V X 9$,fuselage section5 init v tail

$\# \mathrm{x}, \mathrm{y}, \mathrm{z}, \mathrm{label}, \mathrm{seq}$

$0.0,72.03,19.44$, vtailhigh 2,1

$0.6,72.03,9.56$,vtailhigh2,2

$1.0,72.03,9.36$,vtailhigh2,3

1.2,72.03,8,vtailhigh2,4

$0,72.03,6.8$, vtailhigh2, 5

$0.0,72.03,19.44$, vtailhigh2,1

\#,NONCVX10,fuselage platform

$\# \mathrm{x}, \mathrm{y}, \mathrm{z}, \mathrm{label}, \mathrm{seq}$

$0,0,5.22$, nose sec 1,1

$3.19,7.88,4.44, \mathrm{sec} 2,2$

$3.36,21.06,4.27, \sec 3,3$

3.36,50.3,4.27, sec 4,4

$1.2,72.03,8, \sec 5,5$

\#,-REFPOINT

$\# \mathrm{x}, \mathrm{y}, \mathrm{z}$, diameter,label

$0,7.91,0$, refpoint

$\$$, TRNCENTR

$\# x, y, z$, diameter,label

$0,35.9050,0$,turncenter

$\#$ -

$\$$,WHEELS

$\# \mathrm{x}, \mathrm{y}, \mathrm{z}$, diameter,label

$0.0,7.91,0.65,1.3$, nosewheel

$4.86,35.16,0.65,1.3$,maingear

$6.14,35.16,0.65,1.3$,maingear

$4.86,36.65,0.65,1.3$,maingear

$6.14,36.65,0.65,1.3$,maingear

$1.37,38.4,0.65,1.3$,aftgear

$2.53,38.4,0.65,1.3$, aftgear

$1.37,39.84,0.65,1.3$, aftgear

$2.53,39.84,0.65,1.3$, aftgear

\$,END

$0,0,0$ 


\section{APÊNDICE 3 - DADOS DA INST_SBKP}

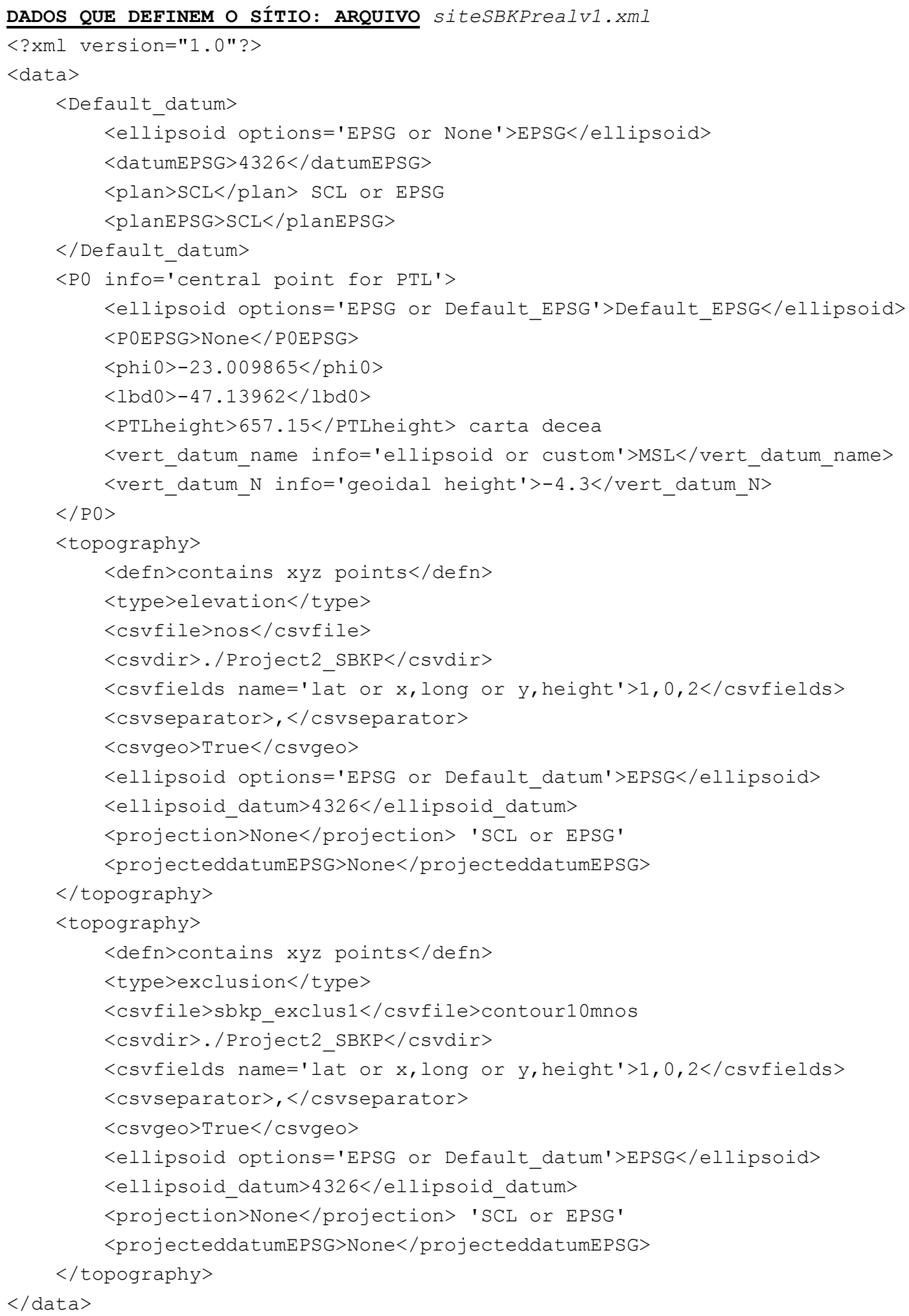


DADOS QUE DEFINEM A PISTA: ARQUIVO runway_SBKPV2.xMI

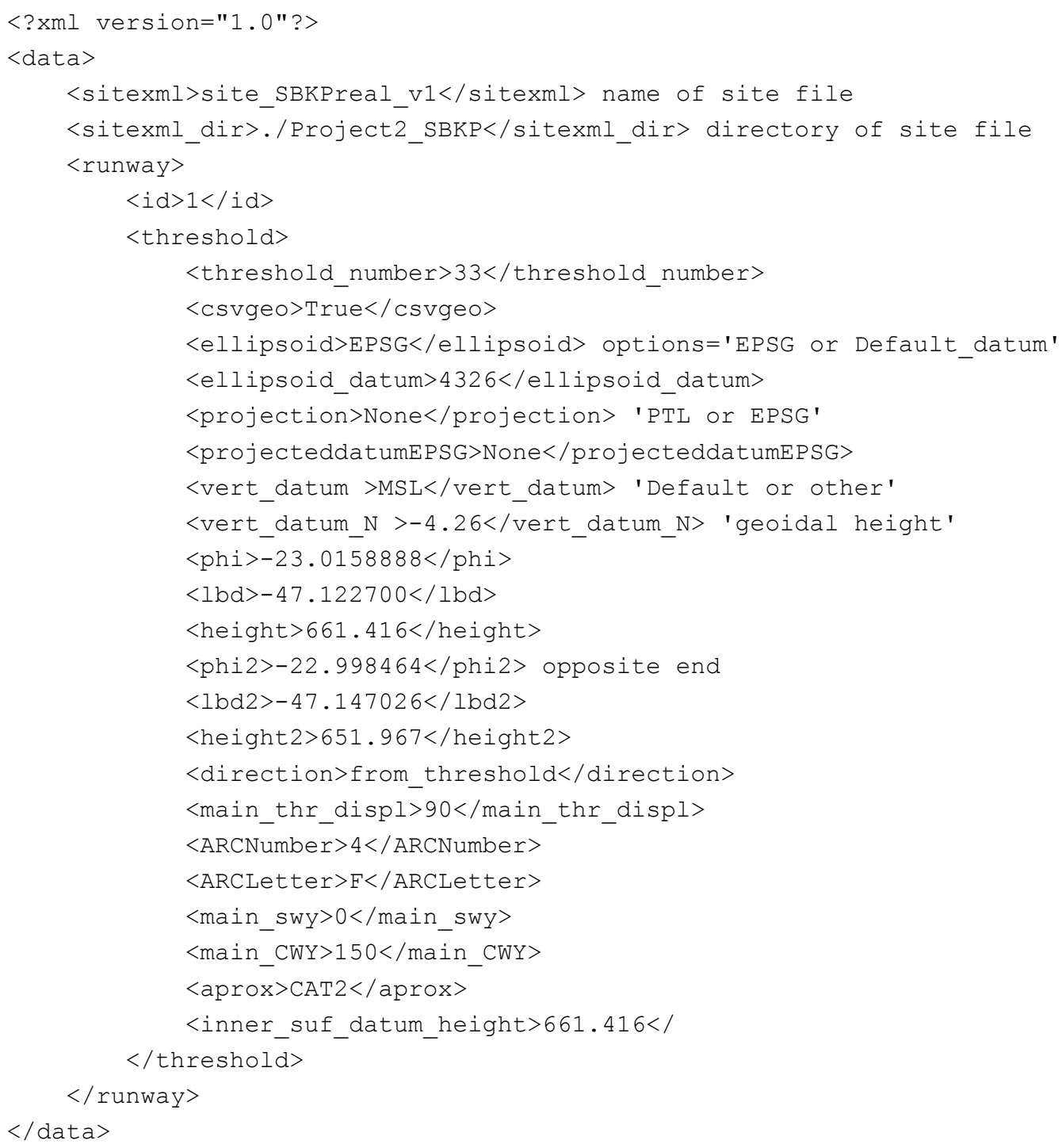




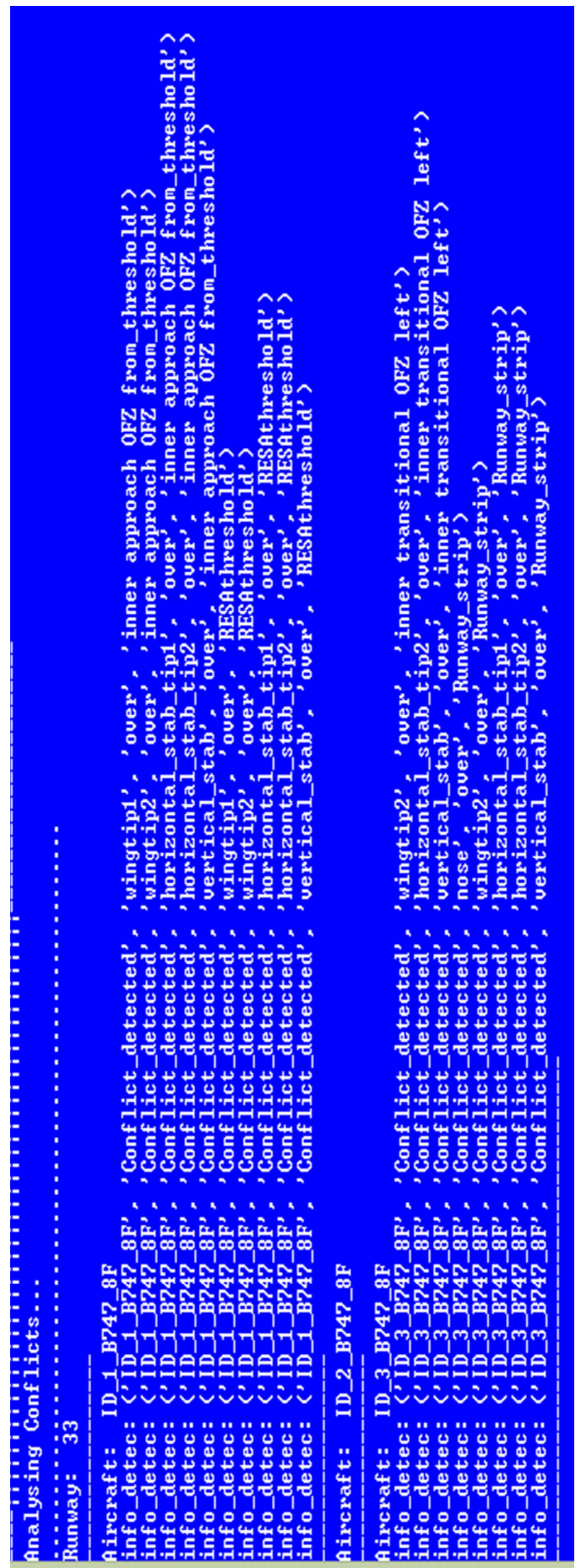




\section{ANEXO 1 - CARTA ADC DO AEROPORTO SBKP}

CARTA DE AERÓDROMO (ADC)

CAMPINAS/ Viracopos, INTL (SBKP) AERODROME CHART (ADC)

ELEV 2170

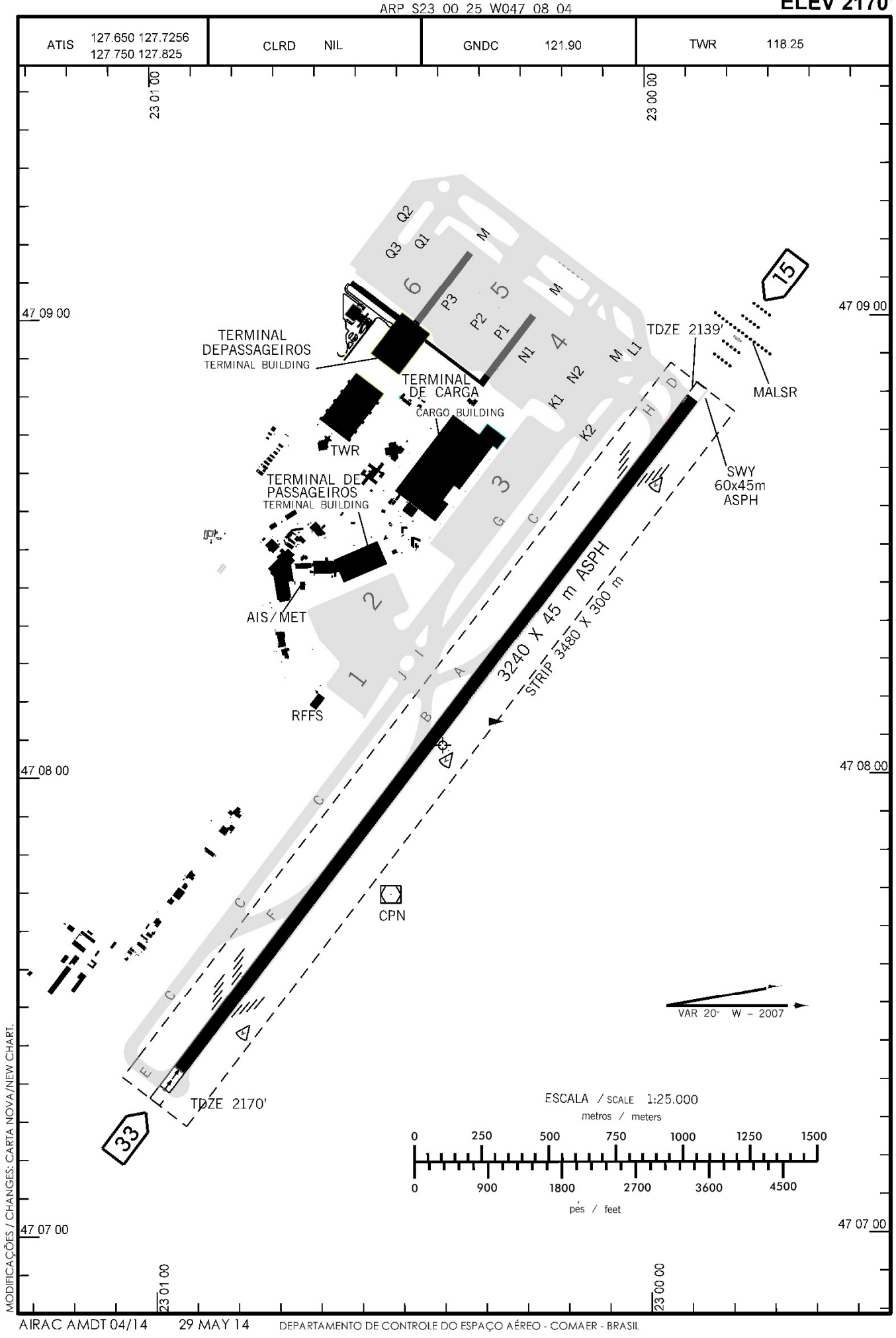


ADC - SBKP: INFORMAÇÕES COMPLEMENTARES/ COMPLEMENTARY INFORMATION

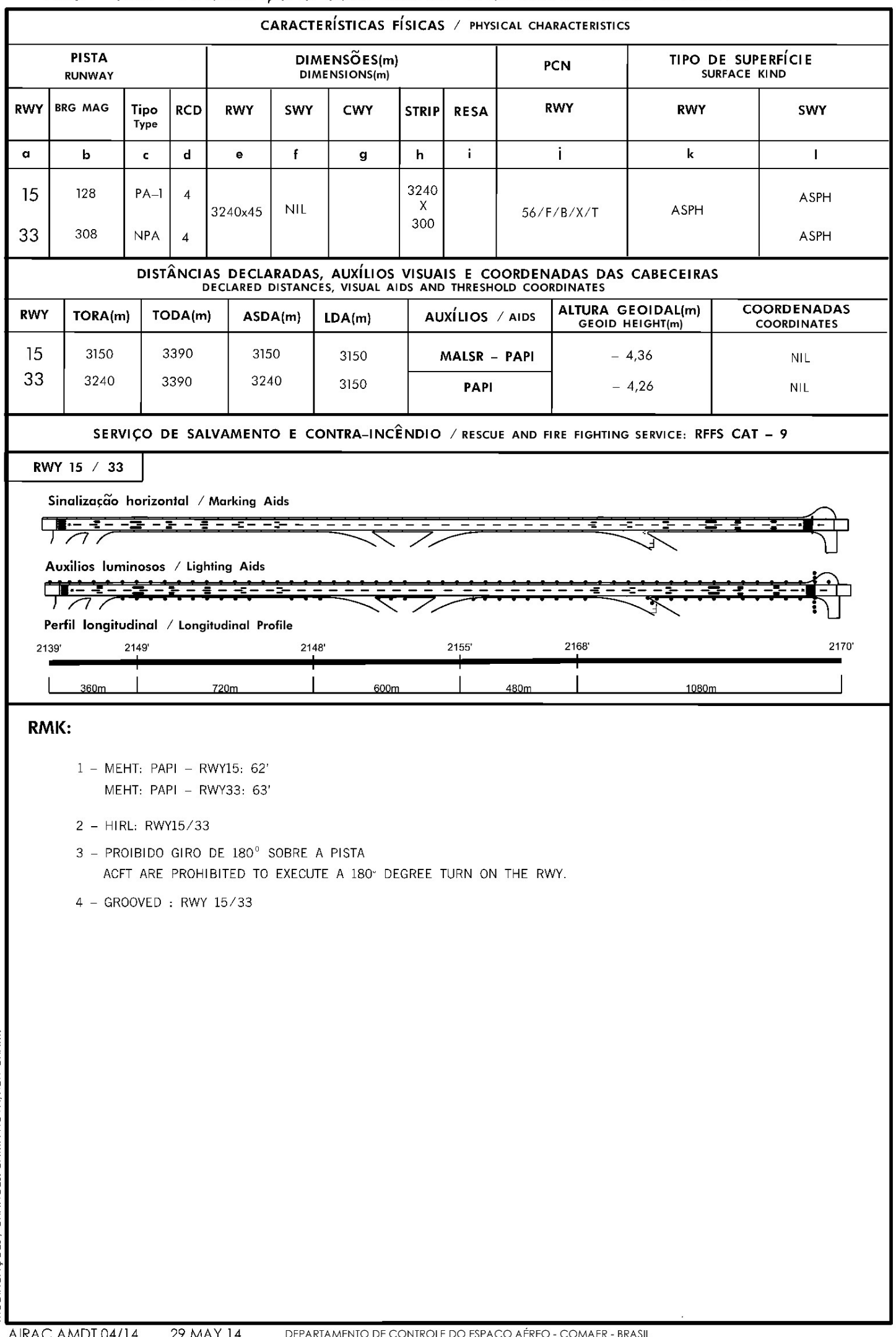

FONTE: (BRASIL, 2014) 


\section{ANEXO 2 - EXEMPLOS DE CÓDIGOS EPSG, PADRÃO WKT}

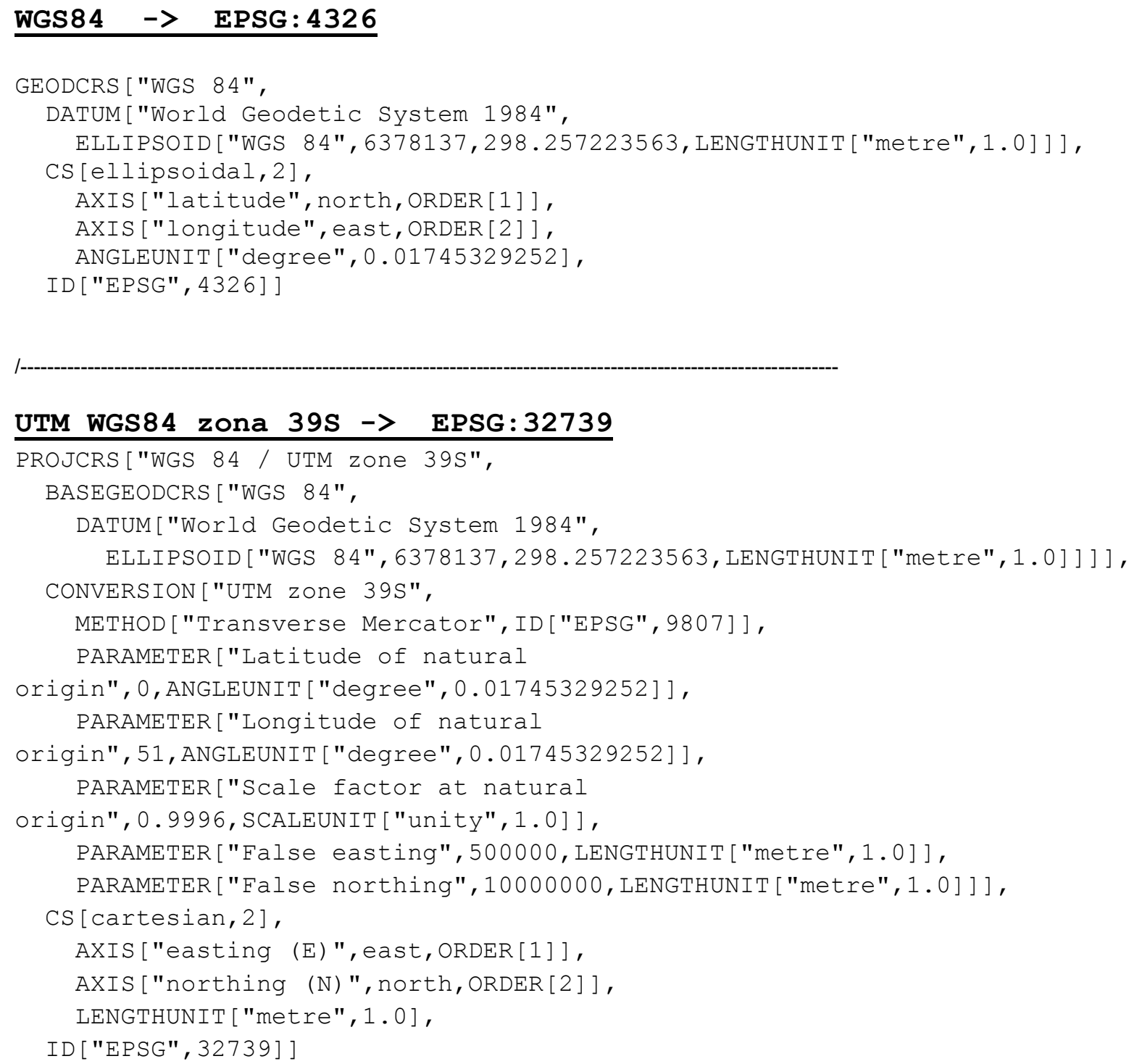

*Uso do padrão de representação WKT para dois CRSs: o EPSG4326 é geográfico e o EPSG é projetado. **Fonte: https://www.epsg-registry.org/ . Acesso em 13/02/2017. 